Academy of Sciences, Russian Federation Institute for Dynamics of the Geospheres

\title{
Geologic and Tectonic Characteristics of Rockbursts
}

\author{
V.V. Adushkin \\ Director of IDG RAS \\ V.A. Charlamov \\ S.V. Kondratyev \\ Y.S. Rybnov \\ V.M. Shemyakin \\ I.A. Sisov \\ N.M. Syrnikov \\ S.B. Turuntaev \\ T.V. Vasilyeva
}

June 1995

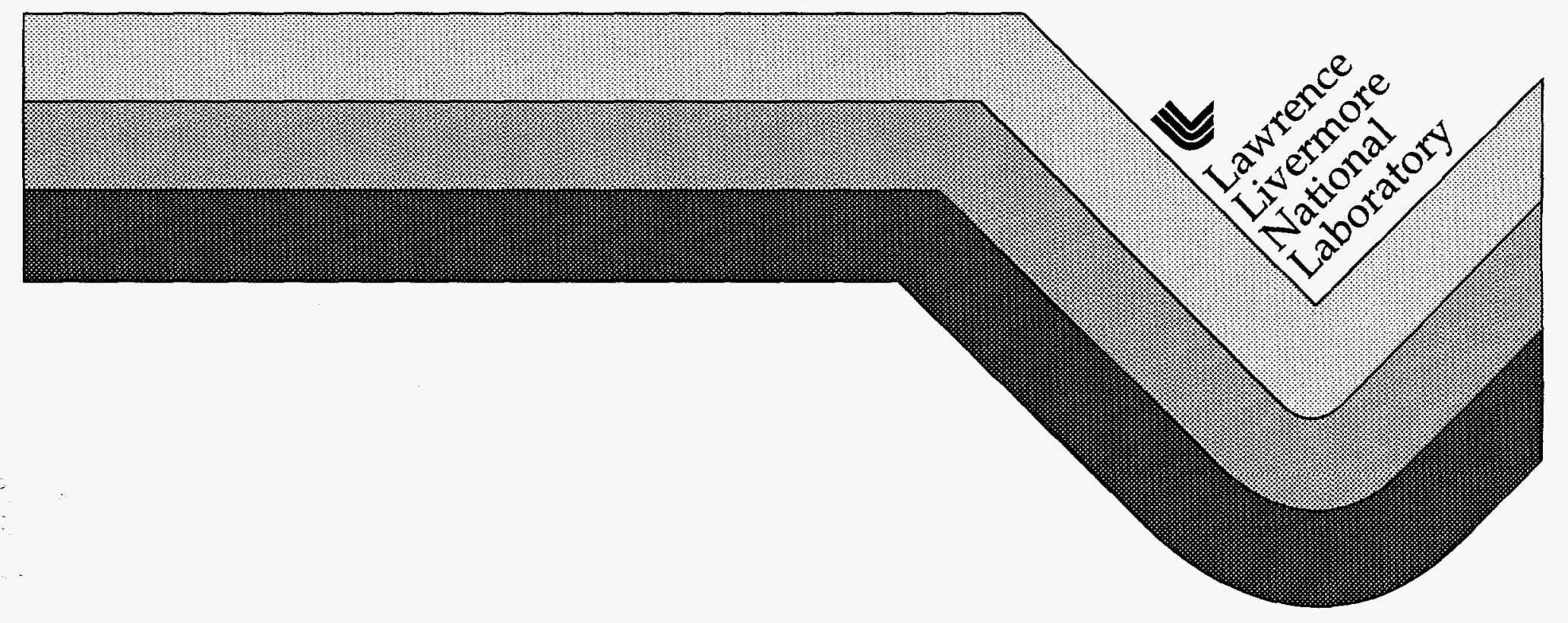




\section{DISCLAIMER}

This document was prepared as an account of work sponsored by an agency of the United States Government. Neither the United States Government nor the University of California nor any of their employees, makes any warranty, express or implied, or assumes any legal liability or responsibility for the accuracy, completeness, or usefulness of any information. apparatus, product, or process disclosed, or represents that its use wuuld not infringe privately owned rights. Reference herein to any specific commercial products. process, or service by trade name, trademark, manufacturer, or otherwise, does not necessarily constitute or imply its endorsement, recommendation, or favoring by the United States Government or the University of California. The views and opinions of authors expressed herein do not necessarily state or reflect those of the United States Government or the University of California. and shall not be used for advertising or product endorsement purposes. 


\section{DISCLAIMER}

Portions of this document may be illegible in electronic image products. Images are produced from the best available original document. 


\section{INSTITUTE FOR DYNAMICS OF GEOSPHERES RUSSIAN ACADEMY OF SCIENCES $* * *$ \\ UNIVERSITY OF CALIFORNIA \\ LAWRENCE LIVERMORE NATIONAL LABORATORY}

\section{GEOLOGIC AND TECTONIC CHARACTERISTICS OF ROCKBURSTS}

Technical Report

CONTRACT No. B239743

Moscow - 1995 
Project executors:

N.M.Syrnikov

V.M.Shemyakin

S.B.Turuntaev

S.V.Kondratyev

Y.S.Rybnov

I.A.Sisov

T.V.Vasilyeva

V.A. Charlamov 


\section{CONTENTS}

INTRODUCTION

1. Dynamic phenomena in highstressed rock massifs . . . .10

1.1. The rockbursts. . . . . . . . . . . . .10

1.2. Evalution of rockburst danger. . . . . . . . .17

1.3. Comprehensive system of instrumental

investigations for the rock massif and

opening state. . . . . . . . . . . . . . . . . .

2. Tectonic-physical characteristics of Khibiny massif and rock pressure manifestations. . . . . . . . . 35

2.1. Khibiny massif. . . . . . . . . . . . . .35

2.2. Man-made influences to massif. . . . . . .38

2.3. Seismic circumstances at the Kirov district mining enterprises territory. . . . . . . . 40

2.4. Comparative analysis of seismic catalogues and explosions journals. . . . . . . . . 43

2.5. The rock pressure manifestation features at the deposit completion in Khibiny. . . . . . 44

3. Results of natural measurements in Khibiny. . . . . 47

3.1. Kirovskij mine. . . . . . . . . . . . .47

3.2. Man-made earthquake at Kirovskij mine. . . . . 50

3.3. The relative displacements measurements. . . . .54

3.4. Seismoacoustic measurements. . . . . . . 57

3.5. The study of geoelectric fields in the rock massif. . . . . . . . . . . . 60

4. North-Ural bauxite deposit (PA Sevuralbauxitruda, SUBR). 68

4.1. General characteristics of mines seismicity of SUBR. . . . . . . . . . . . . . . 68

4.2. Seismic activity variation in the time. . . . .69

4.3. Spatial distribution of seismic events. . . . .75

5. Dissipative processes in a rock massif and the problem of stability of its structural elements. . . .81

6. New ideas in destruction mechanics. . . . . . . . 96

CONCLUSION. . . . . . . . . . . . . . . . . . . . . . . . . .

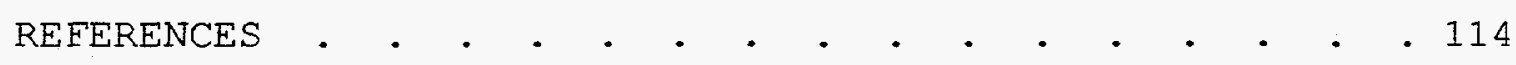




\section{NT ROD UCTION}

The modern mining enterprises have attained such scales of engineering activity that their direct influence to a rock massif and in series of cases to the region seismic regime doesn't provoke any doubts. Excavation and removal of large volumes of rock mass, industrial explosions and other technological factors during long time can lead to the accumulation of man-made changes in rock massifs capable to cause catastrophic consequences.

The stress state changes in considerable domains of massif create dangerous concentration of stresses at large geological heterogeneities - faults localized in the mining works zone. External influence can lead in that case to such phenomena as tectonic rockbursts and man-made earthquakes.

The rockbursts problem in world mining practice exists for more than two hundred years. So that its actuality not only doesn't decrease but steadily mounts up as due to the mining works depth increase, enlargement of the useful minerals excavations volumes as due to the possibility of safe use of the rock massif potential energy for facilitating the mastering of the bowels of the Earth and for making that more cheap.

First information about rockbursts happened at tin mines in England are related to the beginning of XYIII century. In second half of XIX century the rockbursts began to be registered at coal mines of Europe and since that time the attention to the rockbursts problem was paid in mining technology.

The ores excavations volume increase, large variety of geological features and exploitation conditions of developed deposits and underground constructions, the increase of depth of mining works help to the mass arising of those phenomena and promote the necessity of the rock pressure dynamic manifestations systematical registration, of studying their nature and of development of reliable methods of their prognosis and effective measures of prevention.

To present time the large actual material is accumulated about rockbursts (before all at coal mines), the effective complex of prophylaxis measures has been developed and implemented. At series of enterprises the special service of prognosis and struggle against rockbursts operates.

The rockbursts are provoked by the accumulation of potential energy of elastic compression of rocks and its sudden release at immediate fracture of the rock domains stressed to some limit with subsequent manifestation of deformations, shear and oscillations of surrounding massif.

The rockburst nature has much in common with earthquakes. The stress-strain state of Earth crust is not regular in space 
and time. In distinct regions especially in those where geotectonic processes are registered the massif stress state depends not as much upon the rocks gravity force as upon the stresses acting in the Earth crust. So in Mountain shoria regions and at Kola Peninsula the horizontal component of stress field in virgin massif 1.5-3 times more than the vertical one.

The idea about similarity of rockbursts with natural earthquakes had been expressed long ago and repeatedly. But two considerations opposed to its adoption. First, the seismicity was treated as the result of the tectonic forces action whereas the rockbursts and other dynamic phenomena observed in mines were treated as the result of rock pressure action - the stresses gravitational field created by the rock weight and complicated by the stresses redistribution around mining openings and other irregularities contained in the massif. second, the possibility of dynamic phenomena in mines was connected to existence of free surfaces, outworked planes, whereas the earthquakes happen in a medium where the considerable emptiness absent which would correspond to the scale of those natural phenomena are deliberately absent.

The deciding moment for points of view to the nature of rockbursts and earthquakes to be drawn together was the discovery of considerable forces of nongravitational nature by direct measurements in mines those forces being identified as the tectonic ones. At that it was pointed out that just those rocks are have increased inclination to the different dynamic phenomena arising in which the stresses take place excessive with respect to those which could be conditioned only by the rock weight.

Besides, now the existence of tectonic rockbursts is established the hotbeds of which arise at large distances from excavated cavities. According to that feature as well as according to wave characteristics it is difficult to feature them from natural tectonic earthquakes. The tectonic rockbursts appeared to be that missing link which embraced whole variety of dynamic phenomena - from acoustic emission emitted by the rocks samples to the phenomena of induced and natural seismicity into one series.

Man-made earthquakes arising in the Earth crust as a result of human activity are provoked by bumps many of which can develop into tectonic rockbursts with destruction of mining cavities and other underground and overground objects. Here the necessity to study bumps in detail arises and to work out the effective measures for their prognosis and for creation of safe conditions to exploit the underground constructions of different purpose. 
According to existing ideas the man-made earthquakes differ from natural regimes of seismic energy apportionment. The large number of foreshocks is characteristic for them preceding bumps and slow diminishing of aftershocks as well as increased numbering due to not deep lying of a hotbed that is why they can be initiated easier, the curve of their repeatedness has larger slope.

Main conditions of man-made earthquake forming are the presence of strong frail rocks with high level of tectonic stresses in a mining works region, of large areas and volumes of mining excavation as well as of technological explosions as a trigger mechanism of the large blocks spasmodic shear processes or of avalanch-like crack forming.

The development of useful minerals deposits leads to the change of the stresses field existing in the Earth crust provoked by the rock pressure redistribution as a result of underground openings arranging. The noticed increase of mining works scales provides essential increase of man-made influence to the regions adjacent to mining enterprises with developed infrastructure. The processes of deformation, shear and destruction of rocks arising by that being different to natural processes in the Earth crust are more localized and short-timed and more dynamical. Besides the natural seismic activity in deposit region is increased as a result of redistribution of stresses in the massif. The level of induced seismicity at ore deposits during five years has increased more than for an order (according to energy).

The seismic regime study - traditional area of seismological research having hundreds of scientific publications. At the same time the research devoted to the study of seismicity regime induced by mining works carrying out are highly not numerous. The study of the rockbursts seismic regime perceiving already existing experience of studying of natural seismicity gives an opportunity to use already accumulated experience for practical programs of prognosis and prevention of rockbursts as well as for estimation of general tendencies in induced seismicity regime changes. On other hand incongruosity in the natural seismicity phenomena interpretation can be eliminated by studying those conditions in which their mines analogies arise as far as these conditions are attainable for direct studies.

As it known as the form as the intensity of mine seismicity experience definite evolution in time. The weak manifestations of induced seismicity in a form of walls and roof peeling, rock bouncing, slaughtering begin at mining works carrying out after attaining some critical depth strongly dependent upon local geological conditions which are different in different regions with different types of tectonics. 
Microbursts and rockbursts begin to arise at the depths which exceed to 200-300 $\mathrm{m}$ the critical depth. In the beginning the rockbursts arise immediately after explosion works, the bursts hotbeds are situated near excavations. At later stages the considerable part of rockbursts (up to 50\%) arise without any time connection to explosions and not only near to excavations but at considerable distance from them as well - the tectonic rockbursts arise. The induced seismicity regime acquires still more spontaneous character to remind the natural seismicity regime.

In the paper (Gibowitz, 1990) is shown that the seismic events released energy maximum directly connected to mining works is $10-20 \mathrm{~m}$ before or behind of works front depending upon the development manner and at the level of fulfilled works either higher or lower depending upon the strength features of rocks containing the ore body; the events distribution for hours of a day and days of a week is well correlated with mining works regime. The tectonic rockbursts don't possess such implicit spatial-time connection with mining works. The energy of those events is mainly higher than of events of first type, the hypocenters very often are situated at considerable distance from excavations and usually are related to geological irregularities in solidity.

The purpose of present work is to study the engineering activity influence to processes occurring in the upper part of Earth crust and in particular in a rock massif. The rock massif is treated in those studies as a geophysical medium - such approach takes into account the presence of block structure of medium and the continuous exchange of energy between parts of that structure. The idea "geophysical medium" is applied in geophysics sufficiently wide and stresses the difference of actual Earth crust and rock massifs from the continuous media models discussed in mechanics.

The approach to geophysical medium as to hierarchicalblock system with similar between themselves statistical distributions of blocks for dimensions inside each level is developed in papers (Sadovsky et.al.,1987) where the analysis for objects and phenomena essentially differing with scales from each other was fulfilled. In a work (Rodionov et.al.,1986) the mechanism of continuous dissipation and energy redistribution in geophysical medium is discussed creating the prerequisites for arising in it the dissipation structure: the structure manifestation is defined by the process character, the deformation velocity is used as a parameter of medium state defining the dimensions of heterogeneities at which the stresses concentrations arise during characteristic time of process. 
Thus, physical and mechanical features of such medium and in particular different scale levels of its structure have to be manifested with dependance upon external influence - upon its scale, intencity and duration. Particular manifestations of the rock massif block structure will be defined by the scale and character of external natural and man-made influences.

The rock massif research should include the study of characteristics of its block structure and of this structure manifestations at dynamic and static influences. At present time the vast scientific literature has already existed devoted to the study of rock massifs, tectonic stresses in them and to the interaction of massif with underground constructions erected in its thickness. In works (Muller, 1971, Petukhov et.al..1984, Turchaninov et.al.,1989) the rich experimental material was generalized accumulated at mining enterprises in different regions of the Earth: geomechanical and geologicalstructural characteristics of rock massifs, methods of natural observations, technology of mining works etc. However, the rock massifs mechanics is so far at the stage of its forming and its main principles has not yet sufficiently formulated. That is explained by enormous complexity of the geophysical medium and actual rock massif model creation.

In spite of noted large experimental material the research at mines is reduced to the study of distinct practical questions. In last tenths of years the complex study of those phenomena is organized at distinct mining enterprises, the network of seismic stations with real-time data processing is equipped and points of slow deformations measurements with the aid of inclinometric stations. For successful implementation of such complex approach to the rock massif study the solution of questions of instrumental-methodic equipment of research is necessary before all as well as the development of physical models of rock massif.

In the first part of present report the review of theoretical description of rockbursts is given, the review of information about the rockbursts presented in scientific literature, man-made earthquakes and manifestations of mines seismicity as well as the set of the rock massif state parameters measurement system - the system of geomechanical monitoring.

In the second part the present information about tectonophysical and geological-structural features of Khibiny massif, seismic regime of the region, man-made influence to the massif defined by mining works (in particular the data about industrial explosions at Production Association "Apatit") and data about dynamic manifestations of rock pressure in underground mines. 
In the third part the data of natural measurements carried out by authors at mines of PA "Apatit" are given. The man-made earthquake of 1989 is described in detail, the measurements results for shears at geological irregularities, seismoacoustic emission and geoelectric potential at industrial explosions and rockbursts.

In fourth part the seismicity of North-Ural boxites mines (Production Association SUBR) is discussed.The SUBR is the most rockburst dangerous mines on the Russia territory. The history of seismicity development at the mine is delivered confronting with the increase of mining works depth and the features of the mines region tectonic composition. The examples of rockbursts are given which were most significant from the point of view of consequences. Some statistical characteristics of seismic regime are calculated: constants of magnitude-frequences relationship, distributions of time of waiting for events etc. The confronting of seismic regime with the explosion works regime is carried out. The methods of the seismic regime analysis are proposed for a rock massif subjected to influence of mining works.

In fifth part of report the basic clauses of the mechanical model of solid body with dissipative structure are given used to compute the deformation regime changes at manmade influences to massif. The results of problem computing about stresses concentration at the fault in Khibiny (man-made earthquake mechanism) and about the stress state in vicinity of a cylindrical gallery with large cross-section at its cutting are delivered.

The sixth part is devoted to theoretical description of the rock beyond-limits deforming questions.

The main inferences and proposals of authors are given in the conclusion. 


\section{DYNAMIC PHENOMENA IN HIGHSTRESSED ROCK MASSIFS.}

\subsection{The rockbursts .}

At present time different points of view exist in mining science to the rockburst arising mechanism. According to most widely spread ideas the rockburst is a result of destruction of a high stressed part of rock massif in the influence zone of mining excavations arising in conditions at which the velocity of the stress state change in that part exceeds the stresses relaxation velocity in it. The energy of a rockburst is composed of the energy accumulated in the destructing rock volume and of the energy accumulated in surrounding massif. By that the conditions of "soft" loading are implemented i.e. income of energy out of external environment exceeds the possibility of its absorption at destruction. Those clauses are related to the same extent as to rockbursts occurring in pillars and in side parts of rock massif as to rockbursts of a bump type arising at shears in a block massif along present of newly arising weakening surfaces.

Depending upon the intensity of manifestation the rockbursts are divided into four groups: bouncing, bumps, microbursts and the rockburst proper.

Bouncing is manifested in breaking off the distinct pieces from the rock stressed massif accompanied by sharp sound.

Bump (deep rockburst) is manifested by rock destruction in the massif depth without its throwing into in a mining opening. Externally the bump is accompanied by a sound, massif shaking, apprarance of dust, falling the rock off the opening walls.

Microburst is manifested in an insignificant destruction and throwing out the rock into an opening without any serious harm to the opening itself as well as to mechanisms situated in it.

The rock burst proper is presented with fast occurring destruction of a rock massif with throwing out of considerable volumes of rock into underground openings, destruction of a support, destruction of machines and mechanisms. The burst is accompanied by a sharp sound, forming of large amount of dust, air wave and massif shaking. The shaking is felt at the surface within a radius $5-10 \mathrm{~km}$ and is registered with seismographs at a distance tenths and even hundreds kilometers from the burst place.

Such dynamic phenomena as sudden gas outbursts in coal mines are not discussed in given report. 
The seismic disturbance energy is the best characteristic of the rockburst force in spite of definite inexactness. However by that the role of physical factors of the massif overstressing is not discussed. That is why the classification of rockbursts according to a physical feature - the reason of their arising (bursts of pressure, shock rockbursts and bursts of breakup) as well as according to topological feature - the place of a rockburst manifestation (rockbursts in pillars, in side parts of massif, in openings cut across useful mineral and others).

The local classifications of rockbursts exist applied at the mines of SAR, India and other countries.

It is evident that the main reason of dynamic manifestations of rock pressure is upgraded irregular stress state of a rock massif defined by the depth of development, initial field of stresses, by geological structure, by physical-mechanical features of rocks and by the region tectonics. At the background of averaged stresses at modern depths of mining excavations the extremely discrete distribution of stresses takes place due to the irregularity of the rock massif mechanical features, presence of tectonic stressed zones near to developing faults of different rank and due to tectonically stressed zones and unloading zones which are provoked by the massif shear along uneven surfaces of block contacts, tectonic disorders, weak streaks, rock layers.

It follows from here that when solving questions of regional prognosis of deposits burst danger, of cutout of a deposit into mines fields, of selection of order and sequence of deposits completion the averaged stresses can be used then it is necessary to be oriented to the stress state estimation by instrumental methods at deciding questions of prognosis and prevention of rockbursts. It is sufficient by that to receive only relative characteristics of a stress state related to the danger of manifestation of these or those dynamic phenomena, to difficulty of supporting of mines etc.

The special place in the theory belongs to the regularity of rock massif bump-formed deformation in the process of the mining works carrying out. The essence of regularity consists in the change of stress-strain state and energy under influence of mines development in a massif with discrete stresses distribution being as a whole or in parts in limited stress state occurs bumping-like at the expense of distinct acts of destructions. The destructions occur in conditions of income (release) of energy from adjacent areas of a rock massif i.e. in conditions of "soft" loading.

The focus (hypocenter) of underground rockburst is some volume in massif thickness within the limits of which the process of release of energy accumulated during long time 
occurs. In a geological sense the focus is the break or group of breaks along which almost immediate displacement of masses occurs. The elastic expansion of rock massif adjacent to the destruction focus create seismic waves of great force spreading to tenths and hundreds of kilometers. Due to its action the strong rockbursts are similar to small earthquakes for which the values of released energy witness. Thus, the main defining conditions of rockbursts arising are physical-mechanical features of a system "containing rocks - useful mineral", the mining works manner and of rockburst danger - the ability of rocks to accumulate the elastic deformations potential energy.

The rockbursts are manifested in variety of forms, in different cinditions, at different stages of mining works development.

The most strong rockbursts known to world practice occured at salt mines.

So, the rockburst at the potassium mine "Merkas"' (Germany) occured at 1958 was registered by seismographs at the territory from Moscow to spain. Several rockbursts taking place at the mine "Kirkland lake" (Canada) were registered by seismic stations at the distance more than $900 \mathrm{~km}$.

In December 1988 at potassium mine in Thuringia (Germany) the powerful rockburst occured accompanied by the pillars mass destruction at a site $2000 \times 1000 \mathrm{~m}$ at the depth $800-1000 \mathrm{~m}$. The magnitude of this man-made earthquake appeared to be equal to 5 , the intensity in nearby populated points attained VI-VII, 50-60\% of houses were destroyed, the surface went down at distinct sites to $1 \mathrm{~m}$.

Strong rockburst occured in 1960 at gold ore deposit Kolar (India). The rockburst was initiated by explosion works. About 200 repeated rockbursts occured next to first burst. Considerable destructions of mining openings were registered at the site with dimensions about $700 \mathrm{~m}$ along course and $600 \mathrm{~m}$ in vertical direction. The rockbursts at this deposit began from the depth $300 \mathrm{~m}$ as long ago as in the century beginning and occur at different depths without dependance upon the ore body development manner. The most strong events had an intensity from 6 to 6.5 numbers according to Richter scale and were registered at the distance up to $750 \mathrm{~km}$ from the mine ( Krishnamurthy \& Shringarputale, 1990). With the aid of the seismic detectors network established at 1978 during 8 years of observations more than 9500 seismic events were registered 156 of which were classified as rockbursts. During last time the considerable recession of seismic activity is noticed connected to the transition to the specially developed method of mining works carrying out. 
The dynamic manifestations of rock pressure in a form of rockbursts and mines seismicity are observed at deep goldproducing mines of SAR.

At the mines witswotersrand the goldcontaining layers are developed at depths up to $3 \mathrm{~km}$ and more. The dynamic phenomena with energy from $10^{-5}$ to $10^{9}$ Joules (the magnitude from -6 to 5 ) in a frequency range from 1 cycle $(\mathrm{Hz})$ to more than 10 kilocycles $(\mathrm{kHz})$. The most rock - dangerous one is the depth range from 1200 to $2400 \mathrm{~m}$, the probability of bursts higher and lower than that being small. The seismic activity level is characterized for example by following frequency of seismic events: during 19711600 dynamic phenomena were registered with magnitude from 2 to 4.2 .

At the mine Kloof after creation in 1983 of the seismic detectors network during five years of observations more than 9000 seismic events were registered (Waldeck, 1990). The magnitude-frequences relationship inclination in magnitude form is changed from 0.77 to 0.89 in different periods of time, the seismic activity $A$ - from 2.96 to 3.45 which yields the magnitude of a maximum expected event nor larger than 4.0. That value for other mines of region is 4.8 .

The gold extraction at the mine Western Deep Levels is carried out from large depths (about 45\% of works are carried out at depths more than $3000 \mathrm{~m}$ ) (A.V.Zyl Brink, 1990). Beginning with 1970 the registration of microseismic events related mainly to dikes and faults is carried out at the mine. The strongest event had a magnitude 4.2 .

Let's note a seismic event interesting to given work at the mine Mount Charlotte (Australia) where the goldcontaining quartz veins are developed situated between inclined faults Charlotte and Reward (Lee et al.,1990). The rocks are durable, hard. The ore body is oriented almost vertically downward. Maximal stresses are oriented subhorizontally along an axis north-south and are $12 \mathrm{MPa}$. The number of seismic events were increasing at approach of works to the fault Reward. The seismic event with magnitude 3.0 occured when the block development at the depth $650 \mathrm{~m}$ has just begun. By that the displacement (up to $20 \mathrm{~mm}$ ) along a site $200 \times 40 \mathrm{~m}$ belonging to the fault Beta - thin fault (2 mm thickness) parallel to the larger structure Flanagan along which the displacement of smaller value occured, too. In a work (Lee et al.,1990) the importance of taking into account the positions of faults and projected excavations with the purpose to decrease the burst danger.

The copper-nickel mines of sudbury basin (Canada) since thirties confronted the rockbursts problem. More than 1000 of rockbursts were registered at mines Inco Ltd. during 1934 to 1965. The mines seismicity has sharply increased in 1984: 
during 8 months about 120 rockbursts occured (maximal magnitude $M_{n}=4.0$ ) entailed the human victims and stopping of one of mines (Plouffe et al.,1990). The seismic stations network created in 1985 registers about 10 seismic events every month with $M=1.5$ hypocenters of which are localized directly in the mining works zone and 15 with hypocenters close to the works zone. In 1987 at the mine creighton 35 considerable seismic events were registered with maximal magnitude 3.6 .

At the lead-zinc mine Lucky Friday (USA) the rockbursts has appeared in sixties. The registered rockbursts are related to two types: destruction of pillars and shears along faults (Williams T.J., Cuvelier D.J.,1990). The hypocenters of events are distant from the works zone to the distance from several meters to hundreds of meters. The strongest rockburst occured in 1969 and had a magnitude 3.5.

At the mines of Canada (Milne \& Berry, 1976; Scoble, 1986; Hasagava, 1988) the rockbursts occur preferably at the works carrying out in rocks of pre-Cambrian Canadian shield. They were registered at mines of Newfoundland, New-Branswuik, Quebec, Ontario, New Scotland, Saskachevan, British Columbia provinces. So, in Ontario province during 1984105 rockbursts were registered with magnitude from 1.5 to $4.0,84 \%$ of them being manifested as pillars bouncing, 18\% - as deformations and shear of rocks. As a result of rockburst in 1958 at the mine Springhill (New Scotland) 75 people died. In average in Canada the rockbursts are manifested at depths more than $500 \mathrm{~m}$ (Scoble, 1986).

Intensive rockbursts occur in ore district Pribram (Chekhia) (Stenczel,1988) where the polymetallic deposits excavation depth reaches $1800 \mathrm{~m}$. At that deposit the rockbursts appeared in 1962 by relatively small depths of works carrying out. The sharp increase of seismic activity occurred in 19691972 when cleaning works attained the depths 850-1000 m. $52.6 \%$ of rockbursts occur in close vicinity of veins structures during or after completion of cleaning works. In spite of the mining works volume decreasing in recent years the rockbursts activity preserves at constant level.

At copper mines of Legnice-Glogov basin (Poland) since 1972 to 1986522 strong seismic bumps were registered with magnitude 2.5-4.5 (Kazimerczyk et al.,1988). The rockbursts maximum intensity falls to 1980. Two seismic zones are singled out according to the seismicity character which are localized along both sides of large tectonic irregularity - Berdjikhovsky slip.

At Tashtagol mine (Russia) the dynamic phenomena in a form of bouncing began to be manifested from the depth $300 \mathrm{~m}$, the rockbursts - from the depth $600 \mathrm{~m}$. Initially the dynamic 
phenomena only accompanied the mine explosions but further they began to be manifested during some time after explosions and then without any explicit connection to explosions as well. Altogether about 340 dynamic phenomena were registered in the works zone since 1959 including 40 microbursts and 11 rockbursts. It was defined that the energy of one of rockbursts corresponds to 100-ton explosion (Ilyin,1987). In the paper (Grik et al.,1988) the geodesic observations results for the Nagorniy fault state at Tashtagol deposit are discussed. It was found that during three years the maximum horizontal displacements in the fault vicinity were $65 \mathrm{~mm}$, vertical ones $90 \mathrm{~mm}$ at average values 28 and $25 \mathrm{~mm}$ respectively.

At copper mine Lyubin. (Poland) since 1971 to 1984543 strong seismic events with energy class $K>5.5$ were registered 72 of which with $\mathrm{K}>6.5$. At present time the works are carried out at the depth about $1000 \mathrm{~m}$, up to 100 strong seismic bumps occur every year. The rockbursts focuses are localized mainly in roof rocks (Szelag et al.,1985).

The rockbursts at coal deposits having their specific features are not discussed in present report. We shall mention only some examples of rockbursts at coal mines.

At the mine of Uritsky name (Russia, KIzelov basin) the rockburst occured at the pillars excavation. The burst was accompanied with sharp sound, forming of large amount of dust and strong seismic effect. The gallery appeared to be heaped up with coal at the extension of $40 \mathrm{~m}$, the gallery support was destructed.

The rockburst at coal mine Hausham in Bavaria occured at excavation of two approached coal layers at the depth $760 \mathrm{~m}$. The strong air wave accompanied the burst and forming of large amount of dust, the metallic support was damaged at the extension of $6 \mathrm{~m}$ from coal-face.

At the mine Concordia in Rhein-Westfalia district the rockburst occured in cleaning zone at the site with extension $25 \mathrm{~m}$ at the depth $800 \mathrm{~m}$ and entailed the human victims. The rockburst reason in given case was the presence of hard rocks presented by powerful layers of monolith sandstones, the roof hanging over large area and creation of high pressure to side part of layer.

The rockbursts are manifested as microearthquakes at definite conditions. At the mine "Shomberki" (Poland) the noticeable deformations at a rockburst were given to buildings situated in $4 \mathrm{~km}$ from the place where the rockburst occurred. The mine develops the coal layers laying in a form of sinclinal. The powerful layers of hard sandstones are present on the rock thickness which are inclined to overhanging.

The seismic observations results at rockbursts at coal mines in regions of Kladno and Ostrava, data about energy, 
magnitudes and estimations of source dimensions are given in works (Buben \& Rudajev, 1977, Fucik \& Rudajev, 1979).

In Russia besides the mentioned Kisilov basin the rockbursts are manifested at coal mines of Kuznetsk, Donetsk basins, Vorkuta district etc.

The rockbursts cases are known not only in underground openings but in open pits as well being at small depths with sufficiently hard rocks. Such are for example the rockbursts in marble open pits of Vermont state (USA).

The rockbursts reasons are well illustrated by the distinct deposits development practice.

The residual stresses influence formed in the mountain forming process to the rockbursts arising is established at the development of lead-zinc beds in Austria at the depth about 250 $\mathrm{m}$. The development practice of gently sloping and inclined gold ore veins in SAR and of deep copper-nickel deposits of Canada can serve as examples of release of accumulated by rocks energy. According to calculations the elastic energy of the above rocks thickness pressure is $19.6 .10^{3}$ Joules $/ \mathrm{m}^{3}$ in hard rocks at the depth about $1.5 \mathrm{~km}$ from the surface.

It is established that the massif definite zone is rockbursts dangerous then when firstly the rocks are apt to fragile destruction and secondly when the openings have a geometric form promoting the high stresses zones forming due to redistribution of initial stresses. The latter is confirmed at the SAR mines by that there were many rockbursts of nonextracted pillars of different configuration cut by openings of irregular form: geometric irregularities of form (cuts, sharp changes of the cross section etc.) are the reasons of the stresses peaks arising.

At the same time one of reasons of rockbursts at gold mines of witwatersrand began from the depth $300 \mathrm{~m}$ was insystematical development of deposit. The forming of vast open cleaning spaces at several floors supported by the ore pillars situated not systematically led in the final to immediate fall of hanging wall and to strong rockburst similar to the collapse earthquake.

The similar examples of the roof immediate fall at considerably area supported by intercamera pillars are rockbursts at potassium mines "Merker" and "Krugershal" where the area up to $1-3 \mathrm{~km}^{2}$ was embraced by destructions.

Thus, the conditions promoting the rockburst arising can be divided into external, ones connected to the geology and the exploitation of an ore deposit and internal ones featured by different distribution of stresses in massif and by different regime of rock deformation. Otherwise, the rockbursts can occur then when there are large stresses in a massif, the rocks 
accumulate the elastic energy and there are conditions for its quick release.

\subsection{Evaluation of rockburst danger.}

The presence of fragile rocks not inclined to plastic deformations in which the quick forming of cracks occurs is the condition most promoting the rockburst arising. The larger the elastic energy share accumulated in the rock before destruction the more the danger of its immediate release in a form of fragile explosive destruction. By that the main index of rock danger is the rock feature to accumulate the potential energy of elastic deformations.

The energy questions in the rockburst theory at present time are studied not sufficiently although the question of rockburst energy balance was discussed by many researchers (Petukhov et.al.,1969; Petukhov et.al.,1984; Cook, 1965,1976). I.M.Petukhov discussed the connection of rockburst to the change of stress-strain state of a system "containing rocksuseful mineral". The total reserve of potential energy $W$ is composed of two components: the elastic deformations potential energy $w_{f}$ accumulated in useful mineral (coal, ore) and potential energy accumulated at the expense of compression of containing rocks $\mathrm{w}_{\text {ext }}$

$$
\mathrm{W}=\mathrm{W}_{f}+\mathrm{W}_{\text {ext }}
$$

The energy $w_{f}$ can be estimated as

$$
\mathrm{W}_{f}=\sigma^{2} \mathrm{~V} / 2 \mathrm{E}
$$

and the energy Wext can be calculated coming out of that the displacement of containing rocks occurs at rockburst to the value $l_{0}$ at their elastic expansion

$$
\mathrm{W}_{\text {ext }}=1 / 2 \sigma \mathrm{Sl}_{0}
$$

where $\sigma$ - average value of maximum stress in the burst focus, $E$ - the elasticity modulus of useful mineral, V - the rock volume destructed at the rockburst, $S$ - the area of element destructed at the rockburst. Thus,

$$
\mathrm{W}_{\text {ext }}=\sigma \mathrm{S} / 2\left(\sigma \mathrm{m} / \mathrm{E}+\mathrm{l}_{0}\right)
$$

where $m$ - the thickness of useful mineral layer or of the zone of its destruction at the rockburst. The components $W_{f}$ and 
Wext are essentially not similar in the rockburst total energy balance. So at the bouncing, bumps and weak rockbursts the share of $W_{\text {ext }}$ is several percents. At strong rockbursts the most part of energy (about $80 \%$ ) falls to $W_{\text {ext }}$.

The parameter

$$
\mathrm{K}=\mathrm{W}_{\mathrm{ext}} / \mathrm{W}_{\mathrm{f}}
$$

can serve as an index of a rockburst dynamics (Petukhov \& Linkov, 1983).

The accumulated in a focus potential energy $W$ is spent for destruction at the rockburst, is converted into kinetic energy of rock pieces, is dissipated in close zone and its comparatively small part (up to 10\%) is released in a form of seismic oscillations. The study of the quantitative balance of those kinds of energy was not made up to present time. Only seismic energy can be reliably defined with the aid of instrumental methods.

To disclose deposits or their sites dangerous with rockbursts it is necessary to study firstly the rock fragility and secondly their stress state in not disturbed form.

The hard rocks are believed to be burst dangerous when the elastic deformation of which at loading to $80 \%$ of strength limit is not less than $70-80 \%$ of total deformation preceding to the destruction. The potential burst danger can be estimated as a whole according to lithological and petrographical compositions of rocks. So most burst dangerous the rocks containing considerable part of minerals giving the increased fragility to them. The quartzites, granites, granitoids, quartz sandstones etc are attributed to them.

An elastic deformation share in a full deformation of a sample or massif reflects the energy amount accumulated before destruction but at the same time the kinetic energy of destructed rocks plays considerable role in total energy balance of a rockburst. That is why it is necessary to take into account at estimation of burst danger the realization of energy after attaining the limit state.

The similar method was developed by R.Straube for the exploitation conditions of coal deposits in Chekoslovakia. The energy index used by him is characterized by the ratio of energy transmitted to the medium to excessive its amount and enables to judge about potential rock danger. The rocks are believed to be burst dangerous at the value of that index more than $30 \%$.

A method of defining the burst danger was proposed by Petukhov which takes into account the value of work spent to the rocks destruction. In the beginning in a massif site unloaded from the rock pressure the contact strength is defined 
$P_{m}$. Then at different distances from the borehole orifice drilled in stressed massif the contact strength $P_{k}$ is established in a site unloaded from rock pressure and the depth $l_{1}$ of impression of plunger after the rock destruction. The work spent for a rock destruction is calculated according to received data:

$$
\mathrm{A}=0.5 \mathrm{P}_{\mathrm{k}}{ }^{1}{ }_{1}
$$

The degree of the massif sites burst danger is estimated with the formula:

$$
K=A / P_{m} 1
$$

When $K<0.5$ the rocks are attributed to rockburst dangerous ones, when $K>1$ - to not dangerous ones, when $0.5<K<1$ to menacing with respect to rockbursts ones. The index of the rock ability to absorb the energy wet is widely applied in Poland to estimate the rockbursts danger in underground openings which is equal to the ratio of the elastic deformations energy to the lost one in the process of laboratory studies for the compression of a rock sample. The larger $W_{e t}$ the higher the inclining of a rock to the rockbursts. At $w_{e t}>5$ the rocks are believed to be inclined to rockbursts;at $2<W_{\text {et }}<5$ and at $W_{\text {et }}<2$ respectively weakly inclined and not inclined to rockbursts.

In recent time the specialists pay great attention to the study of the rocks beyond-limits characteristics. By that a new characteristic of rock features is introduced - the abatement module defining the steepness of a curve of strength decrease with the deformations increase. The potential burst danger of rocks is decreased with the decreasing of the abatement module.

In practice one of main principles of safe exploitation of deposits inclined to the rockbursts is the decreasing of the rock pressure influence. It is possible to attain the essential results with engineering methods known to mining practice in changing general character of side part of ore body deformation which can lead to the decreasing of burst danger level. The main question is the width of zone where the decreasing of ability to elastic deformation i.e. to accumulation of large reserves of potential energy. The width of zone depends upon the acting stresses around opening, upon general level of stress state of non-touched massif, upon fragile and elastic features of the ore, upon elastic and strength features of containing rocks.

The detailed delivery of those methods can be found in a series of monographs (Petukhov et al., 1984, Bronnikov et al., 1982, Turchaninov et al.,1989), we shall mention only basic 
ones of them. The defending zone can be formed by means of camouflet explosion, drilling of unloading holes of large diameter, pumping of water in the rocks, application of unloading slots of different kind.

Camouflet explosion is the charge explosion of internal action without throwing out the rock (ore). As a measure of struggle against rockbursts can be applied in two forms: camouflet and camouflet-shaking explosion. At the camouflet explosion the rocks sufficient friability is provided. Camouflet-shaking explosion is applied for making the rock friable with simultaneous initiating of possible manifestation of rockbursts.

Unloading boreholes. One of methods providing the rocks ability decrease to accumulation of potential energy is the use of unloading boreholes of large diameter. This method got most wide application at coal mines to prevent rockbursts.

The rock pressure plays an active role to increase the effectivity of the method of mining opening bringing to burst nondangerous state with the aid of boreholes of large diameter. When the borehole is drilled the limit stressed state arises at the walls. The destruction of borehole walls and unloading of massif part occurs. The destruction dimensions increase with the stress state increase.

By pumping of water into rocks or ores the decreasing of their strength and elastic features is attained due to which the potential energy of elastic compression is decreased. The loading maximum is displaced into the massif depth and the inert zone dimension from the exposure side is increased. Several methods of liquid influence to rocks are known depending upon the regime of liquid pumping into the rocks.

The most widely spread one is the hydrostatic method the effectivity of which depends upon the moistening regularity which is attained then when the pumping volume velocity is equal to the liquid absorption by the rock.

The impulse method of pumping is based upon the use of liquid high pressure acting during short interval of time. The impulse pumping is used in media taking the water at relatively high pressures. This method was applied in Russia (at mines of Kuznetsk, Donetsk basins) and in FRG.

\subsection{Comprehensive system of instrumental investigations for the rock massif and openings state.}

The purpose of the system of instrumental observations creation is to provide the massif and openings stability by 
approach: the selection will solve the question about final composition of system. At the same time the necessity of using of series of basic methods doesn't provoke any doubts.

\section{Stress measurement}

The practical methods of stress definition at present time are developed in detail and widely known. It is sufficient to mention only basic ones.

The most widely spread method of stress absolute values measurement is the method based on the measurement of elastic deformations of some element of rock massif at its unloading and elastic restoring of initial dimensions. The technology of works carrying out is concluded in drilling out a kernel to the butt of which the photoelastic sensors are adhered measuring deformations (Turchaninov et.al.,1978). The method is based upon the elastic restoration measurement of the rock element (kernel) at its unloading with the aid of electrical sensors.

In usual practice of underground mines a method based upon the kernel dissection into disks at the holes drilling is often used to have an approximate estimation of the rockburst danger. According to the concavity of disk one can judge about the rock massif stress state near excavation. The method is developing toward the quantitative estimation of stresses. Although the control for the massif stress state according to the intensity of crushing is widely applied however its results are very relative.The reliability of the rockburst danger estimation can be somewhat increased if to confront the results attained with that method with the data of kernel division into disks.

The method of the rocks mechanical features study in a massif by means of pressing a punch into the borehole walls with automatic registration of pressing in diagrams. According to that the contact strength, elasicity module, brittleness coefficient are defined and using corresponding nomograms the rockbursts danger is estimated.

The detailed description of those methods isn't related to the present work purpose.

\section{Deformometry}

Special attention in natural measurements carried out by authors was paid to the slow deformations registration in a massif with the aid of deformographs and inclinometers. These measurements must disclose in the course of mining works the arising of comparatively large deformations exceeding those which were prognosticated by the calculations. 
The quartz deformographs KD-III with sensitivity up to $10^{-}$ 11 developed in the Institute of Physics the Earth of Russian Academy of Sciences and produced in Special Construction Bureau of that institute as well as the pendulum two-coordinate inclinometers NMDS with sensitivity up to $10^{-4}$ angle sec. and inclinometer-deformometric complex NDK having additional water tube inclinometer and other apparats can be used for precision measurements.It should be noted that the construction of special underground pavilions similar to ones equipped in Khibiny is necessary to use those complexes to full extent (Kozyrev et.al.,1988). At Fig.1.2 the scheme of controlobservation crosscut at the mine "Umbozero" is shown (similar crosscut is equipped at Kirovskij mine). The crosscut serves as a supporting point for the rockburst prognosis service. It is divided into isolated sections to improve the geophysical equipment thermostabilization. Concrete posts serving as sensors basements are stiffly connected to the rock. Total length of crosscut - $200 \mathrm{~m}$, the length of side cuts - $20 \mathrm{~m}$, of vertical one $-6 \mathrm{~m}$. The deformographs $\mathrm{KD}$-III are installed in the butt and in the side cut with the base $20 \mathrm{~m}$ and in the vertical cut $-K D$-III with the base $5 \mathrm{~m}$. In rest rooms - the inclinometers NMDS and registering equipment. It is evident that there is no necessity in mass use of such precision equipment: measurement pavilions should be situated on the borders of large blocks and near to most significant faults.

The registration of slow changes accumulated in the massif during several years plays a special role. Such changes can be disclosed with the I class levelling along surface and underground proving grounds. The stationary levelling proving grounds are laid over whole extension of mining openings especially in the geological disruption zones. Such network should embrace several possible blocks (structural bodies) of massif and provide the information about the massif microstructure manifestation: to replenish the geological study data and to disclose the "living" faults along which the noticeable relative displacements of blocks are possible.

The method of relative displacements measurement developed in the Institute for Dynamics of Geospheres Russian Academy of Sciences (Kondratyev, 1989) based upon the string sensor DPS enabling to measure displacements from $10^{-2}$ to several millimeters can be used for multipoint measuring of deformations in a massif. The method is sufficiently simple for mass measurements and can be applied not only to the relative displacement registration of faults junctions and cracks practically in all points difficult to reach but as well for observations for the opening contour deformation as in continuous mode as for periodical measurements during long periods of time. The measurements carried out with the aid of 
that method in Khibiny showed its high reliability in conditions of acting mine as well as the possibility of continuous measurement of dynamic displacements in explosion wave and of the after-explosion comparatively slow displacements of faults junctions in massif. It should be noted that sensor DPS is able (being different from abovementioned KD-III and NMDS) to stand against considerable dynamic strike (up to 4-5 m/s) which makes it to be suitable for the massif state control in extreme conditions.

The sensor string is pulled over a fault or crack (Fig.1.3). One of posts of string is the sensitive element. working part of that post is the steel plate (console) with strain gauge sticked to it. The resistance change of strain gauge is proportional to the string tension change which in its turn is proportional to the posts displacement against each other.

After installation of each gauge at measurement place its dynamic calibration is carried out which enables the amplitudefrequency characteristics of whole measurement channel to be defined in integral manner.

In many cases the methods of stress changes registration with the aid of pressure sensors or deformometers situated and cemented in holes and flat slits are used. At mining enterprises of USA, Canada and other countries the multiwire extensometers are applied rather widely. A case of the extensometers application with automatic registration of displacements at the coal mine "Kaiser" (Canada) should be noted.

The method for defining the places of large displacements and exfoliations of rocks reminding the multiwire extensometers method is based upon the break of electric wire. The method is convenient for the massif controlling between two openings. Two wires are put down into the hole at definite depth. In case of rock exfoliation the electrical circuit at the place of wires connection is broken in first turn. According to that which of circuits has stopped to conduct the current the place of exfoliation happens to be known. The method simplicity enables to create a definite system of control at the mine with own resources.

The most mastered control method for the openings states is the method of measurement of the opening contour elements convergence. Taking into account the convergence enables to define the preburst situation according to the rock strain rate. It is quickly increased before rockburst and then ceased immediately.

Methods of microseismic control and seismoacoustic emission registration 
One of the rock massif diagnostic methods is the microseismic oscillations registration method permitting to single out the massif domains in which the rock pressure redistribution process as a result of man-made disturbances creates complicated processes of massif destruction at the large-scale irregularities and at microlevel which leads to appearance of seismoacoustic signals of different frequency and intensity. The natural seismoacoustic emission registration methods were applied sufficiently widely at coal mines and ore mining enterprises.

The microseismic multichannel stations with operative processing of information are effective at present time for the operative production control and for prognosis of state and behavior of rocks massifs.

The microseismic station defines the coordinates of the birth-places of acoustic emission signals in the rock massif being developed and gives an opportunity to observe their distribution in the process of forming of a focus of the rock pressure manifestation. The received information about the intensity of mounting and decay of microseismic events enables to prognosticate ahead of time the likely place, time and intensity of rockburst.

At the mine "Star" (USA) with the aid of microseismic station the possibility of a rockburst at the depth $2.3 \mathrm{~km}$ was predicted. The system has defined the focus forming domain and the time moment at which one should expect the dynamic phenomenon. The presence of seismic activity at the menaced area is disclosed at several days before a rockburst which enables to take necessary measures to improve the safety of mining works.

In SAR the model seismic stations act at several gold mines. So, at the enterprises of "Blyworwhitezicht" a system based upon the geophones network in underground openings transmitting the seismic activity signals over standard telephone pair cables was used for that purpose. The system operates with the frequency $1 \mathrm{kHz}$ in real-time (on line) and controls continuously the input data corresponding to signals the amplitude of which exceeds a definite preset value. It is possible to calculate the place and the depth of rockburst according to that information. The rockburst place is usually located within the limit $5 \mathrm{~min}$ since the moment of its arising. Such information in a case of large rockburst enables to begin works for saving people situated in close underground openings.

At Kirovsky mine of Production Association "Apatit" the automatic seismic system is equipped and functioning (Melnikov et.al.,1986) embracing the range up to $100 \mathrm{~Hz}$ and using the 
seismometers SM3-VK as the primary transducers. The system is intended for analysis of seismic activity in the mine massif especially in the period of carrying out the explosions and for the prognosis of rockbursts. The system provides the source localization and evaluation of its seismic energy. The practical contribution of the system to provide the mining works safety is acknowledged at present time by the mining specialists.

Authors have developed and tested in nature measurement at mass industrial explosions the system of seismoacoustic phenomena registration in rock massif. Skeleton scheme of registration is given at Fig.1.4. As sensors the piezoaccelerometers of "Bruel \& Kier" Company were used with sensitivity $10 \mathrm{mv} / \mathrm{g}$ and working frequency range up to $10 \mathrm{kHz}$. The amplified signal from accelerometers comes to the input of registrator ROP-3 which transforms it from analogue form into digital one and memorizes it. The registrator works in waiting mode and provides the pulse signals registration with duration from $10^{-4}$ to $40 \mathrm{sec}$. (maximum frequency $100 \mathrm{kHz}$ ). The memory control circuit provides the signal continuous recording in waiting regime and output of information to magnetic recorder or to the system of remote control (SRC) carrying out the control of registrators at considerable distance $(2 \mathrm{~km})$, the gathering of digital information and its visual control. The keyboard of remote control is installed on the surface to record the information on magnetic tape or straightforward to electronic computer.

The system allows to carry out the seismoacoustic measurements in underground openings as in "quiet" situations as in the process of powerful explosion strike to the rock massif.

Experimental studies of stress state of rock massif by geoelectric method.

The interest to the geoelectric phenomena studying in a massif is defined by the possibility of the control method development and of short-range prognosis of the massif stress state changes according to the natural geoelectric fields variations having as local as wide-scale character.

At present time a variety of publications are devoted to that question however there are only few generalizing works and they as a rule are devoted to the narrow research direction (Goxberg et.al.,1988; Tarasov \& Durdin,1983). The creation of sufficiently full review of information presented in the literature is not easy task mainly due not to the information volume but due to their nonconformity. That is why it is necessary to make a series of remarks concerning the basic 
ideas of arising, development and behavior of geoelectric fields in an ore massif.

First. The process of cracks forming at the loading change upon the ore body is laid in the basis of the model of geoelectric fields.

Second.Just the cracks forming process development as in the focus domain as in the domain of event preparation leads to the change of hydrodynamic and electrical characteristics of a rock and as a consequence of that to the activation of mechanical-electrical transducers of different kinds.

It is possible to relate to main types of mechanicelectrical transformations the following ones:

The cracks of ruptures - lead to a fracture of electrical ties and that is why at the boards of cracks the uncompensated charges can arise leading to high stresses.

The cracks of displacement - lead to the rock exfoliation along adhesion zones, to breaking of double electric layers and forming of uncompensated stresses on the crack boards.

The filtration of liquid contained in pores along cracksleads to the electrical current appearance in the ore provoked either by electrochemical or by electrokinetic effects.

Third.Inspite of the evidence of the mechanic-electrical transformations existence in the Nature one should be cautious to the identification of those processes with the electrical fields generation in laboratory conditions. The coming to the spatial scale differing $10^{3} \div 10^{6}$ times can not be pure quantitative which was noted in the series of works (Vorobjev, 1980; Maygkin et.al.,1974). Due to that reason the observations at the volumes with intermediate or even with real line dimensions are so important.

Such opportunities are presented at observations for deformed rock massifs in conditions of their natural loading. That is why the deformation processes of consequences at industrial explosions give an opportunity to study electric processes in volumes with characteristic dimensions in tenths and even in hundreds meters.

With that purpose the method of natural measurements of geoelectric potential was developed. At given method the geopotential is measured with the aid of metallic electrodes $M$ and $N$ (Fig.1.5) rammed in the ground or cemented in the rock. As a result of that the electrodes acquire some potentials and their difference $\Delta U_{m n}$ will be equal

$$
\Delta U_{m n}=E d l \text {, }
$$

where $E$ - the strength of electric field in the measurement area. It is possible to believe the field between electrodes to be homogeneous as a first approximation and then 


$$
\Delta U_{m n}=E \Delta l_{m n}
$$

where $\Delta l_{m n}$ - the distance between electrodes.

The following requirements were claimed to measurement channel (Fig.1.5). In order not to bring in the large errors into the measurements by compensating device the following condition should be fulfilled:

$$
\left(R_{1}+R_{2}\right)<<R_{e l}<<R_{m n}
$$

where $R_{e l}$ - the electrode grounding resistance.

Besides as it could be seen from the measurement equivalent circuit (Fig.1.6) to provide independence of sensitivity in voltage and to carry out measurements with an error not exceeding $10 \%$ the condition should be followed:

$$
R_{e l} \ll<R_{n n}<<R_{i n p}
$$

The value of $R_{m n}$ got by means of natural measurements is within the limits of $4 \div 25 \mathrm{kiloohm}$ depending upon the distance between electrodes $(1 \div 50 \mathrm{~m})$. Coming from those limitations the electrodes parameters were defined: the dia- meter $30 \mathrm{~mm}$, the length of deepened part - $(5 \div 10) \cdot 10^{2} \mathrm{~mm}$.

The registration of seismic and infrasonic oscillations and was carried out in parallel with the geoelectric potential measurements. The serial-production sensor $\mathrm{SV}-10 \mathrm{C}$ is used to measure seismic oscillations which is installed near to the geopotential sensors. The infrasonic registration is carried out by the microbarograph situated in closest vicinity from the seismosensor.

The geopotential is recorded in the frequency band $0 \div 10^{3}$ $\mathrm{Hz}$. The recording of seismic oscillations and infrasonic is carried out in the band $0.1 \div 10^{2} \mathrm{~Hz}$.

Numerous observations and analysis of obtained results enabled to suggest a proposal that the geophysical fields in apatite-nepheline massif are divided into two large groups dynamic and quasistatic ones.

The dynamically changed fields are conditioned by the dynamic relaxation of electrical charge at the cracks forming in a disrupted massif. The quasistatically changed fields are provoked by electrochemical and electrokinetical processes at the filtration of intraporous liquid along the massif cracks in the process of its stress state changing. Given fields are schematically shown at the Fig.1.7. Let's stop at the geophysical fields evaluation in an ore massif. 
The understanding of the cracks electrical relaxation mechanism is important for finding out the geophysical fields nature accompanying the seismic processes and especially for comprehension of the rockbursts electrical precursors etc.

To discuss different mechanisms of cracks relaxation and to evaluate their parameters it is necessary to suggest a crack model and the environment parameters. It is related to the latter: the massif electrical conductance $\sigma$ and its dielectric permeability $\varepsilon$, the dipole theory being laid down as the basis of the dynamically changed geophysical fields evaluation.

According to obtained data electrical resistivity of the Khibin massif rocks is in the range $(5 \div 20) .10^{3} \mathrm{ohm} / \mathrm{m}$ which corresponds to $\sigma$ equal $2.10^{-4} \div 5.10^{-5} \mathrm{ohm}^{-1} \mathrm{~m}^{-1}$.

It is more convenient further to use other form of presenting $\sigma \rightarrow \sigma_{o}$

$$
\sigma_{0}=\frac{\sigma}{\varepsilon_{0}}
$$

where $\varepsilon_{0}$-absolute dielectric permeability of vacuum equal to $8.8 \times 10^{-12} \mathrm{~F} / \mathrm{m}$.

Then $\sigma_{o} \approx(1 \div 2.2) \times 10^{7} \mathrm{~s}^{-1}$.

Let's look on the crack model. We shall call as the crack the cavity in compact massif the nose part of which with a length $l_{0}$ is limited by two planes situated at the angle $\beta$ to each other and continuously coming into the parallel planes with lengths $l_{1}=V_{c r} t$ where $V_{c}$ the crack growth velocity (see Fig.1.8).

The electrical field in a space surrounding the crack is practically concentrated near of the nose the strength lines of which represent circles with centers lying at the intersection line of planes forming the nose (Fig.1.9).

If the potential difference between the crack sides equal to $U_{o}$ then it is possible to write down for a field inside the nose (Lovtsov \& Ponomarev, 1988):

$$
E_{o}=\frac{-2 U_{o}}{\beta R},
$$

where $R<l_{0}$.

The field outside the crack correspondingly is equal to

$$
E_{\text {out }}=-E_{o} \frac{\beta}{\varepsilon(2 \pi-\beta)} \approx-E_{o} \frac{\beta}{2 \pi \varepsilon},
$$


because $\beta \ll 2 \pi$.

On the other hand the discharge current through environment will be $j=\sigma E_{\text {out }}=-\frac{d \delta}{d t}$ where $\delta$ surface density of charge equal to $E_{o} / 4 \pi$.

Then the dependence of the charge surface density at a given element upon time can be written as:

$$
\delta(t)=\delta_{o} \exp \left(-\frac{2 \beta \sigma}{\varepsilon} t\right)
$$

and the charge character relaxation time through environment will be

$$
\tau_{c}=\frac{\varepsilon}{2 \beta \sigma}
$$

For apatite-nepheline ores $\tau_{c}$ has limits (at $\beta \approx 10^{-2}$ ) $1.0 \times 10^{-5} \mathrm{C} \div 2.5 \times 10^{-5} \mathrm{C}$.

Let's estimate the ratio between the crack character growth $t_{c r}=R / V_{c r}$ and $c$ presenting an interest from the point of view of electrical relaxation

$$
H=\frac{t_{c r}}{\tau_{c}}=2 \frac{R \beta \sigma}{V_{c r} \varepsilon} \approx 2 \frac{d \sigma}{\varepsilon V_{c r}},
$$

where $d$ - the crack width in that point where it ceases to be widened.

If $H<1$ then the electrical relaxation has not time to decrease the potential difference between crack sides to any considerable extent.

If $H>1$ then the crack appears to be practically not charged. Letting $d \approx 0.001 \div 0.0005 \mathrm{~m}, V_{c r} \approx 10^{3} \mathrm{v} / \mathrm{s}$ we find that

$H=\left[2(0.001 \div 0.0005) \times(1 \div 2.5) 10^{7}\right] / 5 \approx 4 \div 50$ i.e. $>1$.

In other words the growing crack and high conductance of environment don't provide essential electrization of growing crack and that is why the electrical relaxation is carried out mainly through the environment.

Let's estimate the energy characteristics of radiation. The dipole moment of crack is equal to $P_{i}=q_{i} x_{e m}$, where $\mathrm{x}_{e m}$ - the dimension of emotional crack (Turchaninov \& Medvedev, 1973). Taking into account that the field outside the crack is equal to 


$$
E_{\text {out }}=-E_{o} \frac{\beta}{2 \pi \varepsilon}=\frac{U_{\min }}{\pi \varepsilon x_{e m}},
$$

where $U_{\min }$-Pachenovskij minimum, and $q_{i}=\frac{\sigma \pi x_{e m}^{2}}{4}$, we get

$$
q_{i}=\frac{U_{\min } x_{e m}}{16 \pi \varepsilon}
$$

Then $P_{i}=U_{\min } \frac{x_{e m}^{2}}{16 \pi \varepsilon}$.

It is necessary here to make following note. The real rock massif is always broken into blocks (volumes) of different hierarchical levels by the faults and route cracks system which as a result of external influence of natural or tectonic origin can exchange the accumulated energy. That means that in real conditions such volume is the source of a "noise" electrical field. As far as the volume stress state increases the process of cracks forming is intensified (Mastov, 1988).

The number of possible cracks is limited and is defined by their dimensions. As follows from laboratory and natural tests the connection between maximum possible density of embrional cracks and their dimensions is described as follows:

$$
N_{\max }=\left(\frac{1}{3 x_{e m}}\right)^{3} \text {. }
$$

When $N_{\max }$ is attained the microcracks pour together into a crack and the rock is destroyed (Goxberg et.al.,1988). $N_{\max }=$ $10^{8} \div 10^{9} \mathrm{~m}^{-3}$ for apatite-nepheline ores. Thus, the possibility appears to estimate the maximum strength of electrical field of some rock volume formed by a system of the "elementary" dipole radiators disposed isotropically.

Let each elementary radiator is characterized by some dipole moment $P_{i}$ and let the probability distribution function is given $f_{i}\left(P_{i}, \Omega_{i}\right)$ where $\Omega_{i}$-spatial angle.

At the distances from radiating dipole less than $10^{3} \mathrm{~m}$ (close zone) the known expression of electrostatics can be used (Morgunov \& Poxotelov, 1988):

$$
E=\frac{3\left(k p_{i}\right) k-p_{i}}{R^{3}}
$$

where $R$-the distance to the dipole, $k=r /|R|, r$ - radiusvector from dipole to the reception point.

The statistical average over angles for the isotropic distribution of dipoles yields 


$$
E_{\Sigma}=U_{\min } \frac{x_{e m}^{2}}{16 \pi \varepsilon R^{3}} \sqrt{2 n} .
$$

Supposing that at full destruction the cracks amount doesn't exceed $N_{\max }$ let's estimate the electrical field strength of some loaded massif (volume). At the Kukswoomchorr deposit where the measurements were carried out the typical block is limited with two systems of cracks with azimuths $125^{\circ}$ and $180^{\circ}$ and with average distances between distinct cracks 8 and $17 \mathrm{~m}$ correspondingly (Rybnov, 1993). The small-block crack d state is met as well with the distances between cracks from 1 to $3 \mathrm{~m}$. Assuming that one block takes part in the event preparation (generally speaking it is not true but it is admissible for estimations) let's express the relation for the electrical field strength as

$$
E_{\Sigma}=U_{\min } \frac{x_{e m}^{2}}{16 \pi \varepsilon R^{3}} \sqrt{2 N_{\max } V_{b i}},
$$

where $V_{b l}$ - the block volume.

Substituting the present initial data we get:

$$
E=\frac{(5 \div 20)}{R^{3}}
$$

depending upon the block dimension (from 3 to $17 \mathrm{~m}$ ).

It is evident that the radiation effective domain presents the sphere with the radius defined from the condition

$$
E_{\text {rad }} \geq E_{l e v} \text {. }
$$

Assuming $E_{k v}=(2 \div 3) E_{f}$ from the reference data (Rybnov, 1993) we shall get $E_{f} \approx(1 \div 3) 10^{-4} \mathrm{~V} / \mathrm{m}$. Then the registration domain radius will be equal to $R<50 \mathrm{~m}$. The above numerical estimates don't contradict to the series measurements results in openings with considerable change of stress-dynamical state (mining works with removal of large volume of rocks) in which falls were registered.

The discussed dipole radiation was apriori taken as isotropic one although the mechanisms of its arising generally speaking are anisotropic and that should be manifested in the radiation anisotropy. Given assumption is indirectly confirmed by series of observations for quasistatic geoelectric fields which will be commented below. The presence of even small irregularity provokes the increase of electrical field component perpendicular to the rock cleavage planes 
approximately two times. It is possible to speak in that case about the registration domain enlargement in $1.5 \div 2$ times.

One should note among other methods the hydrobreaking methods, ultrasonic one and different electromagnetic methods as well as radiometric method of radiation absorption by the rocks depending upon their density the latter being applied more and more. 


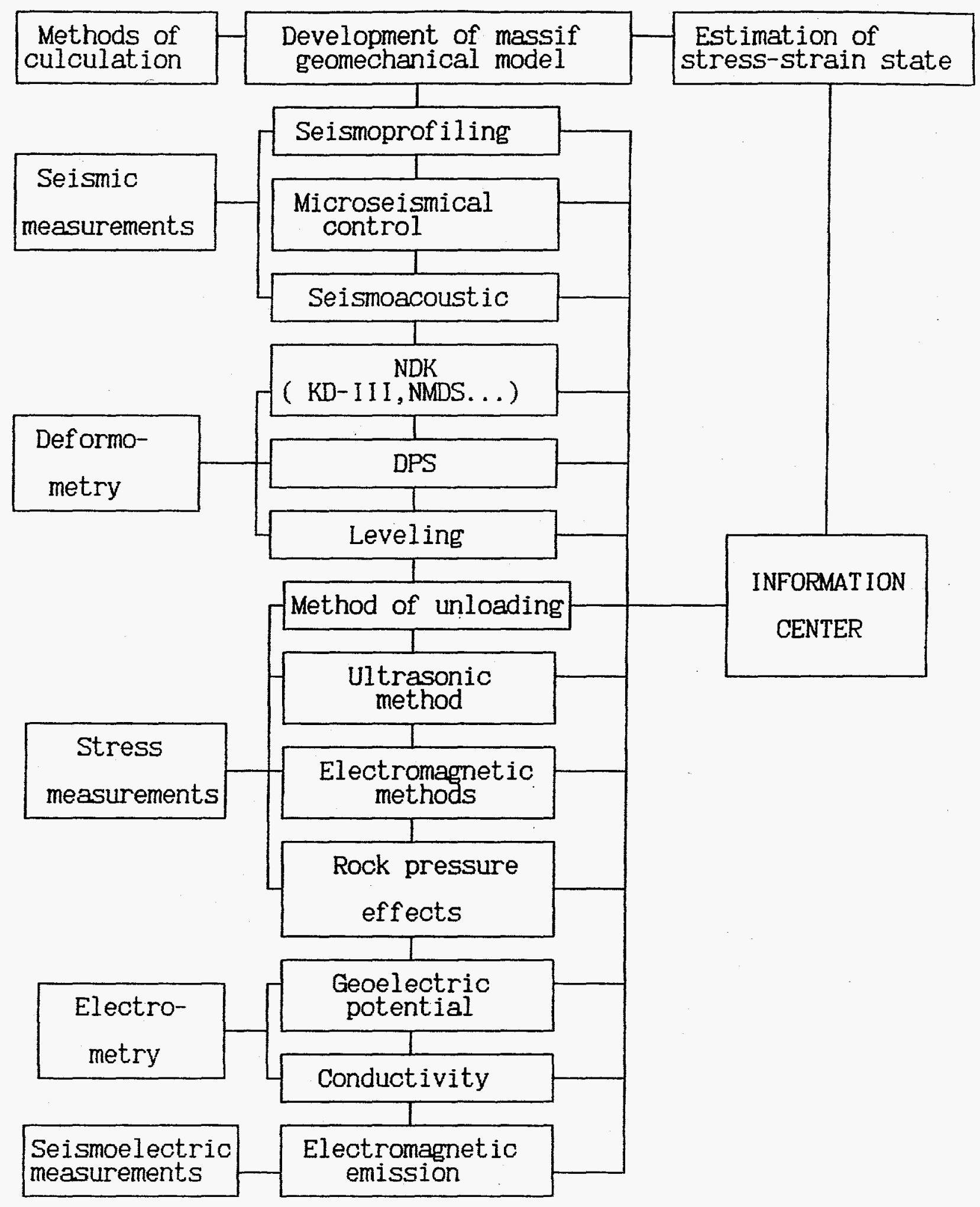

Fig.1.1 The geomechanical monitoring system. 

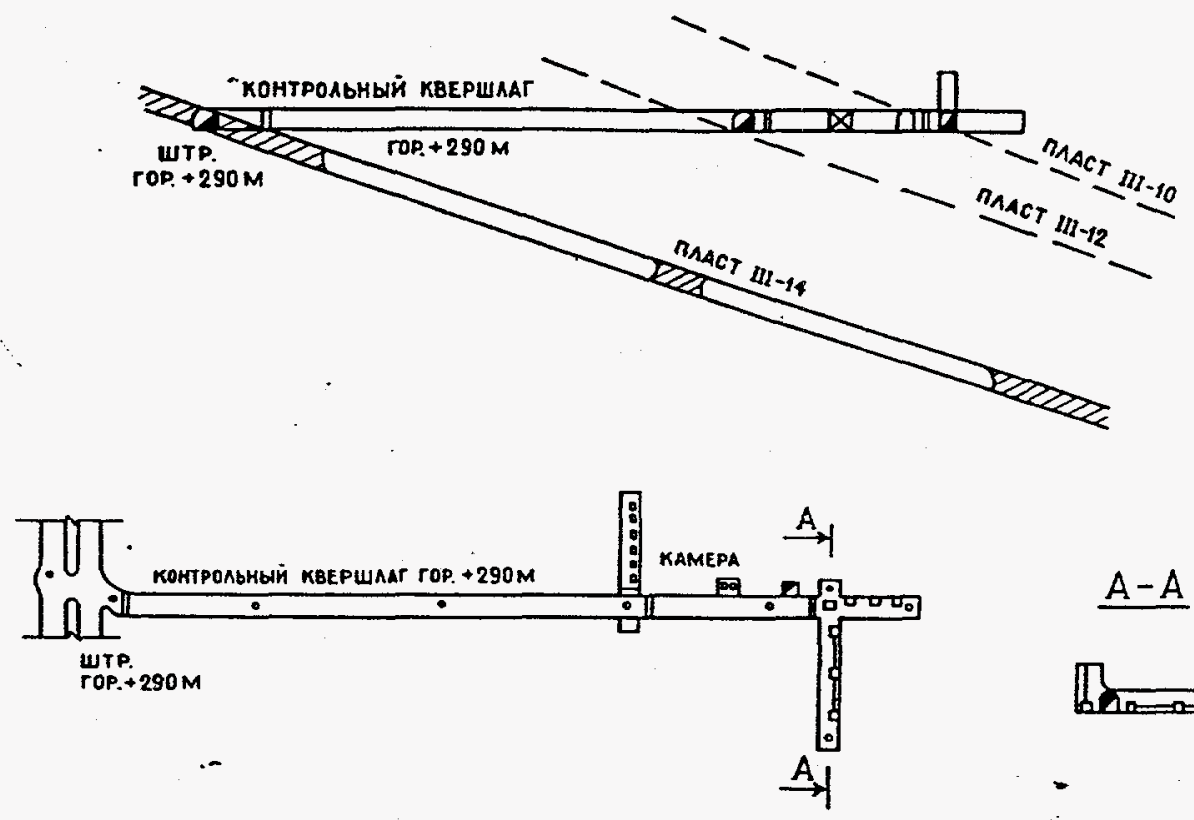

A-A

Fig.1.2. Control-observation crosscut at the mine "Umbozero"

a) vertical section, b) plan.

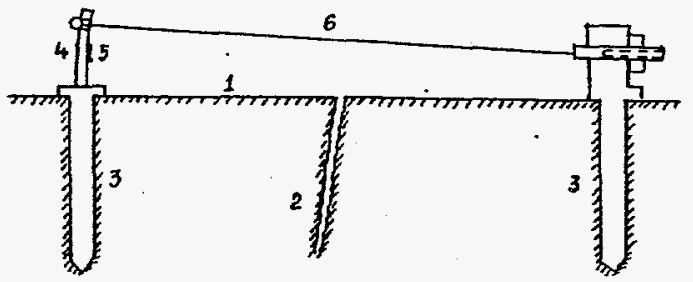

Fig.1.3. The general scheme of DPS sensor

1 - mass surface, 2 - fault, 3 - posts,

4 - console, 5 - strain gauge, 6 - string. 


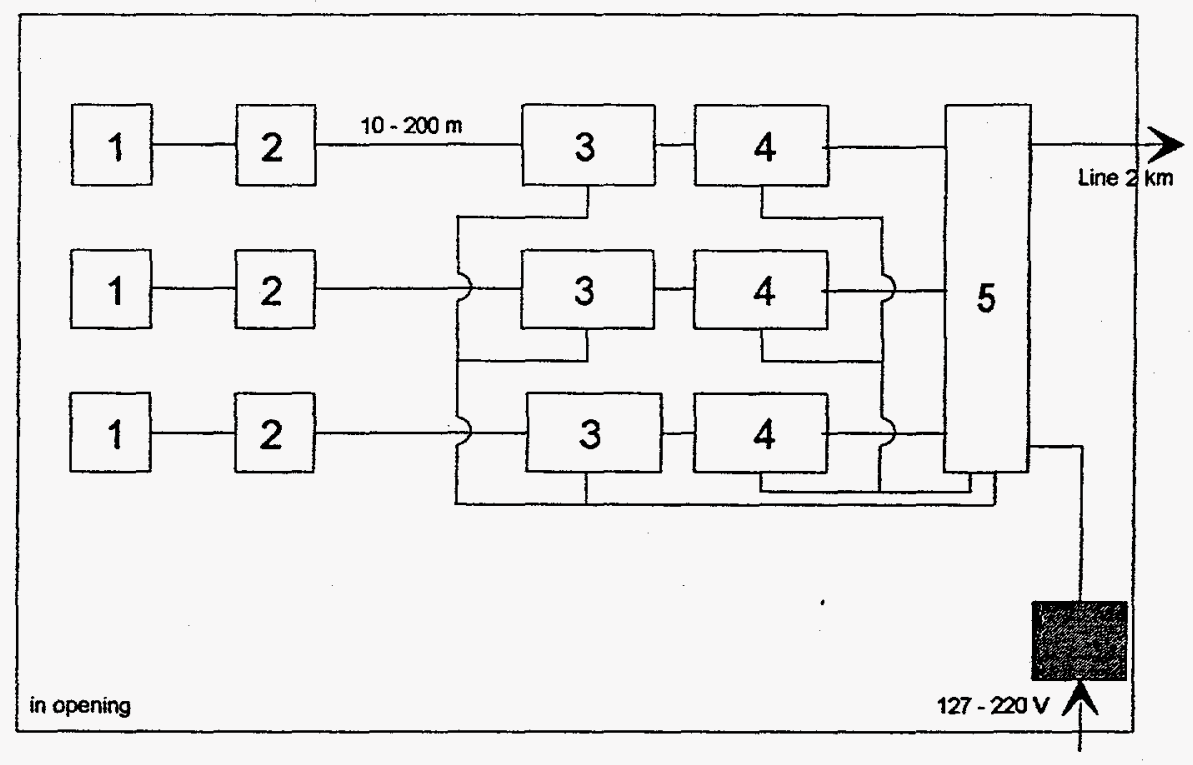

Fig 1.4 Sceleton sheme of seismacoustic registration. 1- sensor; 2- prebooster; 3- booster; SUM-6; 4ROP-3; 5- sistem of remout control (SRC). 


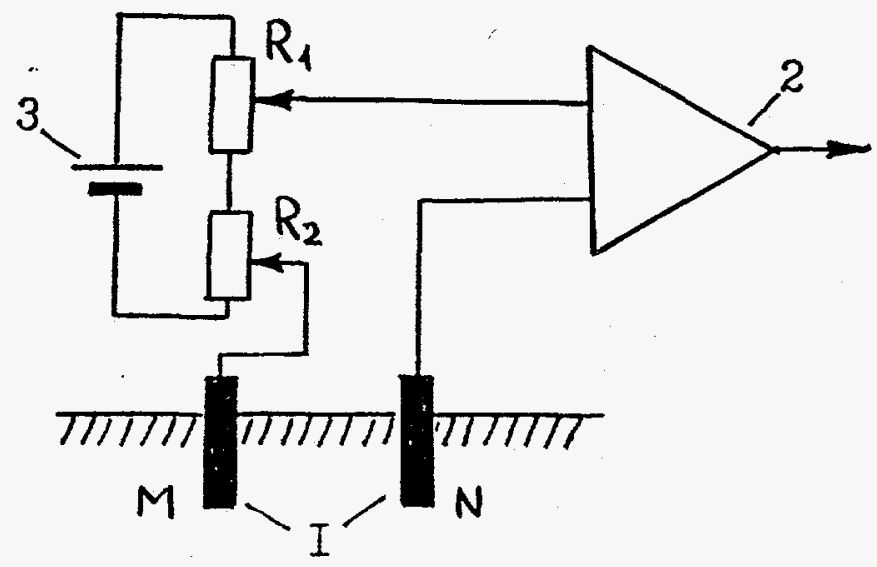

Fig.1.5. Arrangement of measurement the geoelectric potential.

1 - measuring electrodes, 2 - booster,

3 - compensator of tension voltage.

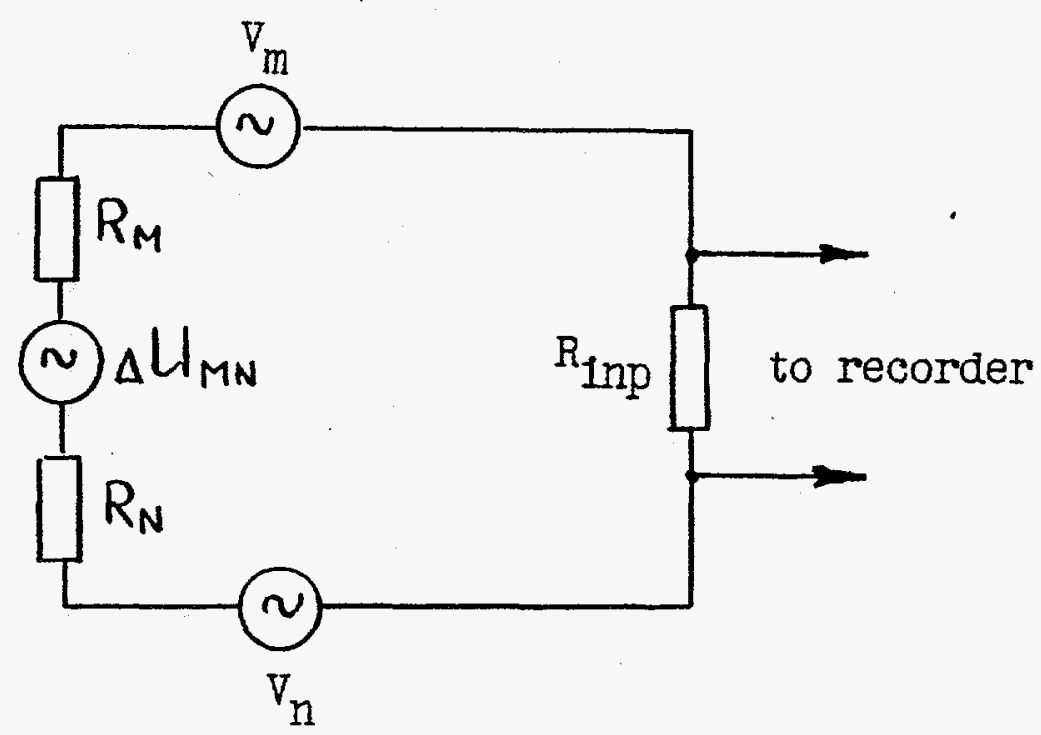

Fig.1.6. Equivalent arrangement of measurement $R_{m}, R_{n}$ - resistance of electrodes, $V_{m}, V_{n}$ - polarization voltage, $R_{\text {inp }}$ - resistanca of recorder. 


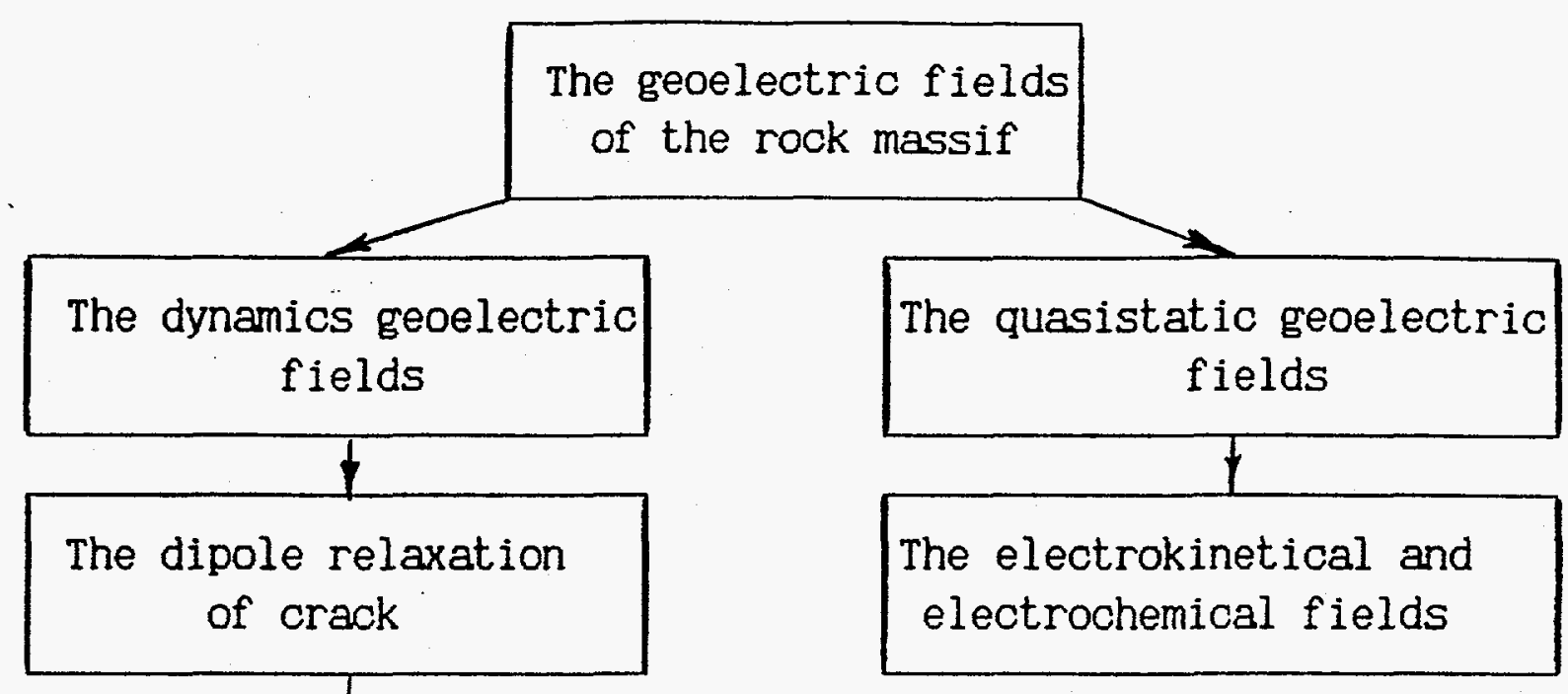

The system of the dipole radiators

Fig.1.7. The geoelectric flelds of the rock massif

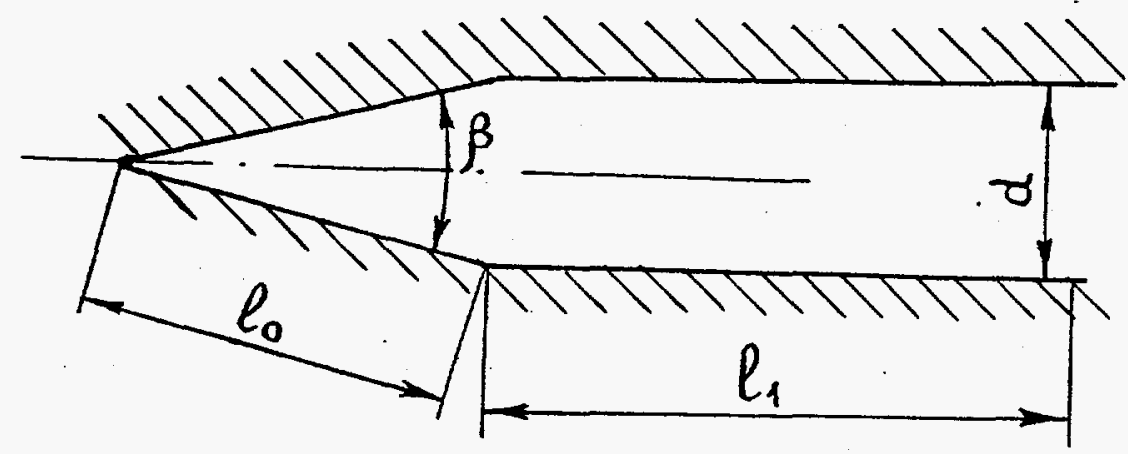

Fig.1.8. Model of crack.

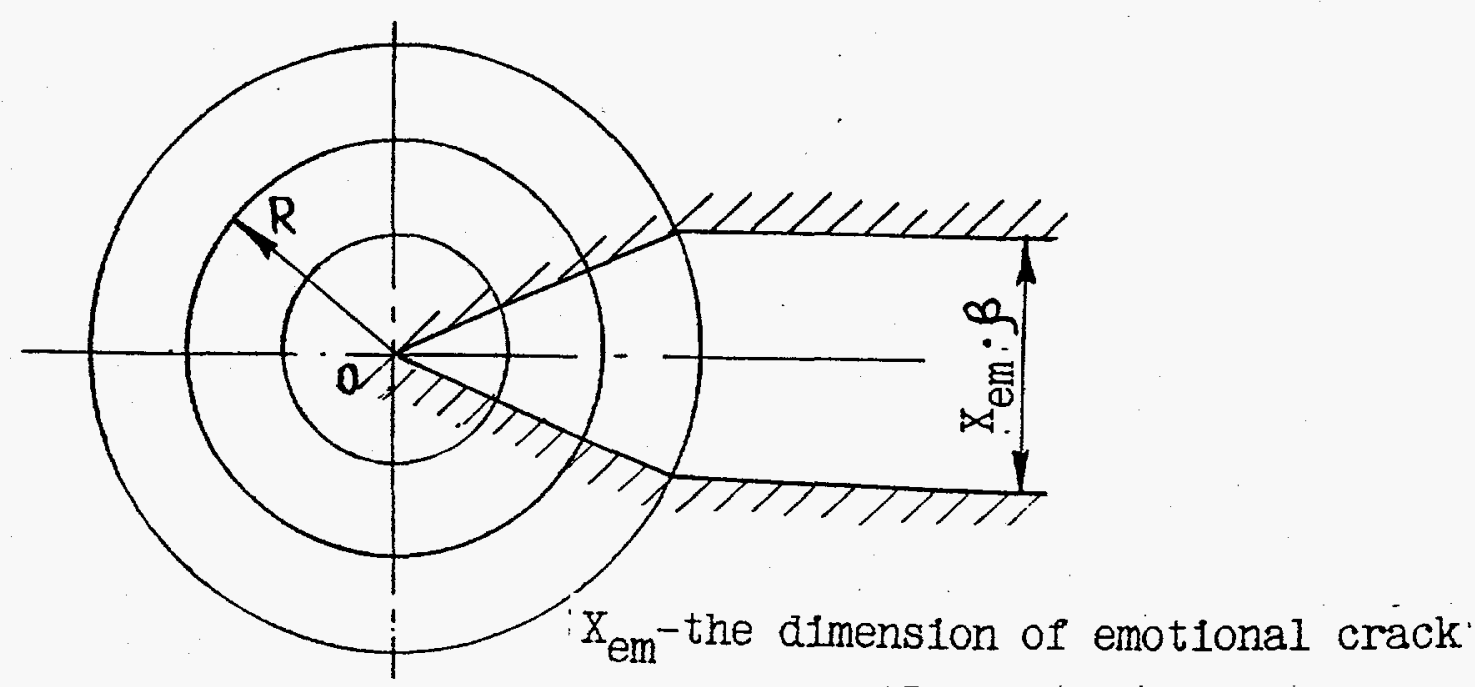

Fig.1. 9. Electric field of crack. 


\section{TECTONIC-PHYSICAL CHARACTERISTICS OF KHIBINY MASSIF AND ROCK PRESSURE MANIFESTATIONS}

\subsection{Khibiny massif.}

The study of rock massif behavior and of the engineering activity influence to physical processes in upper part of Earth crust was carried out by the authors in particular at the example of such objects as underground openings of Khibiny and Lovozero massifs mines of Kola Peninsula. The selection of observations object is defined by the presence in this region of considerable man-made influence to natural massif (redistribution of large masses at excavation of useful minerals, industrial explosions etc.) which may lead to freeing or redistribution of internal energy resources of massif - the potential energy accumulated by the medium. Large-scale engineering influence to geophysical medium presents additional possibilities for its study and is the necessary condition for mastering the study methods - observations for a medium at natural tectonic loadings even in seismoactive regions require the long time and carrying out the observations at large areas. Besides the stress-strain state of rock massif study in a region of large mines is of big practical importance. In particular the studies being fulfilled are directly connected to the solution of a problem of improvement of safe technology of ore excavation which is practically important at present time. Such problem is especially actual due to the ore excavation intensification and due to increase of the mining works depth.

With respect to structural features the Kola Peninsula is the part of Baltic shield included into Russian platform, its territory is composed mainly with pre-Cambrian polycrystallic formations.

According to present data the Baltic shield experiences at present time the raising with maximal velocity $9 \mathrm{~mm} /$ year near to the vertex of Botnic bay. At the Kola Peninsula territory the average rising velocity is $3-4 \mathrm{~mm} / y e a r$. At the Kola Peninsula general rising background it is possible to single out the distinct blocks differential movement. In particular the rising of Khibiny and Lovozero Tundras in after-glaciers time occured with higher velocities compared to the surrounding plain rising velocities at $0.3-1.2 \mathrm{~mm} /$ year.

The seismic data about earthquakes with intensity up to IV-VI in central part of peninsula witness for modern tectonic activity of Kola Peninsula. Epicenters of some earthquakes in Khibiny massif fall to the mining works region and the depth of their focuses is estimated as $5-15 \mathrm{~km}$. 
The Khibiny alkaline massif is situated in the Kola Peninsula central part and represents the intrusion of central type to which the biggest deposits of apatite-nepheline ores are related. The massif relief is expressed by strongly dissected height raised over the plain to $600-800 \mathrm{~m}$. Internal massif structure is defined by concentric disposal of complexes formed during three periods in which of each the rocks are included close according to their composition and genesis.

In tectonic aspect the Khibiny massif presents the hierarchic-block structure of a "broken plate" type with brightly expressed blocks of different rank divided by faults. Geomorphologic and geologic features witness for continuing at present time uprising movements of geodynamic blocks which is confirmed by long high-precision geodesic observations. The vertical differentiated movements velocity within the limits of Khibiny massif is $2-4 \mathrm{~mm} /$ year and reaches $47 \mathrm{~mm} /$ year. The Khibiny massif itself experiences the rising over surrounding plain with a velocity $1.0-1.5 \mathrm{~mm}$ per year. The hierarchicalblock structure of Khibiny massif is shown at Fig.2.1 at which the tectonically active zones are shown with conditioned signs. The Khibiny massif is dissected into series of distinct blocks by six radial faults: Susluayvsky, Malowoodyarsky, Khuelporsky, Central, Nyorkpakhsky and Koashkarsky. The differential movement of distinct blocks singling out at the Kola Peninsula general rising background occured along those faults (Turchaninov et. al.,1978). The central block including Kukiswoomchorr deposit and having total width $12 \mathrm{~km}$ is at present time the most studied structure unit. The characteristic features of that block are inherent to whole massif that is why their generalized description is given below.

Inside the block more high orders of structural irregularities are singled out (Markov, 1977; Turchaninov et. al.,1978). Within the Kukiswoomchorr deposit the series of streaks is disclosed connected to series of tectonic cracks: monchekite streaks having azimuth of stretching $120^{\circ}-130^{\circ}$ and fall angle $70^{\circ}-75^{\circ}$ follow each other in parallel at a distance 80-120 $\mathrm{m}$ and radial cracks - powerful oxidized (acid) zones with azimuth 550-70\%, fall angle 600-900 and with alternation 200-300 m. Still larger order of structural irregularity is defined by four steeply falling systems of large-block crack $\mathrm{s}$. At Kukiswoomchorr deposit the typical block is limited by two cracks systems with azimuths $125^{\circ}$ and $180^{\circ}$ and average distances between distinct cracks 8.3 and $17 \mathrm{~m}$ respectively.

The small-block crack state divides the massif into more small structural units with a distance between cracks from 0.1 to $1 \mathrm{~m}$. 
Thus in Khibiny massif the blocks hierarchy is actually observed to the study of which the given work is directed.

The majority of rocks of Khibiny massif are related to the nepheline sienits. This large group in a mining works place is presented mainly by yolite-urtrites, urtites and rischorrites as well as apatite-nepheline ores with different composition, structure and mechanical features (Table 2.1).

Table 2.1

\begin{tabular}{|l|c|c|c|c|c|c|}
\hline Rock & $\begin{array}{c}\text { Density } \\
\mathrm{g} / \mathrm{sm}^{3}\end{array}$ & $\begin{array}{l}\text { Compression } \\
\text { strength } \\
(\mathrm{MPa})\end{array}$ & $\begin{array}{c}\text { Tensile } \\
\text { strength } \\
(\mathrm{MPa})\end{array}$ & $\begin{array}{l}\text { Speed of } \\
\text { long. wave } \\
(\mathrm{m} / \mathrm{s})\end{array}$ & $\begin{array}{c}\text { Young's } \\
\text { modulus } \\
(\mathrm{MPa})\end{array}$ & $\begin{array}{c}\text { Poisson's } \\
\text { ratio }\end{array}$ \\
\hline Yolite- & 2,9 & 171 & 7.6 & 5360 & $6,5 \cdot 10^{4}$ & 0,22 \\
urtites & 2,8 & 168 & 10 & 5020 & $7,24 \cdot 10^{4}$ & 0,22 \\
Urtites & 2,95 & 160 & 4.5 & 5180 & $7,9 \cdot 10^{4}$ & 0,18 \\
Ore & $(156)$ & $(3.6)$ & $(5660)$ & $\left(7,4 \cdot 10^{4}\right)$ & $(0,29)$ \\
\hline
\end{tabular}

The average values calculated according to the series of measurements are given in the Table. The values for ore are given obtained at measurements in a direction perpendicular with respect to foliation and values corresponding to a direction parallel to foliation are given in the brackets.

Essential feature of the Khibiny massif rocks strained state is the presence of surplus (compared to lithostatic ones) stresses exceeding 5-10 times the gravitational stresses. The anomaly character of rock pressure manifestation is registered in many regions of Earth (Mountain Shoria, Dzhezkazghan, Tadjikistan, Ural, Sweden, USA etc.) by direct measurement. The fields of those stresses are irregular and characterized with considerable gradients in vertical and horizontal directions.

The tectonic stresses measurements in Khibiny massif were carried out by the personnel of Mining Institute of Kola Science Centre of Russian Academy of sciences during series of years (Turchaninov et. al.,1978). The stresses field reconstruction was fulfilled according to geological and seismic data and according to direct measurements with ultrasonic method and by the unloading method.

The results of such measurements for two horizons of Kirovskij mine are given in Table 2.2 for illustration. 
Table 2.2.

\begin{tabular}{|c|c|c|c|c|c|}
\hline Horizon & Depth & $\begin{array}{c}\text { Stresses } \\
\sigma_{3} \\
(\mathrm{MPa})\end{array}$ & $\begin{array}{c}\text { Tectonic stress } \\
\text { component T } \\
(\mathrm{MPa})\end{array}$ & $\alpha_{T}$ & $\beta_{T}$ \\
\hline+322 & $200-300$ & $25 \pm 20$ & $21 \pm 20$ & $90 \pm 30$ & $0 \pm 30$ \\
+252 & $300-400$ & $61 \pm 17$ & $58 \pm 17$ & $60 \pm 30$ & $0 \pm 25$ \\
\hline
\end{tabular}

Tectonic component of stresses was calculated with formula $\mathrm{T}=\sigma_{3}-\zeta \rho \mathrm{gH}$ where $\zeta=v /(1-v)$-coefficient of side thrust $(v-$ Poison's ratio), $\alpha_{T}$ - azimuth of tectonic stresses vector, $\beta_{T}$ - inclination of the tectonic stresses vector to the horizon in grades. The absolute values of $\sigma_{3}$ and indicated root mean square deviations witness for the presence in massif of the considerable tectonic stresses acting in subhorizontal direction. The strain tectonic component exceeds 5-10 times the gravitational stresses $\rho \mathrm{gH}$ and the value $\mathrm{T}$ is comparatively constant at the deep horizons sections - within the limits $40-$ $60 \mathrm{MPa}$ as under the valleys bottom as under the mountain peaks.

The measurements in distinct points of horizon +252 yield following values of stresses.

In the area of east haulage way ( 8 ort) at the depth $430 \mathrm{~m}$ $\sigma_{3}=27-32 \mathrm{MPa}, \sigma_{2}=0.5-0.6 \sigma_{3}, \sigma_{1}=\rho \mathrm{gH}=12 \mathrm{MPa}, \alpha_{T}=80-1000$.

In first ort in the area of east haulage way $\sigma_{3}=20-31$ $\mathrm{MPa}, \sigma_{2}=0.3-0.4 \sigma_{3}, \sigma_{1}=\rho \mathrm{gH}=9 \mathrm{MPa}, \alpha_{T}=90^{\circ}$.

The stresses $\sigma_{2}$ and $\sigma_{3}$ act in subhorizontal plane. At deepest horizon +166 the stresses are registered (in laid lateral) $\sigma_{3}=30-50 \mathrm{MPa}, \sigma_{2}=0.4-0.6 \sigma_{3}$. Given data witness for high level of tectonic stresses in massif.

\subsection{Man-made influences to massif.}

The Production Association "Apatit" - one of large enterprises for excavation and processing of phosphoruscontaining ores. The Association is created on the basis of the apatite-nepheline ores deposits unique with their reserves of Khibiny group situated in the Kola Peninsula center.

Kukiswoomchorr deposit developed by Kirovskij mine since 1933 is presented by powerful lens falling to the North-East at the angle $26-32^{\circ}$. The ore excavation had begun with mastering 
of mine horizons of deposit which are entirely completed at present time. Two deep horizons are under exploitation +322 and $+252 \mathrm{~m}$ with total project productivity 10.8 millions tons a year.

The exploitation works at Yuksporskoye deposit were begun in 1953. At present time the mine horizons $+530,+460$ and +410 $\mathrm{m}$ are completed.

The deposit Apatit circus is exploited by the Raswoomchorr mine since 1964. Three mine horizons are exploited: $+600,+530$ and $+410 \mathrm{~m}$. The delivery of excavated ore is carried out by ore passes to the railway horizon (mark $+430 \mathrm{~m}$ ).

The deposit Plateau Raswoomchorr is exploited by the quarry "Centralniy" since 1964. The works are carried out at 9 horizons from mark +835 to $+970 \mathrm{~m}$. The ore from that quarry biggest at PA "Apatit" is poured through deep ore passes to the horizon of permanent railway tunnel (mark $+380 \mathrm{~m}$ ). At the expense of high concentration and permanent technical reequipment of mining works the production capacity of quarry was increased from 12 to 18 millions tons a year during 5 years) 1975-1980), from 18 to 22 millions tons during 2 years and from 22 to 25 millions tons during 2 years as well. The excavation intensification at the "Centralniy" mine provided the main increment of production volumes of Association in 70-80th years.

The mine "Vostochniy" developing deposits Koashva and Nyorkpahk includes 2 quarries. The development of Koashva deposit with surface mining technology began at 1978. The project capacity is 7.0 millions tons. Both deposits are to be developed with underground methods after the upper part completion with surface mining technology.

The scales of man-made influence to massif in given region could be evaluated from the fact that there are in Khibiny more than 40000 linear meters of underground openings and about 100 millions tons of rock mass extracted annually. The unloading of corresponding zones of massif is accompanied by the other zones loading in places of waste storage. Those processes influence to the massif state as a whole and are fixed by the precise levelling in a form of corresponding rises of the Earth crust sites. Such influence is illustrated at the example of slow displacements of the Yukspor tunnel sections. The removal of large volumes of rock mass is discussed in present work as main reason of the balance breaking of natural massif provoked the man-made earthquake.

The massif is subjected to regular local dynamic influences at carrying out large industrial explosions. The power of underground industrial explosions reaches $300 \mathrm{t}$, total power of explosions at open quarries - 400-500 t. 
Thus the Khibiny massif seems to be very interesting object to study the man-made factors influence to seismic regime and to mastering of observation methods.

\subsection{Seismic circumstances at the Kirov district mining enterprises territory.}

The Earth crust at Kola Peninsula according to geographic data has a stratum-block structure. The thickness of Earth crust is 43-36 km decreasing from west to east. The earthquakes focuses are related to upper part $(5-15 \mathrm{~km})$ not exceeding 20 $\mathrm{km}$. The local godographs indicate to essentially larger velocities of seismic waves compared to other platform areas and generalized Jeffris-Boullien and Herrin godographs (Sharov, 1989).

With respect to dynamics aspect the Kola Peninsula is remote continental outskirt of Atlantic-Boreal rift structure and is characterized by the weak compressing forces presence inside of Earth crust manifesting in boulder-block fault and fault-uplift displacements (Bajitskij \& Kremenetskaya, 1989). The stresses freeing zones or main seismogenic zones are localized in the intersection knots of tectonic faults of different ranks. One of such knots - Kildin-Kovdor knot of seismic activity is characterized by weak and not deep earthquakes $(\mathrm{H}<10 \mathrm{~km})$ of Khibiny massif.

The information about the seismicity of studied region is contained in different seismic catalogues. In 1956 swedish seismologist M.Bot published "Catalogue of Fennoscandia earthquakes in 1891-1950" in which mainly microseismic data about earthquakes of western part of Fennoscandia are gathered and there are no information about eastern (Russian) part. That omission was to sufficient extent liquidated by the works of G.P. Gorshkov and G.D. Panasenko (Gorshkov, 1947; Panasenko, 1957) in which the detailed description of macroseismic and instrumental information is given about all earthquakes registered in Karelia and at Kola Peninsula before 1955 inclusive. Since 1977 G.D.Panasenko began to publish with an index the Materials of world data center through the Interbranch Geophysical Committee - catalogues of the Fennoscandia earthquakes since 1951 to 1985. Those catalogues are based mainly at instrumental observations and include the Kola Peninsula and North Karelia territories, the seismic sources of artificial origin being filtered off in that (explosions at mining enterprises and industrial construction sites). Due to dense network of seismic stations since 1970 the certain registration of all seismic phenomena within the Fennoscandia limits with magnitude more than 3.0 is provided but for considerable part of region of more weak ones as well. For a period 1951-1980 11 earthquakes in Kola Peninsula were 
registered including those in Kirovskij district (with radius $100 \mathrm{~km}$ from seismic station Apatityl - 4 earthquakes. $E$. 0. Kremenetskaya began to publish "Bulletins of the North Europe earthquakes" (Publishing House of Kola Branch of USSR Academy of Sciences) according to materials of soviet seismic stations Apatity, Anderma, Pyramide, Barentzburg, Polar sunrises and Umba which include the earthquakes of Northern part of USSR and European sector of Arctic. To present time the bulletins for 1986-1987 are published which contain data about 10 Kola earthquakes with magnitude from 2.5 to 4.4 . Only one of those earthquakes at May 141987 among those earthquakes had a magnitude 2.8. The seismological catalogues data were laid down into the base of division of soviet territory of Baltic shield into seismic districts. The Baltic shield territory in southeast part of which the Kola Peninsula is situated is rather quiet place with respect to seismic activity but within the limits of Russian platform the Baltic shield is related to one of three areas (besides Voronezh rising, pre-Ural area and Middle Ural) of comparatively increased activity. According to the data about 50 not deep earthquakes for 1626-1974 the Baltic shield including Kola Peninsula are attributed to the 6 number zone of seismic activity which is extended from ural to northern coast of Kola Peninsula. Maximum level of earthquakes of this zone corresponds to the magnitude 5.4 and is defined mainly by the Kandalaksha inlet earthquakes. The relative displace- ments of platform blocks in the zones of contiguity of which the tectonic stresses concentration occurs serve as the sources of oscillations at the earthquakes of this type.

The number of earthquakes increase in Khibiny during last years attracts the intent attention of researchers majority of whom connects that phenomenon to the large-scale mining works influence to the Earth crust under which the redistribution of stresses occurs not only in a close zone but at considerable distance from them as well.Besides at the loading processes (cleaning works) or additional loading (forming of large waste or tails storages) the deformation regimes of different geodynamic blocks are disrupted and the course of natural geodynamic processes of the Earth crust development in region are activated which in turn changes the seismic regime and is manifested in the seismicity growth.

The general tendency to the seismicity increase in Khibiny has outlined since the second half of eighties and several periods of utmost activity are marked at that background for passed time. As an example the seismic events in region are given below in December 1993 (Kuzmin et. al., 1994).

At December 91993 in $04 \mathrm{~h} 21 \mathrm{~m} 19.3 \mathrm{~s}$ in the Kirovskij mine area the earthquake was registered the magnitude of which was 
$M=1.7$. The earthquake epicenter was defined just at the mine within the limits of a block-pillar, horizon $+252 \mathrm{~m}$.

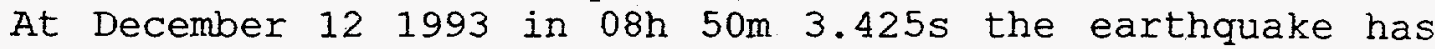
occured with magnitude $M=3.8$. It was felt in settlement Kukiswoomchorr and in Kirovsk town as one with magnitude 6 and 5 correspondingly. The earthquake epicenter was situated just within the limits of northern part of the Kirovskij mine horizon $+252 \mathrm{~m}$. The depth of a focus is estimated as 500-1000 m from the Earth surface.

At December 161993 in $19 \mathrm{~h} 33 \mathrm{~m} 2.3 \mathrm{~s}$ the earthquake has occured the magnitude of which was $M=2.3$. The coordinates of epicenter were defined according to the "Apatity" seismic station and "ARRAY" system data and corresponded to the Kirovskij mine works area. According to witnessing of the Kukiswoomchorr dwellers it was accompanied by strong seismic bump (like strong mass explosion) and underground boom.

At December 171993 in $06 \mathrm{~h} 47 \mathrm{~m} \mathrm{20.6s}$ the earthquake has occured the magnitude of which is estimated as from 2.0 to 2.6 . The epicenter position is limited by the mining works carrying out area of Kirovskij mine.

At the same day in $12 \mathrm{~h} 22 \mathrm{~m} 28.4 \mathrm{~s}$ the earthquake was registered the magnitude of which is estimated as from $M=2.0$ to $M=2.7$. The earthquake epicenter also was situated in close vicinity of Kirovskij mine. According to witnessing of Kukiswoomchorr settlement dwellers both those events were felt in a form of underground bump and were accompanied by a boom.

The focuses of all earthquakes occured for that period are situated at the depth not exceeding 500-1000 $\mathrm{m}$ from Earth surface i.e. those are small-focuse earthquakes which represents one of features of man-made (induced) seismicity.So close disposition of the earthquakes epicenters limited by the Kirovskij mine works area where the cutting of a block-pillar was carried out at the horizon $+252 \mathrm{~m}$ and temporal connection of those events enables to believe that this period of the seismicity activation is directly connected to mining works and conditioned by sharp change of mining-engineering situation.

The epicenters disposition analysis shows that all earthquakes with rare exception occured in the active faults zones and are grouped in closest vicinity to mining works area. As the mining works are developing $i . e$. with an increase of total amount of extracted ore at the mines since the exploitation beginning the area embraced by the earthquakes epicenters is increased. The earthquakes begin to be manifested at still more distance from mines which witnesses for that the bigger number of geodynamic blocks are involved into the activation process and the seismic active zone area is increasing. 
Thus the Kirovskij mining industrial district according to the map of division into seismic districts of 1980 which is a normative document for civil and industrial construction is attributed to the surface concussion zones with 6 numbers at maximum possible natural earthquakes with focuses in the Earth crust at depths $5-15 \mathrm{~km}$.

\subsection{Comparative analysis of seismic catalogues and explosions journals.}

The comparative data for 1989-1990 are given in Tables 2.3-2.5 for explosions at Yukspor, Kirovskij and Centralniy mines according to explosions journals and seismological catalogues of Helsinki university (Seismic events in Northen Europe, 1989).

only the seismic stations data of Northern countries are used in Helsinki catalogue (without soviet stations) situated at the distance not less than $300 \mathrm{~km}$ from mines. The earthquakes epicenters are defined with the aid of adequately selected two-layers models of Earth crust and regional godographs and the magnitudes - in single manner according to a special regional scale using the oscillations duration in seismic mode.

At the Yukspor mine during January-october 198923 explosions were made with the powers from 2 to $220 \mathrm{t}$, at Kirovskij mine during January 1989 -June 1990 - 63 explosions with powers from less than 1 to $260 \mathrm{t}$. At both mines the explosions are carried out in mines without throwing out to the surface. Practically all explosions are timed to sunday at Kirovskij mine and Friday at Yukspor mine. The explosions of both mines actually are often coincided in time and sometimes are made in close moments of time. Let's note that at April 16 1989 after the explosion at Kirovskij mine (240 tons) provoked the man-made earthquake 2 minutes later the explosion at Yukspor mine was made (120 tons).

At Centralniy mine the open explosion works are made in Tuesdays and Fridays with powers from 50 to 550 tons. Altogether 89 explosions were made for 1989.

As it seen from Table 2.3-2.4 the explosions at mines are disclosed by the northern stations network at distances more than $300 \mathrm{~km}$ with the powers more than 10 tons. The discrepancy in true and seismological times are as a rule within the limits of 1 minute which corresponds to the time mark precision in duty works journals. The precision of seismological times at using of regional godograph is usually not worse than 1 second.

At explosions at Kirovskij mine the seismological epicenters are related to 2 points with coordinates $67.7{ }^{\circ}$, $33.70 \mathrm{E}$ in $3-6 \mathrm{~km}$ to north-west (17 explosions) and $67.6{ }^{\circ} \mathrm{N}$, $34.0^{\circ} \mathrm{E}$ in $10-15 \mathrm{~km}$ to south-east (10 explosions) relative to 
the true epicenter position. For explosions of Yukspor mine the epicenter of majority of explosions coincides with a point with coordinates $67.7{ }^{\circ} \mathrm{N}, 34.0^{\circ} \mathrm{E}$ with a distance about $12 \mathrm{~km}$ from the mine center. The seismological epicenter of majority of explosions is related to the same point $(66$ of 84 explosions) at mine "Centralniy" which corresponds to approximately east drift to $7 \mathrm{~km}$. As a whole it is possible to believe that the epicenters defining precision according to seismological data in average is $7-10 \mathrm{~km}$ especially so for strong explosions.

At Kirovskij and Yukspor mines for explosions with powers 100-250 tons the magnitudes defined according to oscillations duration vary within the interval 2.3-3.1. At the Centralniy mine the similar magnitudes for explosions with power 70-500 tons lay in the numbers range 2.1-3.1. In all cases those values are less for more than 1 than the man-made earthquake magnitude of April 161989 (Chapter 3).

Let's note that there are many cases when the seismic catalogues don't give the magnitude value for strong explosions or define it by a value less than 2 .

\subsection{The rock pressure manifestation features at the deposit completion in Khibiny.}

The rock pressure at apatite mines came to be manifested in a form of peeling, bouncing, dynamic slaughtering from the depth $100 \mathrm{~m}$ at the sites situated lower than the valley bottom. The rockbursts appeared at the depth 300-400 m. Altogether 20 rockbursts occured and all of them did in closest vicinity from broken tectonic irregularities near to which the external features of rockburst danger are registered.

The rockburst analysis given below and their interconnection with the district block structure of mines in Khibiny is fulfilled by employee of the Geological Institute of Kola Science Center of Russian Academy of Sciences Tryapitsyn V.M. (Tryapitsin \& Syrnikov, 1991).

The faults influence zone estimation dimensions taking into account their thickness was made along the openings situated near the faults. The tectonic irregularities were divided into five groups according the thickness: less than 2 $\mathrm{m}, 2-4 \mathrm{~m}, 4-6 \mathrm{~m}, 6-8 \mathrm{~m}, 10 \mathrm{~m}$ and more and taking that into account the samples of the sites extension with external features of a rockburst danger were made. The histogram of the influence zone dimensions distribution depending upon its thickness for 43 samples is shown Fig.2.2. In general case the external rockburst danger features in openings are manifested at the distance from a fault which 5-10 times exceed its thickness. The stresses measurements with unloading method 
show that in the fault influence zone the maximal horizontal stresses are increased 1.5-2 times and are 60-80 MPa.

The analysis of rockbursts occured at Kirovskij mine of PA "Apatit" was carried out taking into account the basic structural and mining factors of a rockburst danger: the cleaning works influence zone, the influence of openings to each other, the depth of excavation, the distance from large cracks. Nine rockbursts of 14 (Table 2.6) occured in the zones of high rock pressure near to tectonic irregularities, five ones are distant from the cleaning works border for more than $300 \mathrm{~m}$. In all cases the rockbursts occured near tectonic irregularities at the distance from them not more than $30-40 \mathrm{~m}$. In nine cases the bursts occurred in adjacent openings in the zones of high rock pressure. This group of rockbursts is remote from faults for a distance up to $40 \mathrm{~m}$. Four rockbursts occurred in lonely openings outside the cleaning works influence zone not near to faults i.e. in those cases only one of listed factors influenced the rockburst danger - faults.

The scheme of block structure of the Khibiny apatite mines district is given at Fig.2.3. The faults localization was defined on the basis of geomorphologic analysis of topographical maps of different scale and deciphering of aerial photographs. The maps with the scales 1:2500000 (I rank), 1:500000 (II rank), 1:100000 (III rank), 1:25000 (IV rank) were analyzed. The tectonically active "living" faults are presented at the scheme which manifested their activity during 10-16 thousands years i.e. in after-glacier time, their traces are directly discovered in relief.

The existence of those faults and their localization are confirmed by geological, tectonical and hydrogeological features as well as by the geological documentation of barings, openings and prospecting drilling holes. On the basis of tectonophysical analysis of crack tectonics and instrumental measurements the stresses fields in disclosed blocks and ones at their borders are defined.

The faults presence in the high horizontal stresses conditions can be the basic factor of rockburst danger at carrying out the mining works. Because this factor was not taken into account at projecting and construction of Kirovskij mine and as a result of that the complex of openings was laid down in the fault influence zone. All forms of rock pressure were noticed here including the rockbursts. The bumps spatially oriented along the fault under which even monolith concrete opening support is subjected to destruction are systematically registered by a seismic station.

Thus the faults should be treated as structural irregularities of different rank provoking the general stresses field changes and as the weakening planes along which the 
instant movements of blocks with the seismic energy excretion (tectonic rockbursts).

The tectonic rockbursts the consequences of which are spreaded to sites of large dimensions represented the most denger. Four tectonic rockbursts occured at the Khibiny apatite mines.

The tectonic rockburst occured at Yukspor mine in a pillar block between two fronts of cleaning works. The pillar dimensions are $65 \times 70 \times 70 \mathrm{~m}$, the rock strength $150-160 \mathrm{MPa}$, the depth from the surface $300-350 \mathrm{~m}$. The value of maximal tectonic stresses 20-30 MPa. The steeply sloped monchekit dike with a thickness $5-8 \mathrm{~m}$ crosses the pillar along a diagonal. The rockburst was registered by the seismic station as an earthquake with intensity II-III. The horizontal shift within the limits of whole pillar occurred along the dike complex steeply sloped system. The value of displacement was $3-5 \mathrm{~cm}$. The rockfalls were noticed in all openings crossed by the fault. The volume of rockfalls exceeded $180 \mathrm{t}$. 
Table 2.3

Industrial explosions in Kirovskij mine

\begin{tabular}{|c|c|c|c|c|c|}
\hline \multicolumn{3}{|c|}{ Explosion journals of mines } & \multicolumn{3}{|c|}{ Seismic catalogues } \\
\hline Data & $\begin{array}{l}\text { Time } \\
\text { (Moscow) }\end{array}$ & Power $(t)$ & Time (UTC) & Magnitude & $\begin{array}{c}\text { Coordinates } \\
\varphi_{\mathrm{N}} \lambda_{\mathrm{E}}\end{array}$ \\
\hline 1 & 2 & 3 & 4 & 5 & 6 \\
\hline $\begin{array}{r}8.01 .89 \\
15.01 .89 \\
29.01 .89 \\
5.02 .89 \\
5.03 .89 \\
19.03 .89 \\
2.04 .89 \\
9.04 .89 \\
16.04 .89 \\
30.04 .89 \\
14.05 .89 \\
16.07 .89 \\
23.07 .89 \\
30.07 .89 \\
6.08 .89 \\
15.10 .89 \\
29.10 .89 \\
6.11 .89 \\
6.11 .89 \\
26.11 .89 \\
10.12 .89 \\
17.12 .89 \\
24.12 .89 \\
31.12 .89 \\
7.01 .90 \\
21.01 .90 \\
4.02 .90 \\
11.02 .90 \\
18.02 .90 \\
25.02 .90 \\
4.03 .90 \\
8.03 .90 \\
25.03 .90 \\
1.04 .90 \\
8.04 .90 \\
22.04 .90 \\
30.04 .90 \\
13.05 .90 \\
25.0590 \\
27.05 .90 \\
17.06 .90 \\
24.06 .90\end{array}$ & $\begin{array}{r}8.53 \\
7.20 \\
10.18 \\
10.20 \\
9.55 \\
9.40 \\
10.40 \\
8.46 \\
10.35 \\
9.55 \\
9.45 \\
9.20 \\
10.04 \\
8.50 \\
9.57 \\
9.20 \\
8.19 \\
9.00 \\
9.02 \\
9.35 \\
10.05 \\
7.45 \\
8.30 \\
7.31 \\
9.24 \\
10.03 \\
9.30 \\
8.33 \\
6.48 \\
8.45 \\
7.55 \\
8.23 \\
9.32 \\
9.05 \\
7.53 \\
8.30 \\
8.45 \\
8.20 \\
16.06 \\
8.08 \\
9.52 \\
7.51\end{array}$ & $\begin{array}{c}168+1 \\
90+10 \\
110+13 \\
10 \\
12 \\
10 \\
13 \\
154+6 \\
230+9 \\
240+19 \\
7 \\
120+4 \\
150+6.5 \\
152 \\
12 \\
12 \\
98 \\
220+10 \\
100 \\
170+10 \\
230+8 \\
85 \\
10+60 \\
142 \\
150 \\
17 \\
10 \\
9 \\
120 \\
127+10 \\
127+73 \\
8 \\
170+15+70 \\
173+3 \\
16++170 \\
10 \\
10+211 \\
12 \\
3 \\
150+5 \\
133+18 \\
4.5\end{array}$ & $\begin{array}{r}5.53 \\
4.19 \\
7.17 \\
6.54 \\
6.42 \\
4.46 \\
6.35 \\
5.52 \\
\\
6.04 \\
4.50 \\
\\
5.19 \\
5.58 \\
5.59 \\
6.35 \\
\\
\\
4.30 \\
6.25 \\
7.02 \\
5.31 \\
3.47 \\
5.45 \\
4.55 \\
5.32 \\
5.06 \\
3.53 \\
4.47 \\
4.21 \\
12.05 \\
4.08 \\
5.50\end{array}$ & $\begin{array}{l}2.6 \\
2.9 \\
2 \\
2.9 \\
2 \\
2.5 \\
2.4\end{array}$ & $\begin{array}{l}67.6-34.0 \\
67.7-33.7 \\
67.7-33.7 \\
67.6-34.0 \\
67.7-33.7 \\
67.7-33.7 \\
67.58-33.68 \\
67.7-33.7 \\
67.7-33.7 \\
67.7-33.7 \\
67.6-34.0 \\
67.6-34.0 \\
67.6-34.0 \\
67.7-33.7 \\
\\
67.7-33.7 \\
67.7-33.7 \\
67.7-33.7 \\
67.6-34.0 \\
67.7-33.7 \\
67.7-33.7 \\
67.7-33.7 \\
67.6-34.0 \\
67.7-33.7 \\
67.7-33.7 \\
67.7-33.7 \\
67.7-33.7 \\
67.6-34.0 \\
67.6-34.0 \\
67.7-33.7\end{array}$ \\
\hline
\end{tabular}


Table 2.4

Industrial explosions in Yukspor mine

\begin{tabular}{|c|c|c|c|c|c|}
\hline \multicolumn{3}{|c|}{ Explosion journals of mines } & \multicolumn{3}{|c|}{ Seismic catalogues } \\
\hline Data & $\begin{array}{l}\text { Time } \\
\text { (Moscow) }\end{array}$ & Power ( $(t)$ & Time (UTC) & Magnitude & $\begin{array}{l}\text { Coordinates } \\
\varphi_{N} \lambda_{E}\end{array}$ \\
\hline 1 & 2 & 3 & 4 & 5 & 6 \\
\hline $\begin{array}{r}29.01 .89 \\
3.02 .89 \\
26.02 .89 \\
3.03 .89 \\
12.03 .89 \\
17.03 .89 \\
19.03 .89 \\
23.04 .89 \\
11.06 .89 \\
2.07 .89 \\
20.08 .89 \\
27.08 .89 \\
10.09 .89 \\
29.10 .89\end{array}$ & $\begin{array}{r}8.57 \\
13.30 \\
6.34 \\
14.15 \\
6.05 \\
14.30 \\
8.09 \\
6.18 \\
7.37 \\
2.40 \\
10.40 \\
0.54 \\
7.44 \\
8.19\end{array}$ & $\begin{array}{c}167 \\
3.5 \\
220 \\
2 \\
50 \\
2 \\
110 \\
120 \\
140 \\
6 \\
77 \\
77 \\
190 \\
140\end{array}$ & $\begin{array}{r}5.57 \\
3.34 \\
3.05 \\
5.10 \\
2.15 \\
3.37 \\
6.40 \\
20.53 \\
3.43 \\
5.19\end{array}$ & $\begin{array}{l}2.3 \\
2.7 \\
2.4 \\
2.7 \\
2.7\end{array}$ & $\begin{array}{l}67.7-33.7 \\
67.6-34.0 \\
67.6-34.0 \\
67.6-34.0 \\
67.7-33.7 \\
67.7-33.7 \\
67.6-34.0 \\
67.6-34.0 \\
67.6-34.0 \\
67.6-34.0\end{array}$ \\
\hline
\end{tabular}


Tálé 2. 5

Industrial explosions in Centralniy mine

\begin{tabular}{|c|c|c|c|c|c|}
\hline \multicolumn{3}{|c|}{ Explosion journals of mines } & \multicolumn{3}{|c|}{ Seismic catalogues } \\
\hline Data & $\begin{array}{l}\text { Time } \\
\text { (Moscow) }\end{array}$ & Power $(t)$ & Time (UTC) & Magnitude & $\begin{array}{c}\text { Coordinates } \\
\varphi_{\mathrm{N}} \lambda_{\mathrm{E}}\end{array}$ \\
\hline 1 & 2 & 3 & 4 & 5 & 6 \\
\hline $\begin{array}{r}3.0189 \\
6.01 .89 \\
10.01 .89 \\
13.01 .89 \\
17.01 .89 \\
20.01 .89 \\
27.01 .89 \\
3.02 .89 \\
7.02 .89 \\
10.02 .89 \\
14.02 .89 \\
17.02 .89 \\
21.02 .89 \\
2.03 .89 \\
7.03 .89 \\
14.03 .89 \\
17.03 .89 \\
21.03 .89 \\
24.03 .89 \\
1.04 .89 \\
7.04 .89 \\
11.04 .89 \\
14.04 .89 \\
18.04 .89 \\
21.04 .89 \\
28.04 .89 \\
6.05 .89 \\
13.05 .89 \\
16.05 .89 \\
19.05 .89 \\
23.05 .89 \\
26.05 .89 \\
30.05 .89 \\
2.06 .89 \\
6.06 .89 \\
9.06 .89 \\
13.06 .89 \\
16.06 .89 \\
20.06 .89 \\
23.06 .89 \\
27.06 .89 \\
30.06 .89 \\
7.07 .89 \\
11.07 .89 \\
14.07 .89 \\
18.07 .89 \\
21.07 .89 \\
25.07 .89 \\
28.07 .89\end{array}$ & $\begin{array}{l}13.00 \\
12.16 \\
12.00 \\
15.06 \\
13.11 \\
12.46 \\
15.11 \\
15.01 \\
13.09 \\
12.40 \\
19.01 \\
13.02 \\
19.08 \\
16.20 \\
12.08 \\
13.10 \\
13.00 \\
14.50 \\
13.15 \\
13.20 \\
15.18 \\
13.00 \\
13.02 \\
12.25 \\
15.40 \\
15.06 \\
13.56 \\
13.51 \\
12.31 \\
15.31 \\
13.14 \\
13.03 \\
12.31 \\
15.30 \\
13.01 \\
15.30 \\
13.26 \\
13.05 \\
13.25 \\
15.00 \\
18.40 \\
15.40 \\
15.33 \\
13.20 \\
15.30 \\
13.00 \\
15.50 \\
12.30 \\
15.20\end{array}$ & $\begin{array}{l}147.7 \\
340.4 \\
123.6 \\
396.8 \\
195.1 \\
338.3 \\
237.9 \\
353.2 \\
126.8 \\
305.7 \\
89.8 \\
295.2 \\
529.4 \\
411.7 \\
135.2 \\
232.7 \\
268.2 \\
153.5 \\
308.3 \\
214.5 \\
303.8 \\
148.2 \\
146 \\
66.6 \\
370.6 \\
345.6 \\
343.5 \\
335.8 \\
118.3 \\
349.7 \\
83.1 \\
353.5 \\
120.9 \\
316.9 \\
86 \\
210.1 \\
87.1 \\
224.4 \\
120.1 \\
305.5 \\
144.9 \\
315.5 \\
210.1 \\
144.8 \\
329 \\
79 \\
368 \\
201 \\
313.9\end{array}$ & $\begin{array}{r}9.02 \\
8.25 \\
11.40 \\
11.06 \\
9.56 \\
9.56 \\
8.31 \\
11.31 \\
9.17 \\
9.05 \\
8.36 \\
11.35 \\
9.02 \\
11.32 \\
9.27 \\
9.06 \\
9.26 \\
11.01 \\
14.43 \\
11.40 \\
11.34 \\
9.16 \\
11.34(3) \\
9.019 .02 \\
11.51 \\
8.32\end{array}$ & $\begin{array}{l}2.2 \\
2.4 \\
(2.9) \\
(2.4) \\
2 \\
2.2 \\
2 \\
2 \\
2.1 \\
2.3 \\
2 \\
2 \\
2.6 \\
2 \\
\\
2 \\
2 \\
2\end{array}$ & $\begin{array}{l}67.6-34.0 \\
67.6-34.0 \\
67.6-34.0 \\
67.6-34.0 \\
67.6-34.0 \\
67.6-34.0 \\
67.7-33.7 \\
67.6-34.2 \\
67.6-34.0 \\
67.9-34.1 \\
67.6-34.0 \\
67.6-34.2 \\
67.6-34.0 \\
67.6-34.0 \\
67.6-34.0 \\
67.7-34.0 \\
67.6-34.0 \\
67.7-33.7 \\
\\
67.6-34.2 \\
67.6-34.0 \\
67.6-34.0 \\
67.6-34.0 \\
67.6-34.0 \\
67.6-34.0 \\
67.6-34.0 \\
67.6-34.0 \\
67.6-34.0 \\
67.7-33.7 \\
67.6-34.0 \\
67.6-34.0 \\
67.6-34.0 \\
67.6-34.0 \\
67.6-34.0 \\
67.7-33.7 \\
67.6-34.0 \\
67.6-34.0 \\
67.6-34.0 \\
67.6-34.0 \\
67.6-34.0 \\
67.6-34.0 \\
67.6-34.0 \\
67.6-34.0 \\
67.6-34.0 \\
67.6-34.0 \\
\end{array}$ \\
\hline
\end{tabular}


Table 2.5 (Cont1nuation)

\begin{tabular}{|c|c|c|c|c|c|}
\hline 1 & 2 & 3 & 4 & 5 & 6 \\
\hline 4.08 .89 & 13.00 & 180.3 & 8.59 & 2.5 & $67.6-34.2$ \\
\hline 8.08 .89 & 13.00 & 156 & 9.01 & 2.0 & $67.6-34.0$ \\
\hline 11.08 .89 & 15.35 & 278 & $11.34(3)$ & 2 & $67.6-34.0$ \\
\hline 18.08 .89 & 16.16 & 383.3 & 11.14 & 2.3 & $67.7-34.0$ \\
\hline \begin{tabular}{|l|}
22.08 .89 \\
25.08 .89
\end{tabular} & $\begin{array}{l}13.00 \\
15.40\end{array}$ & $\begin{array}{l}103.9 \\
218\end{array}$ & $\begin{array}{r}9.01(2) \\
11.40\end{array}$ & 2.6 & $\begin{array}{l}67.6-34.0 \\
67.6-34.0\end{array}$ \\
\hline $\begin{array}{r}28.08 .89 \\
5.09 .89 \\
8.09 .89 \\
12.09 .89 \\
15.09 .89\end{array}$ & $\begin{array}{l}19.00 \\
12.50 \\
13.12 \\
12.40 \\
16.21\end{array}$ & $\begin{array}{r}376.1 \\
90.5 \\
339.5 \\
72 \\
345.9\end{array}$ & $\begin{array}{r}15.02 \\
8.50 \\
9.20 \\
8.39 \\
12.20\end{array}$ & $\begin{array}{l}2.8 \\
2.2 \\
2.2 \\
2.9 \\
2.3 \\
3.1\end{array}$ & $\begin{array}{l}67.6-34.0 \\
67.6-34.0 \\
67.6-34.0 \\
67.6-34.0 \\
67.6-34.0 \\
67.7-33.7\end{array}$ \\
\hline $\begin{array}{r}22.09 .89 \\
29.09 .89 \\
3.10 .89 \\
6.10 .89\end{array}$ & $\begin{array}{l}14.56 \\
16.19 \\
14.27 \\
15.35\end{array}$ & $\begin{array}{l}464.8 \\
438.3 \\
153 \\
215.8\end{array}$ & $\begin{array}{l}12.23 \\
10.57 \\
13.19(30 \\
11.29 \\
12.38\end{array}$ & $\begin{array}{l}3.0 \\
2.4 \\
2.1\end{array}$ & $\begin{array}{l}67.6-34.2 \\
67.6-34.0 \\
67.6-34.0 \\
67.6-34.0 \\
67.7-33.7\end{array}$ \\
\hline $\begin{array}{l}10.10 .89 \\
13.10 .89 \\
18.10 .89 \\
27.10 .89\end{array}$ & $\begin{array}{l}13.25 \\
15.45 \\
15.00 \\
17.51\end{array}$ & $\begin{array}{l}110.2 \\
181.6 \\
256.4\end{array}$ & $\begin{array}{l}12.47 \\
12.01\end{array}$ & $\begin{array}{l}2 \\
2.1 \\
2\end{array}$ & $\begin{array}{l}67.7-33.7 \\
67.6-34.0 \\
67.6-34.0\end{array}$ \\
\hline $\begin{array}{r}1.11 .89 \\
4.11 .89 \\
11.11 .89\end{array}$ & 10.10 & $\begin{array}{l}203.9 \\
374.5 \\
165.25\end{array}$ & $\begin{array}{r}12.01 \\
12.49 \\
7.10\end{array}$ & & $\begin{array}{l}67.6-34.0 \\
67.6-34.0 \\
67.6-34.0\end{array}$ \\
\hline $\begin{array}{r}14.11 .89 \\
17.11 .89 \\
21.11 .89 \\
1.12 .89 \\
8.12 .89 \\
12.12 .89 \\
15.12 .89 \\
19.12 .89 \\
22.12 .89 \\
26.12 .89\end{array}$ & $\begin{array}{l}12.40 \\
14.31 \\
12.20 \\
15.15 \\
15.07 \\
12.40 \\
15.02 \\
13.11 \\
15.10 \\
14.00\end{array}$ & $\begin{array}{l}114.1 \\
375.9 \\
452.4 \\
377.6 \\
461.4 \\
134.7 \\
344.9 \\
158.1 \\
355.3 \\
550.8\end{array}$ & $\begin{array}{r}9.40 \\
11.31 \\
9.21 \\
12.17 \\
\\
12.02 \\
10.07 \\
12.11 \\
11.03\end{array}$ & $\begin{array}{l}2 \\
2.4 \\
2.0\end{array}$ & $\begin{array}{l}67.6-34.0 \\
67.6-34.0 \\
67.6-34.0 \\
67.6-34.0 \\
67.6-34.0 \\
67.6-34.2 \\
67.6-34.0 \\
67.6-34.0\end{array}$ \\
\hline
\end{tabular}


Table 2.6.

\begin{tabular}{|c|c|c|c|c|c|c|}
\hline No. & $\begin{array}{c}\text { Volume of } \\
\text { rockfall } \\
\text { (t) }\end{array}$ & \begin{tabular}{|} 
Distance \\
from \\
border of \\
mining works \\
(m)
\end{tabular} & $\begin{array}{l}\text { Distance } \\
\text { from } \\
\text { faults } \\
\text { (m) }\end{array}$ & $\begin{array}{l}\text { Lonely } \\
\text { openings }\end{array}$ & $\begin{array}{l}\text { Adjacent } \\
\text { openings }\end{array}$ & $\begin{array}{c}\text { Depth } \\
\text { (m) }\end{array}$ \\
\hline 1 & 24 & 3 & 50 & - & + & 470 \\
\hline 2 & 15 & 25 & 50 & - & + & 470 \\
\hline 3 & 8 & 15 & 30 & - & + & 470 \\
\hline 4 & 9 & 20 & 25 & - & + & 470 \\
\hline 5 & 3 & 20 & 25 & - & + & 470 \\
\hline 6 & 4 & 20 & 25 & - & + & 470 \\
\hline 7 & 10 & 18 & 17 & - & + & 470 \\
\hline 8 & 4 & $>300$ & 35 & + & - & 200 \\
\hline 9 & 30 & 5 & 30 & + & - & 220 \\
\hline 10 & 75 & $>300$ & 15 & + & - & 210 \\
\hline 11 & 100 & $>300$ & 100 & + & - & 200 \\
\hline 12 & 35 & 10 & 15 & - & + & 300 \\
\hline 13 & 3 & $>300$ & 5 & + & - & 290 \\
\hline 14 & $\begin{array}{l}\text { Tectonic } \\
\text { rockburst }\end{array}$ & & $<10$ & & & $\approx 1 \mathrm{~km}$ \\
\hline
\end{tabular}




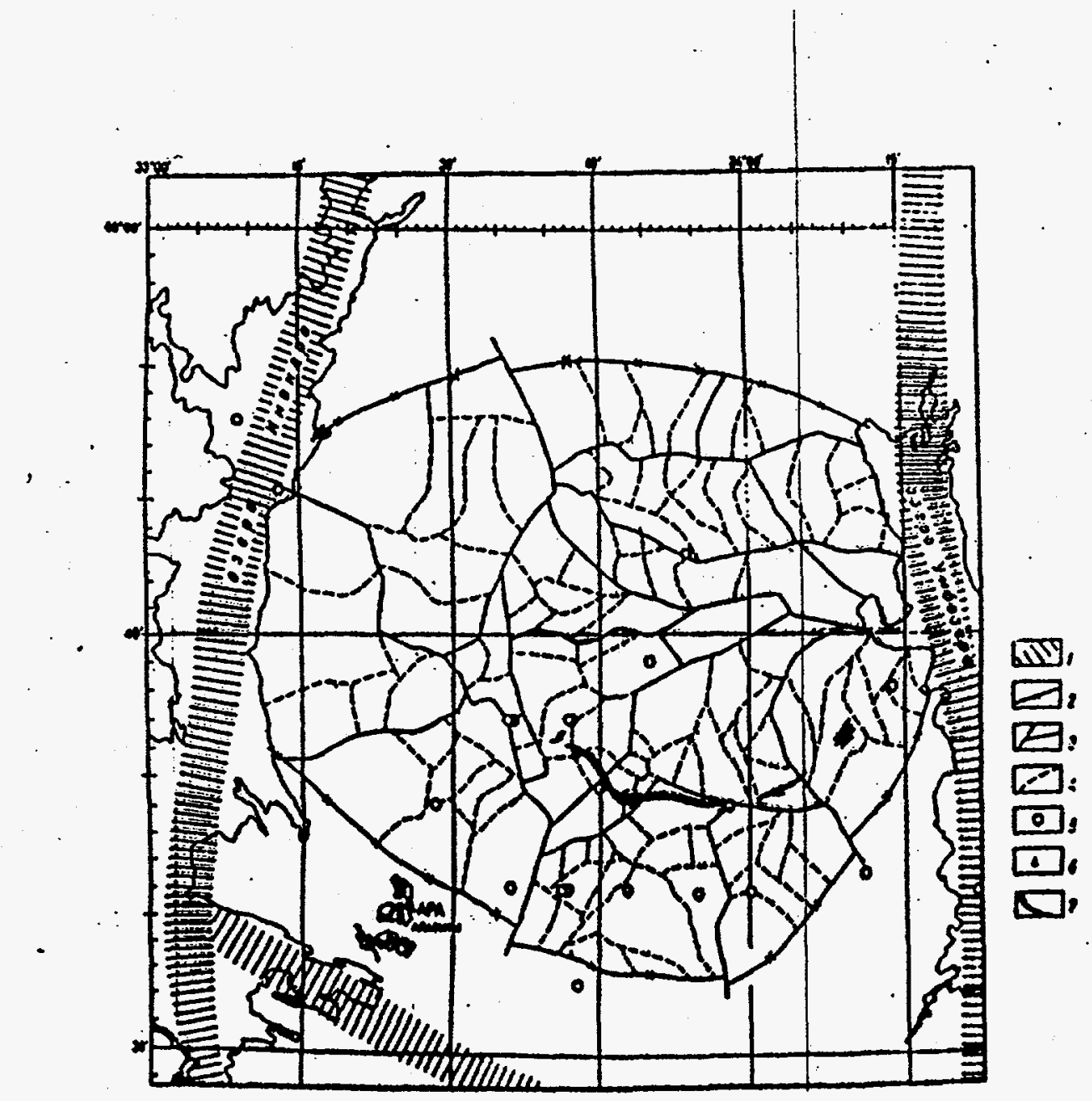

Fig.2.1. Tectonically active blocks in Khibiny massif 1 - regional faults, 2 - Khibiny border faults, 3 - faults of II rank, 4 - faults of IV rank, 5 - epicenters of earthquakes, 6 - seismostation "Apatity", 7 - deposits. 


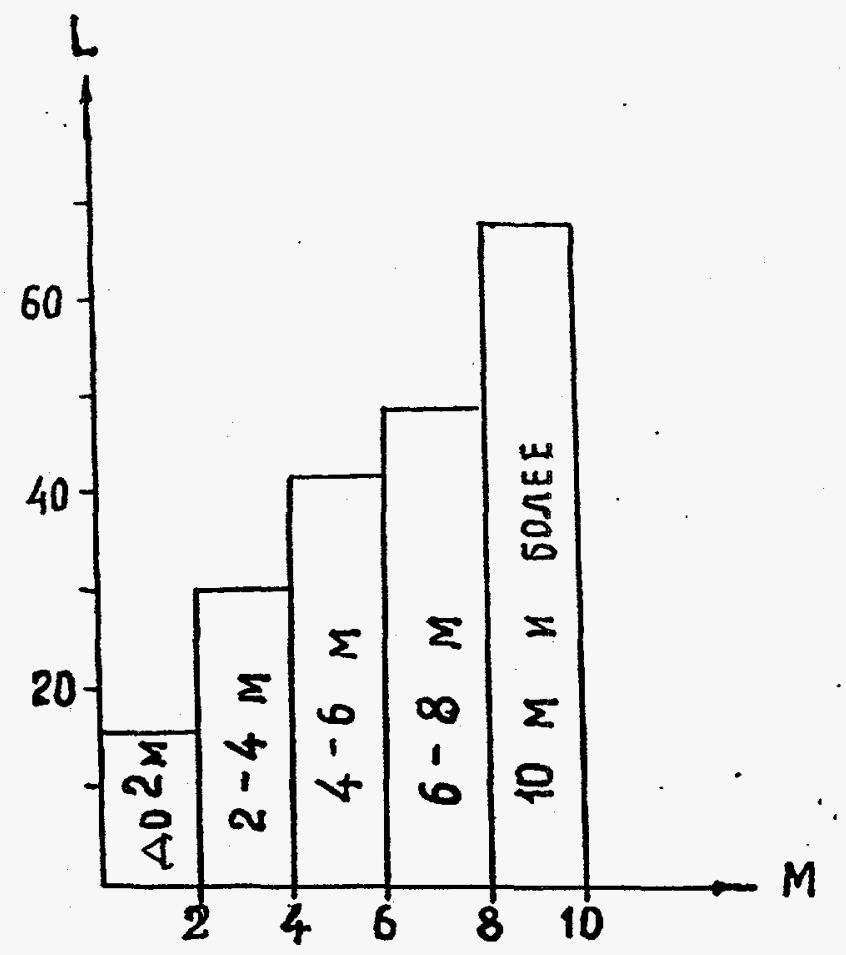

Fig.2.2. Histogram of dimensions of rockburst-dangerous zones at the faults vicinity versus thickness of fault. 

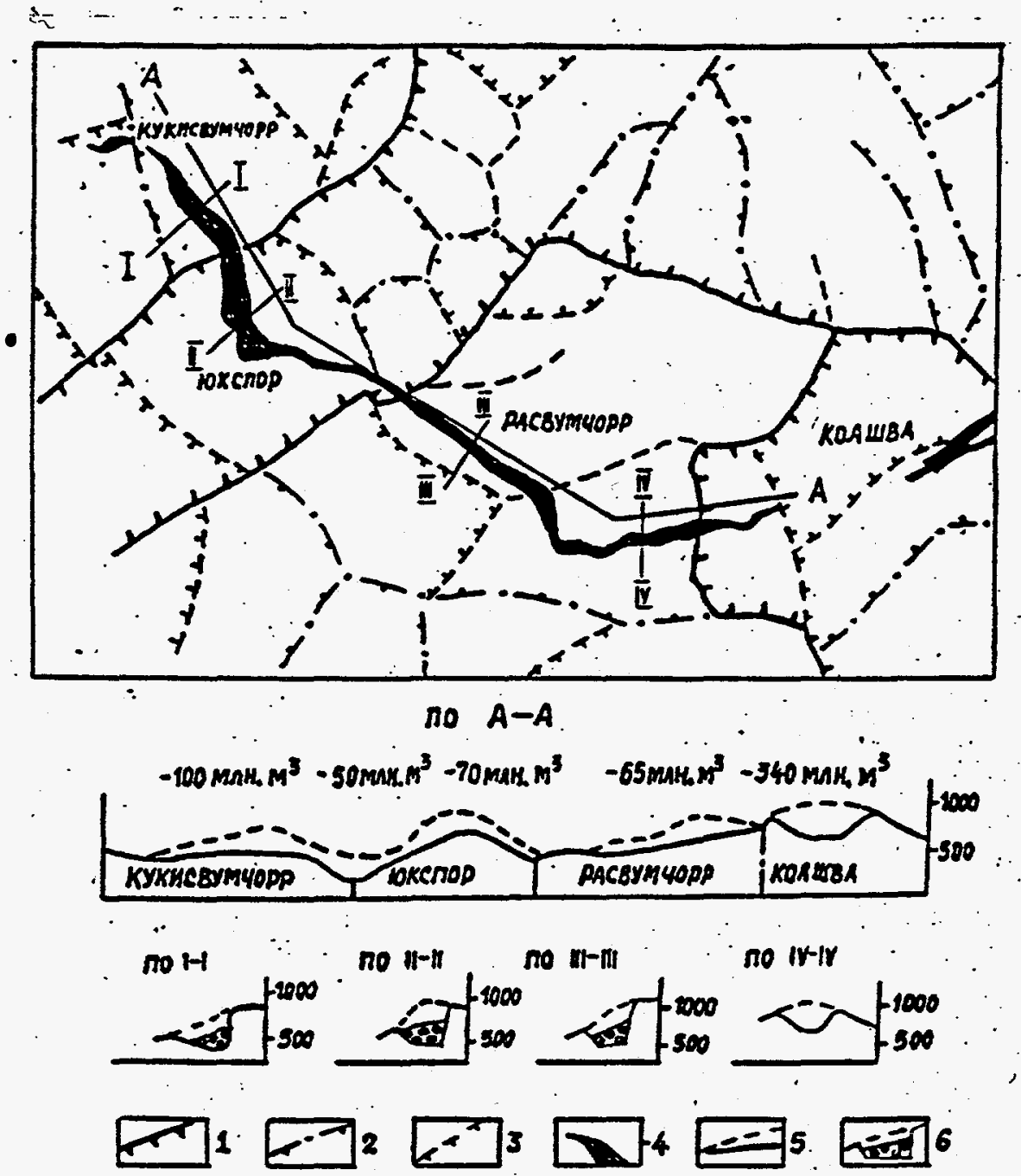

Fig.2.3. Block struckture of the apatite mines district

1 - faults of II rank, 2 - faults of III rank,

3 - faults of IV rank, 4 - apatite-nepheline ores,

5 - surface relief before begining of mining

(dashed line) and modern relief, 6 - destroyed rocks. 


\section{RESULTS OF NATURAL MEASUREMENTS IN KHIBINY.}

\subsection{Kirovskij mine}

The Kirovskij mine according its capacity is one of the biggest underground mining enterprises in Russia. There are the largest depths of ore development in PA "Apatit": at present time the works are carried out at the horizon $+172 \mathrm{~m}$. In spite of that the ore excavation at that most low horizon has not yet begun it is now evident already that the mining works depth increase leads to the increase of all effects of rock pressure noted above. The maximum degree of the geological structures baring with underground excavations is attained which enables to observe visually the structural irregularities at considerable distances as to the depth as to the horizons.

The general scheme of the Kukiswoomchorr apatite-nepheline deposit development is given at Fig.3.1. The ore body is extended $12 \mathrm{~km}$ long, has a thickness from 50 to $300 \mathrm{~m}$ and siope angles from 12 to $30^{\circ}$.

The exavated rock mass is presented by apatite-nepheline ores of rich zone (lense-formed, stripped, large-block and spotty-stripped ore). Physical-mechanical qualities and geological-structural features of the massif are given above. Let's remind that the massif is distinguished by

- high strength of rocks approaching in strength to granites,

- structural irregularity of different scale: from large irregularities, the most large of which is saam fault with thickness $2-5 \mathrm{~m}$ to a network of small cracks with a distance between cracks from 0.1 to $1 \mathrm{~m}$.

- high level of tectonic stresses from 30 to $80 \mathrm{MPa}$.

The power of explosions at the mine is from 150 to $250 \mathrm{t}$ and the dimensions of crushed block - approximately $50 \times 50 \times 70 \mathrm{~m}$. The weakening of explosion seismic influence to underground openings is attained at the expense of proper selection of delay steps at the holes network explosion as well as by cutting the slots system preserving the openings. The block is drilled with a system of sheaf holes a number of which usually is about 1000 units and is defined by the explosion conditions. The charged holes are exploded in groups in definite order with several (up to 20) delay steps (the interval for one step 20 msec.). In this manner the explosion appears to be dispersed in space and in time.

Thus the massif at explosions is subjected to the explosion seismic action and to comparatively quick redistribution of rock pressure: as a result of the rock destruction due to the explosion the considerable volume of 
massif comes into a new mechanical state with other field of stresses.

Besides, after explosion the whole block is removed under pressure of above-situated rocks through prepared funnels and scrapers orts to removal horizons $(+252$ or +322$)$. So, some time later after explosion the whole space occupied with the ore appears to be occupied with loosened rock and the lowering of Earth surface happens which would provoke the further redistribution of rock pressure in the massif.

The detailed description of the apatite-nepheline ore extraction technology at underground excavations of khibiny is given in the work (Turchaninov et.al.,1989). The general description of two of ten explosions is given below during which the main instrumental measurements were carried out in 1987-1993.

The part of plan of horizon +252 is shown at Fig.3.2 at which the borders of blocks are traced with rectangles. The portrayed zone presents the massif undisturbed domain limited in the plane by those zones at north and south in which the ore has been already excavated - so called "pillar-block". According to the plan this domain should be cut off the handing side by the counter-explosions from north and south. The cut off band goes along eastern haulage way. The central part of pillar-block will appear to be unloaded by that which should increase the safety of mining works. So, the rock pressure redistribution effects are to be manifested most bright at the band cutting, the intensity of such phenomena having to be increased as far as the narrowing of pillar-block goes.

The explosion at December 61989 with power $240 \mathrm{t}(80 \mathrm{t}$ at the horizon +322 from the north) in 9.33 Local time (Moscow) was the first one at the cut off band of pillar-block. The explosion was characterized with extremely high level of seismoacoustic emission during 72 hours after its carrying out. The charges 240 and $80 \mathrm{t}$ were exploded simultaneously with usual delay intervals between the holes sheaf explosions. Let's stop in more detail upon the largest one of them because the measurements were carried out just in the zone directly adjacent to the block. The position in the massif and dimensions of block in a scale are given at Fig.3.3, 3.4 (perpendicular sections of block with the sheaf of explosions holes are presented at Fig.3.5). The block dimensions in the plane are $30 \times 90 \mathrm{~m}$, the height - up to $90 \mathrm{~m}$. It is seen that the block embraced almost two horizons in height $(+252$ and +322$)$ to the ore body upper border (OBUB). The domain portrayed in left upper part of Fig.3.4 is filled with a settled dirt of lesser average density $\left(1.9 \mathrm{~g} / \mathrm{cm}^{3}\right)$. But the domain to the right from dashed line - is undisturbed massif. As it seen from the figure the thickness of undisturbed rocks hanging over a block lost 
its strength is at the level +252 about $400 \mathrm{~m}$. At the plane (Fig.3.3) the removal orts 8 and $7 a$ are portrayed in which the measurements were carried out. It should be noted that as far as the ort No.8 at its whole extension was fixed with the concrete layer with a thickness about $0.5 \mathrm{~m}$ the part of ort $7 \mathrm{a}$ between 2 and 3 drifts was not fixed which facilitated the measurements carried out here.

The explosion at December 51993 in 9.50 local time (Moscow) - the crushing of a block which is the last junction section of cut off band. The plan of a part of horizon +252 of Kirovskij mine adjacent to a cut block is schematically given at Fig.3.6. The block dimensions in the plan are approximately $80 \times 55 \mathrm{~m}$, the height $70 \mathrm{~m}$. The total weight of the explosion substances charges at explosion at December 51993 was $255 t$. The amount of destroyed rock mass - about $200000 \mathrm{~m} 3$ (mass $60000 \mathrm{t}$ ). The crushed section was situated in hanging side of ore body under covering rocks collapsed down earlier, the thickness of piles about $500 \mathrm{~m}$. The explosion was carried out in 16 stages with a delay in $23 \mathrm{msec}$ i.e. total duration of explosion was approximately $0.35 \mathrm{sec}$.

The explosive substance gramonite $79 / 24$ is used at all large explosions at PA "Apatit".

The detailed analysis of the explosions seismic influence to the mine excavations doesn't belong to our task that is why we shall limit ourselves with general description of that influence. As it was noted above the weakening of seismic influence is attained by corresponding selection of a sequence and delays at the holes groups explosion (the rock destroyed with explosion of the first groups provides the screening action with respect to the subsequent groups explosion) and by cutting in a case of necessity the special screening excavations slots. The seismic measurements at explosions are carried out regularly by a group of employees of Mining Institute of Kola Science Center of Russian Academy of Sciences under guidance of S.A.Kozyrev. The sensors in those measurements are situated under exploded block and along excavations. The copies of some oscillograms are shown at Fig.3.7 got as a result of measurements at the explosion at March 31990 in 9.32 local time (Moscow) (power 180 t) with an indication of sensor type, a place of its installment and a scale. As it follows from the oscillograms in explosion wave the velocities at the excavation level are comparatively not large: from $1 \mathrm{~m} / \mathrm{s}$ directly before the block up to $0.1-0.2 \mathrm{~m} / \mathrm{s}$ at some distance from it. In those zones where the sensors for seismoacoustic and deformograph measurements are situated the explosion seismic action in all cases was characterized by velocities $0.1-0.3 \mathrm{~m} / \mathrm{s}$. The main frequencies are in the range $20-80 \mathrm{~Hz}$. 


\subsection{Man-made earthquake at Kirovskij mine.}

Man-made earthquake at Kirovskij mine occured at April 16
1989 during carrying out the explosion (10 hours 35 minutes, local time, Moscow). The explosion with power $230 \mathrm{t}$ at horizon +252 was an usual explosion for cutting the in-turn rock block. The delays system with subsequent explosion of the sheaf holes occupied the interval 400-500 msec. Within that interval with some delay from the explosion beginning an earthquake occured which according to its seismic effect in epicenter had the itensity VI-VII. In Kirovsk town distant from the epicenter at $6 \mathrm{~km}$ the external manifestations corresponded to intensity $I V-V$, in a settlement Titan at a distance $11 \mathrm{~km}$ the light oscillations of buildings were observed and in Apatity town remote at $17 \mathrm{~km}$ this phenomenon was registered only with instruments.

The seismic stations data in Apatity, Polar Circle, Kem, Petrozavodsk, Barentzburg and Amderma enable to estimate the magnitude of earthquake as $M=4.8-5$ which correspond to seismic energy $10^{12}$ Joules. The hypocenter depth according to those data doesn't exceed $1 \mathrm{~km}$. An aftershock was registered by three closest seismic stations 12 minutes later after the earthquake. At inspection of mining openings after earthquake it was established that along a fault of $V$ rank presented by the aegirine lode with a thickness $15-25 \mathrm{~cm}$ a crack of north-west extension was formed with sloping down to north-east and the average angle $35^{\circ}$ (Syrnikov \& Tryapitsin, 1990). At whole extension the crack practically coincides with the aegirin lode position which before the earthquake was of little difference with the rest massif according to its strength excluding distinct sections with weakly developed oxidation. Earlier at carrying out the openings near this fault at all three horizons $(+172,+252,+322)$ the peeling of $a$ roof and bouncing were observed. At the sides of formed crack which was opened at distinct parts to $2-5 \mathrm{~cm}$ the fresh traces of friction and reduced into small particles material are traced which enables to judge about the displacement direction and its amplitude. At distinct parts the crack is branched into several subparallel cracks. In openings crossed by formed crack the rockfalis has occurred, the concrete support was destroyed, the cranes, the rails were deformed. The main well and elevator uprising one were destroyed: at the spot of their crossing with a crack the concrete support is destroyed, the conductors and slides of elevator were deformed.

In the plan the extension of cracks is $1.1 \mathrm{~km}$. It was manifested at the site $1 \mathrm{~km}$ limited by almost vertical faults, displaced thickness of the rock mass over crack reaches $400-$ 
$600 \mathrm{~m}$. The mine conditions with its ramificated network of underground openings exposing the geological structures give an opportunity to trace the formed crack to considerable extension in depth as well as to measure directly the value of displacement along it. It was established by the mine-surveyors measurements that the reversed fault formed along the crack with maximal amplitude 8-9 cm: at the horizon $+172-2-3 \mathrm{~cm}$, $+252-6-7 \mathrm{~cm}$, $+322-8-9 \mathrm{~cm}$. Thus the block which has experienced the reversed fault is limited from three sides by steeply sloped faults presented by mutted zones of crushing and from one side (along the displacer plane) by the aegirin vein. All faults were somehow manifested on the surface. The localization of faults and displaced block are shown at Fig.3.8, where the direction of the maximal horizontal stresses action is shown as well.

It is possible to suppose that the process of forming of this large crack itself with the massif displacement along it just was the source of seismic oscillations - man-made earthquake. The disbalance of rock massif could be provoked by the rock mass removal (up to $25 \%$ of initial volume) which led to the free surface drop at $300-400 \mathrm{~m}$ and to decrease of the vertical lithostatic stresses values at 9-12 $\mathrm{MPa}$ at preserving the subhorizontal tectonic stresses acting inside massif as 30$80 \mathrm{MPa}$.

The calculations of stress state and displacements along the fault plane (the computation of that problem is given in more detail in 5 chapter) yield the following results. It is not difficult to get elastic solution for stress state at the fault at the presence of the lithostatic $\rho$ gh and tectonic $T$ stresses for two variants: nondisturbed massif (before mining works beginning) and real state at the earthquake moment taking into account the free surface level deepening and the presence in massif of domains filled with crushed rocks. Such calculations yield the shear stresses increase on the fault plane in the second variant compared to first one. For the mark +252 (the medium of three operating horizons) the value of $\tau$ increases from 9 to $12 \mathrm{MPa}$ for $\mathrm{T}=30 \mathrm{MPa}$ and from 18 to $29 \mathrm{MPa}$ for $\mathrm{T}=50 \mathrm{Mpa}$ (Fig.3.9). This value corresponds to the critical strength values.

The values of elastic displacement along the fault plane $U_{e}(1)$ and $U_{e}(2)$ were calculated for two variants, their difference for the horizons level mentioned above is $\Delta U_{e}=6-8$ $\mathrm{cm}$ which practically. coincides with the measured displacement value. The massif point would be displaced to $\Delta U_{e}$ in the fault plane relatively to its immobile part at the loading change.

According to displacements known from natural measurements and to calculated stress state it is not difficult to estimate 
the shear stresses work value at such displacement. For $\mathrm{T}=30$ MPa the work $A=0.5 .10^{12}$ Joules and for $T=50^{M P a} A=10^{12}$ Joules. The value of A corresponds to elastic energy released in a massif at the displacement along the fault and coincides in an order of value with the earthquake seismic energy estimate $\mathrm{E}_{S}=10^{12}$ Joules.

The seismic energy of industrial explosions the action of which is registered at considerable distances can be estimated according to the seismic station network data of Finland which are given above. Selected from a Table 3.1. events are identified in time and place $\left(67.7^{\circ} \mathrm{N}, 33.7^{\circ} \mathrm{E}\right)$ to particular industrial explosions at Kirovskij and Yukspor mines.

Table 3.1

\begin{tabular}{|r|c|c|c|}
\hline Data & $\begin{array}{c}\text { Time } \\
\text { (Moscow) }\end{array}$ & $\begin{array}{c}\text { Power of } \\
\text { explosion ( } t)\end{array}$ & Magnitude \\
\hline 5.01 .89 & 7.20 & 100 & 2,5 \\
26.02 .89 & 6.34 & 220 & 3,1 \\
9.04 .89 & 8.46 & 160 & 2,7 \\
23.04 .89 & 6.18 & 120 & 2.3 \\
30.04 .89 & 9.55 & 259 & 2,8 \\
30.07 .89 & 8.50 & 156 & 2,9 \\
26.11 .89 & 9.35 & 180 & 2,6 \\
\hline
\end{tabular}

The energy estimate according to the magnitude value yields $10^{8}-10^{9}$ Joules which gives a way to the earthquake energy estimate given above.

It is interesting to note that the large known underground explosions at September $4 \quad 1972$ and August $27 \quad 1984$ at PA "Apatit" in Khibiny had magnitudes $m_{p}=4.6$ and 4.7 (in volume waves) and the explosion of a charge $700 \mathrm{t}$ for collapsing the slope in granite massif on Burlykia river in Khirghizia was characterized by the magnitude 4.2 - 4.1. It is possible to suppose that the amplified seismic effect at the explosion of April 161989 at the surface was conditioned by small depth of center and that the larger part of energy than usually was spent to the destruction of excavations weakened zones and to generation of acoustic wave which means that the energy share spent to forming of regional seismic waves was decreased. 
Thus the massif stress state change as a result of engineering activity of such scale can lead to the forming of large cracks (especially along geological structural irregularities) and to considerable displacements accompanied by the local man-made earthquakes similar to one described here. The explosion action in given case appeared to be a triggering mechanism for the earthquake: the explosion energy appeared to be much less than the earthquake seismic energy.

The main parameters of man-made earthquake are as the estimates show the elastic energy reserve with respect to possible direction of displacement and the dimension of formed crack.

It follows from here that to prognosticate the man-made factors influence it is necessary to know in each rock massif its spatial structure and natural deformation regime besides the stress state.

The situation when the phenomena of rockburst type are initiated by explosion is sufficiently wide-spread. The rockburst at April 281991 occurred immediately after carrying out of explosion with power $150 \mathrm{t}$ at the horizon +252 of Kirovskij mine. The seismic effect externally was felt as still more one subsequent explosion with somewhat less power with some delay with respect to the main one. As it was established by detailed inspection of underground openings 24 hours later the rockburst didn't provoke any destructions of roof and opening walls and according to given classification can be attributed to strong bumps in the depth of massif. At Fig.3.10 the oscillograms copies are presented received at measurements at the surface in a place of Kukiswoomchorr seismic station localization (Fig.3.28) with the aid of the methods of seismic, geopotential and infrasonic registration. It is seen that all three methods have registered the rockburst occurred $9.8 \mathrm{sec}$. later after explosion. The study of spectral characteristics shows that the power spectrum of geoelectric, seismic and infrasonic signals from the rockburst is displaced to more high frequency area (Fig.3.11). The burst was registered by seismic station in Apatite town at the distance $17 \mathrm{~km}$ from the mine. At Fig.3.12 the copies of those recordings are given being presented by E.O.Kremenetskaya. The recording is explicitly singled out with a delay $9-10$ sec. with respect to the explosion. It is possible to estimate the magnitude of that event confronting its amplitude at seismograms to the explosions amplitude. Knowing that the seismic effect of such explosion is characterized according to catalogue (Seismic events in Northen Europe, 1989) $M=2$ it is possible to affirm that the magnitude of registered rockburst is in the interval $1<\mathrm{M}<2$. 
Strong rockburst occurred during carrying out the explosion mentioned above at December 6 1987. According to seismic data the rockburst as and one at April 241991 occured approximately $10 \mathrm{sec}$ later after explosion. That rockburst provoked considerable destructions of openings of haulage horizon. The total volume of flakings into openings was about $50 \mathrm{t}$.

Let's note that the energy of majority of rockbursts in underground openings of Kirovskij mine is not large. So in 1994 several rockbursts were registered in the area of a pillar block. Let's give the data for three of them. The rockburst at August 31994 with energy $E=2 \cdot 10^{5}$ Joules occurred at large depth and hasn't provoke any destructions in openings. The rockbursts at september 111994 with energy $E=4.10^{5}$ Joules and at september 161994 with energy $E=2.10^{5}$ Joules have provoked the flakings of rocks into opening. The flakings volume at the latter of them (the rockburst occurred practically at the +252 horizon level) was about 40 cubic meters.

\subsection{The relative displacements measurements.}

With a purpose to study the reaction of structural elements of massif to explosion influence the measurements were arranged at faults situated in immediate proximity to the explosion place. The fault (Fig.3.2-3.6) is of special interest: this fault is immediate continuation of a fault of $V$ rank along which the displacement occurred at man-made earthquake at April 16 1989. Those two parts of fault are divided with a powerful vertical zone of oxidation (acid zone) which has limited the displacement along the fault into the massif depth. The measurements arranging at that fault had a purpose to carry out an observation for the behavior of fault being at similar conditions and to fix possible large displacements if they would be implemented. At the fotografs Fig.3.13 the output of that fault to the wall of ort No.7 is shown.

At Fig.3.14 the vertical section of that part of massif is given with indication of the mining works level attained to the present moment and of initial position of mountain surface (dashed line). The horizontal stresses in that part of massif are 60-80 $\mathrm{MPa}$. The calculations similar to those fulfilled in chapter 5 have shown that in a case of the balance breaking in that part of massif at the same mechanism as at April 161989 one should expect a man-made earthquake with somewhat less energy $E_{C}=10^{11}$ Joules $(M=4)$.

The second fault crossing the seventh ort between 1 and 2 crosscuts is situated in the increased stresses zone: here the 
roof peeling and insignificant flakings of distinct pieces of rocks were observed.

The sensors were installed at opposite walls of underground opening approximately in $50 \mathrm{~m}$ from the explosion place. Let's note that the temperatures stability in underground openings gives an opportunity to avoid the temperature compensation.

The sensors disposition layout is given at Fig.3.15 The dashed line at the figure is the mentioned fault. The sensors were connected to the bridge preamplifiers installed in immediate proximity and connected to amplifiers with cable lines the signals from the outputs of which were supplied to registering oscilloscopes or magnetic recorders. At Fig.3.163.17 the oscillograms copies are shown received at measurements in 1990, the time zero corresponding to the explosion beginning. Besides the signals from the outputs of preamplifiers were supplied to the digital memory system picking up each of channels with a sampling time fifteen minutes. Altogether 140 values were measured, the patterns of relative displacement $U$ drawn according to those are shown at Fig.3.18. The vertical dashed line at that figure is the explosion moment. The sign "+" at Fig.3.16-3.18 corresponds to the relative remoteness of posts.

It is seen from Fig.3.16 that the frequency range of registered relative displacement of the rocks blocks is very large. It lays approximately within the limits from $40 \mathrm{~Hz}$ to 2 $\mathrm{kHz}$ during explosion. The maximal amplitude absolute value is within the limits from 0.1 to $0.8 \mathrm{~mm}$.

Let's note the following important circumstance. The relative displacement absolute maximum equal approximately $2 \mathrm{~mm}$ registered with the aid of DPS No.6 is situated considerably later (to one second) after the explosion termination (Fig.3.17). The displacement according all other sensors at the same time - lower for an order. That indicates to the complexity of the accumulated tectonic energy excretion mechanism.

Maximal amplitudes of $U$ within the limits of explosion duration and the string length $L$ are given in the Table 3.2. The sign " + ' in it as one at figures corresponds to the posts mutual remoteness.

The deformation values $\varepsilon=U / I$ are given in the Table as well. The value of maximal deformation in explosion wave $\varepsilon_{W}$ can be evaluated with the aid of approximate relation $\varepsilon_{W}=V_{\mathrm{m}} / \mathrm{V}_{\mathrm{p}}$ where $V_{m}$-maximal mass velocity in a massif, $V_{p}$ - the velocity of the longitudinal waves spreading in it. Taking $V_{m}=0.5 \mathrm{~m} / \mathrm{sec}$, $\mathrm{v}_{\mathrm{p}}=5 \mathrm{~km} / \mathrm{sec}$ we shall get $\varepsilon_{W}=10^{-4}$. As it is seen from the Table 
the module of experimental value in distinct cases is noticeably higher.

Table 3.2

\begin{tabular}{|c|c|c|c|c|c|c|}
\hline $\begin{array}{c}\text { Sensor } \\
\text { DPS }\end{array}$ & No.1 & No.2 & No.3 & No.4 & No.5 & No.6 \\
\hline & & & & & \\
$\mathrm{L}, \mathrm{mm}$ & 1621 & 2045 & 1593 & 1740 & 1506 & 4141 \\
$\mathrm{U}, \mathrm{mm}$ & -0.1 & -0.28 & - & -0.41 & -0.8 & -0.47 \\
$\varepsilon_{\text {RES }}, \mathrm{mm}$ & $-6 \cdot 10^{-5}$ & $-1.4 \cdot 10^{-4}$ & - & $-2.4 \cdot 10^{-4}$ & $-5.3 \cdot 10^{-4}$ & $-1.1 \cdot 10^{-4}$ \\
$\varepsilon_{\text {RES }}$ & $2 \cdot 10^{-2}$ & 0.42 & $6 \cdot 10^{-2}$ & 0.36 & 0.3 & 1.2 \\
\hline
\end{tabular}

The strings of sensors No.2, 4, 6 were oriented approximately towards the explosion and those of No.1.3.5 in across direction. According to that the deformation in a wave in homogeneous massif for first group of sensors should have the sign "-" and for the second one - "+". Actually as it is seen from the Table 3.2 in a wave in all cases the deformation has the sign "-".

In 1991 the resistance change of the same sensors was registered with the aid of high precision digital device. The measurements were carried before the explosion and after it. They enabled to get with high precision (an error not more than 2-4\%) the residual displacements values $U_{\text {res }}$ and the residual deformations $\varepsilon_{R E S}=\mathrm{U}_{\text {res }} / \mathrm{L}$. Those values are given in the Table, too. Let's note that in all cases the $\varepsilon_{\text {RES }}$ has the sign " + ".

The results of the relative displacements measurements at the explosion at December 51993 are of the largest interest the cutting of a block which is the last joint section of cutoff band of pillar block. At Fig.3.6 the plan of a part of horizon +252 of Kirovskij mine adjacent to cut block is schematically shown. The relative displacements of the fault sides were registered. The measurements were carried out in a place of the fault crossing with the ort No.6 (Fig.3.19).

The received results in different time scale are presented at Fig.3.20-3.22. Full registration time was 4.5 hours. The vertical dashed line at Fig.3.20 shows the explosion beginning. The sign "+" corresponds to the posts remoteness. At the same 
figures the movement components - one parallel to the fault U and other one normal to it $V$-are shown calculated according to records of DPS No.1 and No.2. The taken positive directions of components $\mathrm{U}$ and $\mathrm{V}$ are shown at Fig.3.19.

As it is seen from the figures the fault sides relative movement has complicated wave character. The periods of such oscillations differs for orders and grow with the time course which witnesses for the involvement into relaxation processes of still larger structural elements of a massif. The displacement maximum got at described measurements $+3 \mathrm{~mm}$ is attained by U-component only 6 minutes after the explosion. Let's note that this value exceeds considerably the values registered with the aid of given method earlier (in 19891992).

As it is shown later the shear stresses concentrated at the fault as a result of large scale mining works can reach the critical values. Besides, at explosion crushing of a block the redistribution of stresses occurs in considerable domain of a massif and the combination of those two factors can lead to breaking its balance. There was no such breaking at the explosion at December 51993 however the fulfilled measurements have fixed the fault noticeable reaction to the cutting of jointing section: the displacements on it appeared to be considerable $(3 \mathrm{~mm})$. The measurements results enable to suppose that during four hours period after explosion the significant relaxation of stresses at the fault occurred which led to the relative displacements value decrease.

The relative movement of rock blocks aroused under influence of the explosion wave has a complicated translational-oscillating character and lasts for a long time (several hours) after its passing.

\subsection{Seismoacoustic measurements.}

The seismoacoustic emission measurement methods enable to single out and to control the massif distinct domains in which the rock pressure redistribution process as a result of manmade influences creates complicated destruction processes at irregularities of medium scale and at microlevel as well as to estimate the localization and dimensions of sources. The measurements of seismoacoustic emission were carried out in openings of horizon +252 in the nondisturbed areas of massif directly adjacent to the cut block (Elisarov et.al.,1994).

The most interesting results are got at the measurements for mentioned explosion at December 61987 - the first one at the cutoff band of pillar block. The powerful rockburst was registered during that explosion carrying out provoked the openings considerable destructions and the damage of 
registering equipment Fig.3.23. The sensors closest to the explosion were situated in haulage ort No.7 of horizon +252 at a distance $20 \mathrm{~m}$ from the cut block edge. From three to five sensors were used simultaneously in different points of massif. The registration was carried out during 48 hours before the explosion and during several days after it until the seismoacoustic emission was brought to the level of the beforeexplosion background. The largest part of received records presents a signal in a form of short periodical impulses with the duration of first phase from 20 to 80 mcsec at the background of uniform noise of different frequency and intensity. The similar impulses appear after the explosion, too, at the background of periodic signals with considerably larger amplitude and period.

The sharp intensification of seismoacoustic emission was observed immediately after explosion with gradual change of frequency composition of signals. The spectrums of records received before the explosion have a mutual feature - the presence of a maximum at frequencies $10 \mathrm{kHz}$ (Fig.3.24). The spectrum character changes after the explosion. The signals are divided into two types according to the spectrum character. The part of spectrums has a clearly expressed maximum at frequencies up to $1 \mathrm{kHz}$ and the contribution of high frequencies is negligible small. For other signals the presence of wide spectrum is characteristic: all frequencies are present in the signal up to $10-15 \mathrm{kHz}$ to equal extent.

The general character of signals frequency composition change is similar to all those explosions at which the measurements were carried out. During 24 hours after the explosion that majority of records has the spectrum with lowfrequency component: their amount 7-10 times larger than the impulses number with high-frequency spectrum. During 24-48 hours after the explosion the frequencies were $200-500 \mathrm{~Hz}$ (Fig.3.24), to the end of 48 hours the maximum at the signals spectrums is displaced to the area of more high frequencies (1$1.5 \mathrm{kHz}$ ) and the second maximum appears in the area $4-7 \mathrm{kHz}$ (Fig.3.25). Further only high-frequency impulses remain in the general seismoacoustic impulses flow and their amount gradually decreases to the before-explosion level background. The described picture was observed most clearly at carrying out the explosion mentioned above at December 6 1987, other explosions were different only by the time of emission going to the background level: at the explosion at March 251990 this period was equal 36 hours.

The initiators of signals so different according to their characteristics are real sources. The high-frequency signals are similar to signals registered before the explosion. The estimate of dimensions of the source of such signals yields a 
value $0.25-0.5 \mathrm{~m}$ which corresponds to the size of rock pieces exfoiliated from the opening walls and witnesses for that the appearance of such signals before and after explosion may be attributed to the destruction processes in surface layer of openings under influence of rock pressure.

The source of low-frequency signals is as the estimates have shown the massif zone destructed by direct action of the explosion and mainly the block of nondestructed medium contiguous upon the area crushed by the explosion. The dimensions of corresponding sources are 10-100 $\mathrm{m}$ which in the order of value corresponds to linear dimensions of cut block $(30-70 \mathrm{~m})$. The considerable decrease of the low-frequency signals amount witnesses for the intensive destruction processes ceasing in that part of a massif.

Let's note that similar picture of the seismoacoustic emission manifestation was registered at the explosions at copper mine in China (Yuan \& Changdo, 1990).

The frequency of the seismoacoustic signals appearance can serve as other parameter to estimate the massif change state after explosion. At Fig.3.26 the diagram of moments of their registration at three intervals equal in duration: before the explosion and for 48 hours subsequent to the explosion. The vertical unit segment corresponds to the event registered by one of sensors, the segment of double length - to the registration by two channels, the length of segment equal to three means that the event was registered by three and more sensors simultaneously. The frequency of signals appearance 48 hours after the explosion is practically equal to the background one.

The histogram of number of observed during 24 hours impulses is shown at Fig.3.27 from duration of their first phase for the explosion at April 9 1989. If 24 hours later after the explosion the signals with duration of first phase 80 mcsec and more are registered then 48 hours later the histogram practically doesn't differ from the background one.

To estimate the time duration during which the consequences of explosion to massif are manifested the following quantitative parameters of seismic emission can be used:

1) the frequency of seismoacoustic impulses - its increase with time and full ceasing of the signals appearance with lowfrequency component $(200-1000 \mathrm{~Hz})$

conditioned by the destruction processes in exploded block and in neighboring ones;

2) the number of registered impulses - decreasing of their amount to the background level (before the explosion);

3) the duration of first phase of impulses - the signals presence with the duration of first phase larger than before 
the explosion indicates to the presence of after-explosion processes of the rock pressure redistribution and to the destruction in a massif and their absence - to the ceasing of those processes.

Thus, the developed system of registration of seismoacoustic emission can be used for the rock massif state diagnostics at powerful dynamic influences and can have the practical application to the safety control at carrying out the explosions: the seismoacoustic emission decrease to the background level can serve as the estimation of the massif return time in a state safe for mining works carrying out.

\subsection{The study of geoelectric fields in the rock massif.}

First observations for geoelectric fields induced in the rock massif were carried out in the district of seismic observatory "Kukiswoomchorr" according to a scheme shown at Fig.3.28. The geoelectric potential measurements were fulfilled with the aid of two reception lines, the line OM being oriented to the explosion carrying out place in the opening zone and the line ON - to the mine explosions. Each line consisted of two metallic electrodes with a length approximately $1 \mathrm{~m}$ rammed in the ground at the distance $40 \mathrm{~m}$, the electrode (0) was common. The building of observatory stands at sedimented and alluvial rocks with relatively small thickness of the layer that is why the electrodes were rammed in the ground to full length.

The registration of seismic oscillations and of infrasonic was carried out according to known methods (Rybnov, 1993; Kondratyev et.al.,1994) parallel to the geoelectric potential measurements. The geoelectric potential was recorded in the range $0 \div 10^{2} \mathrm{~Hz}$. The registration of seismic and infrasonic oscillations was carried out in the range $0.1 \div 100 \mathrm{~Hz}$.

The approbation of method was fulfilled at 4 underground explosions and at 10 explosions in open pits. The explosions parameters are given in the Table 3.3 .

The explosion carried out at April 281991 is of largest interest as a result of which the rockburst occurred registered by the geopotential sensors as well as by the seismic and infrasonic transducers. The registrogrammes of listed disturbances are shown at Fig.3.10.

The seismic and infrasonic oscillations from the explosion of April 281991 are characteristic for other explosions. So the spectrums of direct seismic wave (see the interval I at Fig.3.10) are in the range $8 \div 15 \mathrm{~Hz}$ depending upon the explosion power and are shown at Fig.3.11a.

The local infrasonic spectrums (see the interval I at Fig.3.10) induced by the ground oscillations in reception point 
are more high-frequencied $(14 \div 18 \mathrm{~Hz})$ and the range of registered frequencies is more narrow (see the Fig.3.11b).

Table 3.3

\begin{tabular}{|c|c|c|c|}
\hline Data & $\begin{array}{c}\text { Power, } \\
(\mathrm{t})\end{array}$ & $\begin{array}{c}\text { Registration } \\
\text { zone, (km) }\end{array}$ & $\begin{array}{c}\text { Depth of } \\
\text { explosion, ( m ) }\end{array}$ \\
\hline 25.03 .90 & 170 & 2,5 & $100-120$ \\
25.03 .90 & 70 & 1,8 & $100-120$ \\
28.04 .91 & 150 & 1,2 & $100-120$ \\
23.08 .92 & 90 & 2,1 & $100-120$ \\
\hline
\end{tabular}

The epicentral infrasonic (see the interval II at Fig.3.10) induced by the ground oscillations over the explosion epicenter and propagating in near-ground waveguide with the sound velocity has more low frequency and its spectrum is displaced to the range $3 \div 8 \mathrm{~Hz}$ (see Fig.3.11c).

The analysis of infrasonic amplitude characteristics from explosions shows that the pressure in local wave $\left(\Delta P_{\text {loc }}\right)$ is in the range $1.8 \div 2.2 \mathrm{~Pa}$. The pressure in epicentral wave $\left(\Delta P_{e p}\right)$ changes from $2.2 \mathrm{~Pa}$ to $7.5 \mathrm{~Pa}$ and to each explosion the relation $\Delta P_{e p} / \Delta P_{l o c}>1$ is always fulfilled.

The rockburst already mentioned above at the explosion of April 281991 was registered by all measurement channels. As it is seen from the Fig.3.10 the rockburst occurred 9.8 sec later after explosion beginning and was accompanied by the intensive infrasonic and by powerful geoelectric potential.

The direct seismic wave (see the interval III at Fig.3.10 is commensurable with an intensity to the wave from the explosion and the spectrum maximum is situated in the area $16.5 \mathrm{~Hz}$ (see Fig.3.11a).

The presence of local infrasonic (see the interval III at Fig.3.10) with the amplitude $\Delta P_{l o c}=1.5 \mathrm{~Pa}$ and of the spectrum maximum at the frequency $19 \mathrm{~Hz}$ (see Fig.3.11b) as well as of epicentral infrasonic (see the interval IV at Fig.3.10) with the amplitude $\Delta P_{e p}=1.8 \mathrm{~Pa}$ and the spectrum maximum at the frequency $9.5 \mathrm{~Hz}$ (Fig.3.11C) enabled to estimate the rockburst power and its depth. According to received estimates $q$ is in 
the range $(3.6 \div 5) \times 10^{9}$ Joules at the depth $50 \mathrm{~m} \div 80 \mathrm{~m}$ respectively. The lag of epicentral infrasonic with respect to the local one enabled to estimate the distance to epicenter which is equal to $0.55 \mathrm{~km}$.

The geoelectrical impulse (see the interval III at Fig.3.10) had a length $0.2 \mathrm{sec}$ at the amplitude $130 \mathrm{mV}$ however its polarity was negative. That indicates to that the signal came from opposite direction. Therefore the rockburst occurred not in the district of opening which is confirmed by visual observations.

The received experimental data enable to estimate the threshold sensitivity of geoelectric method at surface control for seismic events in a rock massif. Long-range observations after explosions have shown that the energetics of those events according to the seismic station "Kukiswoomchorr" data doesn't exceed $10^{6}$ Joules. The facts of those events registration through geoelectric and infrasonic channels were not disclosed. That is why if to connect in first approximation the infrasonic level to the geopotential amplitude then coming from real conditions of infrasonic revealing $(\Delta P=1 \mathrm{~Pa})$ and from the similarity theory it is possible to evaluate the events energetics. According to evaluations this threshold may be $(2 \div$ 3) $10^{8}$ Joules, the depth of event being not more than $100 \mathrm{~m}$ and the registration zone less than $0.5 \mathrm{~km}$.

The measurements at massif surface have shown the principal possibility to apply the geoelectric potential method to control the manifestations of seismic character. However those studies have ascertained only the fact of the event itself without an explanation of its arising mechanism and as a consequence of that have not given the control instrument for the stresseed state change preceding to the rock pressure dangerous manifestation. The further studies (since 1991 to 1993) were carried out in underground opening with that purpose.

The geoelectric potential method workability checking according to the control for the stress state change induced by explosions carrying out was fulfilled at the fault in the 6 ort district with a scheme shown at Fig.3.29. In parallel the displacements measurements on the fault were carried out in the same points using the DPS-method delivered above. The displacements measurements were of self-dependent character (for estimation of shear stresses at the fault) and were used for the comparison to the geopotential measurements results.

The characteristic record of displacements and of the geopotential change from the explosion of December 51993 is given at Fig.3.30. The results were got by the minute averaging of real signal. The measurements materials at the fault show 
that the displacements and corresponding to them changes of geopotential are well correlated $(R=0.8 \div 0.87)$. Besides, the large number of seismic events after explosion and corresponding to them change of geopotential were registered (see Fig.3.31). The got results are well correlated with the Kukiswoomchorr seismic station data. The dependance of average number of events (exceeding of signals of given level) in time unit upon the time interval after explosion is given at Fig.3.32. The geoelectric background level in the area of 6 and 7 orts is equal to $0.5 \div 2 \cdot 10^{-4} \mathrm{~V} / \mathrm{m}$.

The anisotropy of physical-mechanical characteristics is the important feature of apatite-nepheline rocks (Turchaninov \& Medvedev, 1973) along and perpendicular to the junction planes. Usually the rock anisotropy according to the geopotential distribution is defined as $K_{A}=U_{y} / U_{x}$ where $U_{y}$ - the difference of potentials measured between two electrodes installed along the line perpendicular to the junction planes; $U_{x}$-in parallel to the junction planes. For electric indices of apatitenepheline rocks the anisotropy is within the limits of $2 \div 3$ (Bondarenko, 1972).

The origin of quasistatic geoelectrical fields in a rock massif is connected to the filtration of intraporous liquid which is known as an electrokinetic transformation. In that case the liquid filtration velocity $v$ and the $\Delta P$ electric current density $j$ are connected to the pressure gradient $P$ and to the electrical field strength with following equations (Migunov, 1987):

$$
\begin{aligned}
& j=E m \gamma+\frac{\Delta P m \varepsilon \xi}{4 \pi \eta} \\
& v=-\frac{E m \varepsilon \xi}{4 \pi \eta}-\frac{\Delta P k}{\eta}
\end{aligned}
$$

where $m$ - the rock porousness, $k$ - the rock penetrability, $\Delta P$-the pressure gradient, $\xi$-electrokinetic potential, $\eta, \varepsilon, \gamma$ - dynamic viscosity, dielectric constant and electric conductivity of a liquid.

As it is seen from given equations the porousness and penetrability of a medium exert essential influence upon the change of $E$ as well as the pressure gradient depending upon the massif stress state. In their turn $m$ and $k$ as physicalmechanical values must be anisotropic. Hence, at the stress state change the electrical field anisotropy change should be observed. The experimental verification of given statement was 
carried out as in openings with settled stress state where the mining works are absent as in openings with considerable change of stress state.

For comparative analysis and with a purpose of guaranteed elimination of the stress state change influence and of anisotropy $m$ and $k$ the measurements at unloaded volume of rock were fulfilled. Corresponding natural experiment in one of underground openings was stated in following manner. The selected rock volume of cubic form $(1 \times 1 \mathrm{~m})$ without seen fracture (cracks and irregularities) was separated from basic massif along three planes (the fourth one was the opening surface, the rest two - connected to massif) by the slot drilling along the perimeter (Fig.3.33a). The ultrasonic and geoelectric measurements were carried out in the process of such separation. Here we are interested in the last measurements series at the unloaded volume.

The characteristic records of potentials difference received in that experiment are shown at Fig.3.33b. The anisotropy is practically absent in the measurements data: $K_{A}=1.02 \div 1.1$.

Similar measurements were carried out in the real stressed massif in the zone where there no mining works were carried out during measurements period ("quiet" massif) and in the mining works zone with considerable change of stress state. As a latter one the massif area was selected where the works for constructing of release craters under a block prepared to the explosion. As a result of those works the support pillars section decrease occurs upon which the block is leaned and, hence, considerable changes of stresses in pillars.

The characteristic records of potentials difference in first and second zones are given at Fig.3.34-3.35. There the approximating lines are drawn characterizing the current average potentials difference as well. From comparison of figures it is seen that the difference of averaged in quiet massif is less than in a massif with considerable stress state.

The analysis of the geopotential anisotropy defined as $K_{A}=U_{y} / U_{x}$ is presented in a form of histograms. At Fig.3.36 it is shown the $K_{A}$ distribution for a massif in the mining works absence. The confidential interval of $K_{A}$ deviation at reliability 0.95 is equal to $0.9 \div 2$ at sample average 1.52 . At second histogram (Fig.3.37) the $K_{A}$ distribution is shown in second zone. The deviation interval of $K_{A}$ is equal to $2.8 \div 4.3$ at sample average 3.6 .

Hence, the stress state changes provoke the rock anisotropy considerable changes according to the geopotential distribution (up to three and more times) and measured 
parameter $K_{A}$ can serve as the characteristic of inhomogeneous stress state of a massif.

The obtained data witness for the utility of stated supposition that the anisotropy of $E$ is conditioned by the stress state change and by the movement of intraporous liquid along and perpendicular to the junction planes of apatitenepheline rock.

In the period of measurements carrying out in second zone the weak rockburst (a bump) occurred immediately in the registration place at December 231991 in 12 hours 14 minutes. The authors who were present in the opening have fixed the considerable acoustic effect, dynamic water discharge from technological holes and insignificant rockfalls into openings. Besides, the dynamic process of the holes $(100 \mathrm{~mm})$ deformation drilled in the opening wall was fixed the displacement occurred of comparatively small block with dimensions about $20 \mathrm{~m}$ towards the opening direction has actually occurred.

The geopotential measurements results in that period in a place of rockburst are given at Fig.3.38. The summationdifference method of signal detection was laid down in the basis of processing widely known from the detection theory (Tichonov et.al.,1980). The initial data for the processing were averaged each-minute values of $U_{x}$ and $U_{y}$. The output function was computed according to formula:

$$
F=\frac{\left|U_{y}+U_{x}\right|}{\left|U_{y}-U_{x}\right|} .
$$

All observations in second zone were processed according to that method. Comparatively small changes of stress state (at December 18, 19, 20 and 24 1991) are characterized by small variations of $F$ (from 0.2 to 2 ). However at the curves corresponding to December 23 there are 2 clearly expressed considerable deviations (maximums). The value $F_{2}=26$ corresponds to the mentioned weal rockburst and the value $F_{1}=14$ registered 30 minutes before the burst - to the visually noticed insignificant falls in adjacent openings.

Simultaneously in the same place the measurements of electrical resistivity of apatite-nepheline ores were carried out. At Fig.3.39 the dependances of the e The local infrasonic spectrums (see the interval $I$ at Fig.3.10) induced by the ground oscillations in reception point are more highfrequencied $(14 \div 18 \mathrm{~Hz})$ and the range of registered frequencies is more narrow (see the Fig.3.11b). 
lectrical resistivity averaged at minute interval are given in two directions: in parallel to junction planes $\rho_{x}$ and perpendicular to them $-\rho_{y}$. As it is seen from received results the weak rockburst moment in opening zone corresponds to the electrical resistivity increase. By that $\Delta \rho$ - root mean square deviation of $\rho$ from its current mean value in the process of event preparation was gradually decreasing and at the moment of rockburst was practically equal to zero whereas the considerable minute variations of $\rho_{x}$ and $\rho_{y}$ were observed in previous days (Fig.3.40). The following is important: the rockburst moment fixed by means of the electrical resistivity method coincides precisely in time with maximum of $F_{2}$ (Fig.3.38) got with the aid of geopotential method. That is why it deems to be purposeful to use the electrical resistivity method together with geopotential method for the rock massif stress state control. By that as it is seen from Fig.3.38-3.40 and as the studies results show the electrical resistivity method is best to be used for long-range prognosis $(24 \div 72$ hours) and geopotential method - for operative control $(1 \div 2$ hours) of events.

The obtained results enable to speak about the workability of method, the absence of false maximums for all time of measurements being a hopeful factor.

Fulfilled studies enabled to analyze some totality of information about the geoelectrical fields behavior in a rock massif and to give a description of processes preceding the seismic event.

At given stage of studies two groups of geoelectrical fields are defined - dynamic and quasistationary ones accompanying the process of change of the stress-strain state in rock massif.

Disturbances of given geoelectrical fields are localized near the focus of future event in space and in time and have 3 stages.

First stage - the development of process of crack forming accompanied by the geoelectrical impulses amount increase and by the quasistationary geoelectric fields anisotropy intensification. The geoelectric impulses decrement with the distance and may be registered at distances considerably exceeding the dimensions of a irregularity itself. The quasistationary fields anisotropy is manifested only in the irregularity itself.

Second stage - the sharp increase of a number of geoelectrical impulses, increase of their amplitude and duration, the development of anisotropy process. The seismic 
event moment is characterized by anisotropy maximum and by considerable decrease of a number of geoelectrical impulses.

The second stage duration from sharp intensification of all geoelectrical fields to the event itself is in a range from several minutes to their tenths.

Third stage - the period of transition into the background state. However it is not excluded that at some conditions this stage can immediately come into the second one.

The area of the geoelectrical control method for stress state of rock massif depends upon the event focus dimensions and at the study given stage the radius of zone of reliable control doesn't exceed $150 \mathrm{~m}$. 


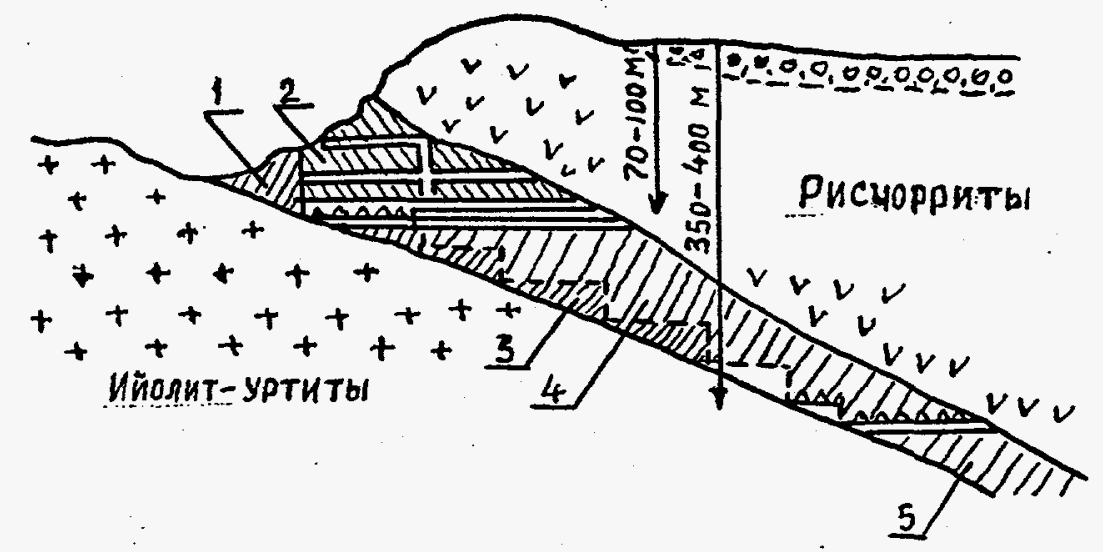

कasion

Fig.3.1. The general scheme of the Kukiswoomchorr apatite-nepheline deposit development

1 - zone of the open mining,

2 - blocks near the mass surface,

3 - deposit floor,

4 -zones with normal conditions of mining,

5 - highstressed zones. 


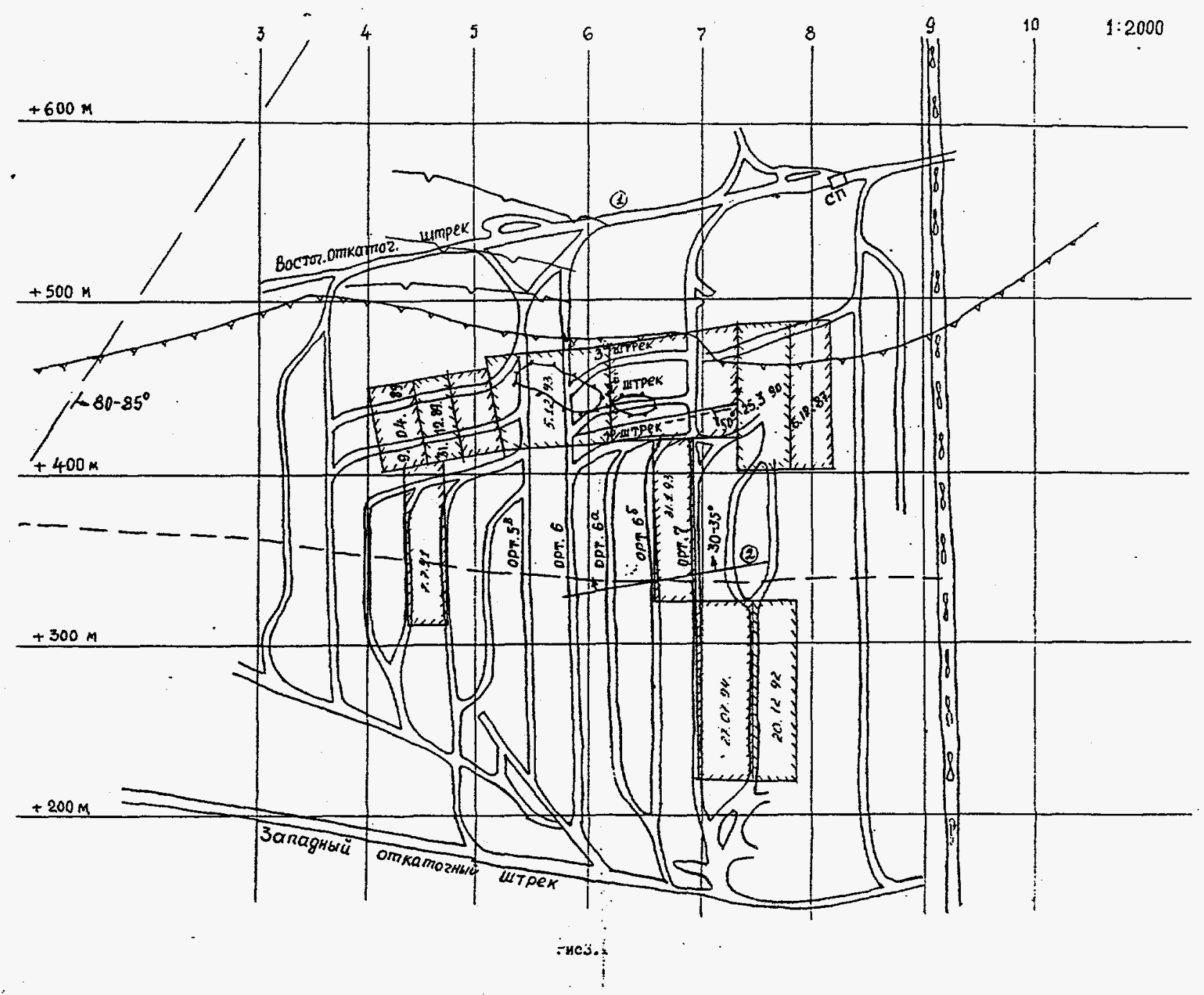

Fig.3.2. Part of plan of horizon +252 .

("pillar - block") rectangles - cut blocks

"6.12.87" - data of explosions

1 - east lanlage way

2 - fault. 


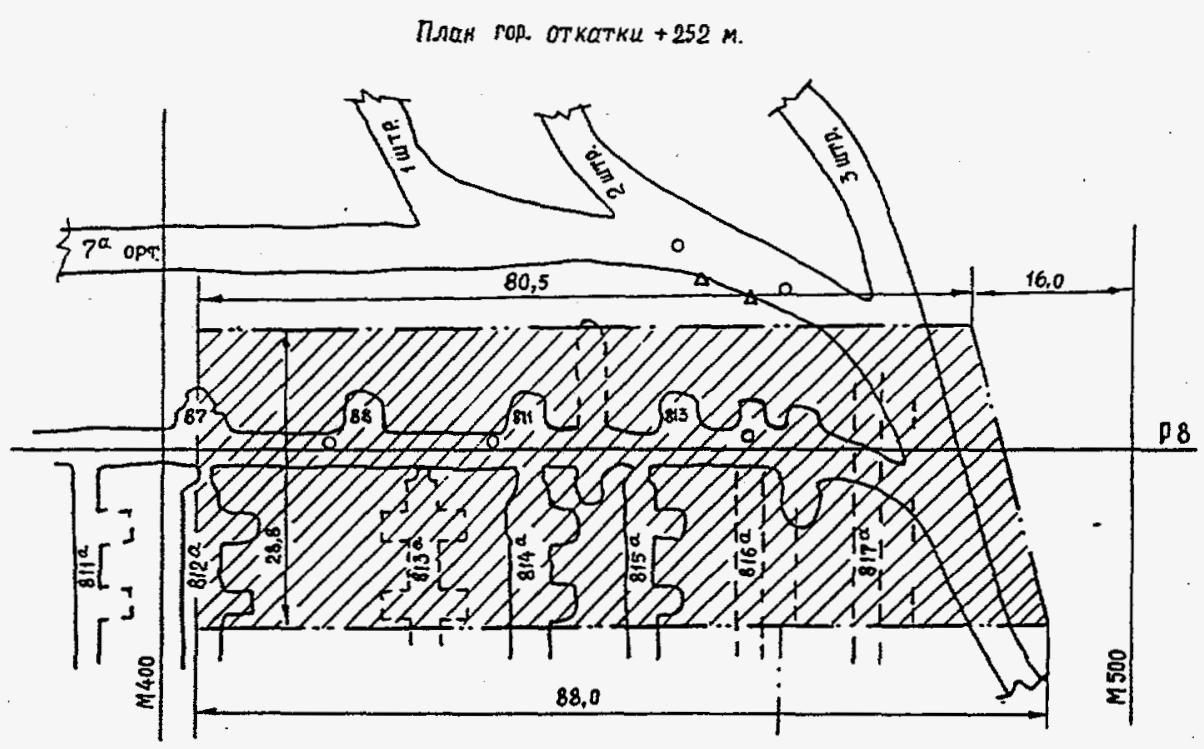

Fig.3.3. Plan of the block (explosion 6 December 1987). 


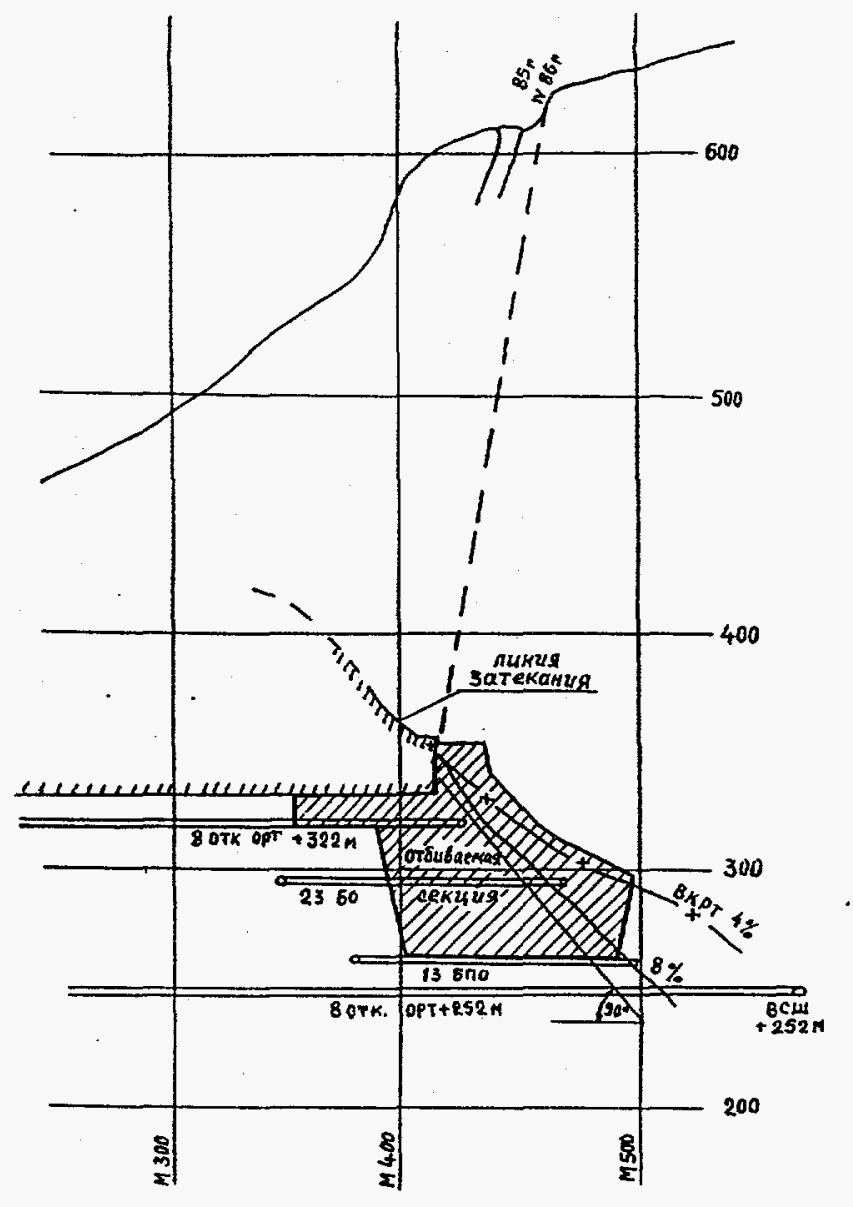

Fig.3.4. Vertical section of the block (explosion 6 December 1987) 1 - block, 2 - ore body upper border. 


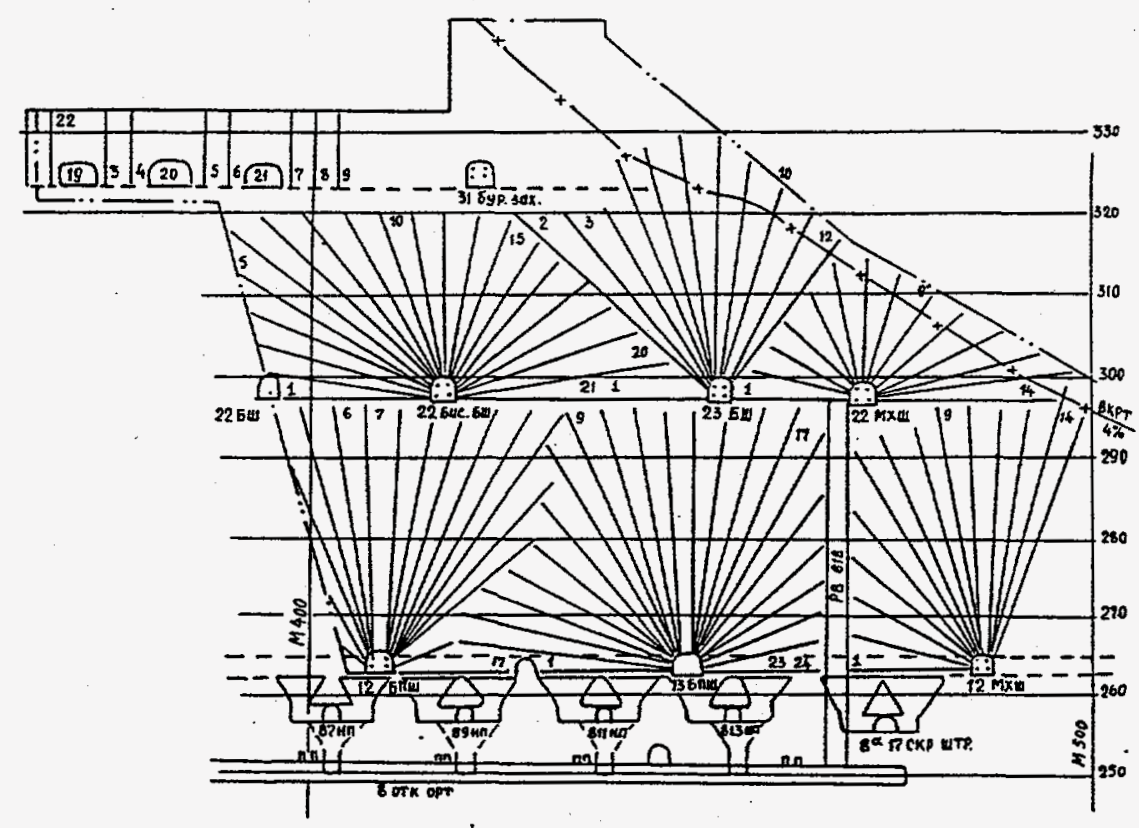

iastistas:

Fig.3.5. Vertical section of the block (6 December 1987) with the sheaf of explosions holes. 


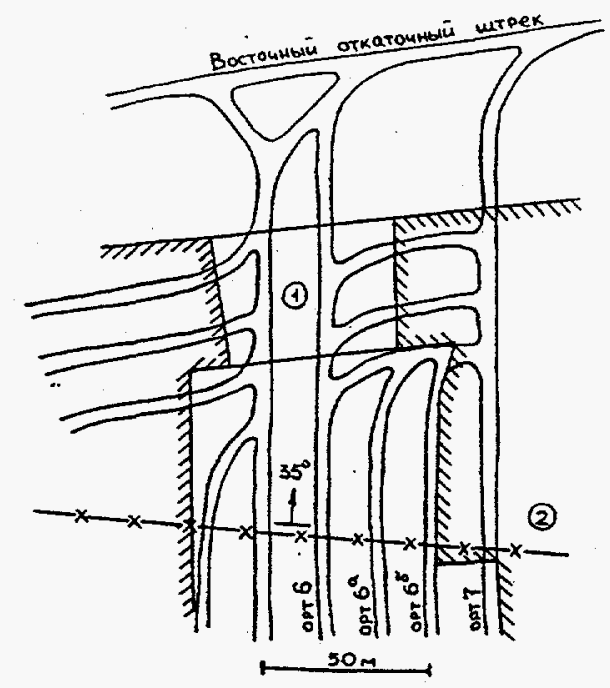

Fig.3.6. Plan of the part pf horizon +252

(last junction section of cutt off band, explosion 5 December 1993) 1 - block, 2 - fault.

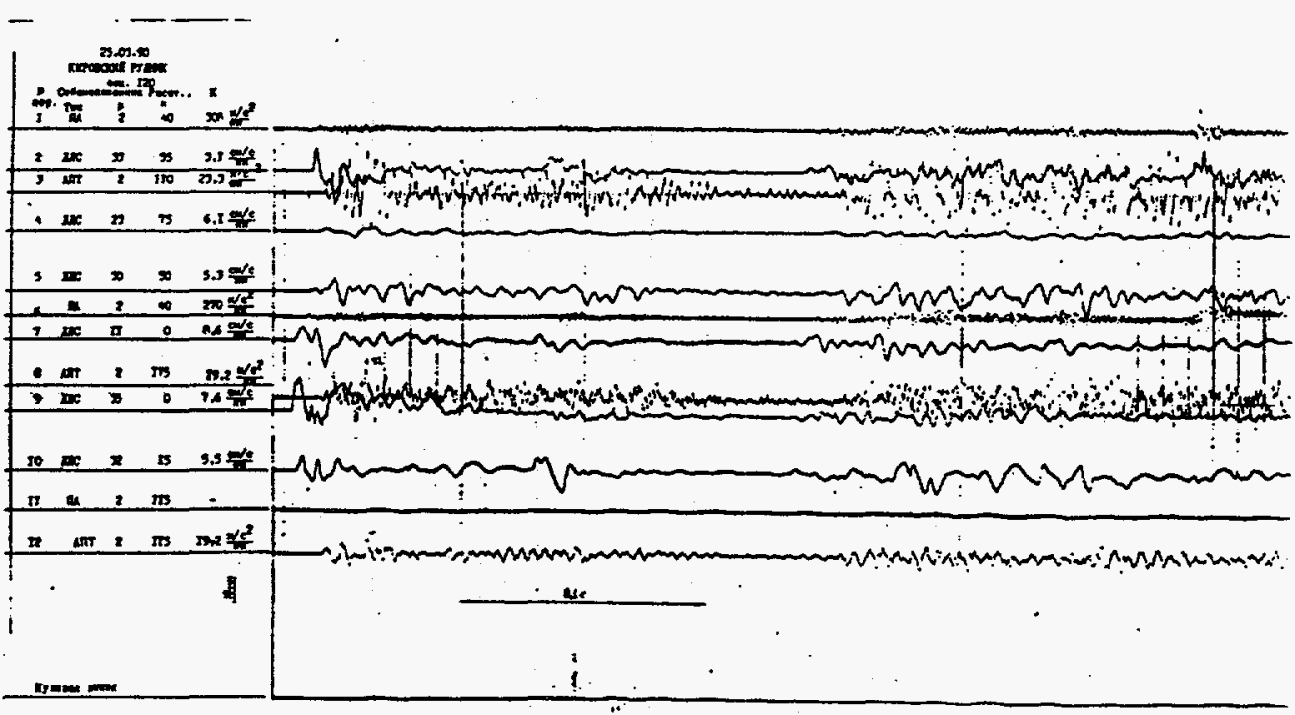

Fig.3.7. Seismic measurements in underground opening at horizon +252 (S.A.Kozyrev). 


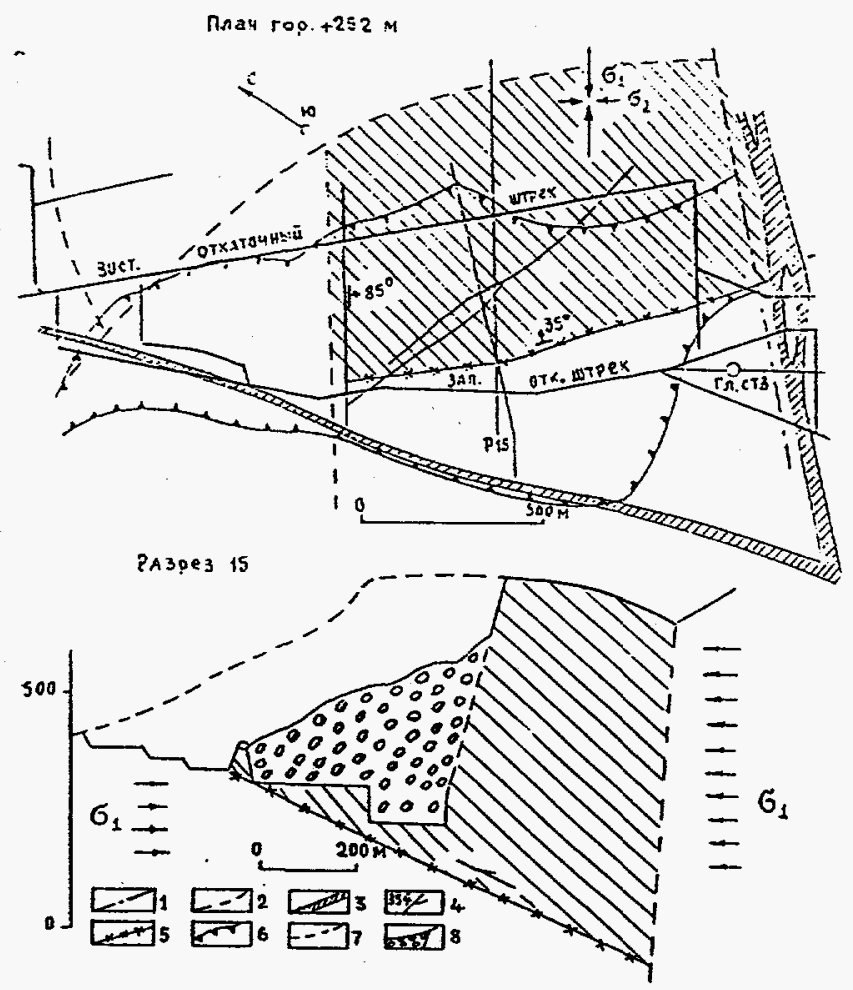

Fig.3.8. Part of plan of horizon +252 (a) and section acording to P15 (b). 1,3 - faults of IV rank; 2,4 - faults of V rank;

5 - the fault of $\mathrm{V}$ rank along whick the displacement occured; 6 - border of destroied rocks;

7 - surface relief before the begining of mining;

8 - modern relief and destroied rocks; 


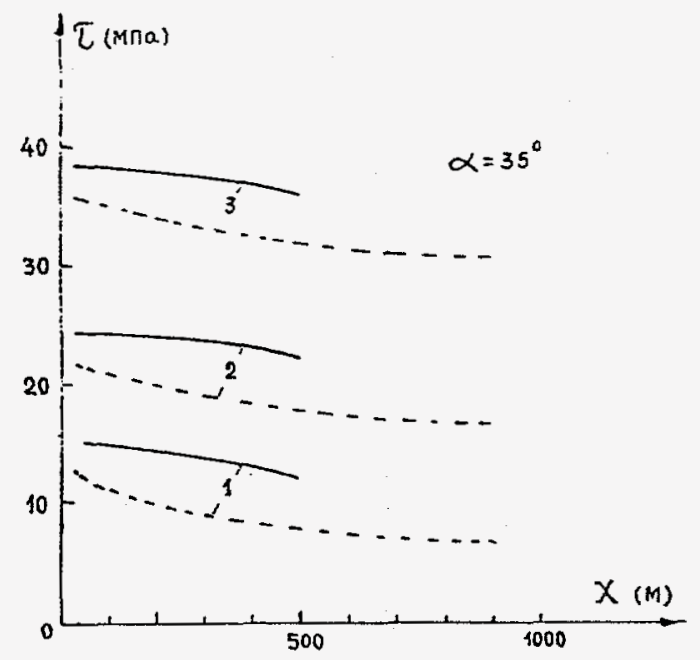

Fig.3.9. Shear stresses on the fault plane.

$1-\mathrm{T}=30 \mathrm{MPa}, 2-\mathrm{T}=50 \mathrm{MPa}, 3-\mathrm{T}=80 \mathrm{MPa}$

$\mathrm{X}$ - horizontal distance.
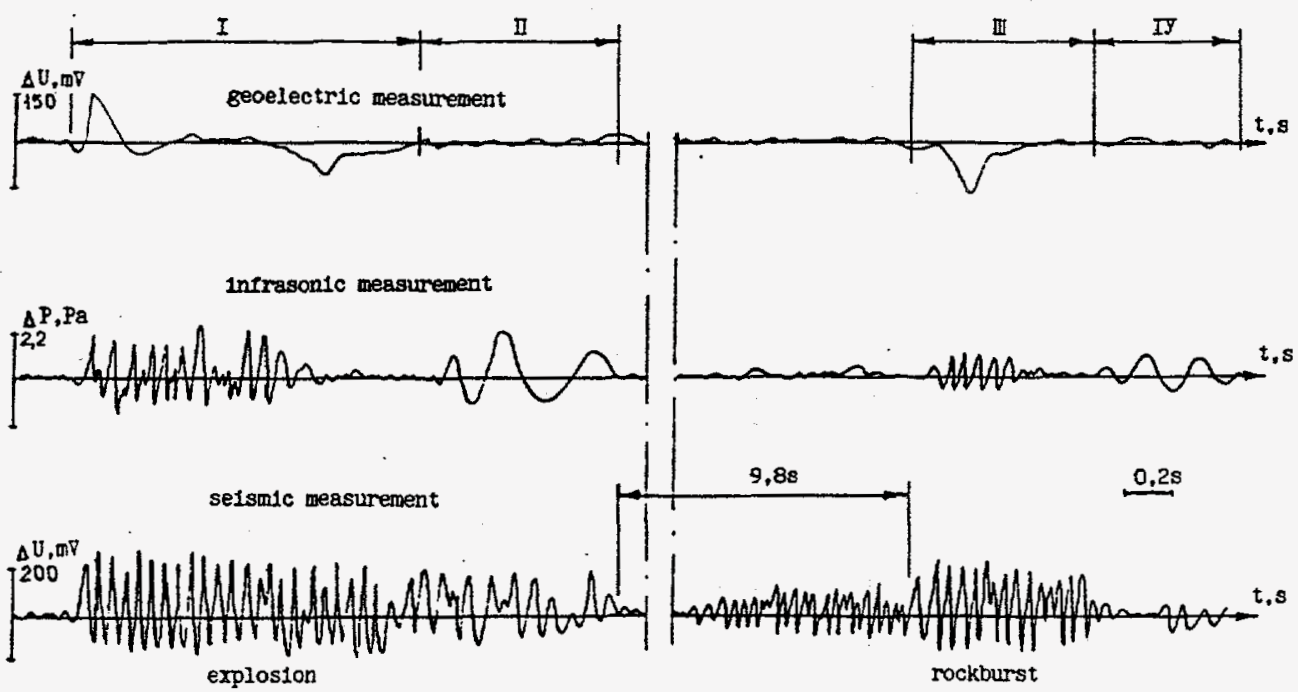

Fig.3.10. The recordings of the explosion and rock burst 28 April 1991 by seismic, geopotential and infrasonic methods in Kukiswoomchorr station. 
a)

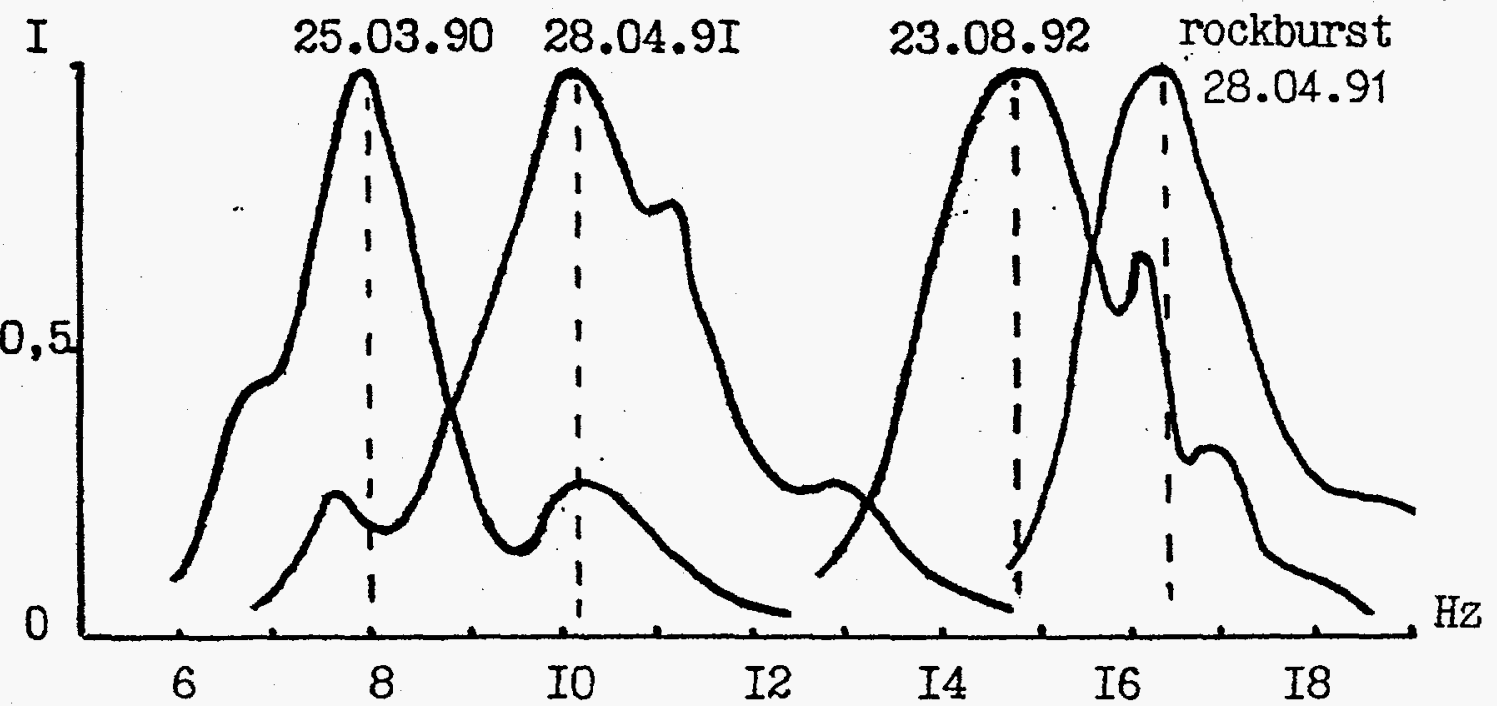

b)

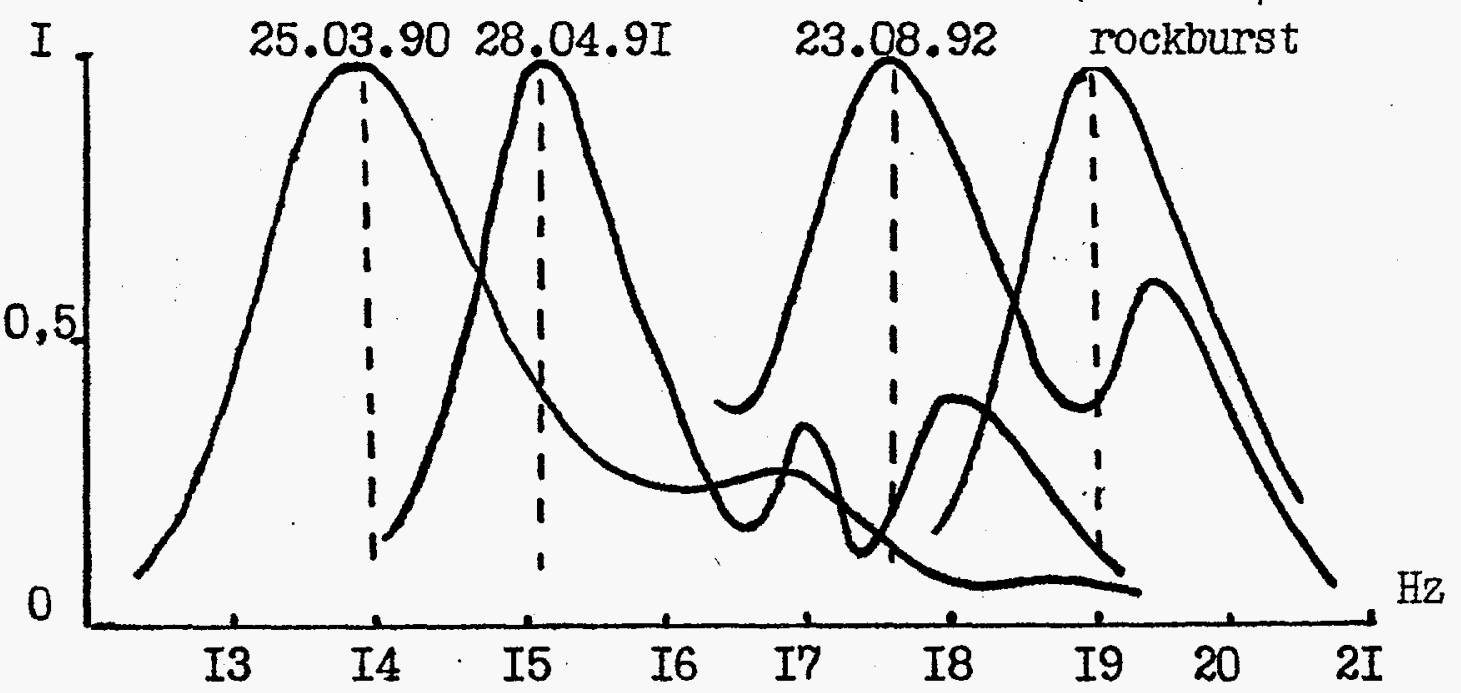

c)

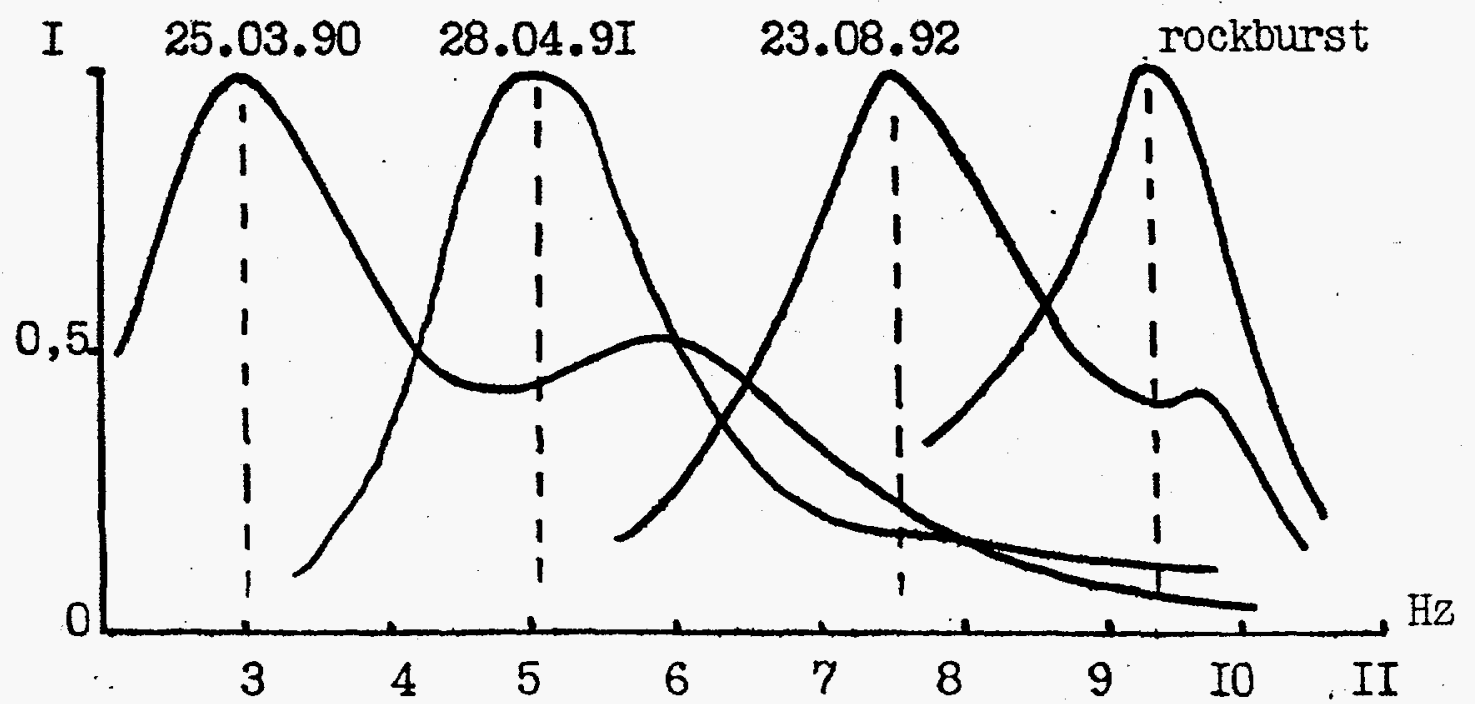

F1g.3.II. Spectrums of the recorded signals from

underground explosions

a-spectrums of the selsmic signals;

b-spectrums of the local infrasonic;

c-snectrums of the epicentre infrasonic 


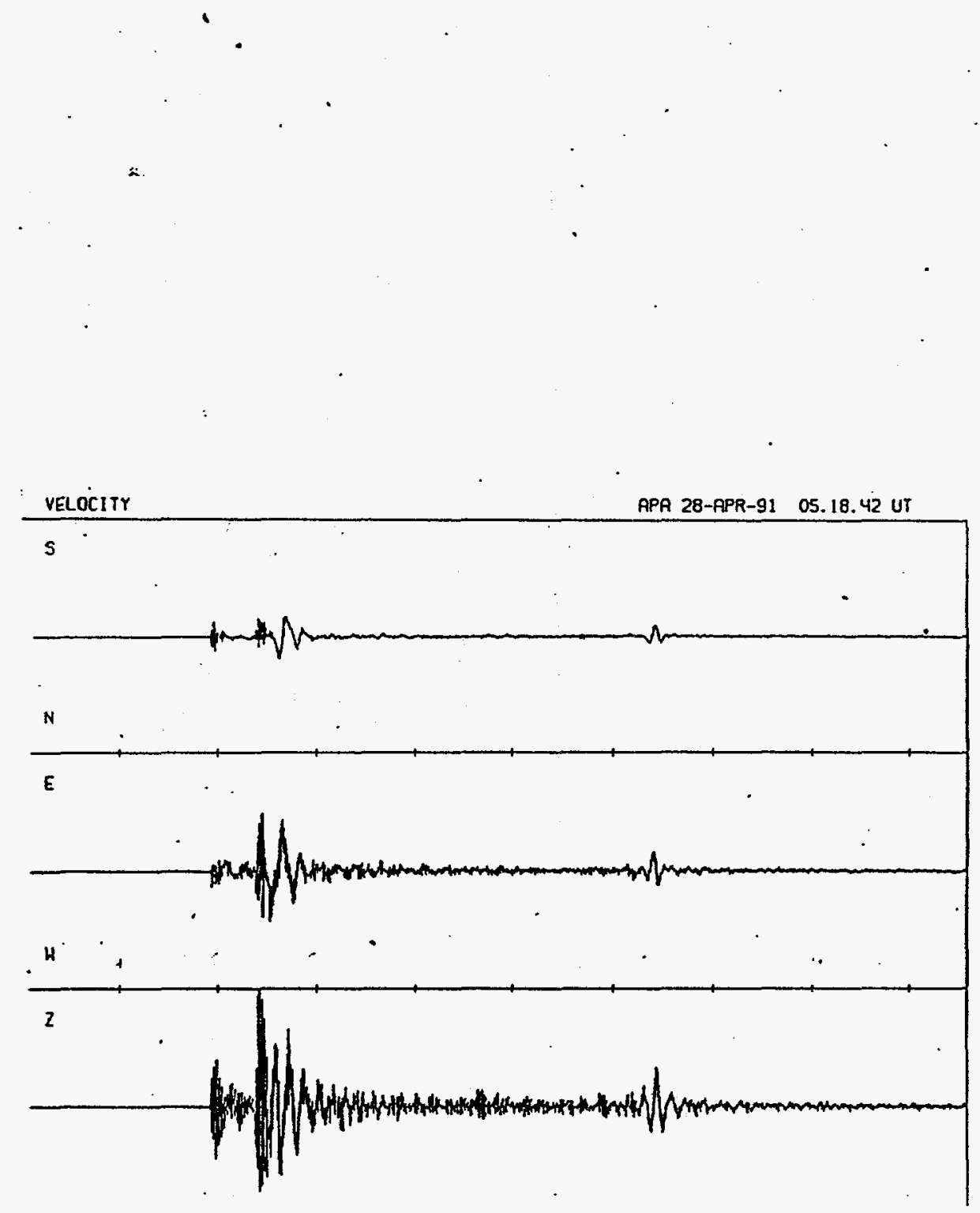

Fig.3.12. The recordings of the explosion and rockburst 28 April 1991 by seismic station in Apatiy town. 

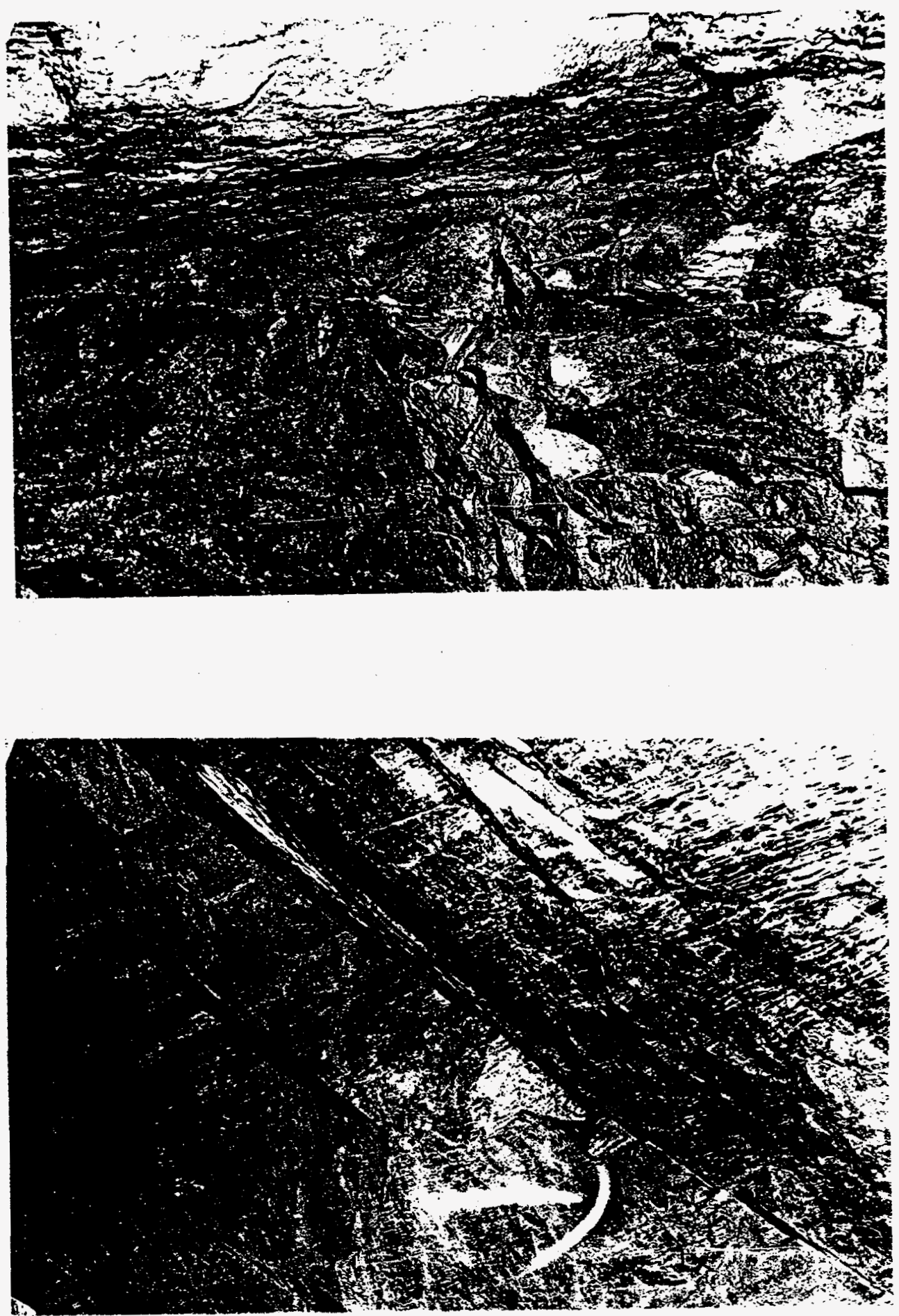

Fig.3.13. The output of the fault to the roof and wall of ort No.7. 


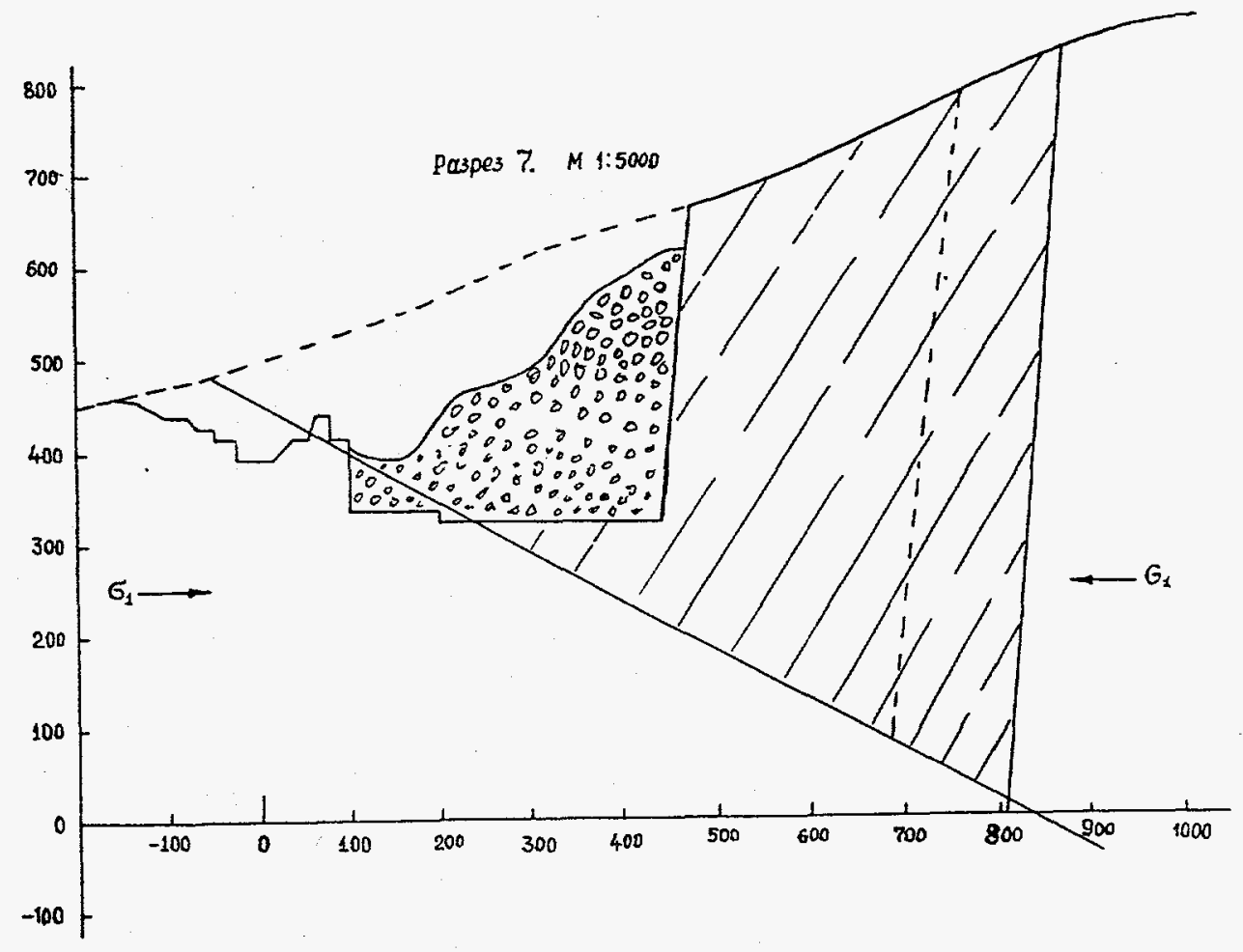

Fig.3.14. Vertical section of the massif in the zone of measurements.

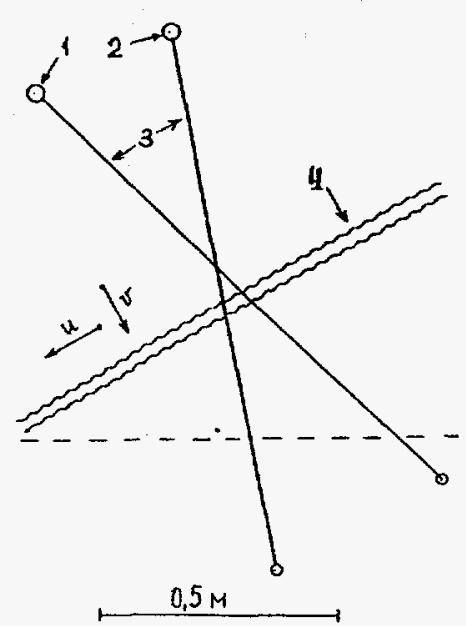

Fig.3.15. The DPS sensors disposition layout in opening (ort N7) $a$ - northern wall b-southern wall. 

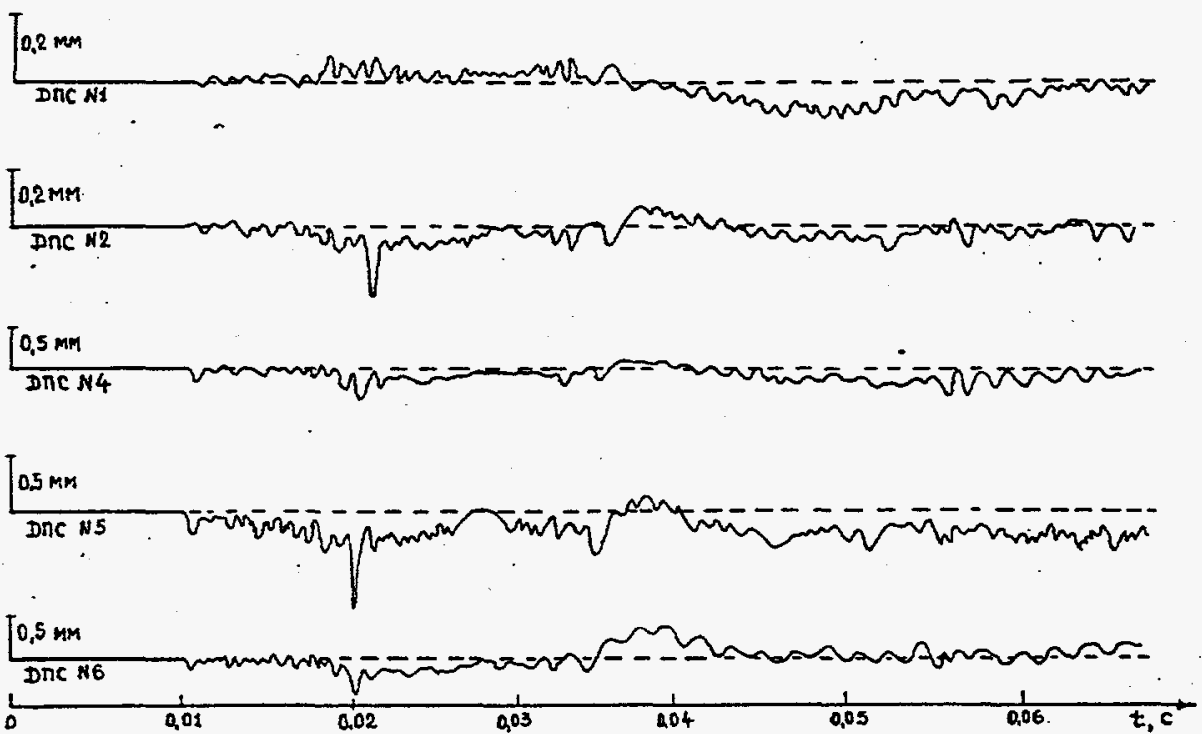

Fig.3.16. The relative displacements recording (oscillograms copies) 25 march 1990.

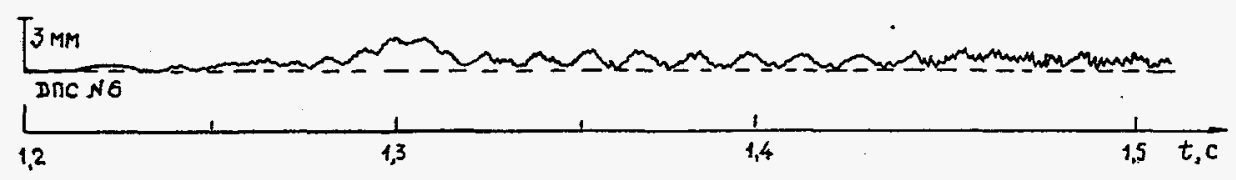

Fig.3.17. The relative displacements recording (oscillograms copies) 25 march 1990. 


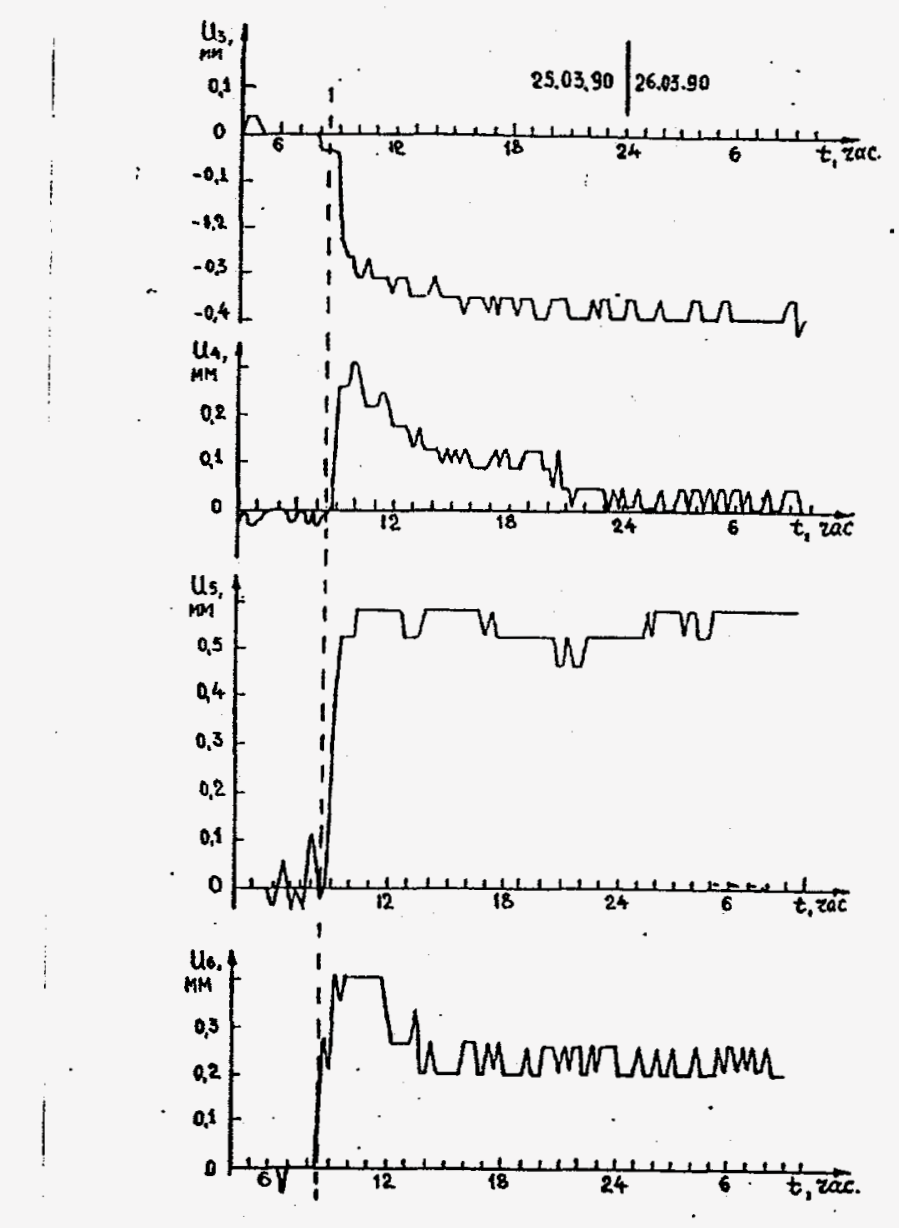

Fig.3.18. The relative displacement recordings (digital memory system) 25 march 1990 .

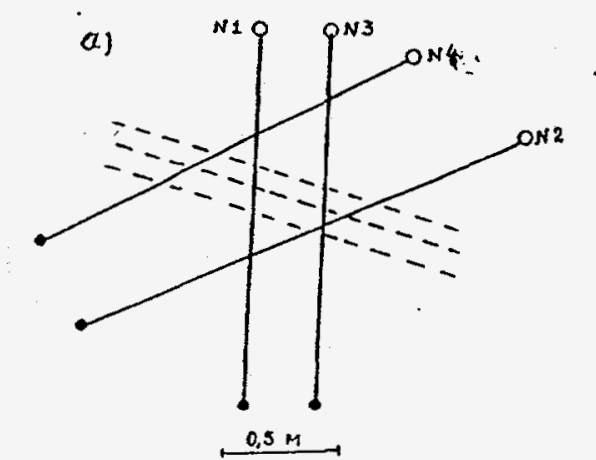

б)

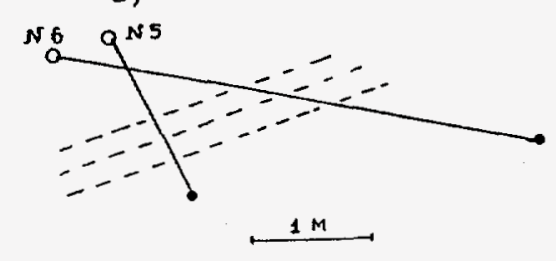

Fig.3.19. The DPS sensors disposition layout in opening (ort N6) 1 - DPS N1, 2 - DPS N2, 3 - string, 4 - fault. 

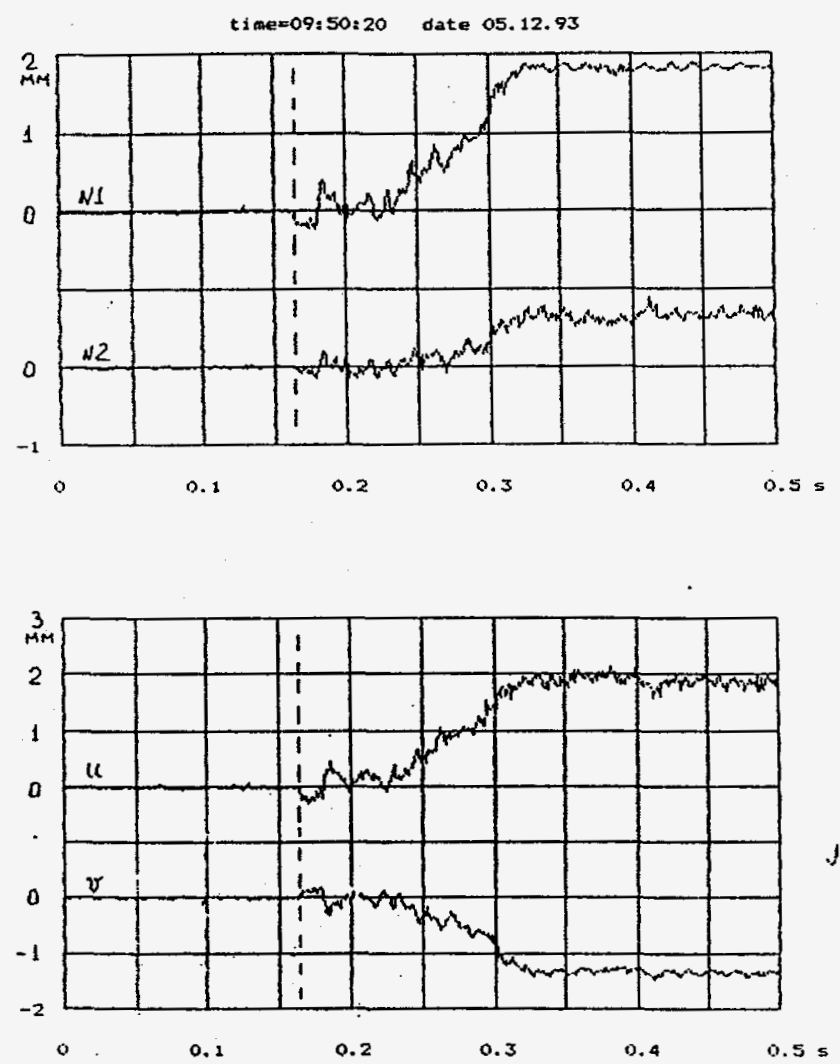

Fig.3.20. The relative displacements of the fault sides 5 December 1993. (time scale - 0,5s). 

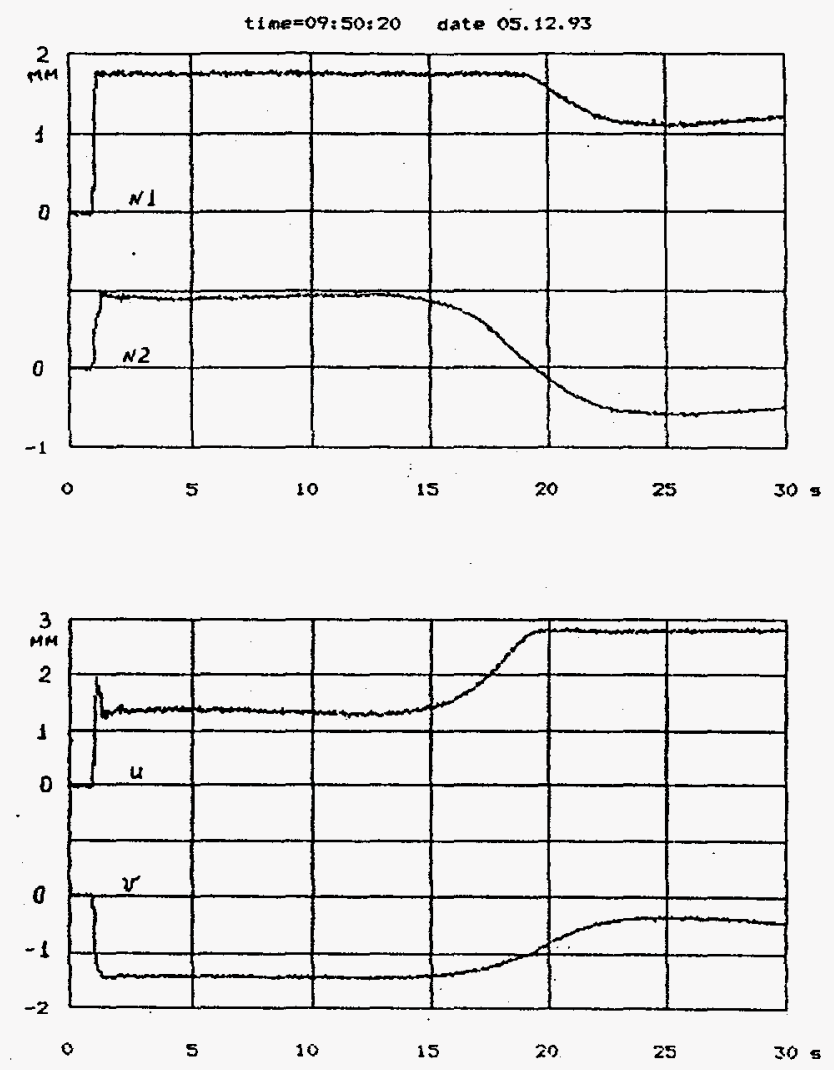

Fig.3.21. The relative displacements of the fault sides 5 December 1993. (time scale - 30s). 

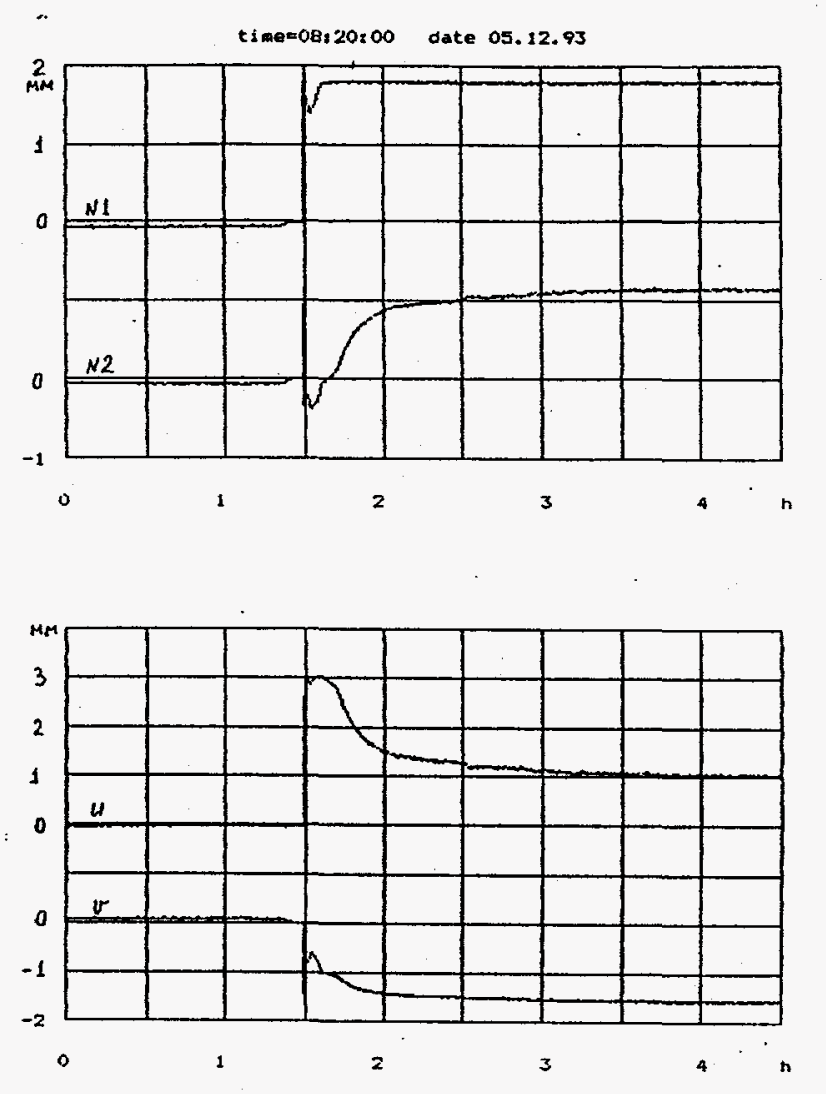

Fig.3.22. The relative displacements of the fault sides 5 December 1993 . (time scale - 4,5h). 


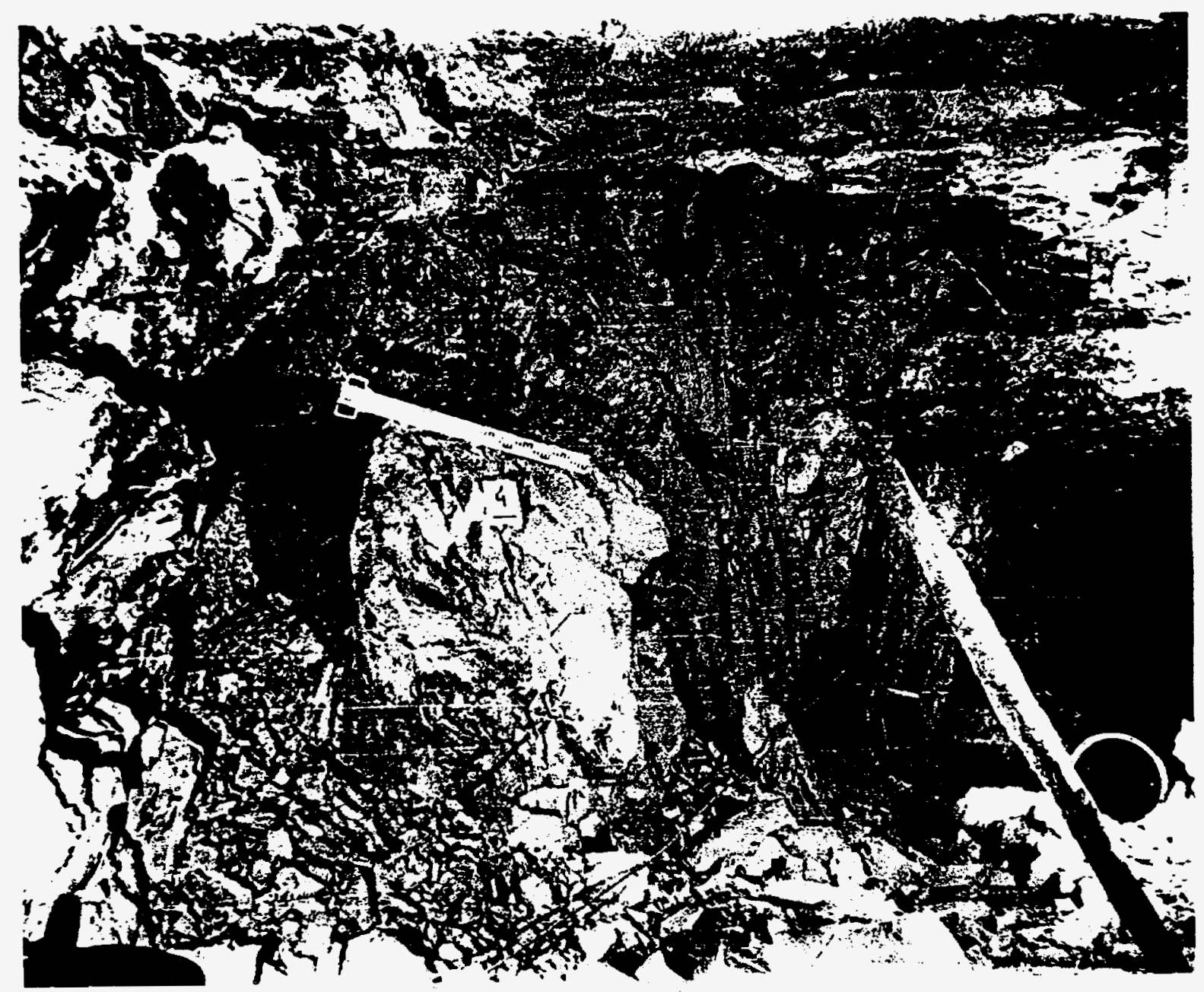

Fig.3.23. The throwing out of rock blocks into opening (rockburst 6 December 1987). 

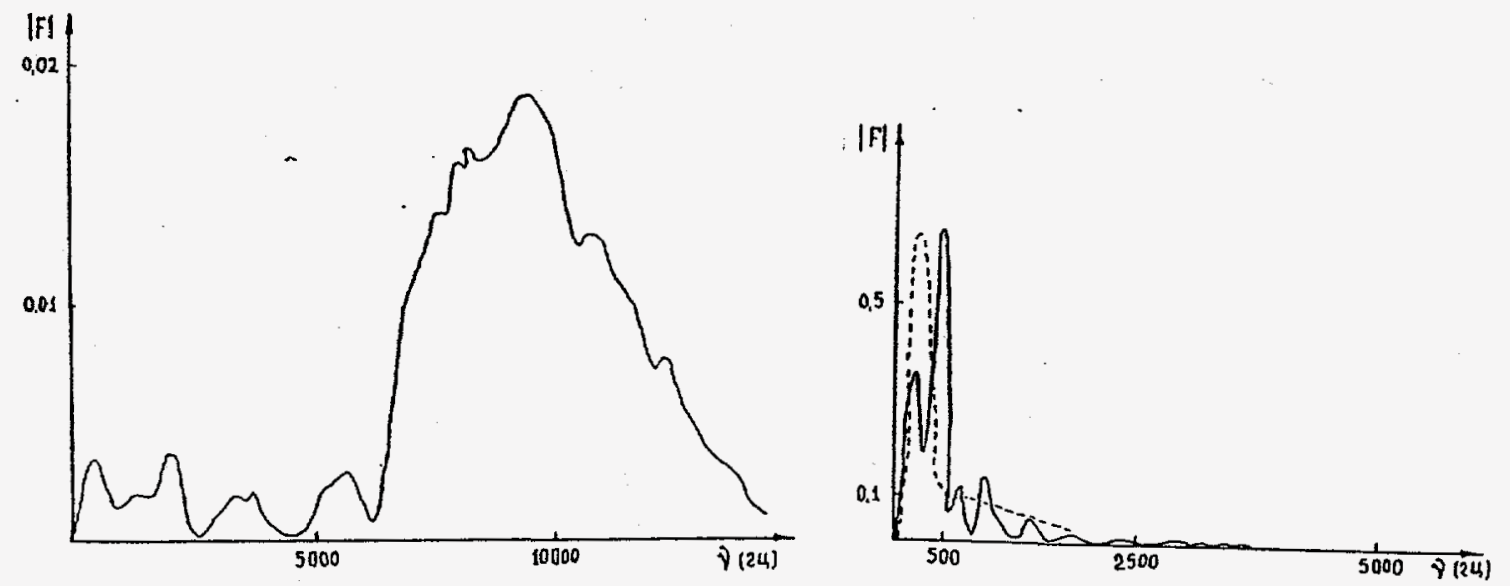

Fig.3.24. Spectrums of seismoacoustic signals

a) before explosion, b) first day after explosion.

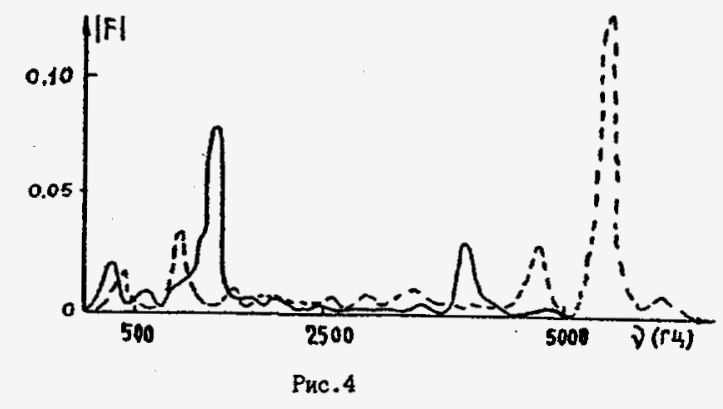

Fig.3.25. Spectrums of seismoacoustic signals

(solid line - second day, dashed line - third day after explosion). 


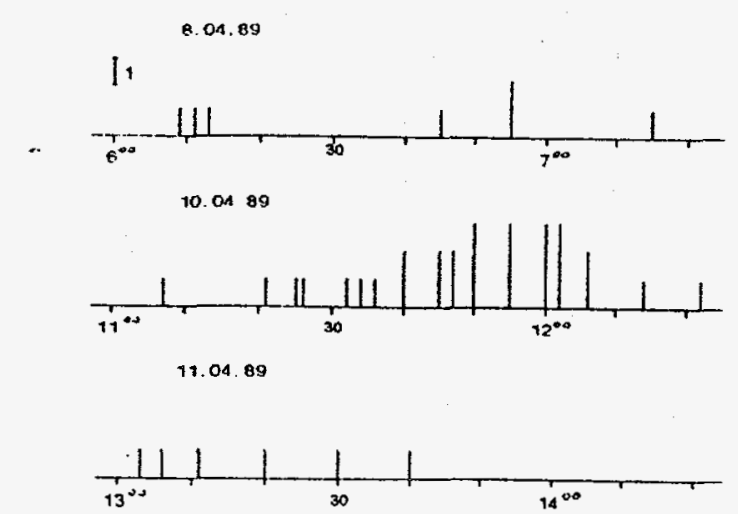

Fig.3.26. Diagram of moments of seismoacoustic signal registation.
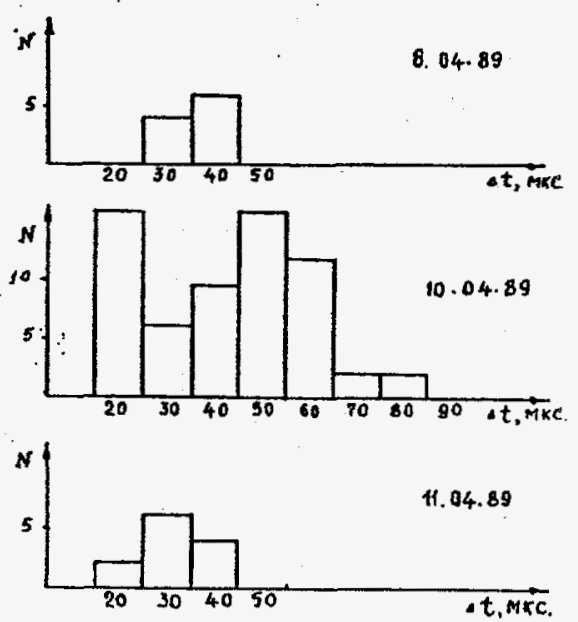

Fig.3.27. Histogram of number of impulses versus duration of the their first phase. 


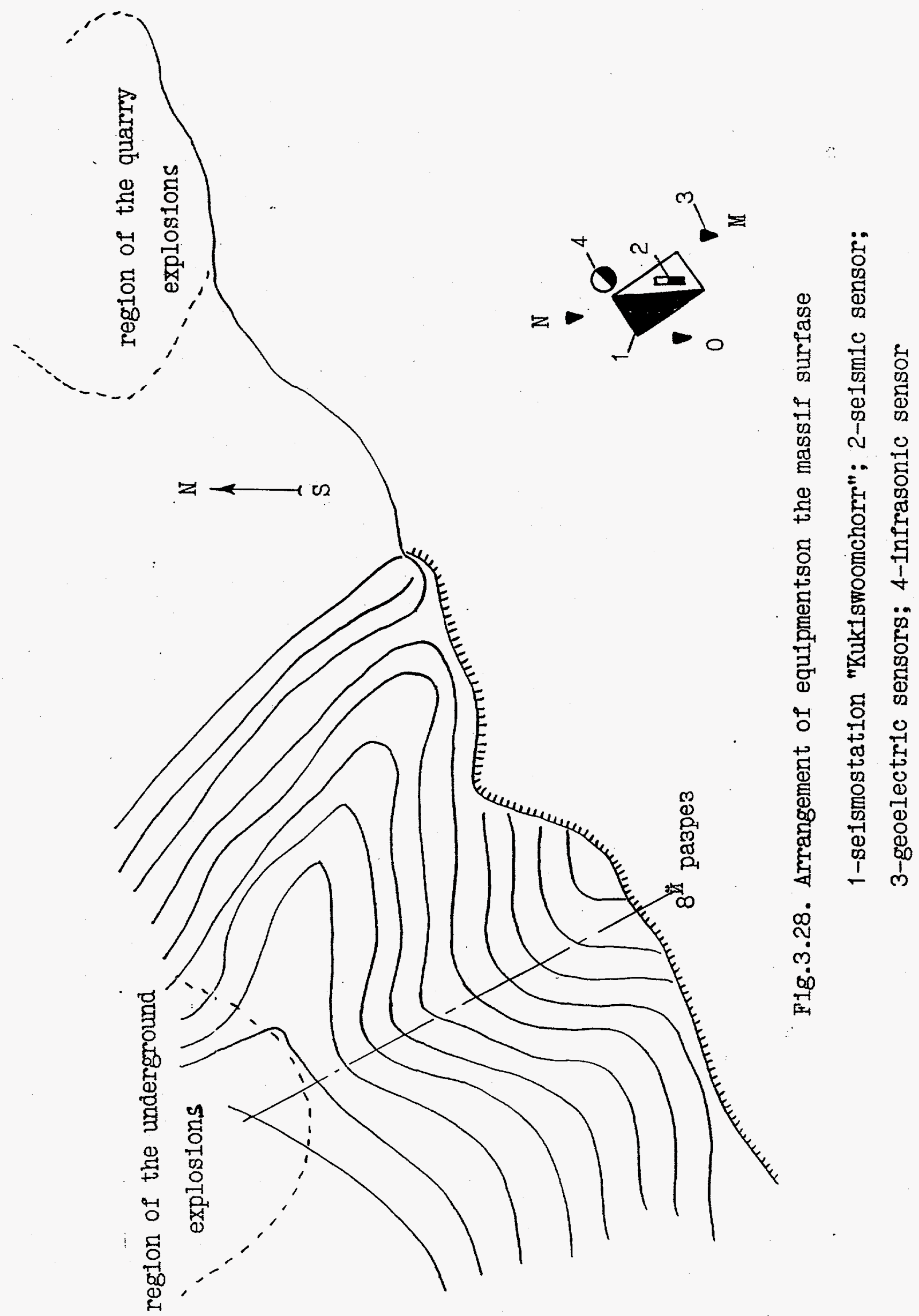



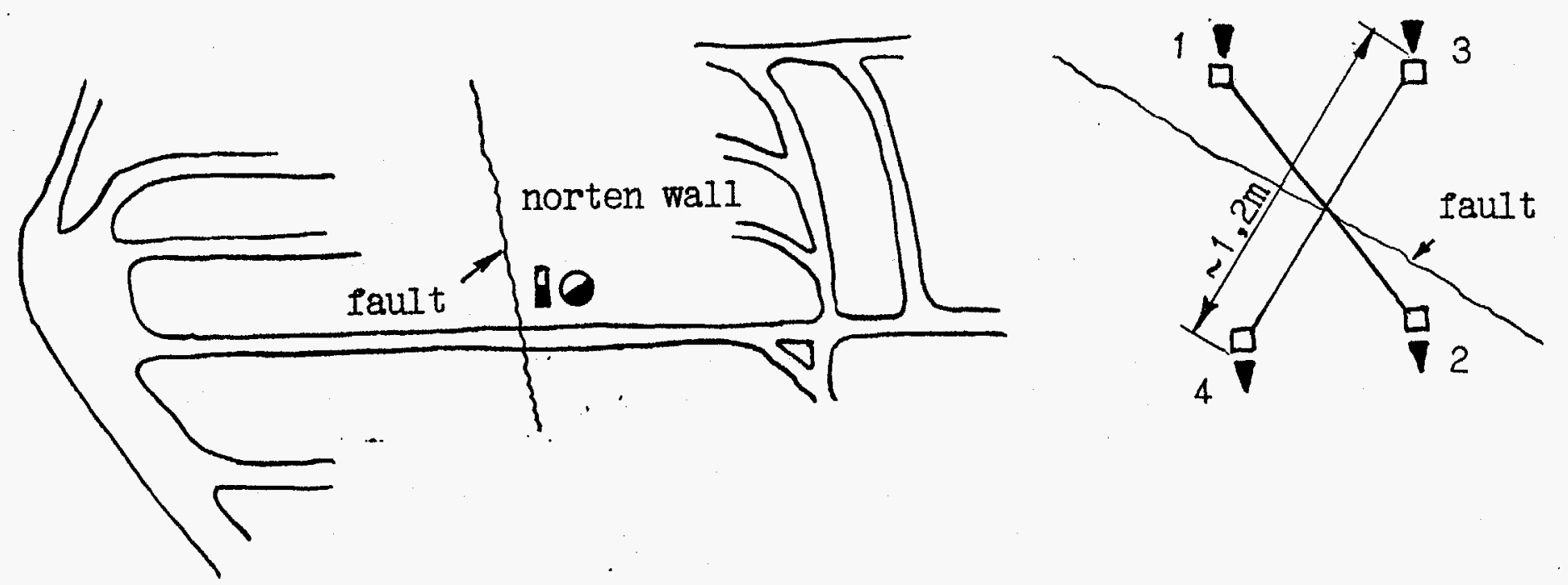

F1g.3.29. Arrangement of equipments in the underground openins $\nabla$ - geoelectric sensors; - selsmic sensors;

- Infrasonic sensors; $\square-\square$ - sensors of the relativ displacements 


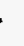
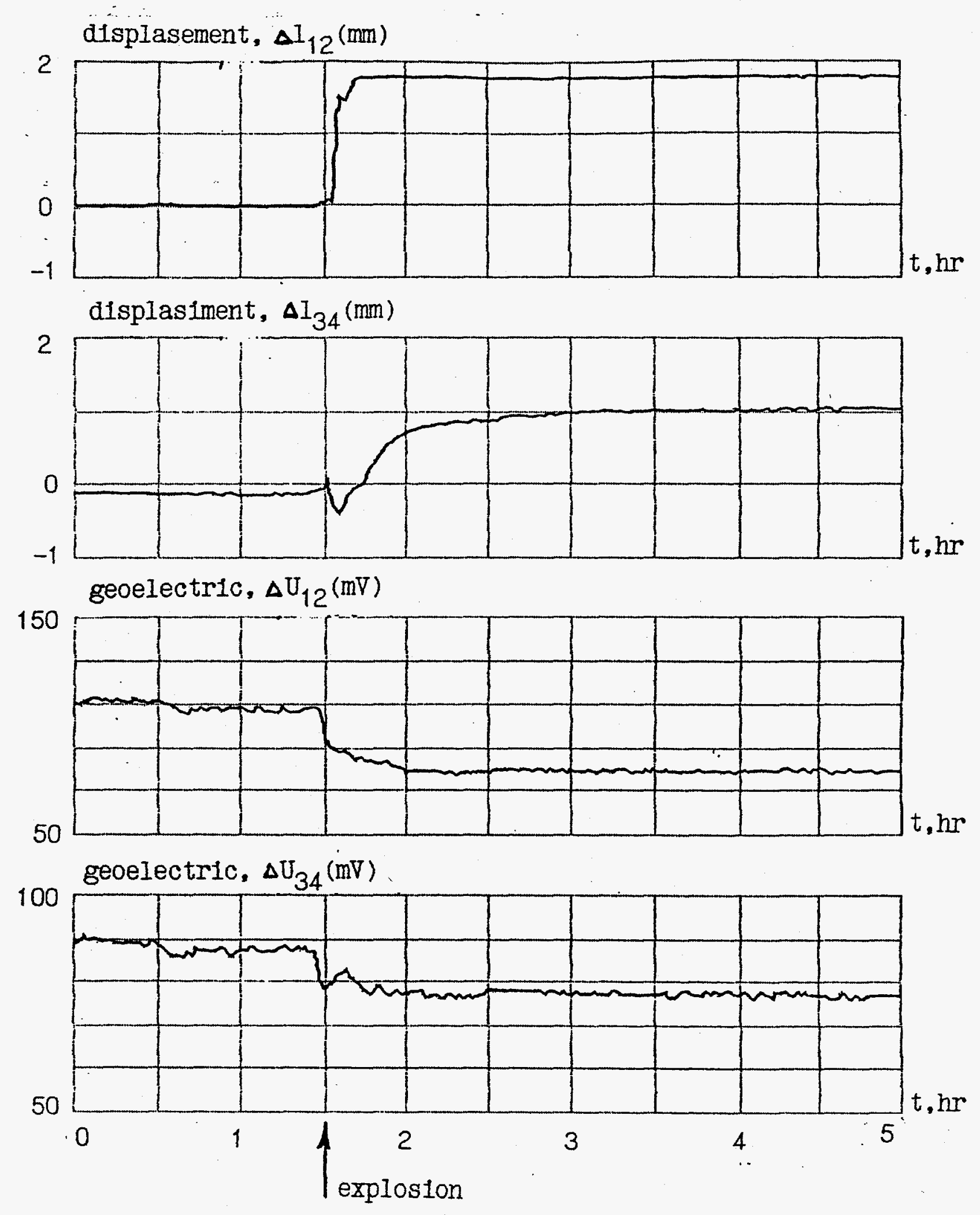

Fig.3.30. Geopotential and displace variation on the fault (explosion December 5 1993) 


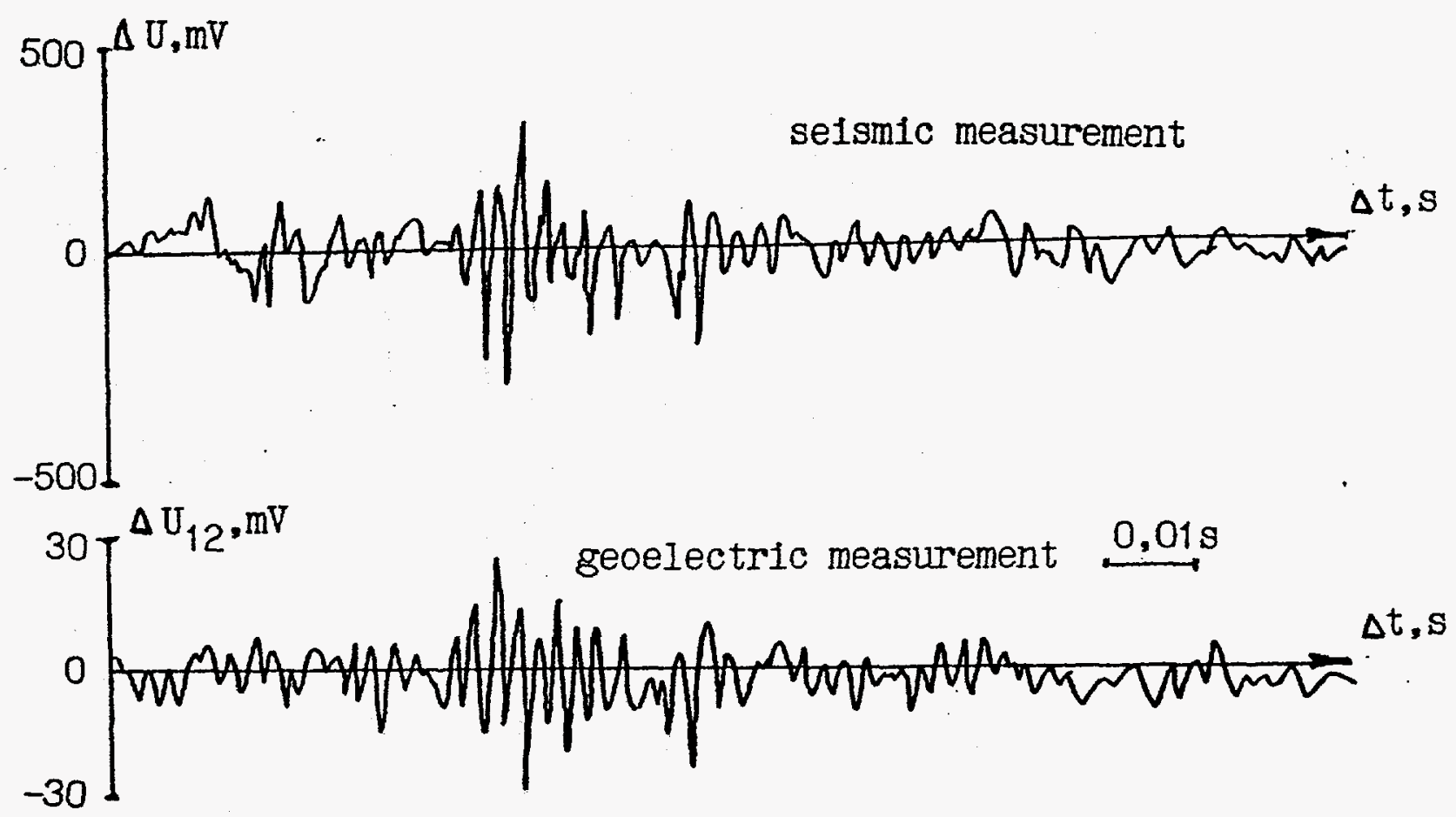

F1g.3.31. Osc1lograms of the selsmic and geoelectric signals after explosion

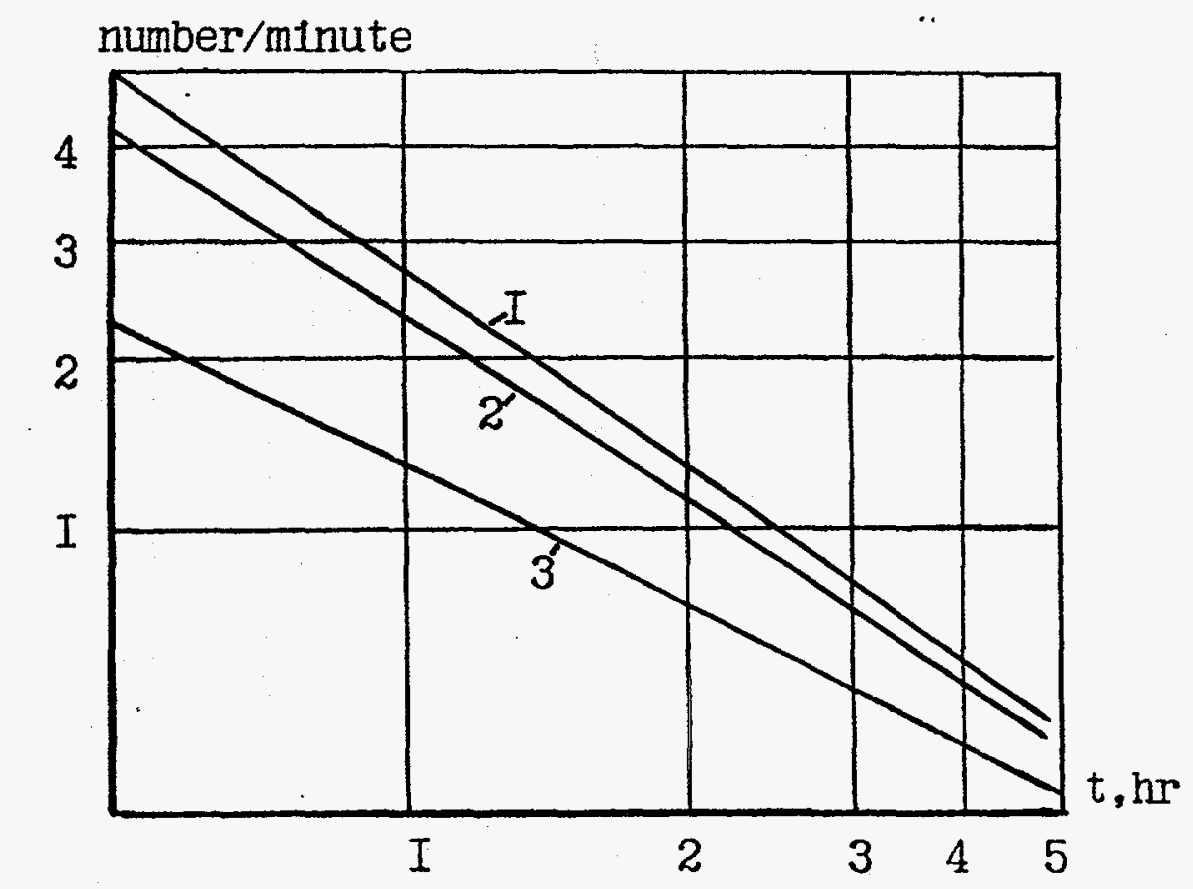

F1g.3.32. Number of the events after explosion

1-measurements of the relative displasements;

2-geoelectric measurements;

3-seismostation "Kukiswoomchorr" 
a)

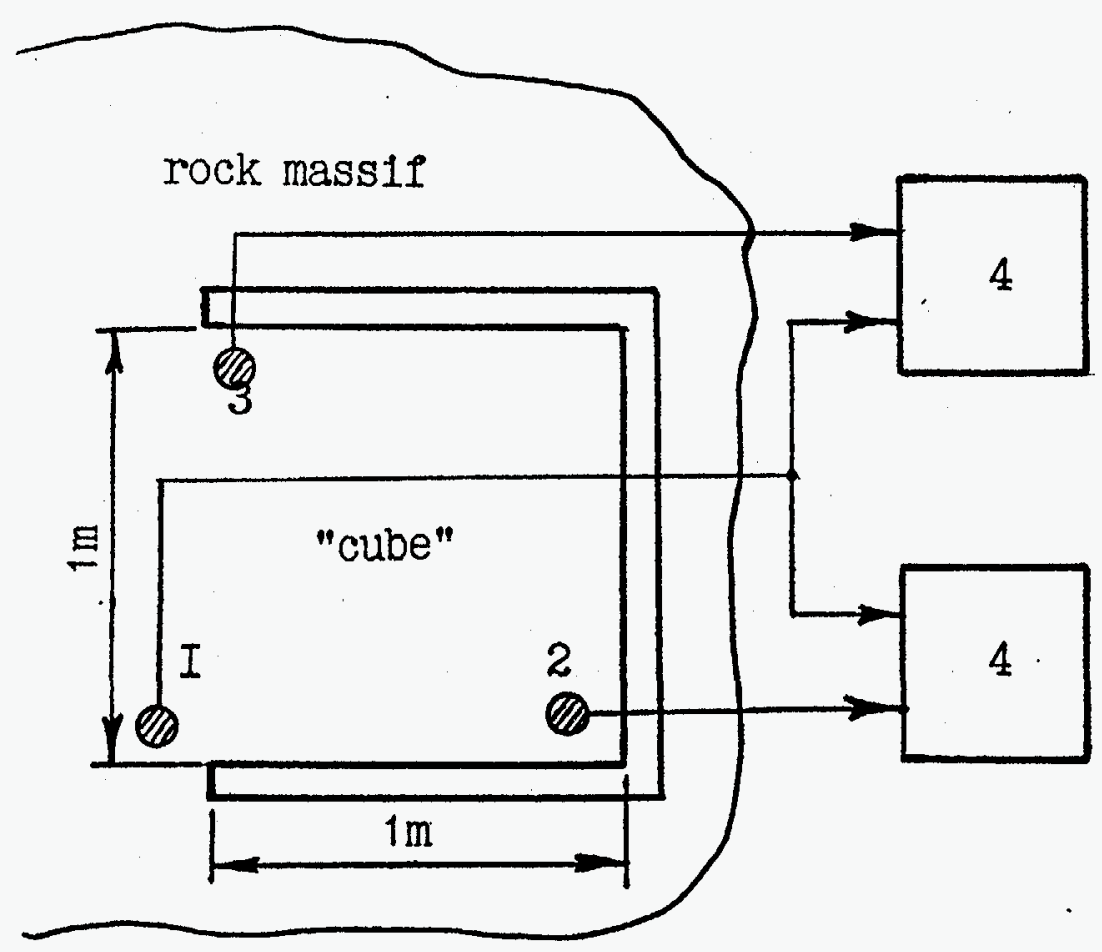

b)
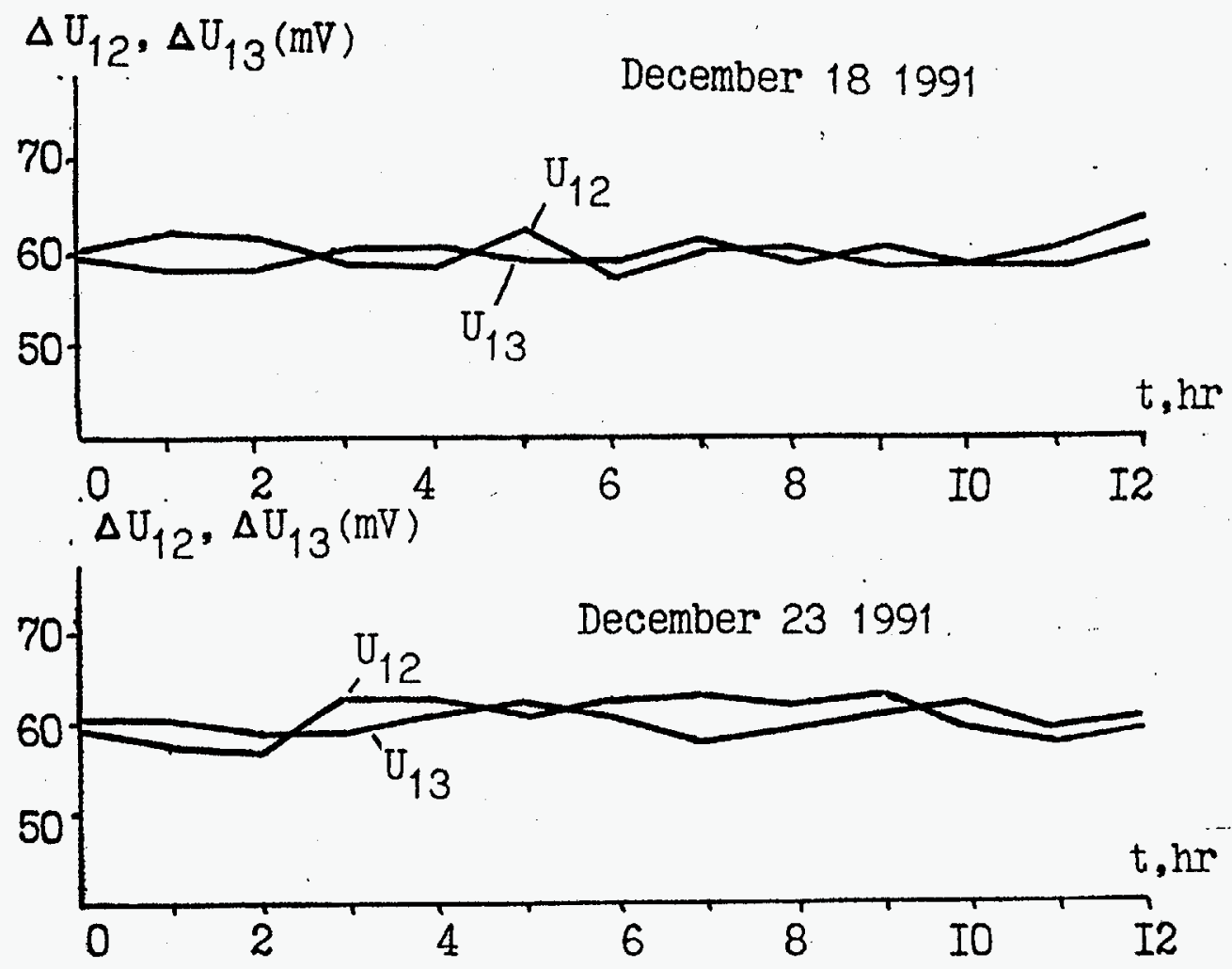

F1g.3.33. Arrangement of equipments in the rock volume of cublc form (a) and the characteristic records of potentials difference (b)

1,2,3-geoelectric sensors, 4-recorder 


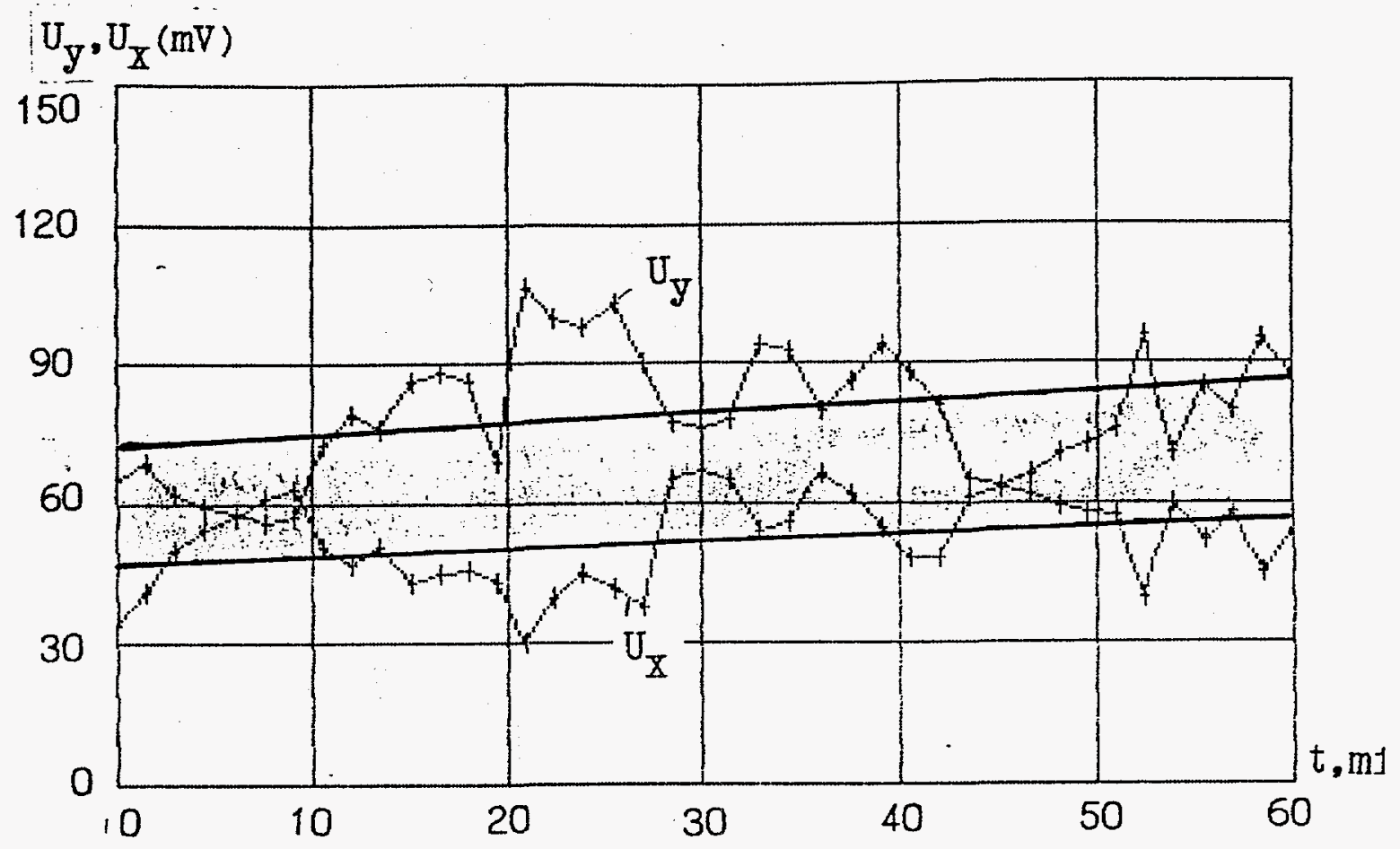

Fig.3.34. Difference of the potentials $U_{y}$ and $U_{x}$ measured in the "quiet" massif (*-*-*) and their line approximation (---)

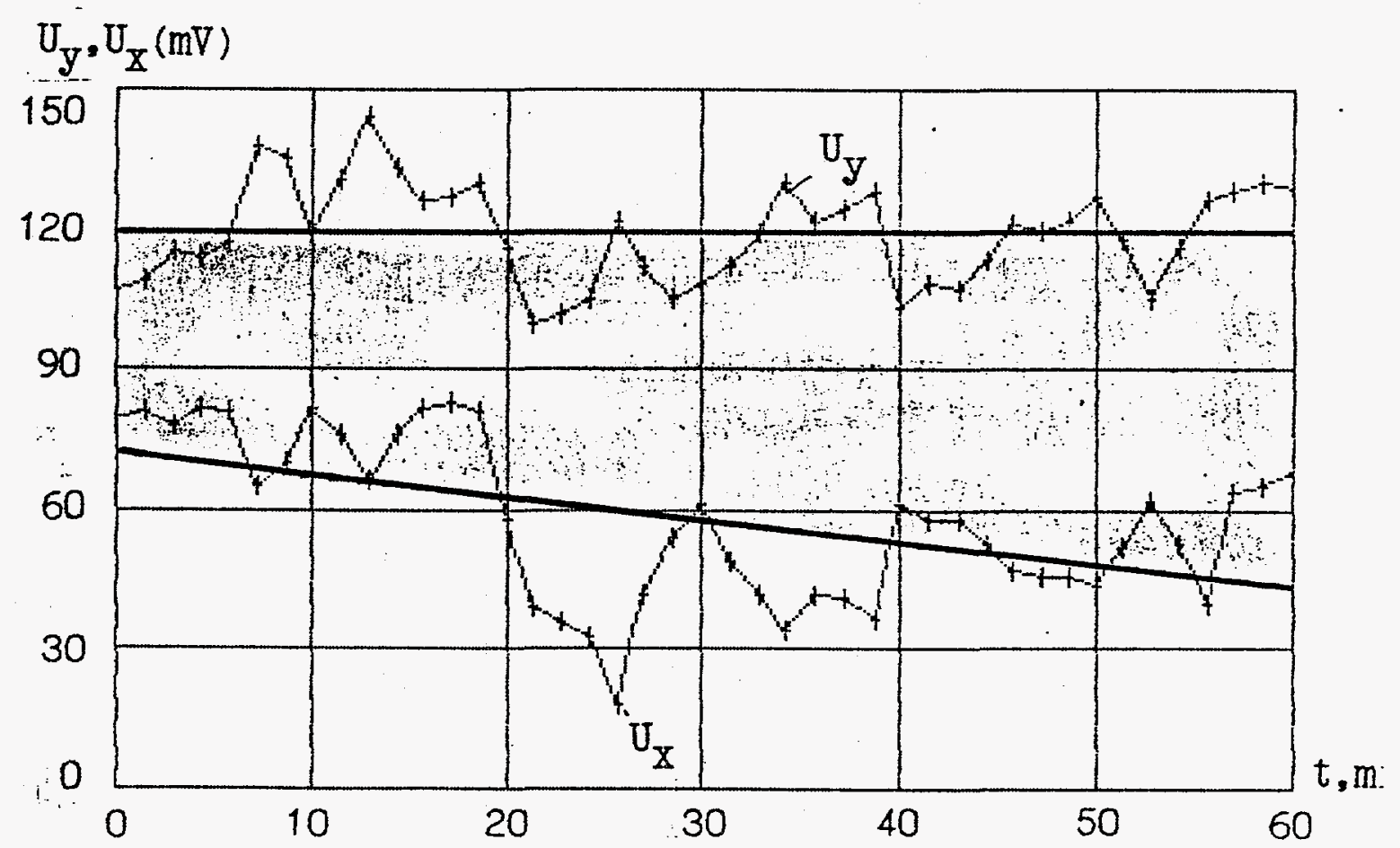

Fig.3.35. Difference of the potentials $U_{y}$ and $U_{X}$ measured in the zone with considereble change of stress state $(*-*-*)$ and their Iine approximation (---) 


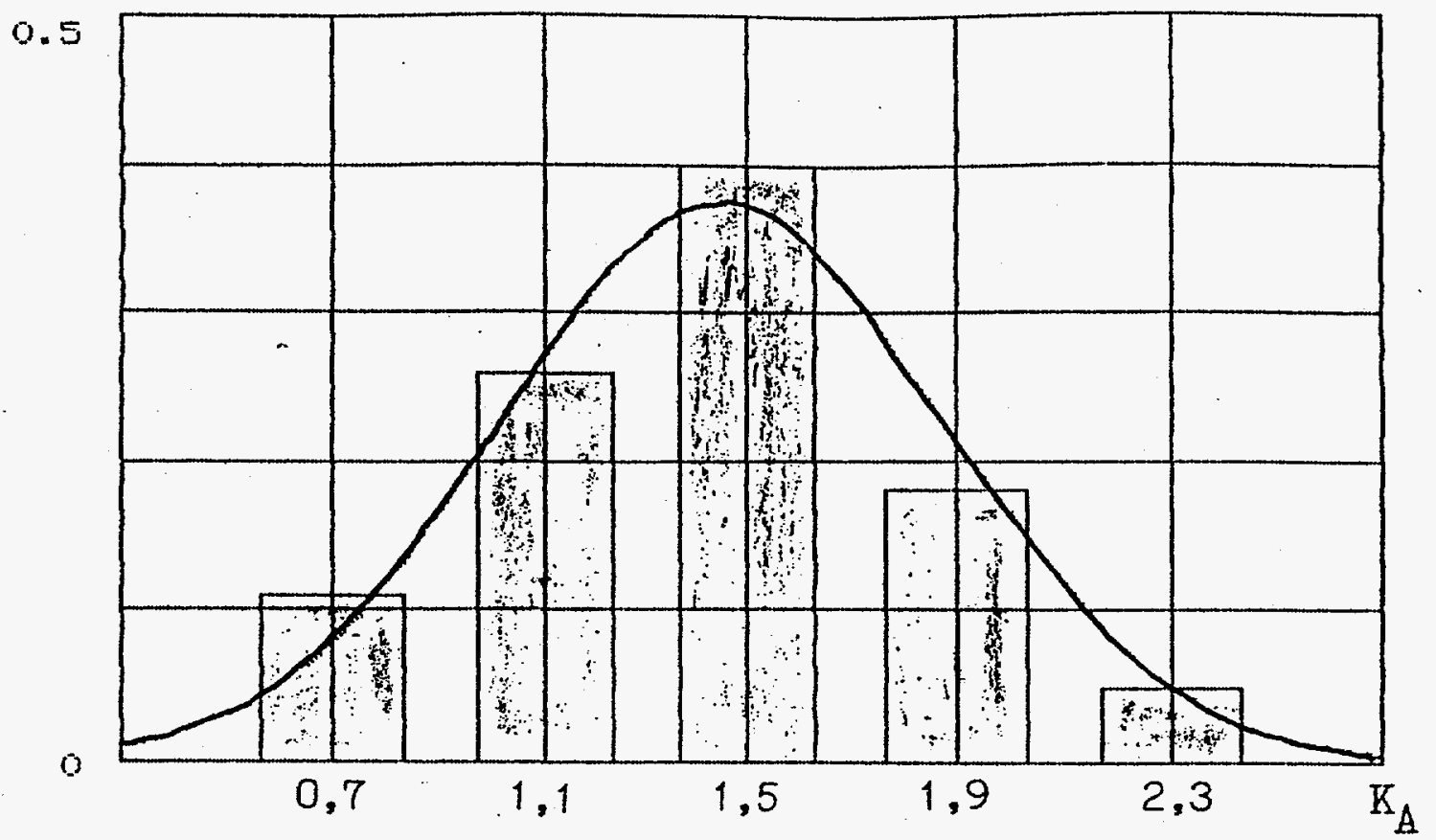

Fig.3.36. Distrubution $K_{A}$ in the "quiet" rock massif

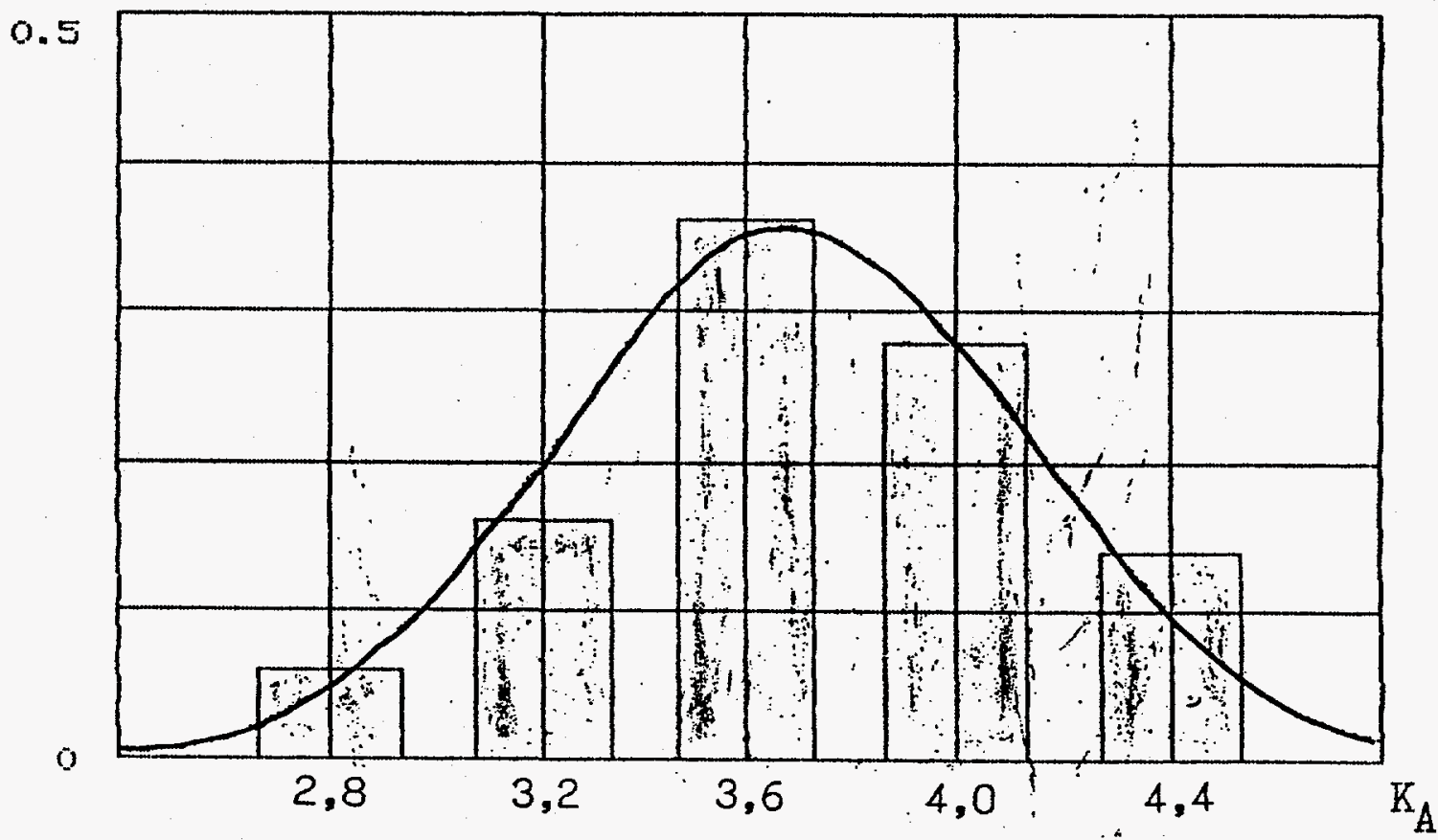

F1g.3.37. Distrubution $K_{A}$ in the zone with considereble of stress state 

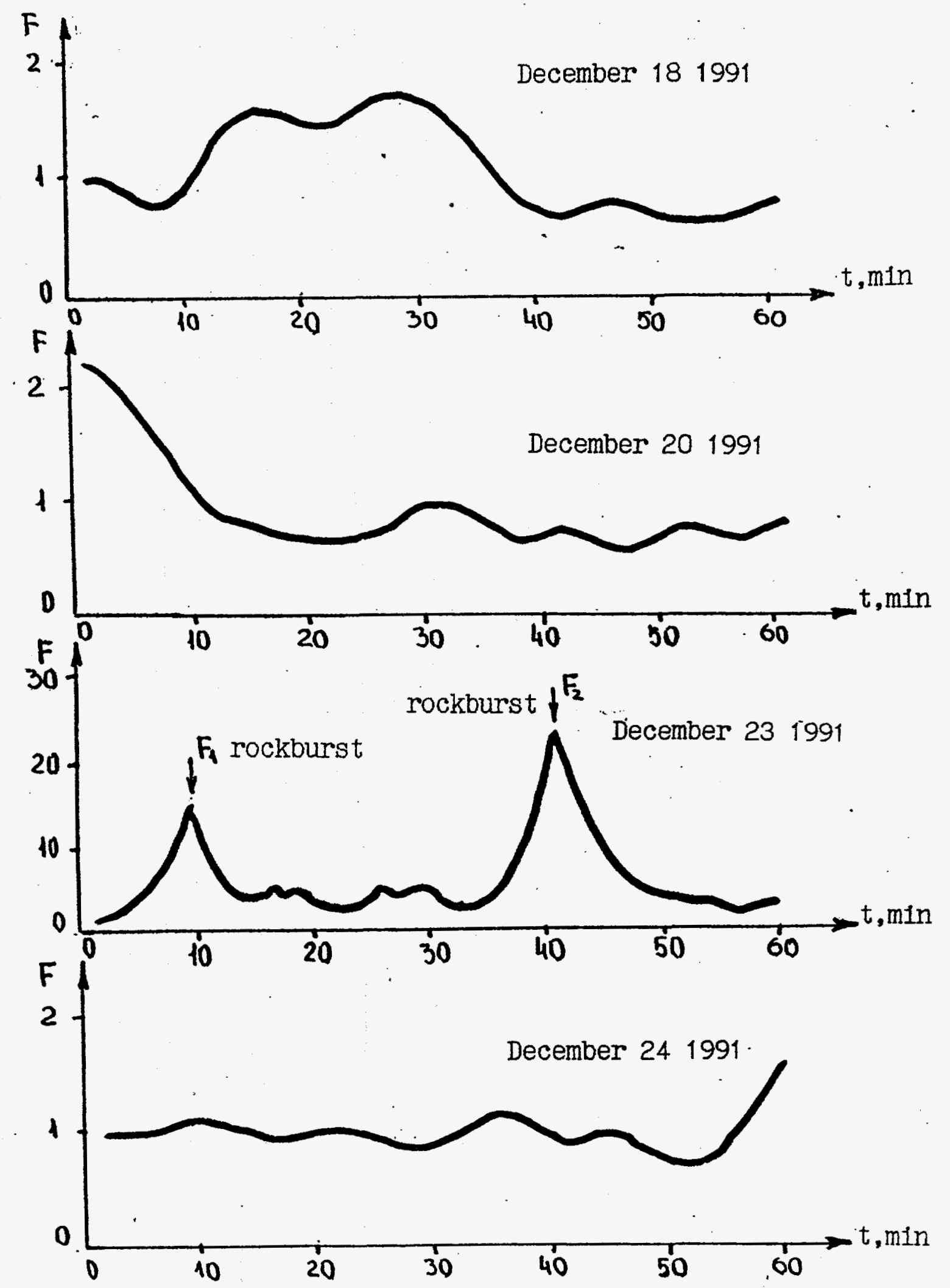

F1g.3.38. Changing "F" in the zone with considereble change of stress state 


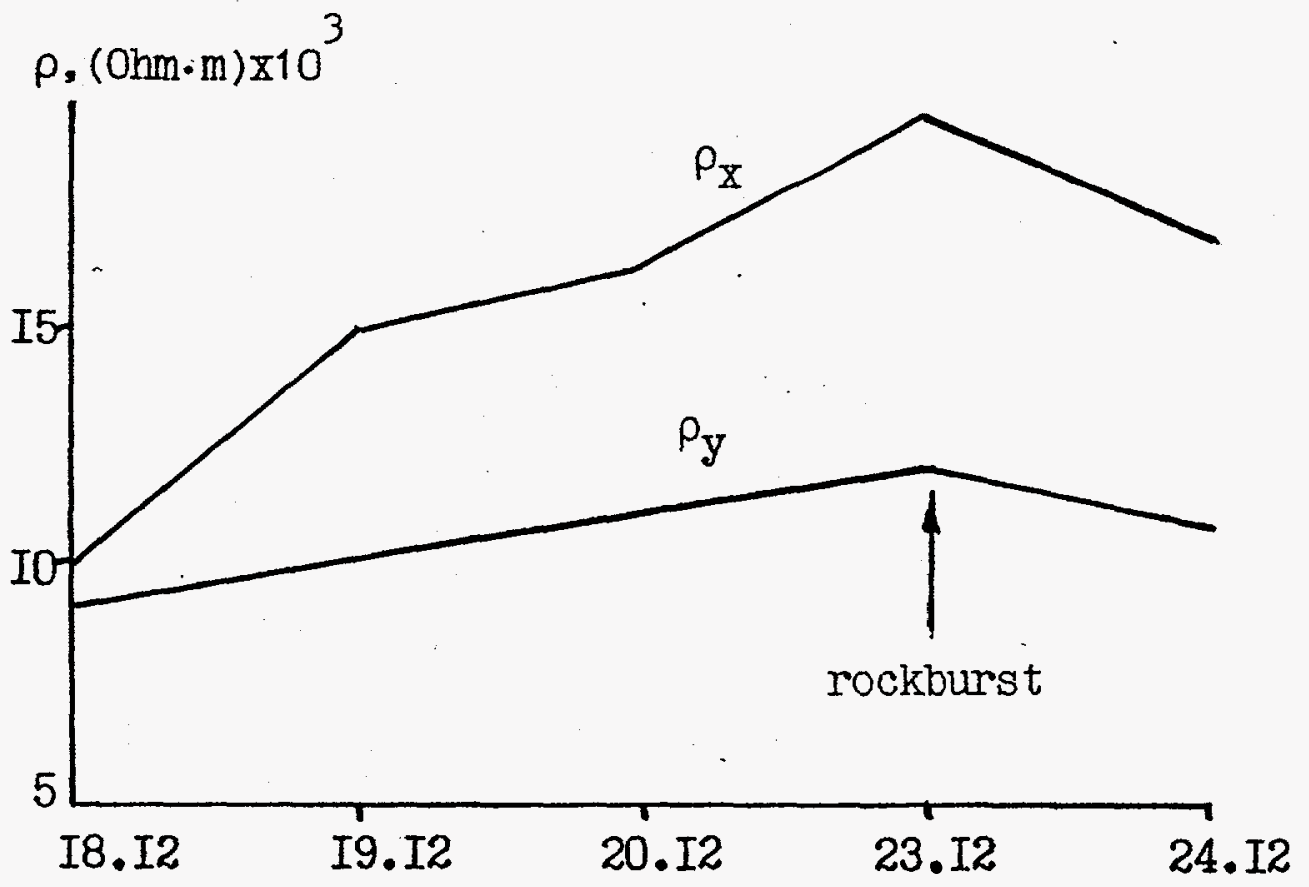

Fig.3.39. Variation of the electrical resistivity in the zone with considereble change of stress state

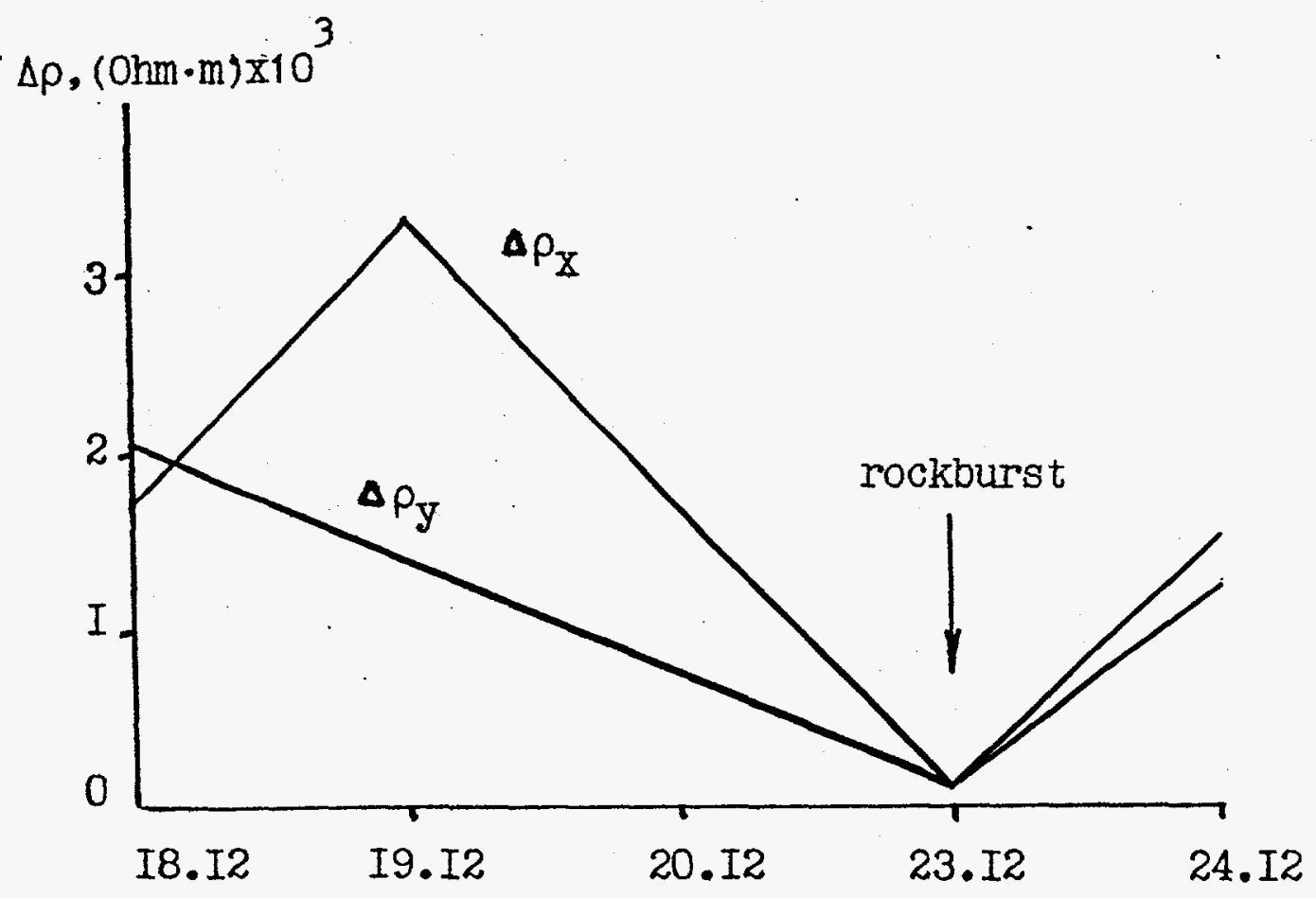

F1g.3.40. Root mean square deviation of " $\rho$ " from 1ts current mean value 


\section{NORTH-URAL BAUXITE DEPOSIT (PA Sevuralbauxiteruda, SUBR).}

\subsection{General characteristics of mines seismicity of SUBR.}

The North-Ural bauxite deposit is situated in east foothills of northern part of Ural mountains (approx.690 of north latitude, $60^{\circ}$ of east longitude). The bauxite deposits form the tectonic block $18 \mathrm{~km}$ wide situated along center line of Petropavlovsk near-meridional anticlinal elevation. The block is divided by faults from adjacent synclinal flexures. Bauxites are deposited at the uneven surface of roughly foliated limestone, consist of three subhorizons with thickness up to $25 \mathrm{~m}$ and covered with bituminous thin foliated limestone with thickness from 4 to $75 \mathrm{~m}$. At the site of recently most rockburst dangerous mines the ore body falls to the east at the angle about $30^{\circ}$, at the depth about $700 \mathrm{~m}$ being split by tectonic fault falling to the west so the western part of ore body is sunk relatively to the east one to 300-400 $\mathrm{m}$ (Fig.4.1). The ore body development was initiated in thirties by open-cut manner in its outfits to open surface. During last two decades the velocity of the mining works deepening was approximately 20-25 $\mathrm{m}$ a year. The maximum main stresses at quarry mines at the depth $530 \mathrm{~m}$ are:

- mine 13 - 49 megapascals, the axis is oriented to latitude direction and falls to the west at the angle $300^{\circ}$;

- mine 14 - 52 megapascals, the axis is oriented to the north-west direction and lies in a plane falling to the west at the angle $20^{\circ}$;

- mine 15 - 63 megapascals, the axis is oriented to the sublatitudional direction and lies in horizontal plane.

The rockbursts began to be manifested at SUBR from the depth $340 \mathrm{~m}$. First rockburst influenced the mining works happened in september 1970 in a period of explosion works carrying out in stoping face of mine 14. In the same 1970 the rockburst happened in solid massif in the shaft of mine 15 at the depth $728 \mathrm{~m}$ and at cutting of the mine 14 shaft at the depth $625 \mathrm{~m}$. As a result of rockburst at August 141981 the collapse of roof at the area 15 thousands of sq.m took place. Due to the rockburst danger in 1982 the cutting of two shafts of mine 12 at the depth $1200 \mathrm{~m}$ was stopped (the project depth $1600 \mathrm{~m})$. Until 1984 about the half of all rockbursts inspected at the USSR mines has happened at SUBR. At present time about 1000 of dynamic event are registered by North-Severouralsk seismic station every year with energy from 100 to $10^{9}$ joules.

The presence of dense network of seismic sensors enabled to attain the high precision of the hypocenters coordinates 
defining -- \pm 25 meters and to get the unique catalogue of seismic events.

At February 261987 the rock tectonic burst happened with seismic effect corresponding to an earthquake of 9 energy class $(M=4.3)$ and felt at the surface within the radius $18 \mathrm{~km}$ [Poghinez, Mikulin, 1988]. The hypocenter of event was situated at the depth about $330 \mathrm{~m}$ in a massif of underlying rocks in the region of tectonic break. The amplitude of displacement along the fault was $49 \mathrm{~mm}$.

The rockbursts and microbursts in operating 'stopes add approximately up to $2 \%$ of all dynamic events. $48 \%$ of seismic events are observed in 50-meters zone of mining, $49 \%$-- in depleted working, 3\% -- in a massif ahead of the face [Kolessov, 1987]. By carrying out the works using the roof layers collapse method happened $20 \%$ of rockbursts, using the method of camera-post development -- 33\%, using the method of cameras with backfilling -- 23\%, so that there is no explicit dependence of seismic activity upon applied manner of development.

\subsection{Seismic activity variation in time.}

Study of seismic regime is traditional area of seismic studies accounting hundreds of works as motherland as foreign seismologists. At the same time research works concerning study of regime of seismicity induced by mining are not so much numerous. Let's note the work [Voinov et al., 1987] fulfilled using the same material as the present work.

The general illustration of the induced seismicity regime evolution can be gotten from the data about the rockbursts intensity at SUBR mines given in [Catalogue..., 1985] as well as in the rockburst cards compiled at SUBR. In Fig.4.2 the histograms reflecting the rockbursts intensity at mines $13,14,15$ since 1970 are shown. As a measure of intensity of destruction caused by rockburst the value of annual sum of cubic roots of rock volumes thrown off into excavation at each rockburst is taken.

One can see from histograms that the general tendency of the induced seismicity evolution is gradual increase both the number of rockbursts and their intensity. In the beginning the growth of number of rockbursts was accompanied by outbursts the rocks which volumes were not more than $100 \mathrm{~m}^{3}$. Since 1978 at mines 14 and 15 the rockbursts began to arise with outbursts' volumes of hundreds and even thousands of cubic meters. In general it is in agreement with an observation that the rockbursts intensity grows as far as the works front is deepened. Nevertheless it is not difficult to note that during 
recent decade the growth of rockbursts activity was explicitly accelerated: it increased quicker than the depth did.

In Fig.4.3 the time variations of seismic activity in mines 14 and 15 are presented. The data have been received with the help of the seismic network. Seismic activity is one of the most widely used characteristic of the seismicity (Ponomarev \& Tejtelbaum, 1974) which allows to convert the discrete distribution of seismic events, described by three-dimensional coordinates, time and energy, to the continuous distribution. As a measure of the activity either the number of events, happened in the area of fixed size during some time interval, or the sum of raised to some power energies of these events is used. It has been shown by Sadovsky and Pisarenko (Sadovsky \& Pissarenko, 1991) that the power $b / 3$, where $b$ is slope of magnitude-frequency relationship, is preferable. In the studied region $b$ is equal to 1 approximately. That is why as well as for saving the physical sense of the value, which is used for characterization of intensity of the seismic process, the sum of cubic roots of the energies of events is adopted as a measure of seismic activity in this study. overlap of time intervals is used to reduce an effect of random selection of the initial time interval.

One can see that the almost stable regime with insignificant oscillations is intrinsic to the mine 14 seismicity while the seismic activity in mine 15 grew quickly since the beginning of the stable instrumental observations up to 1984 inclusive. During all period of observations the induced seismicity activity level in mine 15 was essentially higher than one at mine 14. Let's add that the rockbursts activity in mines 14 and 15 was much higher than in other mines of the same district in discussed period of time.

The graphs of occurrence are shown in Fig.4.4 for seismic events at mines 14 and 15 . Slopes of these plots were defined from the magnitude-frequency relationship in energy form:

$$
\operatorname{lgN}=\lg A-\gamma \mathrm{K}
$$

where $\mathrm{N}$-- number of events, A -- seismic activity, $K$-energy class of seismic event ( $\mathrm{K}=1 \mathrm{gE}$, E-energy in joules). They are equal to 0.63 for the events in two mines together, 0.59 -for events happened in mine 15 and 0.82 -- for events happened in mine 14. All those values are higher than the usual slope (b-value, or $\gamma$-value in this case) for natural seismicity equal in average to 0.5 (Sadovskij \& Pissarenko, 1991). It means that the considerable number of weak seismic events takes place, especially at mine 14 .

Change of number of deep seismic events in time was analyzed with respect to the phenomena in the excavations 
vicinity. The ratio of annual number of events which depth of hypocenters were more than $600 \mathrm{~m}$ to events annual number which depth of hypocenter were not exceeding $600 \mathrm{~m}$ for a year is shown in Fig.4.5. It is seen that the tendency to the increase of number of deep events is observed.

The distribution of seismic events of different energy classes in hours of $a$ day is shown in Fig.4.6. The distributions of events of energy class from 2 to 4 have sharply expressed peaks during hours of explosion works. The distributions of events of class 5 and more don't have such peaks. It is possible however to note that these distributions are statistically inequivalent: first one is constructed for more than 8000 events but the second one -- for 210 events. In order to avoid such inequivalenty the distributions of weak events for two random samples were constructed containing approximately the same number of events as a whole catalogue of strong events. These distributions are shown in Fig.4.7. It is seen as before that the distributions have distinctly expressed peaks falling at the explosion works time. To check the randomness of the strong seismic event distribution in hours of a day the time series of random values was generated distributed by Poisson law with characteristics (an average value and number of terms) coinciding with corresponding characteristics of distributions of weak and strong events in hours of a day. The comparison of Poisson series to observed series was carried out with the aid of Kolmogorov-Smirnov test. The strong events distribution in hours of a day is described by Poisson law i.e. is random with significance level 0.9997; for weak events the significance level is 0.0129 so there are no basis to treat this series as random.

Thus, the regime of strong seismic events doesn't depend upon the explosion works time but is defined by other reasons. The distributions of seismic events number in months for all years of observation period are shown in Fig.4.8. The absence of season oscillations of seismic activity level is seen from these distributions.

The distribution of the time intervals between successive seismic events is presented in Fig.4.9,10. The time intervals between all subsequent events were computed to construct this curve (how much time passed from first event to second one, from second event to third one, from third to fourth, etc.) and the distribution of such intervals was constructed. The distribution of time intervals between successive events (expectation time of event) for seismic event from 5 to 9 class (strong events) is shown in Fig.4.9 and is perfectly described by Weibull formula: 


$$
P=1-e^{-\left(x / x_{0}\right)^{n}}
$$

with parameters $\mathrm{n}=0.81, \mathrm{x}_{0}=23646$. The significance level for correspondence of examined distribution to the weibull law estimated by the $\chi^{2}$ test is $73 \%$, by the Kolmogorov-Smirnov test - $100 \%$.

For weak events (fig.4.10) the Weibull distribution appears to be the best one, too, however with less level of significance: $28 \%$ according to $\chi^{2}$ and $0.5 \%$ according to $\mathrm{K}-\mathrm{S}$ criterion for mine $15 ; 2 \%$ according to $\chi^{2}$ and $0.1 \%$ according to $\mathrm{K}-\mathrm{S}$ criterion for mine 14. It is possible to improve the correspondence to weibull law by cutting studied distribution from the side of short time intervals at the value $20 \mathrm{~min}$. (the points in that interval drop out of this general dependence) -$\mathrm{K}-\mathrm{S}$ criterion yields the significance $28 \%$ for mine 15 and $11 \%$ for mine 14; or at value $120 \mathrm{~min}$. (the duration of explosion works carrying out) -- the criterion $\chi^{2}$ gives significance $68 \%$ for mine 15 and $41 \%$ for mine 14, the criterion $K-S$ gives $50 \%$ for mine 15 and $11 \%$ for mine 14. The significance levels of correspondence to other distributions including exponential one (the distribution of time intervals between events in Poisson process) are close to zero or equal to zero.

Weibull distribution in a form of Rosin-Rammler formula is applied to describe the size distribution of crushed ore in Mining Industry, of size distribution of exploded rock, etc. [Rodionov et al., 1986, Kuznetsov, 1977]. Rodionov et al. (1986) showed that if fragments were distributed as the weibull law, then the single fragmentation act had been made. They showed also that the repeated many times crushing act was producing the lognormal fragments distribution. It was shown by [Kuznetsov, 1977] how to get Rosin-Rammler law on the basis of common probability ideas and imposing some conditions having physical sense. So, the presence of unstressed zone near to the crack leads to that the probability of second crack appearance at the distance $x$ from the first one in the interval $d x$ depends upon the value of $x$, and is proportional to $d x$. This probability increases with the increase of distance $x$.

So far it is not very clear how to pass from the size distribution of fragments to the time intervals distribution between events, even if we treat these events as the cracks forming. We could confirm only that the distribution of values after weibull law is testifying the relation between the probability of the second event appearance during a certain time interval (t) after the first one, and the value of this time interval ( $t$ ); and, also, the dependence of probability of the appearance of the event within an interval (dt) from the 
availability of the event in the previous time intervals. Thus, the seismic process in the examined region is the Markov chain but not the Poisson's process, so that the seismic activity at present is a probability function of the activity at the previous time. On this basis the prognosis phenomena could be looked for.

Let's consider now the seismic activity variations at mines 14 and 15 of SUBR in more detail. As it was noted above the sum of cubic roots of the energy of events (i.e., the value characterizing the linear dimension of a zone radiating the seismic impulse) happened in the area of fixed size during some time interval is taken as the measure of seismic activity. To reduce the influence of random selection of initial position of the area and of time interval the overlapping of areas and intervals is used. The value of this one is defined by the smoothness of the received distributions of the seismic activity process and by solved problem. Let's consider only the time component of activity change i.e. instead the function $A(x, y, z, t)$ we shall study the function $A(t)$. We shall only separate the seismicity fields of mines 14 and 15 in space -the areas separated from each other by large tectonic break. one month is selected as a time step. As it will be shown further the number of events happening during one month is representative (in average about 50 events every month happen). The possibly smaller size of interval is in agreement with prognostication purposes however the minimum acceptable value is limited by the requirement for the sample to be representative.

Smoothing of received curves was made by the method of moving average. First, the seismic activity for the 6 monthsperiod has been calculated, then, half-year time interval has been shifted by a month. After that, the half-year seismic activity has been calculated again and the interval has been shifted once more, etc. The results were normalized on average. obtained in such a way variation of seismic activity registered in the field of 15 mine is presented in Fig.4.11a. Three curves are shown: for all events, for weak $(K<5)$ and for strong $(K \geq 5)$. It is seen that the character of shown curves doesn't depend upon the energy of events included into consideration which proves the adequateness of received samples, i.e., about the similarity of studied process at different energy levels.

On the basis of the seismic flux intensity change graph the presence of three components of that flux can be supposed, so that the activity function can be present in a form of three terms: 


$$
A(t)=A_{p}(t)+A_{r}(t)+A_{t}(t)
$$

where $A_{p}$ is high frequency random oscillations of
activity, $A_{r}$ is a regular component, $A_{t}--$ slow variations, trend. Such "scaling" is applied among other methods in nonlinear dynamics at the analysis of systems behavior with the purpose of attractors revealing. Let us find coordinate conversion, which would allow us to reveal a regular component of the function $A(t)$. For this purpose let us convert the coordinates $(A(t), t)$ into the phase coordinates ( $A(t)$, $d A(t) / d t)$, which are "the activity" -- "velocity of activity variation". The point in such coordinates defines the state of a seismic process: its intensity and velocity of intensity variation. The phase portrait of process described by the curve 1 in Fig.4.11a is shown in Fig.4.11b. It is seen that the point in phase space is moving rather chaotically. After additional smoothing for two closest points and piecewise-linear coordinates conversion according to formulas:

$\begin{array}{rlr} & A:=A-0.38-0.03 t & 0 \leq t \leq 42 \\ A=A-1.34+0.01 t & 42 \leq t \\ (d A / d t)^{\prime}= & d A / d t-0.04+0.0007 t & 0 \leq t \leq 42 \\ (d A / d t)^{\prime}= & d A / d t & \end{array}$

the function $A(t)$ acquires an appearance shown in Fig.4.11d. One can see that the phase trajectory shows an outward spiral progression from some point to the circles with the close parameters (to quasi-stable limit cycle).

The time variations of the seismic process intensity at mine 14 and results of smoothing and removal of trend are shown in Fig.4.12a, corresponding final phase portrait -. in Fig.4.12b. For the mine 14 it has a form of internal limit cycle (possibly, of a center), the trajectory describes the inward spiral. The coordinates transformation used to remove the trend was carried out with formulas:

$$
\begin{aligned}
A^{\prime} & =A-1.06+0.03 t-0.0007 t^{2} & & 0 \leq t \leq 50 \\
A^{\prime} & =A-1.40+0.04 t-0.0007 t^{2} & & 50 \leq t \\
(d A / d t)^{\prime} & =d A / d t+0.01-0.001 t & & 0 \leq t \leq 50 \\
(d A / d t)^{\prime} & =d A / d t+0.06-0.002 t & & 50 \leq t
\end{aligned}
$$

Outward spiral trajectory corresponds to the amplitude increase of the seismic process intensity oscillations, inward - to the oscillations amplitude decrease. The form and dimensions of received attractors bear perhaps an additional information about seismic process which is still in prospect to 
be realized. So the seismic process activity oscillations are not rigorously harmonical, their period manifests the tendency to the growth at mine 15 (from approximately 10 months to 20) and to oscillations around the value 15 months at mine 14 . At the same time the attractors presence enables to forecast the increase and decrease of rockburst activity within the mines field to an accuracy of random component which has insignificant amplitude.

In Fig.4.13 the curves of the seismic process intensity variations at mines 14 and 15 are compared being subjected to the smoothing and trend removal procedures. One can see that during first half of observations period in activity oscillations some synchronism is guessed in appearance of oscillations of same sign at both pictures. During second half the activity increase at one mine corresponds almost synchronous activity decrease at other one, the mines seismicity begins to experience the phase reversal oscillations.

\subsection{Spatial distribution of seismic events.}

The spatial distribution of seismicity of mines 14 and 15 at the plane is given by the density map compiled according to the sum of data for whole period of instrumental observations (fig.4.14). The data summing was carried out for areas $50 \times 50 \mathrm{~m}$. The main feature of spatial distribution of seismicity is sharply differentiated character of seismicity field not discovering the simple and single-valued connection to the works carrying out: at different sites worked at given time at the same mine the induced seismicity level is essentially different. The distribution of seismicity in the depth is given by Fig. $4.14 \mathrm{~b}$. The relation of main number of events to the ore body plane seems to be natural. However one can see that considerable number of events is situated enough far from ore body (up to $1-2 \mathrm{~km}$ ) which proves considerable scale of that influence which is impacted to massif by the ore extraction.

Let's select for a study the sites with increased seismic activity at mine 14 marked in Fig.4.14 by numbers 1 and 2 . The selection of a border between those sites was carried out on the basis of an idea about seismically homogeneous blocks i.e., about such blocks within the limits of which the seismic activity changes in time in the same way. The procedure of defining of borders of such seismically homogeneous blocks was the following: an area $50 \times 50 \mathrm{~m}$ was selected with the activity largest for whole observations period at the site of increased activity; the curve of seismic activity change in time was constructed using the averaging with moving six months interval 
for that area. Then the area dimension was increased. If the curve of activity changed by that has not changed essentially (there were no new maximums) then the area dimension was again increased. The same procedure was fulfilled for neighboring area of increased activity as well. The activity change in time for areas 1 and 2 of mine 14 is shown in Fig.4.15. One can see that the seismic activity increase occurs at those areas at different moments of time. It is remarkable that when after disclosure of such seismically homogeneous blocks the geodynamic map of mine 14 was inspected then it appeared to be that the border between revealed blocks corresponds to the fault [Batughina, Petukhov, 1984].

Then the position variation in time of the center of maximal seismic activity of each block was calculated (in a plane), the moving six month window being used at calculation: the coordinates of center of that area $50 \times 50 \mathrm{~m}$ were defined at which the maximum seismic energy was released; then the interval was shifted to one month, the next position of center of such area was defined etc. The evolution in time of the coordinate $x$ and of the coordinate $y$ of center of maximum seismic activity of a site 1 of mine 14 are presented in Fig.4.16a, of site 2 - in Fig.4.17a; the curves drawn at those figures correspond to a polynomial of 4-th degree constructed by root mean squares method. In Fig.4.16b and $17 \mathrm{~b}$ the positions which were occupied by the seismic energy maximum in different time are shown and the trajectory of evolution of its averaged position is presented.

The spatial evolution of increased seismic activity can be characterized by the change in time of following values: the position of the center of some area at which the maximum release of seismic energy during selected time interval is registered; the seismic activity value at this area, the "contrast" of seismicity at this area. It is understood under "contrast" here the connection between the maximum seismic activity value and the quantity of areas the seismic activity of which exceeds the selected value.

The average position of the center of maximum release of seismic energy in time was calculated for a series of seismic active sites of mines 14 and 15 of SUBR (fig.4.18) similar to that as it was made for sites 1 and 2 of mine 14 . One can see from those pictures that in some seismically active areas the centers of maximum activity were moving along some chosen directions (sites 2,3 and to some extent 4 of mine 15 and sites 3 and 4 of mine 14) but in other domains the trajectories of those centers displacements describe rather plane figures which are possibly the projections of three-dimensional figures (site 1 of mine 15, sites 1,2 of mine 14). The comparison of 
trajectories of the seismic activity centers displacements with disposition of known faults enables to suppose that the linearity of studied trajectories is observed in seismic active areas related to fault zones but the "spatiality"-- in areas situated between faults (see Fig.4.14). It is possible that the seismicity of first type is connected to the fault zones activation induced by mining works and the seismicity in areas of second type - to destruction of purely man-made nature (destruction of pillars, collapse of roof etc.).

The connection between the areas size at which the seismic energy release is equal to or exceeds a value about $10^{5}$ joules and the maximum seismic activity value in studied area for present time interval is given in Fig.4.19 for three representative sites of mine 15 and two ones of mine 14. That connection can be approximately described by a linear dependence like:

$$
r_{1 i m}=a \cdot A_{\max }+b
$$

in spite of considerable dispersion about $65 \%$ of events fall within the confidential interval of linear relationship. For all three selected sites of mine 15 the coefficients coincide and are equal: $a=0.253, b=-0.37$; for two sites of mine 14 those coefficients coincide with each other, too, but differ from corresponding coefficients of mine 15 sites: $a=0.38, b=-$ 4.93 .

The change in time of seismic activity at the areas of maximum release of seismic energy was studied for different sites of mines 14 and 15. On the basis of disclosed tendencies of the maximum seismic activity centers position change, of the seismic activity level change in those centers and of established dependence of the increased seismic activity area size the map of those areas disposition was constructed at which the total release of seismic energy for a half of year can exceed $10^{5}$ joules (fig.4.20). The circles center position at that map corresponds to expected position of the seismic energy release maximums, the circles diameter -- to the size of area of increased seismic hazard. Significant increase of seismic activity is expected only at site 3 of mine 15 and at site 2 of mine 14 (see Fig.4.14) respectively in southern and central parts.

The presence of large amount of events between which not more than 10 minutes passed is characteristic for SUBR seismicity (about 1000 events -- approximately 15\% of total number) which prove strong grouping of seismic event. It is possible to suppose that events grouped in time are connected 
spatially as well. The epicenters of such pair events are connected by segments of straight lines in Fig.4.21. The parallelism of some lines to each other, the lines grouping might be seen at that figure, the preferential directions to be singled out. However, such analysis is to be fulfilled in space; that problem will be solved further. From other side although the connection mechanism for events of low energy (second and third energy classes) could be proposed for large distances (up to one-two kilometers) that mechanism would require additional substantiation of its reality. That is why the events pairs the distance between which exceeds $400 \mathrm{~m}$ (characteristic dimension of seismic active domains) were excluded of discussion. The lines connecting the epicenters of such events are given in Fig.4.22, the increased seismic activity areas and most considerable faults fixed in mines fields of 14 and 15 mines are shown. It is seen that majority of those lines is situated within the limits of seismic active areas. The considerable part of lines connected the events pairs is related to faults zones however the part of faults is not connected to those lines and the part of lines is not surely to be connected to any fault. That circumstance enables to suppose that pair events arise within the limits of faults zones and the events for which corresponding to them faults can not be indicated are shown by non-mapped active faults of lower rank (such non-mapped faults are often discovered in the course of mining excavations carrying out).

\section{Discussion of results.}

Besides prognostication information the presence of regular component of the seismic events flux can bear the information about general energy state of rock massif. Similar to that as far as the laminar motion of a liquid is changed for a chaotic one at definite velocities of energy supply to heated liquid and then for regular one with forming of convective Benar centers it is possible to expect that at the attaining of definite values by the energy accumulated in a massif and supplied from outside and by the velocity of energy dissipation the regularization in space and in time of energy release at the expense of seismic processes will be observed. In a massif subjected to influence of mining works side by side with the tectonic deformations energy reserve decrease the possibility of that reserve triggering grows due to continuing increase of excavated space volumes and to deepening of works front. The presence of quasiperiodic oscillations of seismic activity proves sufficiently large energy flow being manifested in seismic events. At the same time the average values decrease of 
seismic events enables to suppose the energy accumulated in the massif to be decreased. In such case it is possible expect that the seismic events flux will be sensitive to the amount of manmade influence (to the cutting velocity and to volumes of formed cavities) - that gives an opportunity to influence the seismicity organizing the works regime taking into account the seismic activity change disclosed periods.

About similarities. The idea about the massif coming to new equilibrium -- from seismically activated state in the state of seismic rest -- can be given by the study of the aftershock processes induced by large earthquakes. The large earthquakes can be looked at in definite sense as at the analogies of total man-made process. At any rate some features of the induced seismicity regime remind very much the features of aftershock process development. So just after the main shock arising the mass of comparatively weak "initial aftershocks" arises which are localized in its hypocenter -- similar to that as at the initial stages of induced seismicity appearance the hypocenters of dynamic event are concentrated near to worked out spaces. Then the process of divergence of aftershocks begins consisting of gradual migration of aftershocks into larger vicinity of the main shock fault zone; the phenomenon similar to aftershocks divergence one can see as well in gradual spreading of the seismic events hypocenters far beyond of the worked out spaces limits (up to kilometers).

About forecasting. The data about mounting of rockbursts activity show that the transformation of massifs of mines 14 and 15 into seismically activated state was by no means not of a sudden. The activation can be noticed ahead of time according to appearance and increasing of seismic event the amount of which exceeds practically to two orders the amount of rockbursts themselves. The setting up at least one seismic station capable to register the seismic event with the energy $10^{2}$ joules and more arising in a massif of given mine can give sufficiently representative material for construction of time series the long-range tendencies of which can indicate the induced seismicity activity increase and to predict the probable transformation of the seismic rest state into the seismically activated state ahead of time to several years.

Is the seismic activation state comparatively short-timed, passing or it should be thought to be stationary one at least at time segments presenting practical interest?... The series of considerations incline to that the seismically activated state is temporary one. A massif exhausted its seismic potential in all its more or less large parts during the seismic activation stage restores it later very slowly. So, 
repeated activation within the limits of seismic cycles for most active in tectonic respect oceanic outskirts is estimated by a time interval as hundreds of years. At continents those time intervals are hundreds, thousands and even tenths of thousands of years. 


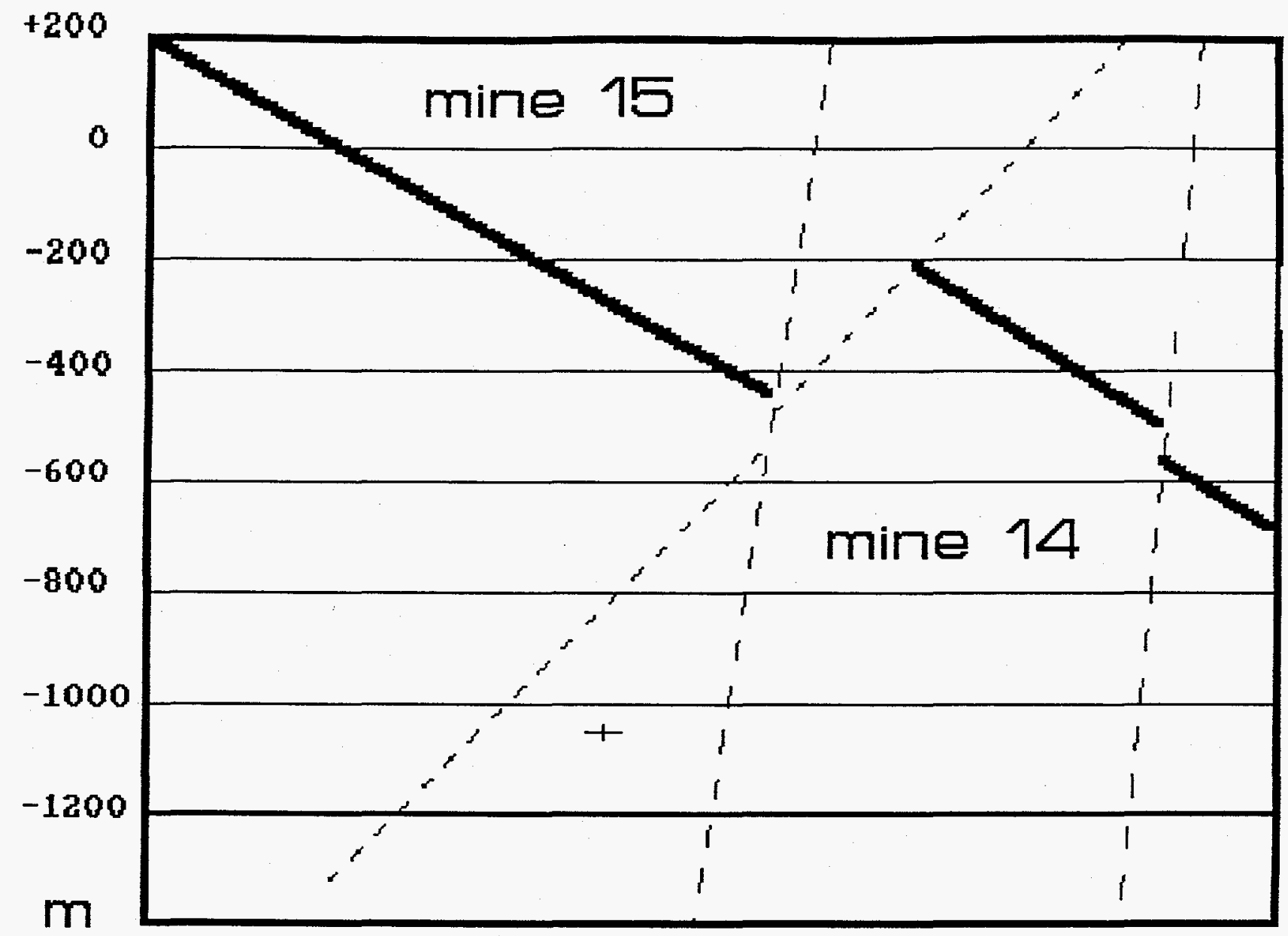

Fig.4.1. View of mines 14 and 15 in west-east section. The main tectonic faults (dotted lines) and ore body (bold line) are shown. 


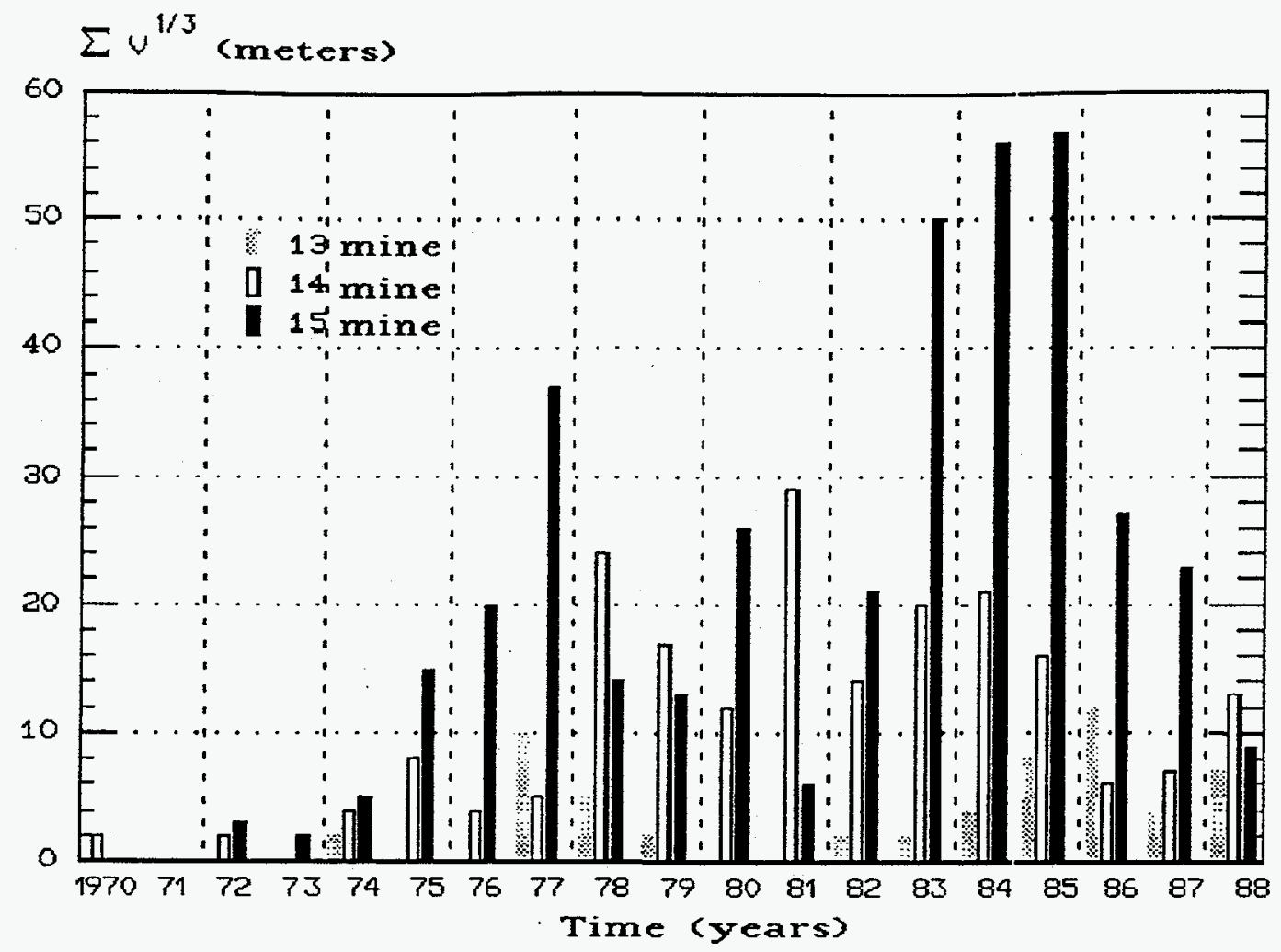

Fig.4.2. Time variations of annual sum of cubic roots of outbursts' volumes at mines 13,14 and 15 .

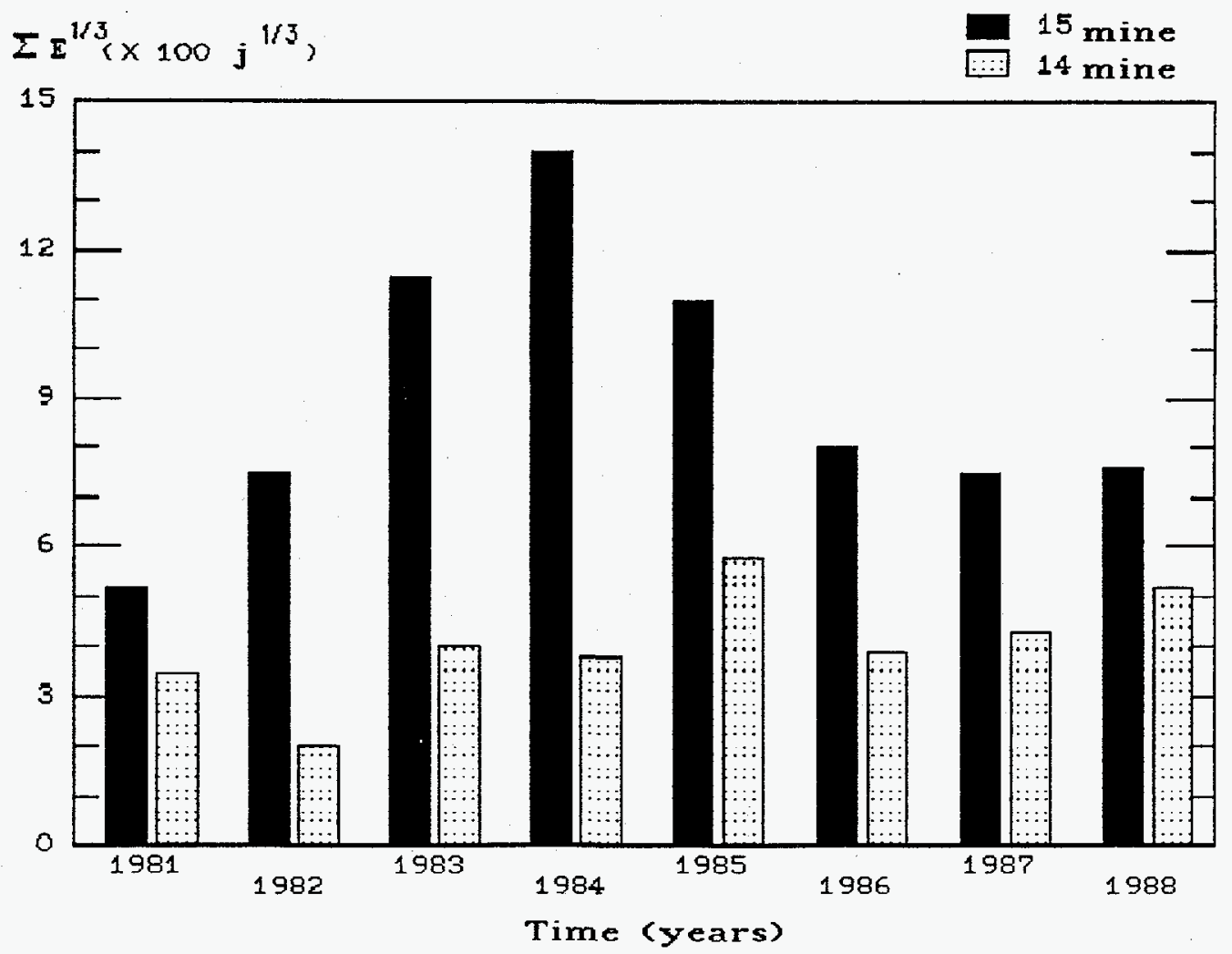

Fig.4.3. Time variations of annual sum of cubic roots of rockbursts' energy at mines 14 and 15 . 


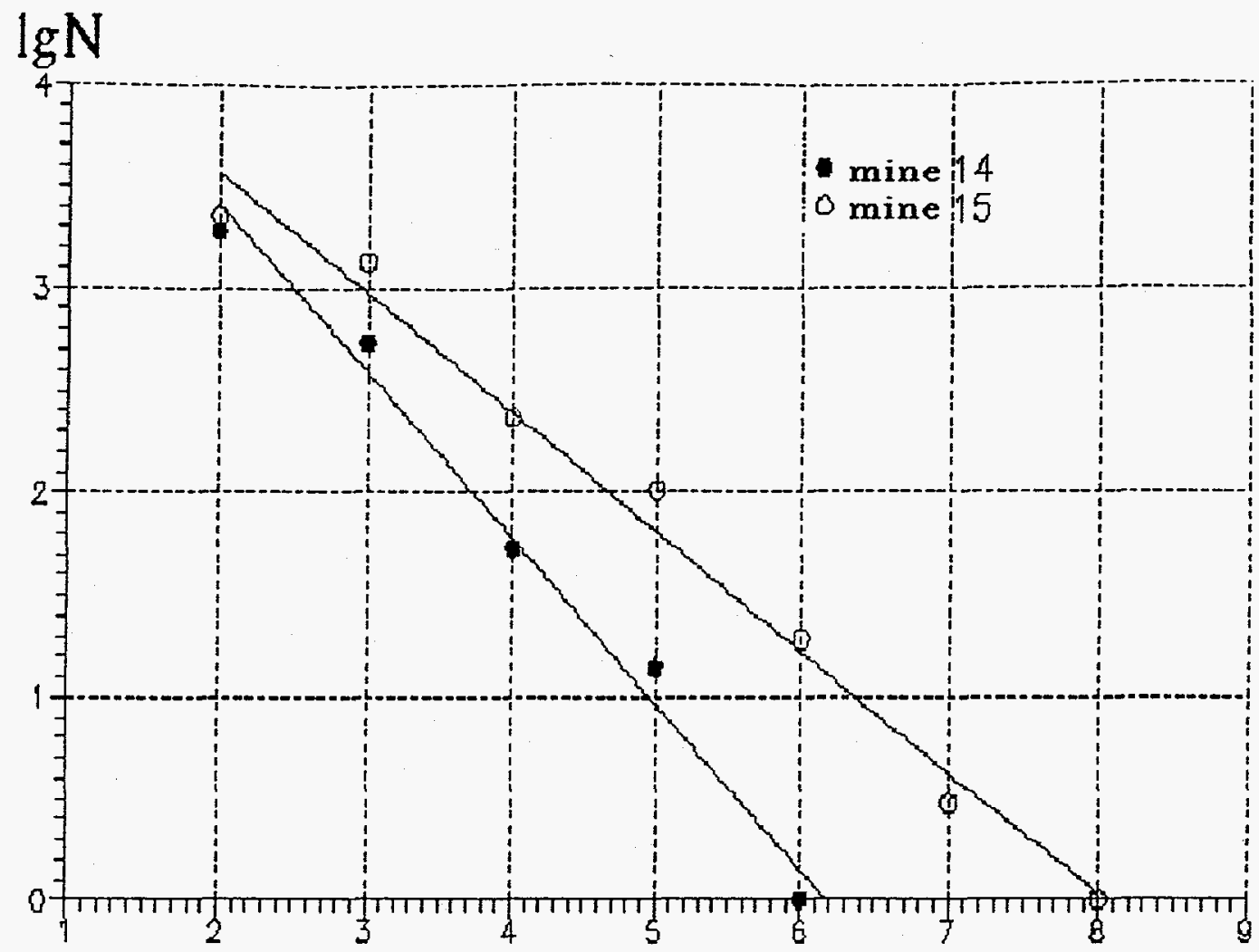

Fig.4.4. Energy-frequency relationship for seismicity in mines 14 and 15.

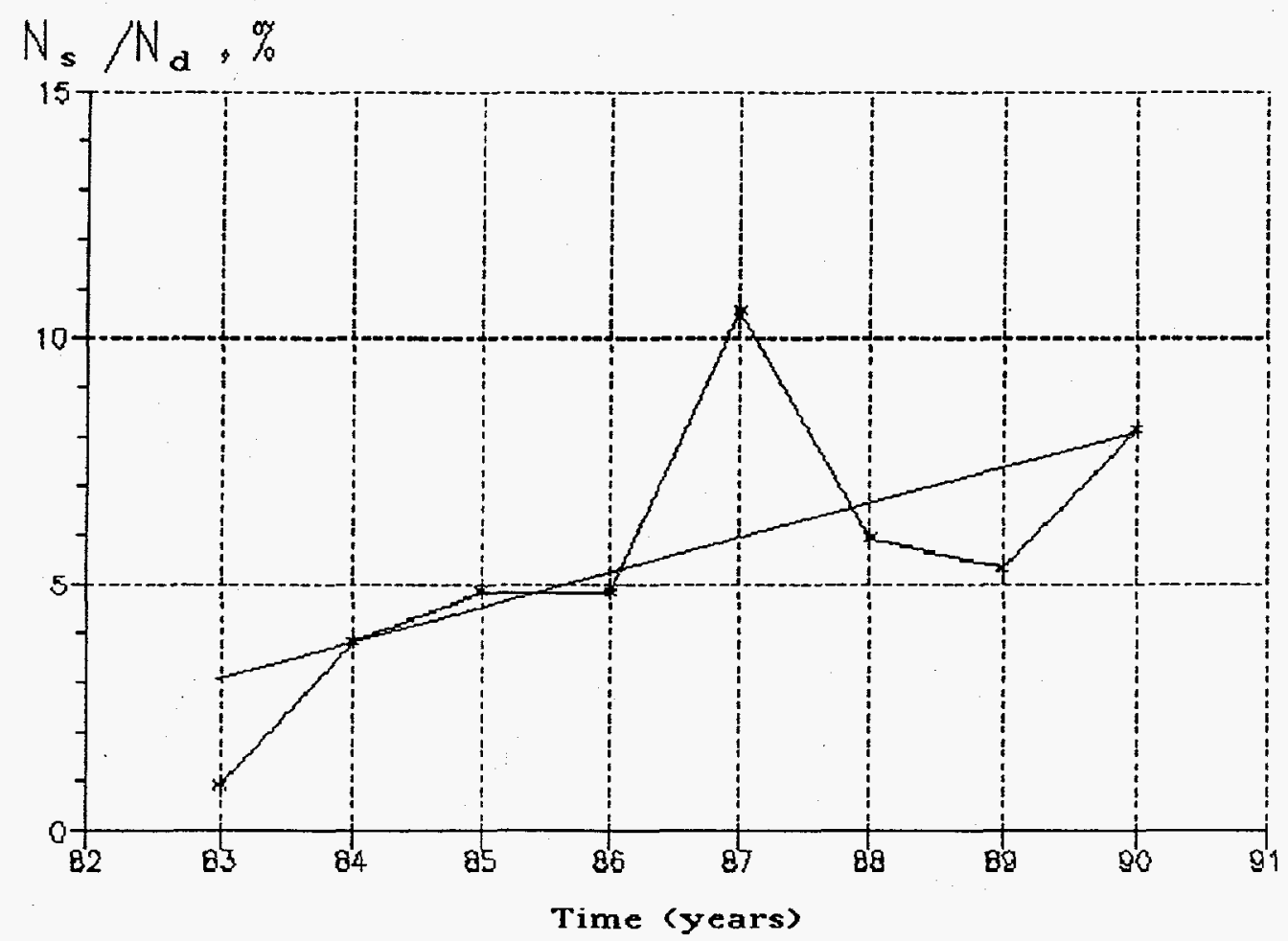

Fig.4.5. Change of the ratio of number of deep seismic events (deeper than $-600 \mathrm{~m}$ ) to the number of near surface seismic events. 

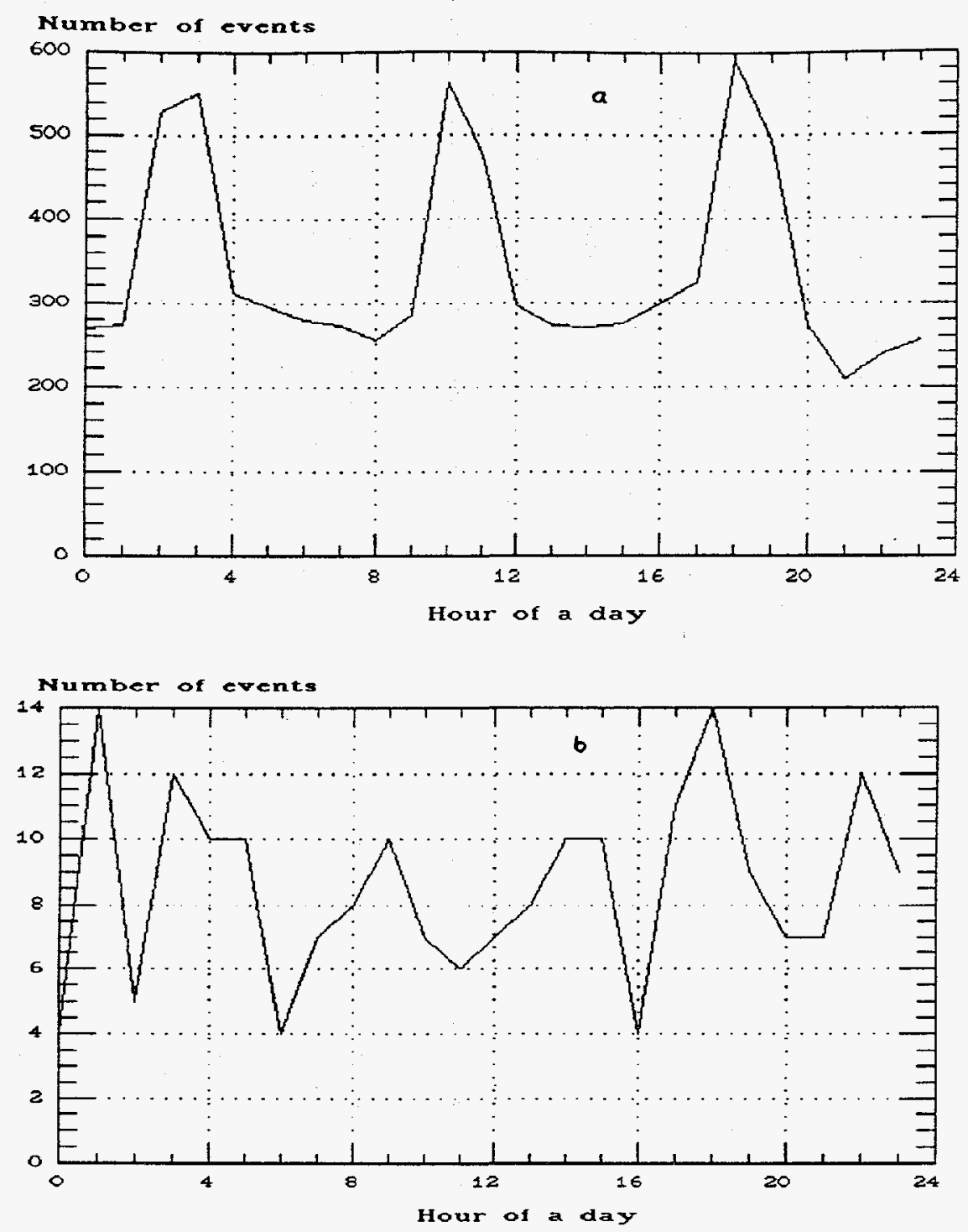

Fig.4.6. Distribution of seismic events of different energy in hours of a day: a energy class from 2 to $4 ; b$ - energy class grater than 5

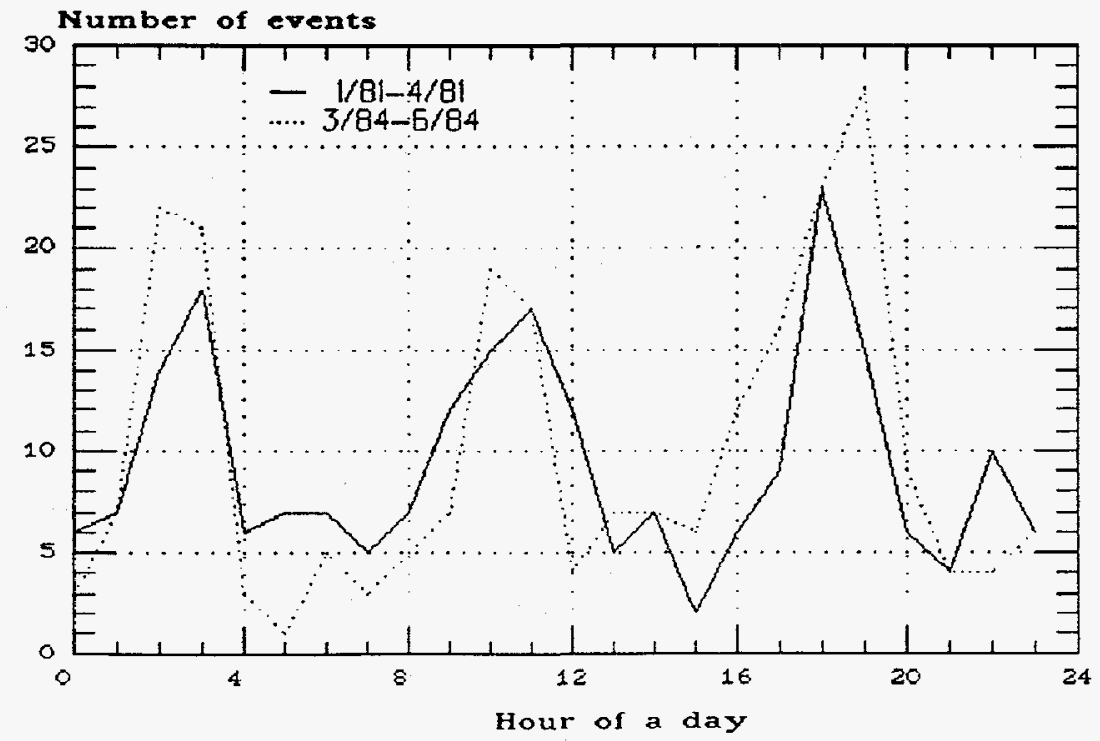

Fig.4.7. Distribution of weak seismic events in hours of a day for two random samnlec 


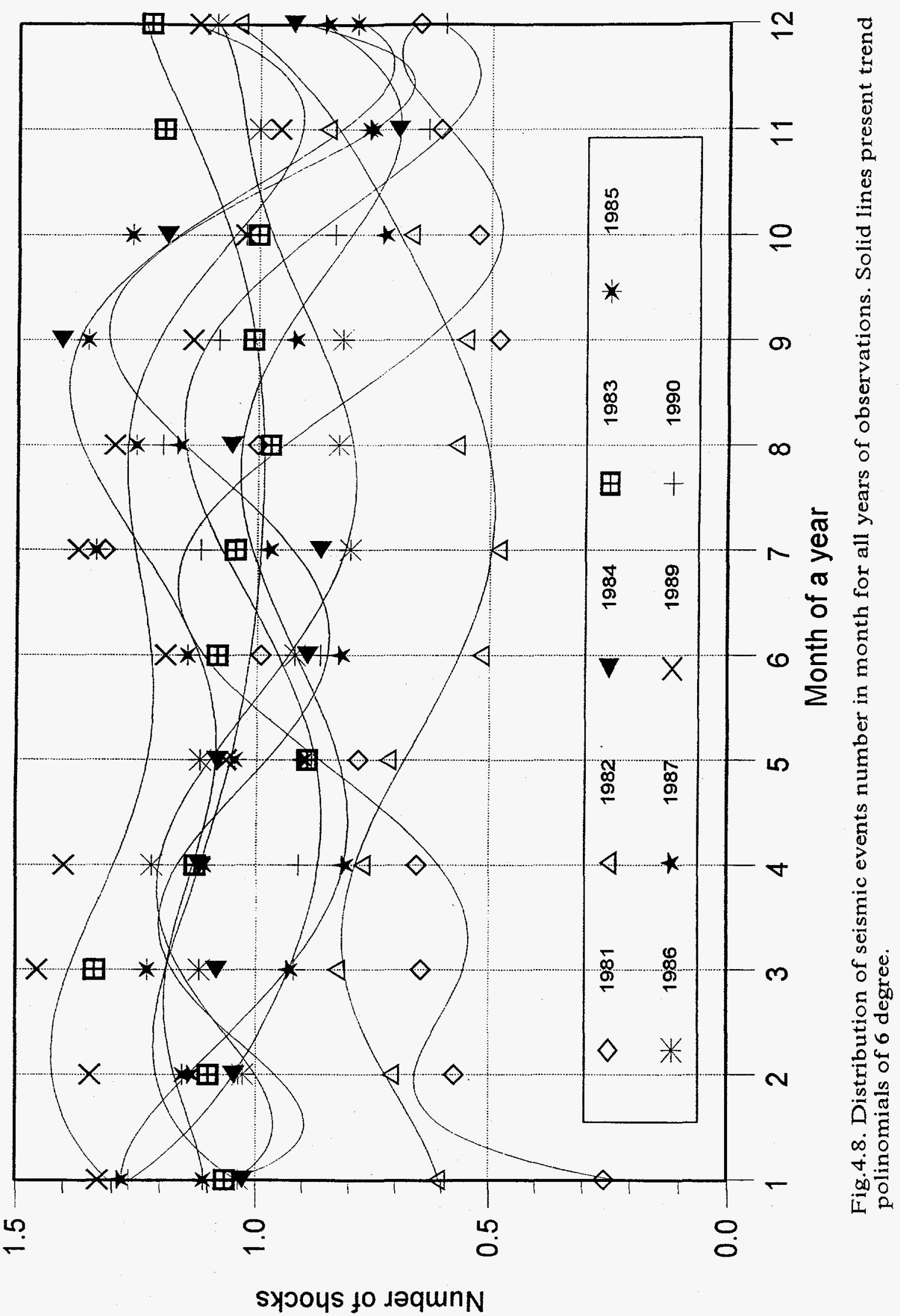


$\mathrm{N}$

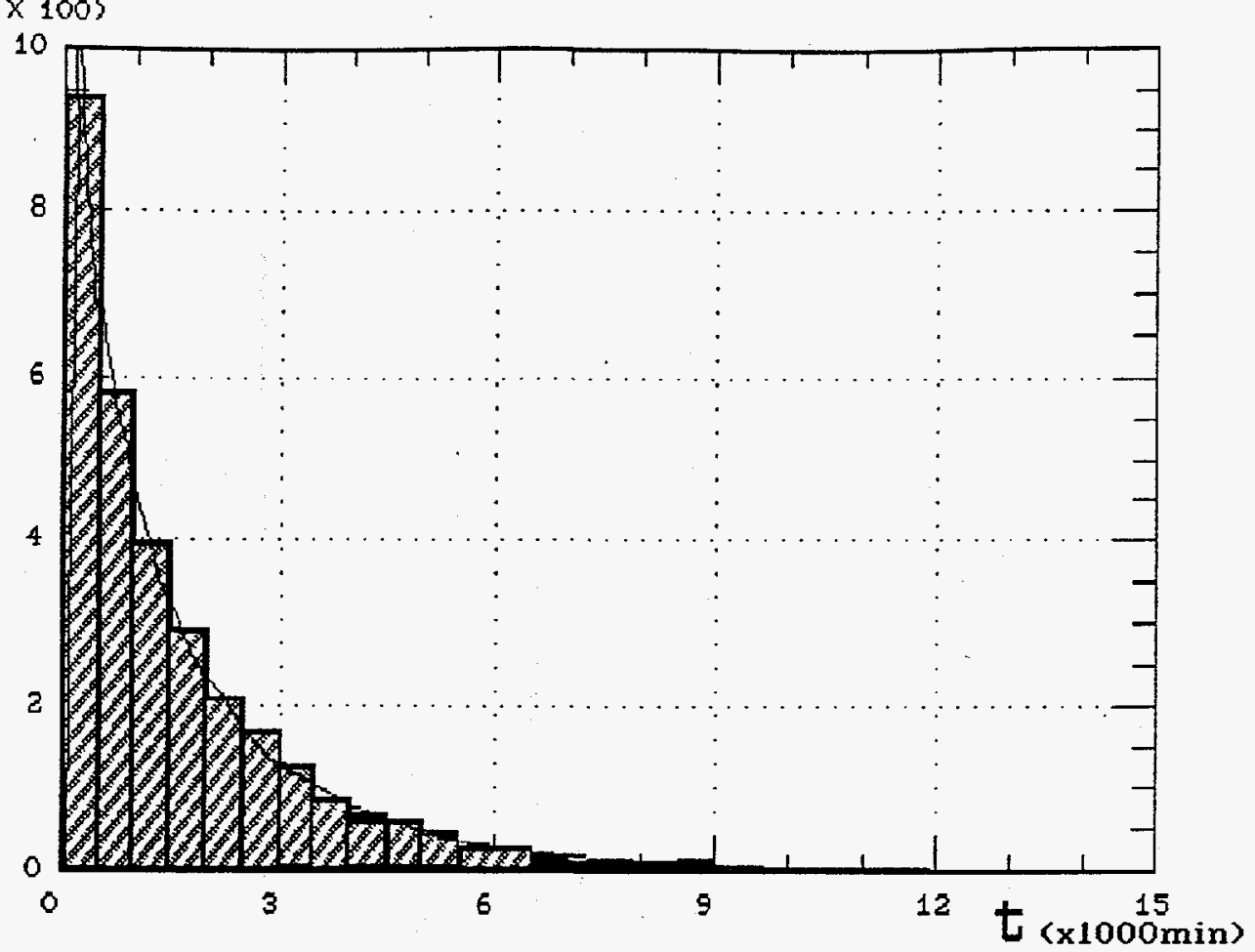

Fig.4.9. Distribution of time intervals between successive seismic events of energy class equal to or grater than 5 . The Weibull distribution is presented by solid line.

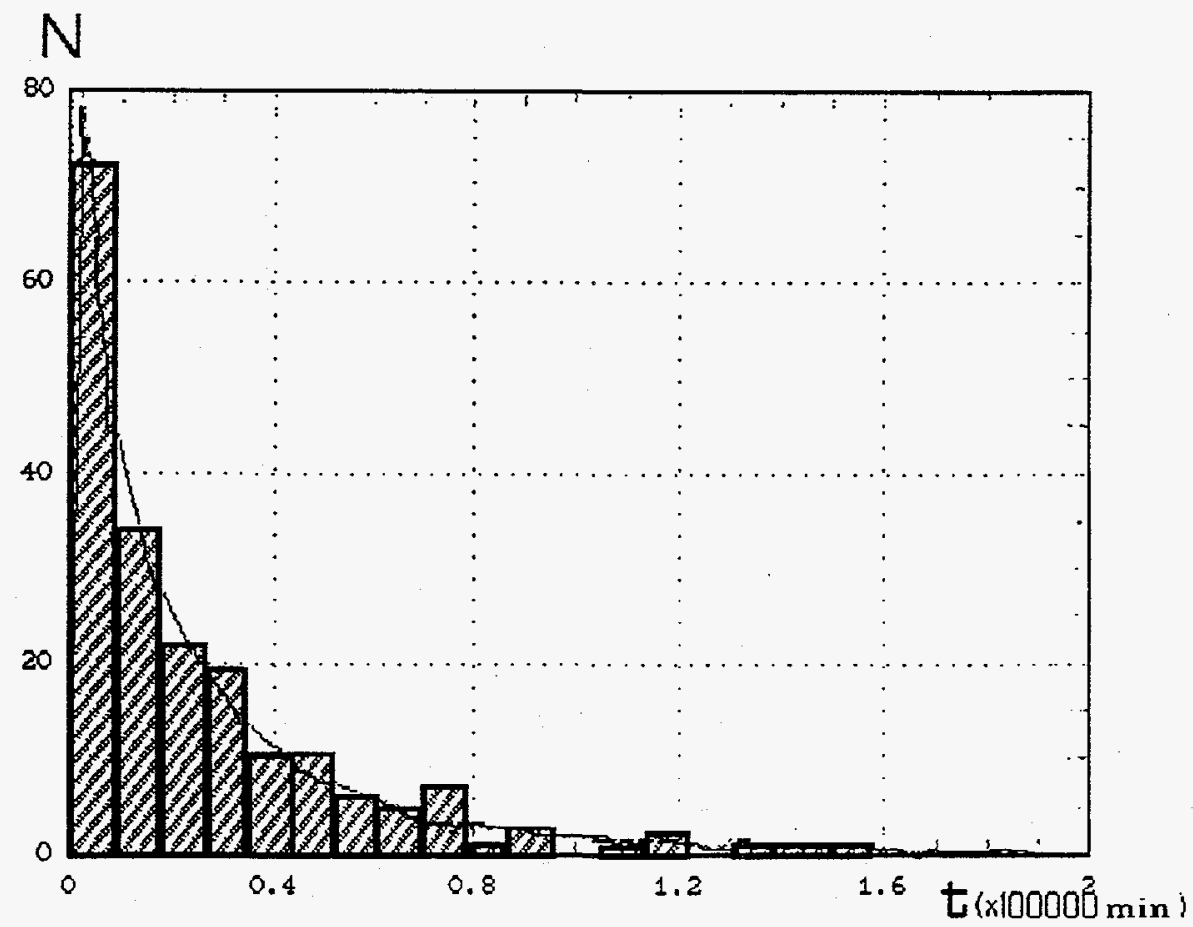

Fig.4.10. Distribution of time intervals between successive seismic events of energy class equal to or less than 4 . The Weibull distribution is presented by solid line. 

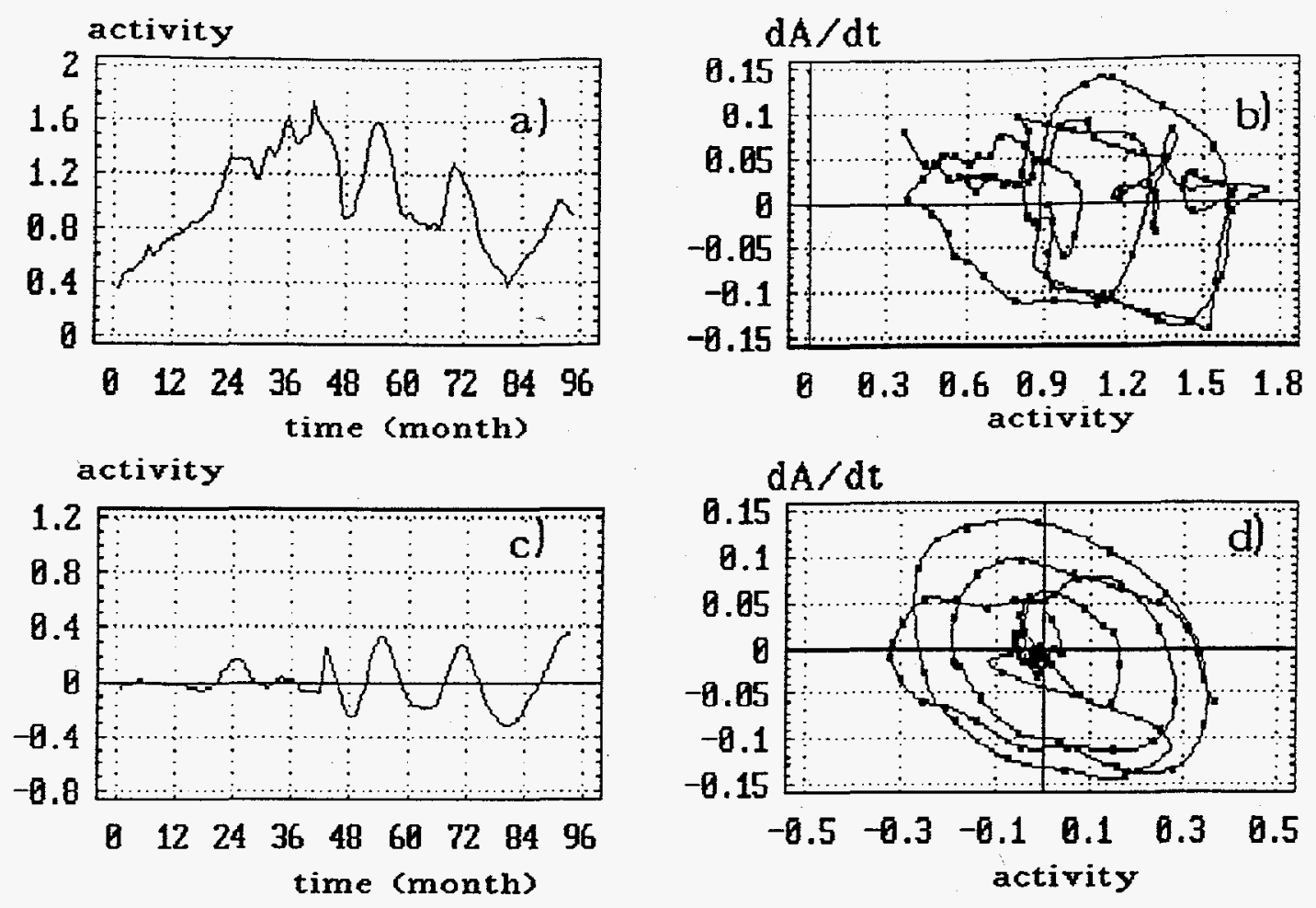

Fig.4.11. Seismic activity in mine 15: a - variation of half-yearly seismic activity which was normalized on average; $b$ - phase portrait of seismic activity; c - variation of seismic activity after smoothing and trend removing; $\mathrm{d}$ - phase portrait after these transformations.
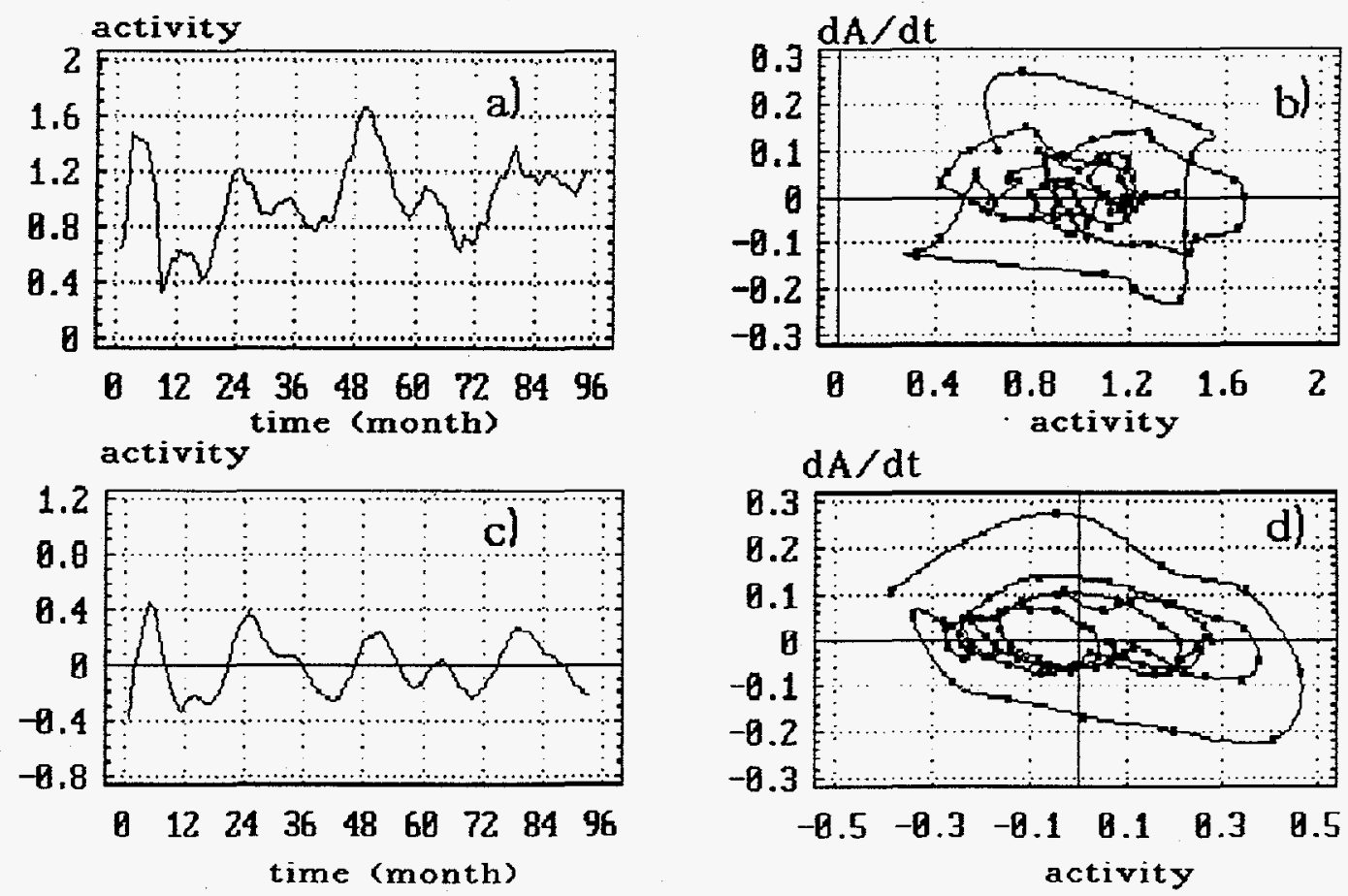

Fig.4.12. Seismic activity in mine 14: a - variation of half-yearly seismic activity which was normalized on average; $b$ - phase portrait of seismic activity; c - variation of seismic activity after smoothing and trend removing; $\mathrm{d}$ - phase portrait after these transformations. 


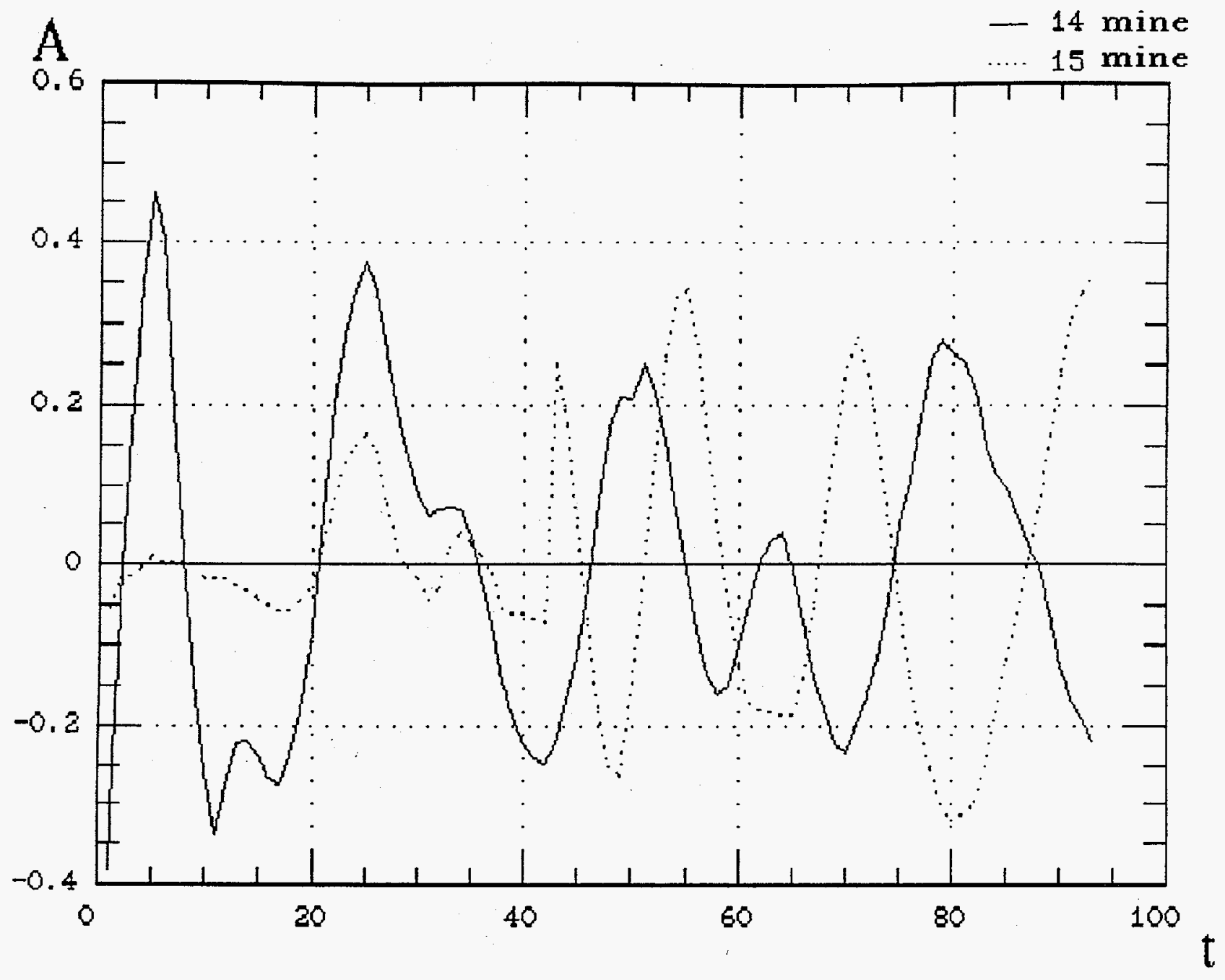

Fig.4.13. Comparison of seismic activity variations at mines 14 and 15. 


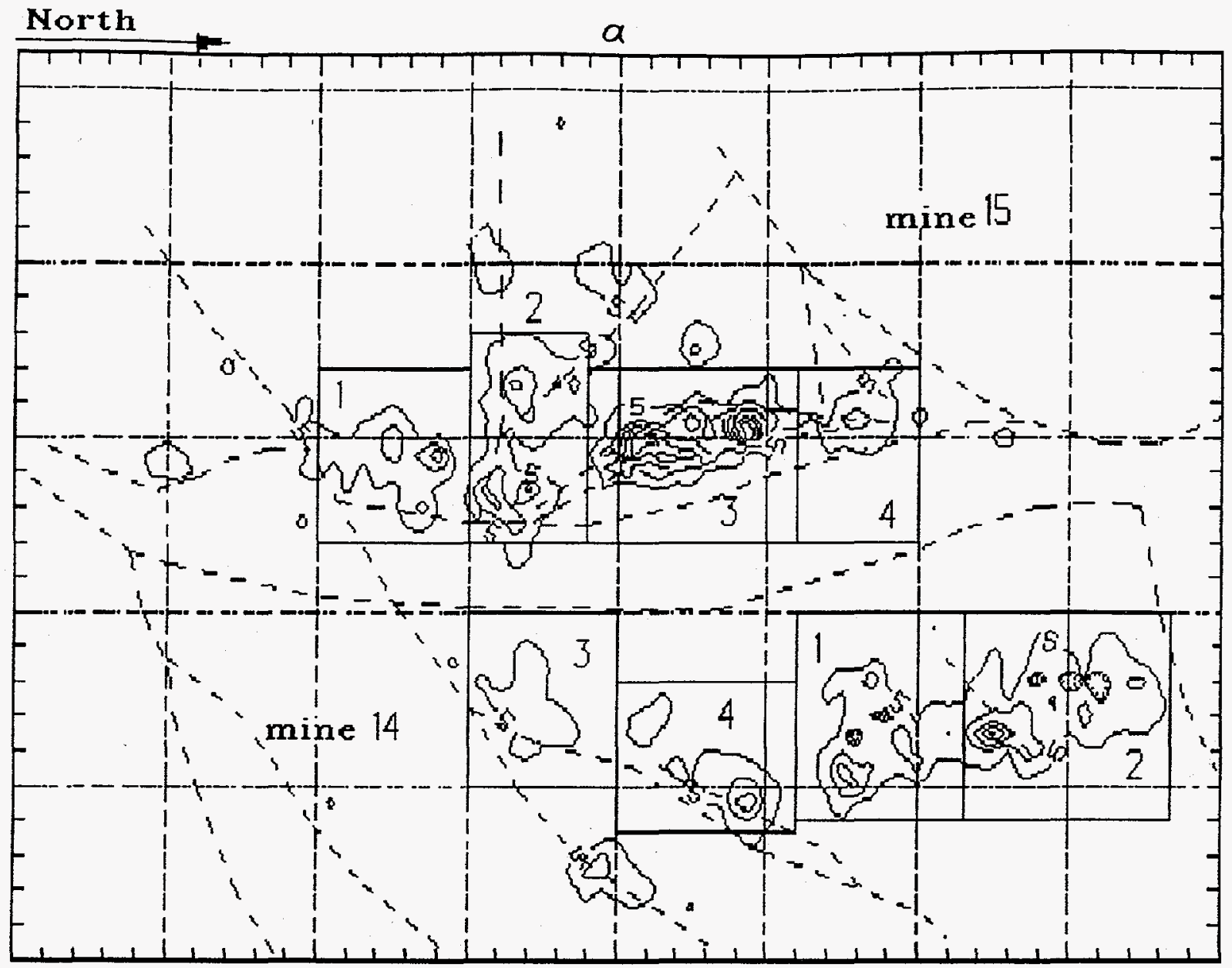

$500 \mathrm{~m}$

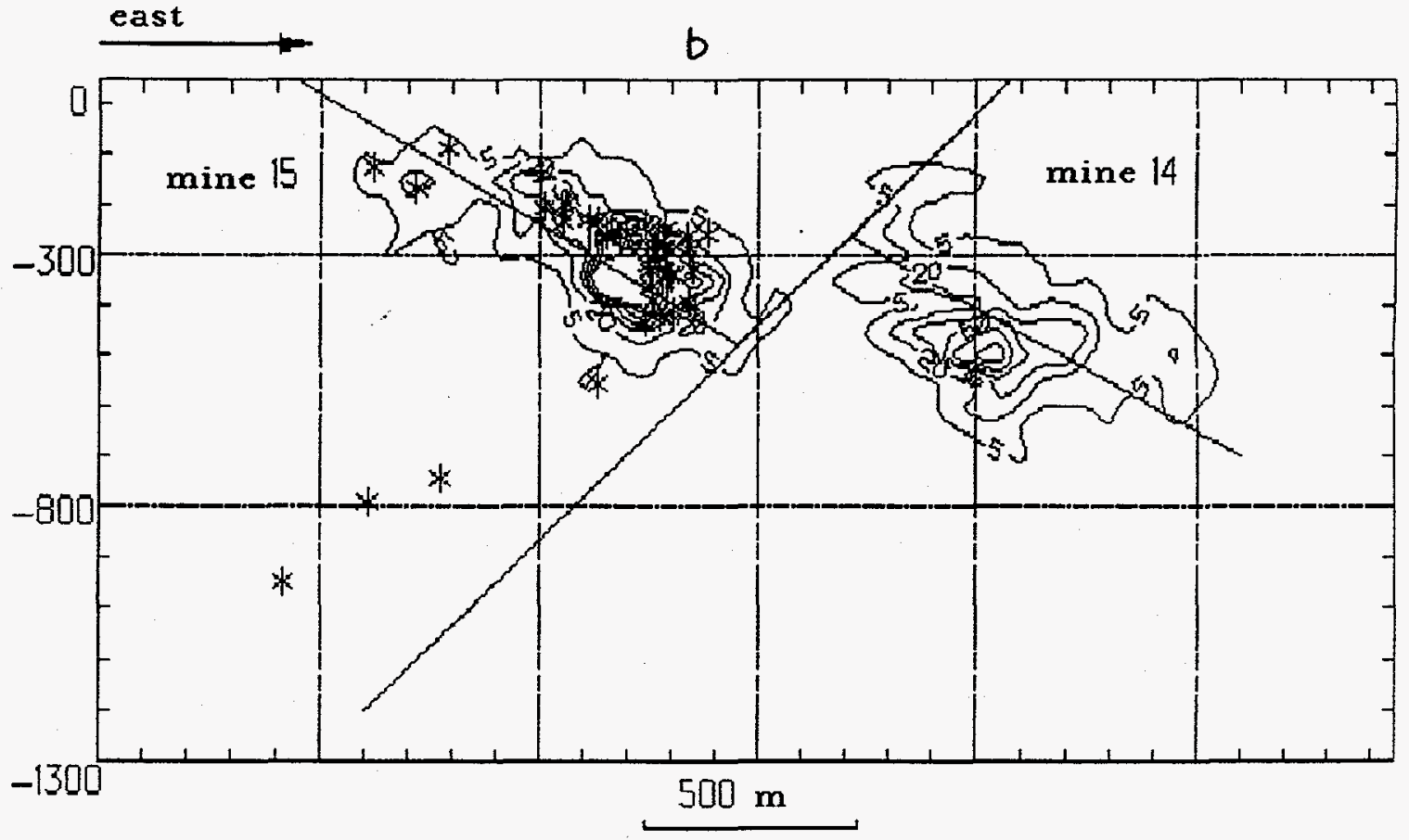

Fig.4.14. Spatial distrubution of seismic activity of mines 14 and 15: a - plan view; b - view in section (hypocenters of strong events are shown). The outer contours corresponed to 5 events per 50 sq.m. 


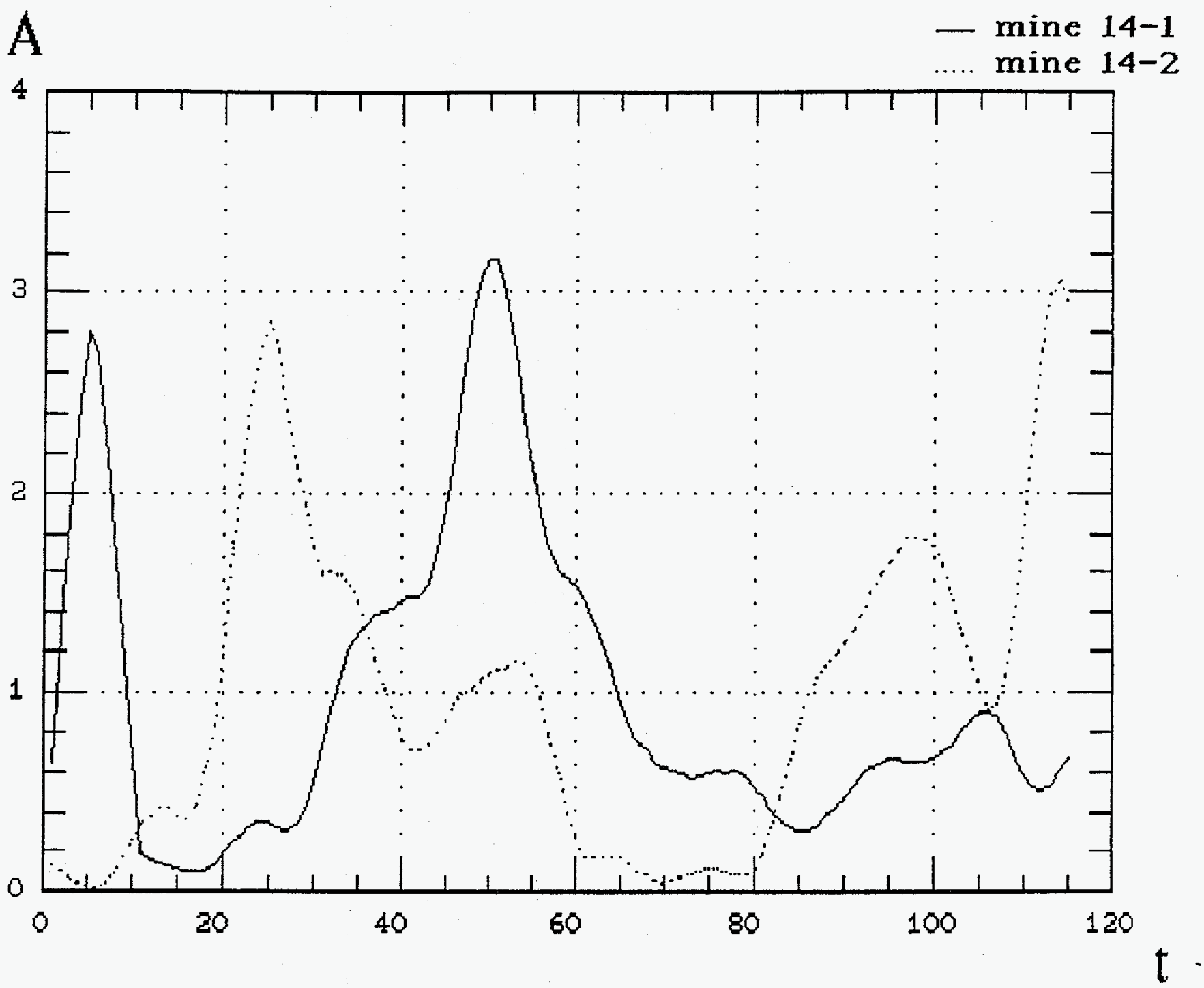

Fig.4.15. Comparison of seismic activity variations in area 1 and 2 of mine 14 

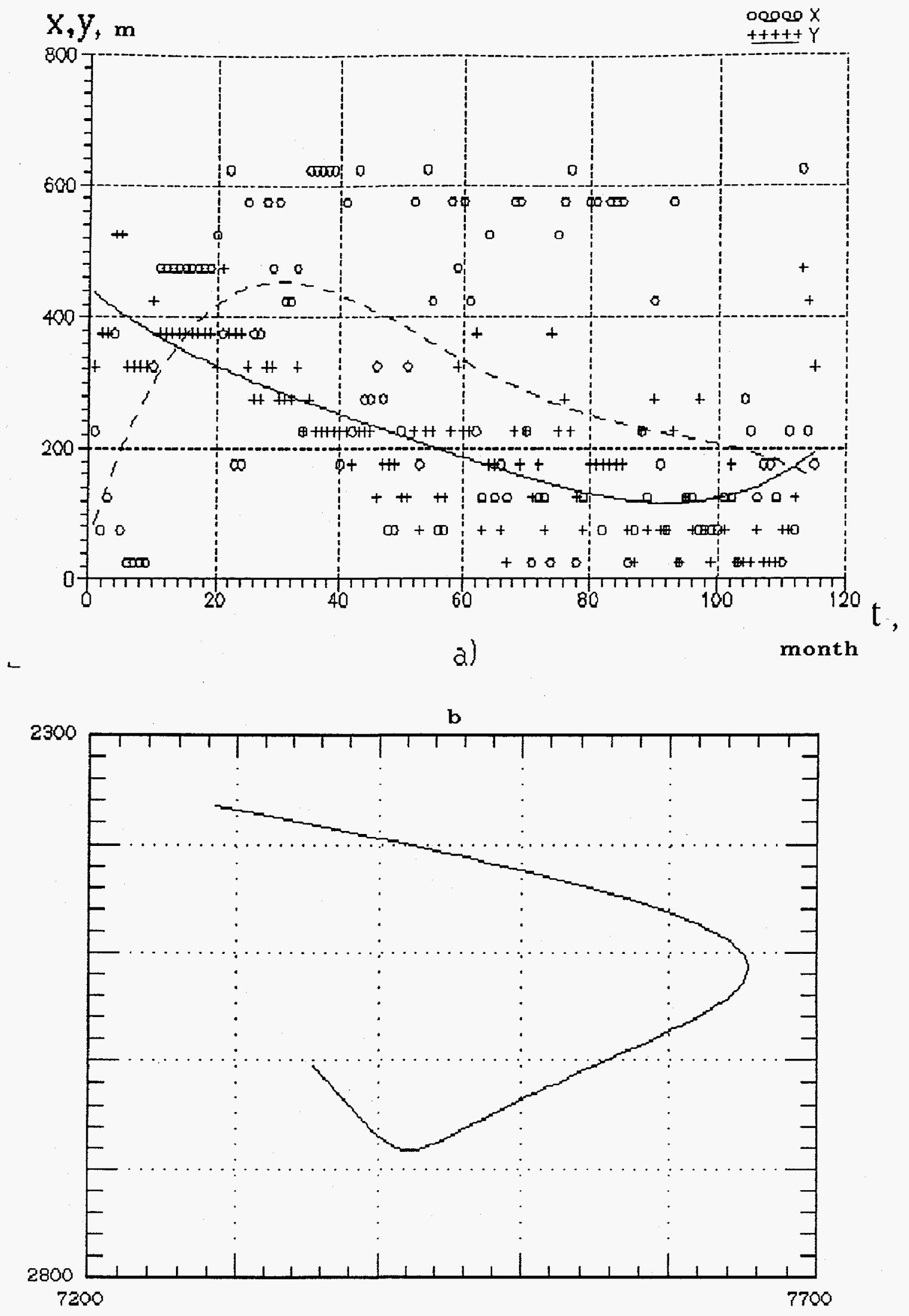

Fig.4.16. Time evolution of the center of maximum seismic activity of a cite 1 of mine 14: $a$ - time plot of coordinates $x$ and $y$ evolution; $b$ - plan view of trend of the center of maximum seismic activity (smoothed by polinomial of 4 degree. 

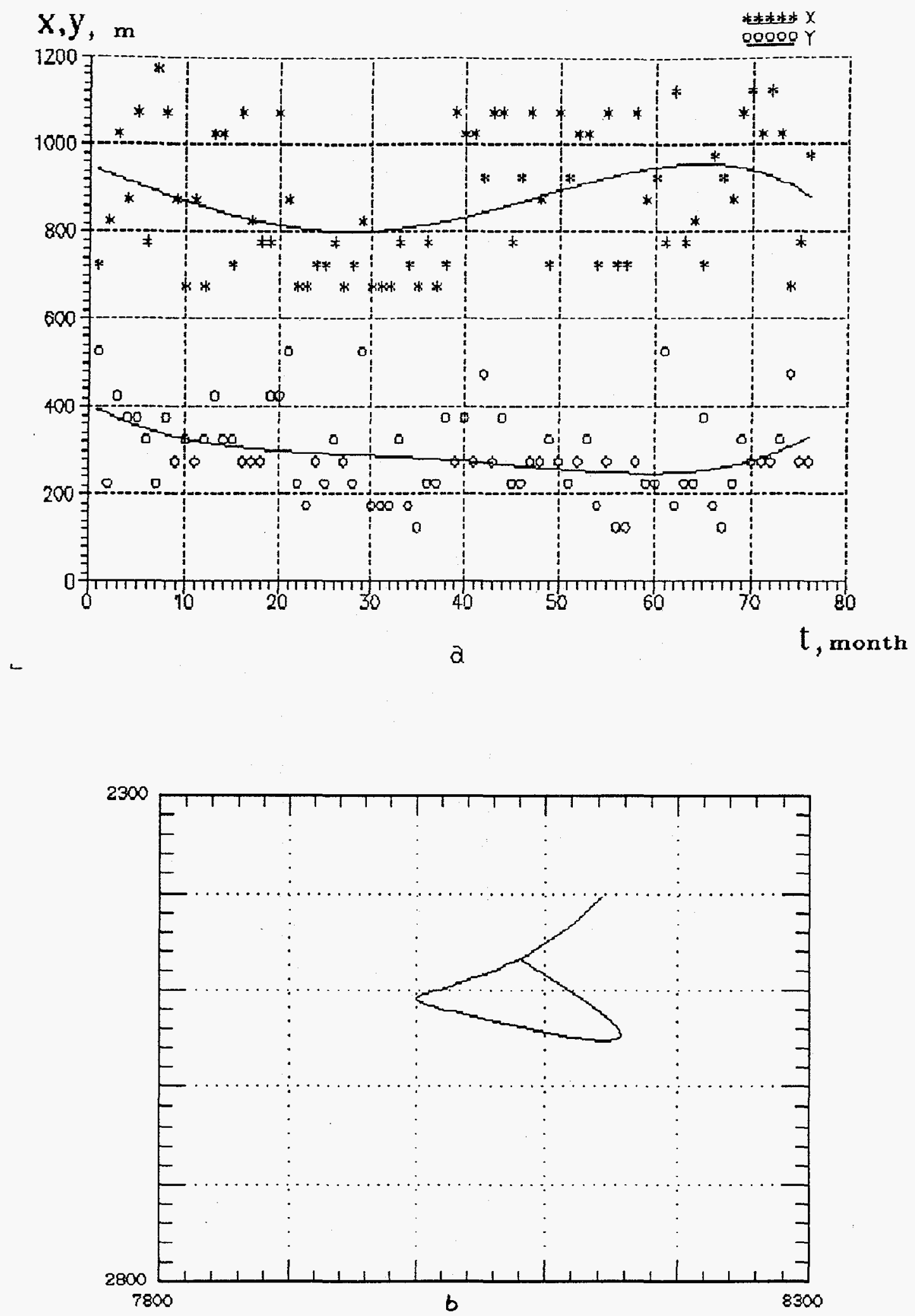

Fig.4.17. Time evolution of the center of maximum seismic activity of a cite 2 of mine 14: $a$ - time plot of coordinates $x$ and y evolution; $b$ - plan view of trend of the center of maximum seismic activity (smoothed by polinomial of 4 degree). 
1500

$y, \mathrm{~m}$ (west)

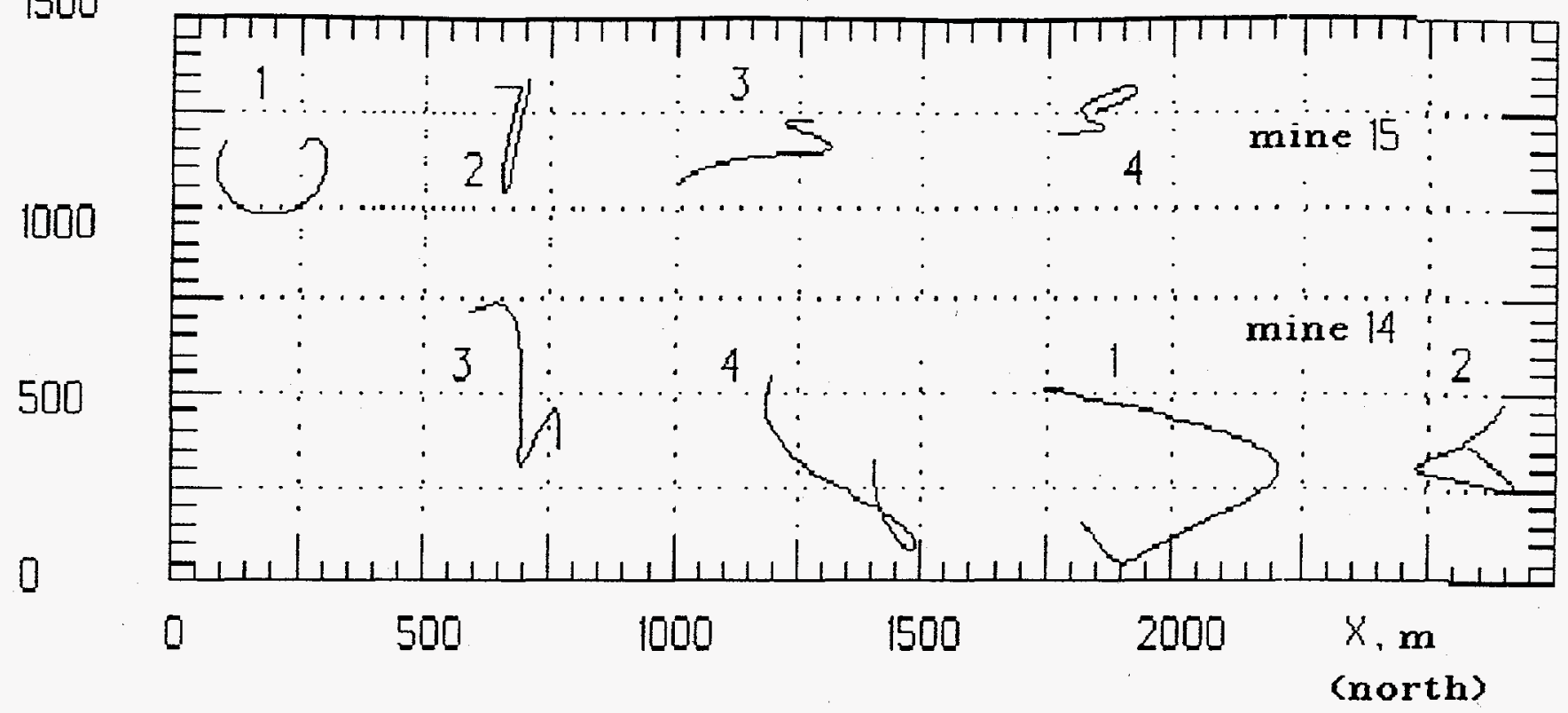

Fig.4.18. Time evolution of the center of maximum seismic activity for series of sites of mines 14 and 15 .

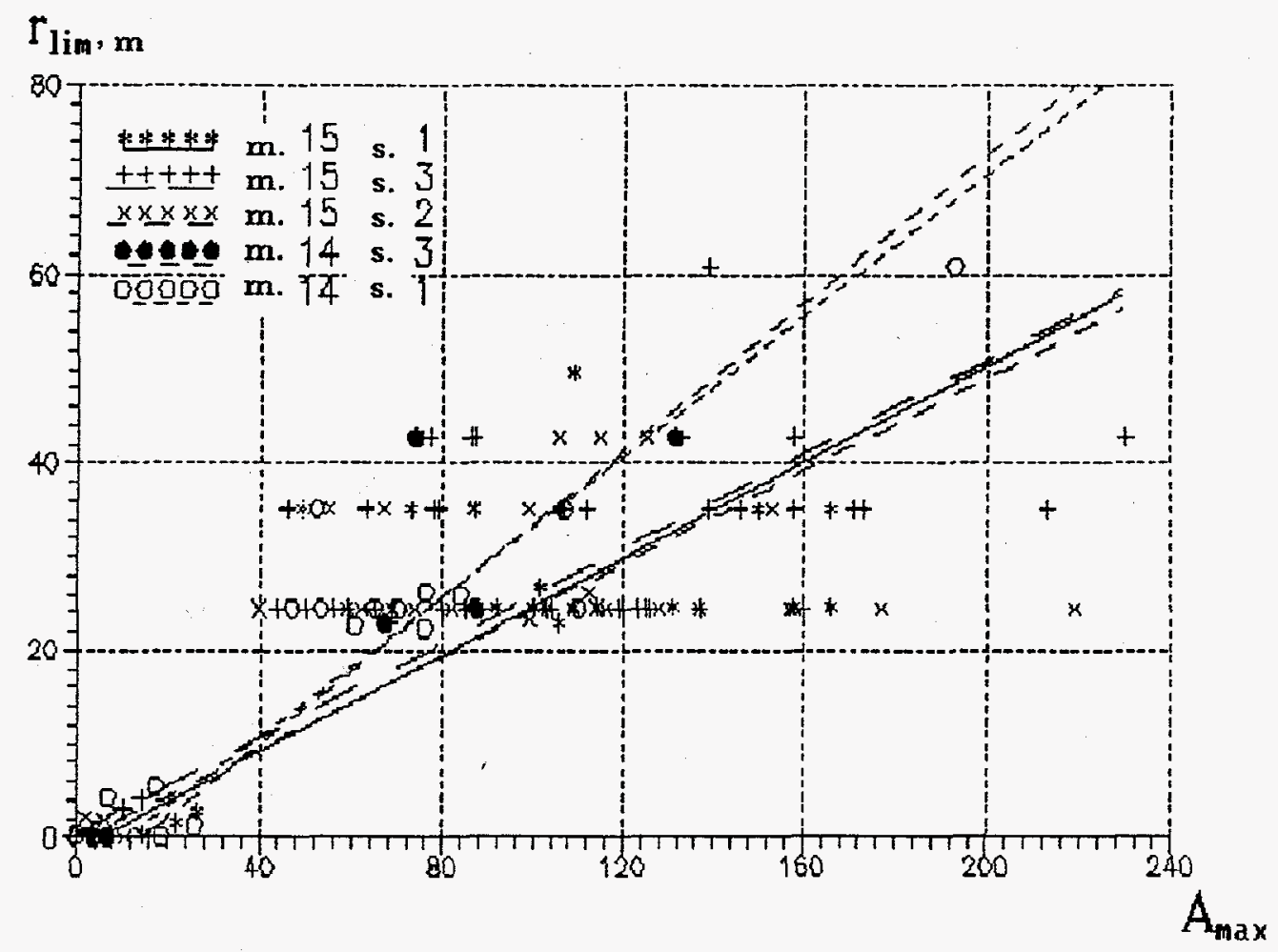

Fig.4.19. The relationship between areas sizes and seismic activity. 


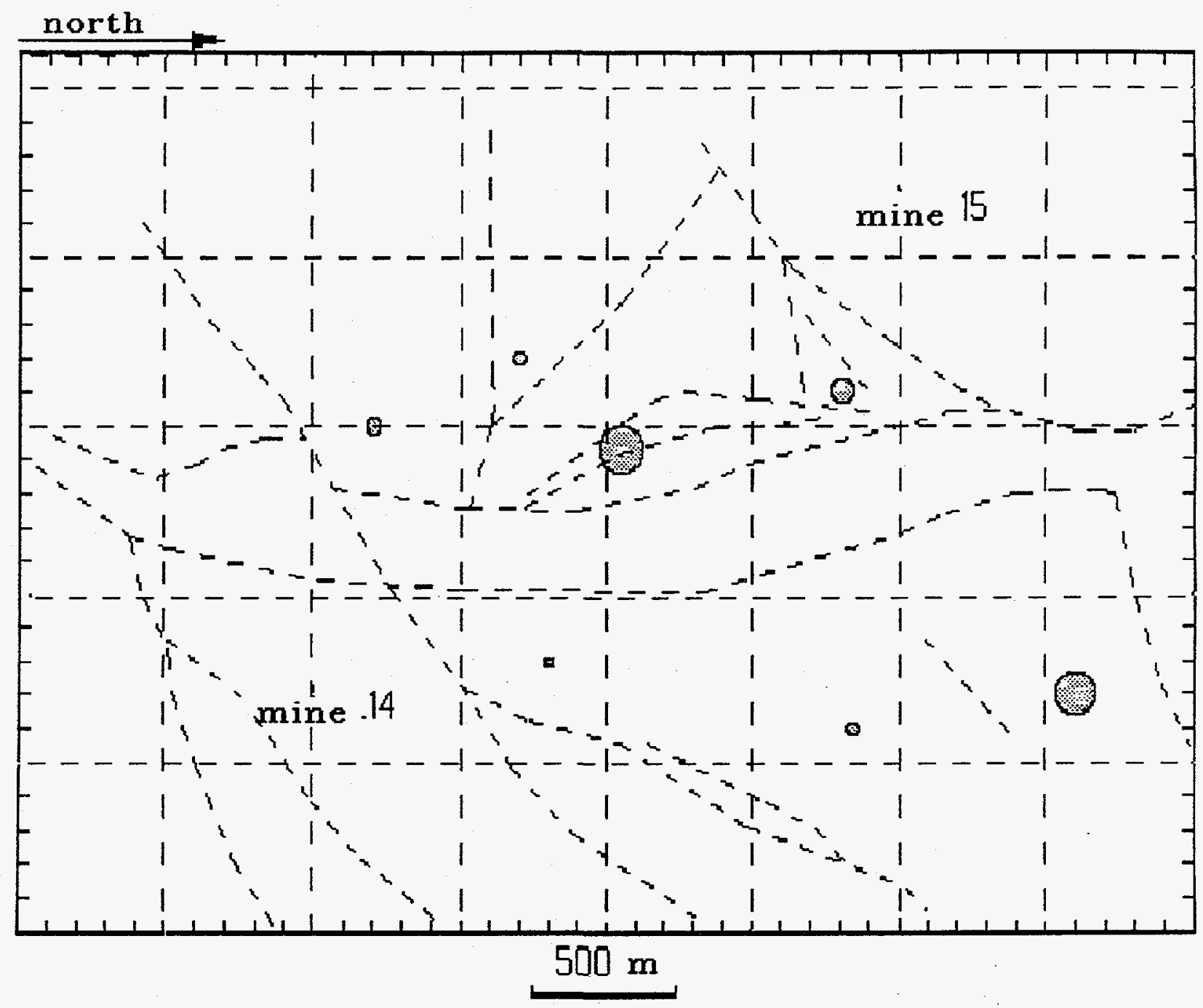

Fig.4.20. Map of forcasting of the increased seismic activity areas location. 


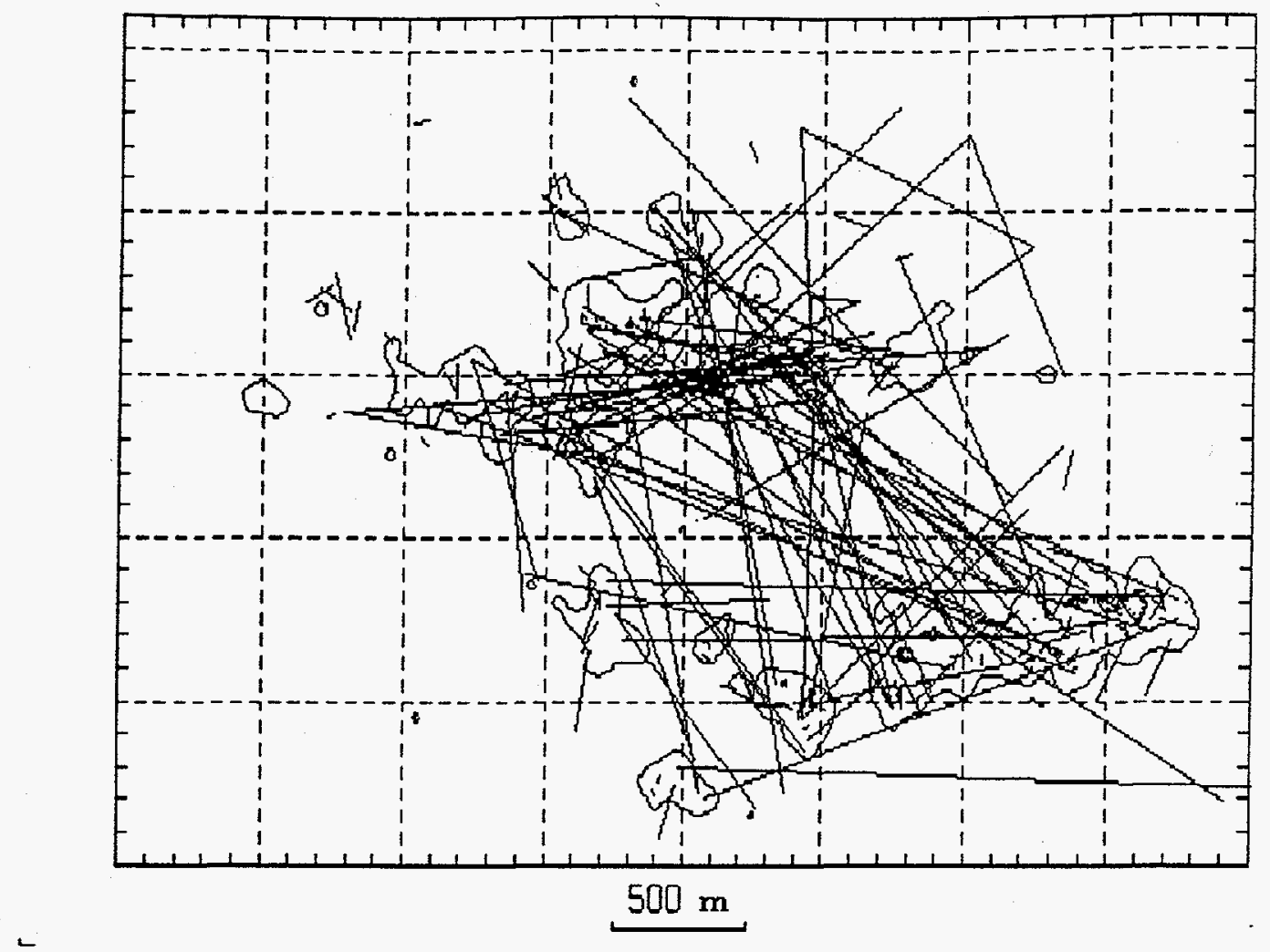

Fig.4.21. Lines connecting the epicenters of pair events. Increased seismecity areas are shown.

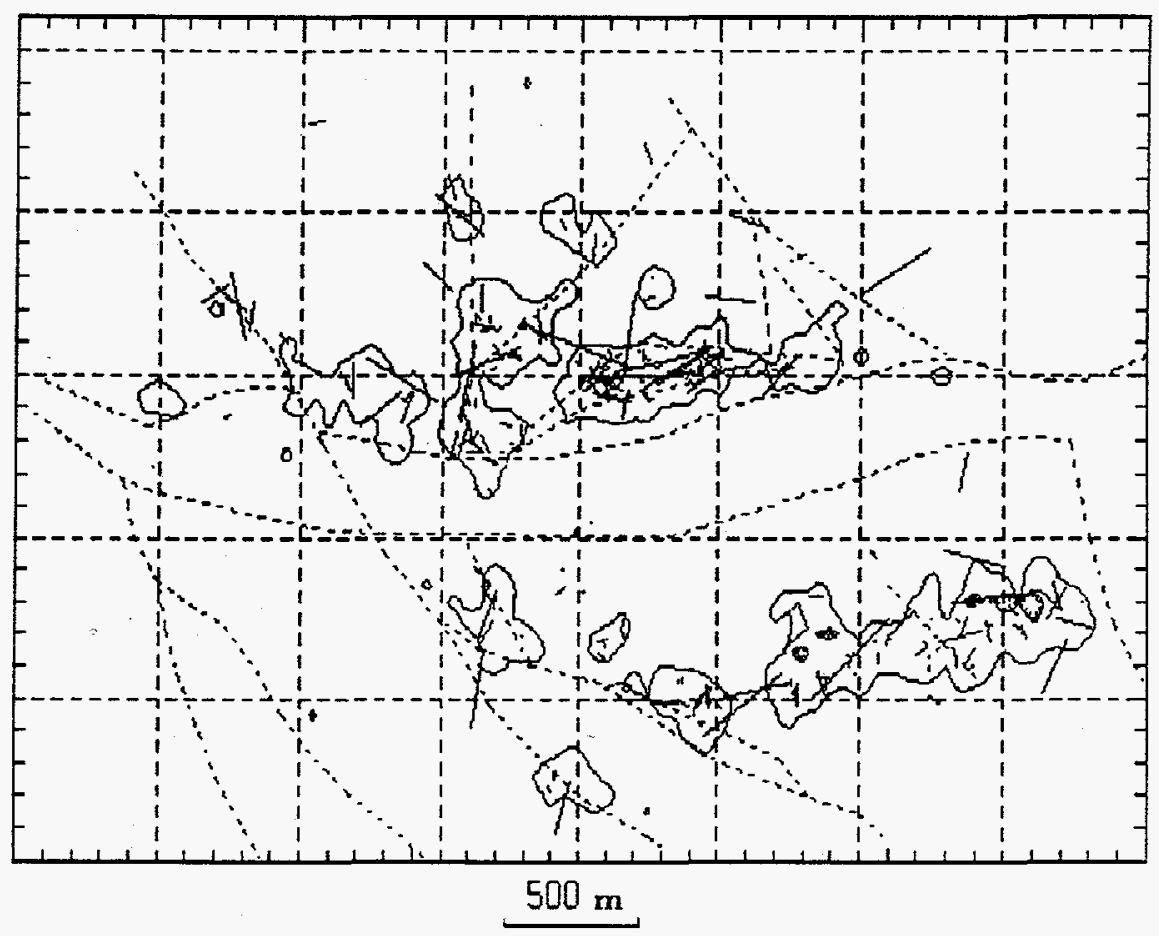

Fig.4.22. Lines connecting the epicenters of pair events, the distance between wich is less than $400 \mathrm{~m}$. Increased seismecity areas are shown. 


\section{DISSIPATIVE PROCESSES IN A ROCK MASSIF AND THE PROBLEM OF STABILITY OF ITS STRUCTURAL ELEMENTS.}

One of main practical purposes of mining and of whole problem of underground space utilization is the prognosis of long-term stability of a rock massif in the vicinity of complicated system of underground openings. For constructions situated at large depths and purposed to long term of exploitation the confronting with that problem is unavoidable: the possibility of long accumulation of the changes in a massif under influence of man-made factors capable to provoke negative consequences for an object is confirmed by numerous examples from mining practice. At the scales growth of mounted construction the influence mechanism of those factors to processes of deformation and destruction in a massif begins to play a decisive role. Modern level of knowledge in the rocks mechanics doesn't allow to predict all aspects of the rock massif behavior in the process of construction and exploitation of large-scale constructions of different purpose. Moreover it is possible to affirm the ambiguity of such behavior and to prognosticate several variants of massif reaction to man-made interference of such scale. The mentioned problem becomes especially actual at projecting and erection of constructions purposed for the long exploitation term: underground nuclear power plants, radiactive wastes storages and other objects of special purpose.

The massif balance established for a long period of its forming is inevitably disturbed at man-made interference accompanied by the removal of considerable volumes of rocks that is why it is necessary to estimate the scales and the danger of such interference. At the excavation of large crosssection openings the zones of stresses increased concentration arise in their vicinity which if not leading to immediate appearance of fracture in a massif or to considerable deformation of underground openings nevertheless continue to exist during long time and may provoke such fracture at additional external influences. The stress state changes in considerable massif areas create dangerous stresses concentration at large geological heterogeneities - the faults situated in the construction disposal zone. The external influence of man-made or natural origin (even comparatively small-scale one) may in that case lead to such phenomena known from mining practice as tectonic rockbursts and man-made earthquakes.

As it was noted to initiate the process of excretion of potential energy accumulated in near-contour zone it is sufficient to have insignificant external influence at definite 
conditions. The relaxation processes in a massif lead to the gradual decrease of risk of the discussed dynamic phenomena arising. It is evident however that one should speak about the time of such risk decrease being applied to the dangerous dynamic phenomenon scale. For instance if the question is about prognosis of the rockbursts in underground openings at which the destruction of only near-contour zone occurs and falls of distinct rock blocks then the largest danger will exist during comparatively short time intervals compared to the man-made interference period (excavation of opening). By that the rockburst of such scale can be provoked by comparatively insignificant external influences (for instance by seismic influence from remote excavation works). If to speak about the large tectonic rockbursts and earthquakes prognosis embracing the massif considerable areas then one should analyze largerscale factors of external influence leading to the dangerous stress state arising at large structural elements and to mind that the stresses in that case will exist during long time. This dangerous time period should be estimated in each particular case.

The influence of natural factors is studied to the least extent of all external influences which can serve as the reason of the anomaly stress state in a massif as the triggering mechanism for rockbursts and man-made earthquakes. The main ones of them are listed in the Table 5.1.

The constant influence of such cyclically changed external burdens to structurally inhomogeneous medium leads to that the different sites of a massif may come to unstable state. The study of those effects by instrumental methods requires to arrange long-term high-precision natural observations at considerable areas and the use of mathematical simulation methods can render essential assistance in arranging of such observations and in analyzing the results.

Hence to prognosticate long-term stability of a massif and of underground openings the accounting in time of the stresses concentration and relaxation processes at massif heterogeneities leading to its structure manifestation is required.

At majority of practical calculations the massif is considered as a homogeneous elastic or elastic-plastic medium which in many cases is sufficient for practical estimates. The real rock massif possesses with considerable heterogeneity conditioned by as noticeable differences of physicalmechanical features of rocks as by the structural heterogeneities presence of different scale: from microscopic ones defined by the dimensions of crystall lattice dislocations to macroheterogeneities - large faults. In present 
$\mathrm{T}$ a b 1 e 5.1

Main natural influences provoking the deformation regime changes.

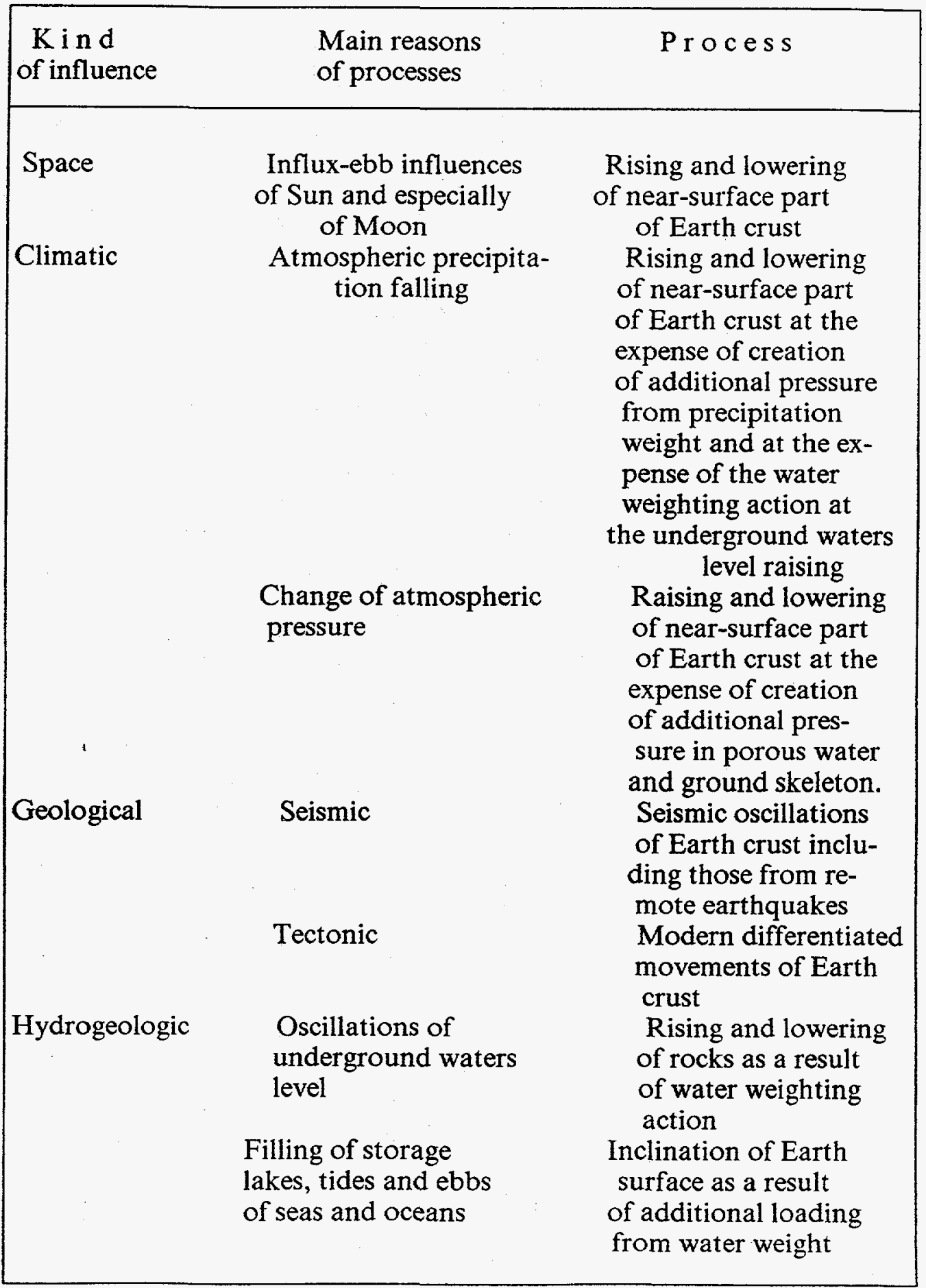


work the mechanical model of solid body with dissipative structure (Rodionov et.al.,1986) is used for the deformation regime changes calculations taking into account the massif rock features, its geological-structural features and time regime of deformation.

Let's give a short characteristics to the model. The solid body is considered to be some ideal continuous medium deformations of which under external forces influence are reversible if the stresses don't exceed the material strength characteristics. At the same time the heterogeneities of different scale are dispersed in the solid body, the distance between heterogeneities of each dimension being much larger that their self dimension. The heterogeneities concentration is defined by the relation:

$$
\frac{l^{3} d n}{d \ln n}=\text { const }=A
$$

Here: I - characteristic dimension of a heterogeneity, $n$ a number. of heterogeneities in the body unit volume, $A$ - a constant defining the density of body filling with heterogeneities. Those heterogeneities are responsible for irreversible deformations: the additional stresses are concentrated and relaxed at them provoking the mechanical energy dissipation.

The constitutive equation for additional (excessive)

stresses at heterogeneities $\Delta \sigma_{i k}$ is :

$$
\frac{d \Delta \sigma_{i k}}{d t}=k \rho c_{t}^{2} \frac{d e_{i k}}{d t}-v \frac{\Delta \sigma_{i k}}{l}
$$

where $\rho$ - density of medium, $c_{t}$ - speed of elastic transverse waves, $\boldsymbol{e}_{i k}$ - strain deviator, $k$ - stress concentration coefficient, $v$ - rate of relaxation. The inelastic stresses are the result of the volume average:

$$
\sigma_{i k}^{\prime}=\frac{1}{V} \int_{V} \Delta \sigma_{i k} d V=A \int_{l_{0}}^{L} \Delta \sigma_{i k} d \ln l L
$$

Here $l_{0}$ and $\mathrm{L}$ - dimensions of minimal and maximal heterogeneity contained in the body or in considered volume if the body is infinite. Total stress in a medium $\sigma_{i k}$ and total local stresses at heterogeneities $\sigma_{i k}^{l}$ are defined by the sums: 


$$
\sigma_{i k}^{l}=\sigma_{i k}^{e}+\Delta \sigma_{i k} \quad \sigma_{i k}=\sigma_{i k}^{e}+\sigma_{i k}
$$

where $\sigma_{i k}^{e}$ - elastic component of total stress. The computation formulas for stresses can be devised in a form of integrals

$$
\begin{aligned}
& \Delta \sigma_{i k}=k \rho c_{t}^{2} \int_{0}^{t} \dot{e}_{i k}(t-\tau) \exp (-v \tau / l) d t \\
& \sigma_{i k}^{\prime}=\frac{2 \rho c_{t}^{2}}{\pi Q} \int_{l_{0}}^{l} \int_{0}^{t} \dot{e}_{i k}(t-\tau) \exp (-v \tau / l) d \tau d \ln l
\end{aligned}
$$

where $Q$ - the medium mechanical quality factor. The last relations connect inelastic stresses in a medium to the massif deformation history: the result of deformation depends not only upon applied loadings but upon the prehistory of deformation process as well. The ambiguity of result witnesses for the body ability to "select" its own reaction to external influence which is a characteristic feature of physically nonlinear media.

\section{Calculations for practical problems.}

The finite elements method was selected as a calculating one (FEM). This method is widely spread in geophysical problems and in problems of mining mechanics. The algorithms of computer implementation of model relations in MFE were developed which enable to carry out the mathematical simulation of natural objects with structure and "memory". In examples described below a two-dimensional problem was solved in a variant of state of plane deformation. The elastic components were calculated according to known formulas of the elasticity theory, the inelastic ones - according to the relations given above. The normalized values of stresses, lengths, deformations, displacements and time were introduced: $\tilde{\sigma}=\sigma / \sigma$. $\tilde{l}=l / l_{*}, \quad \tilde{\varepsilon}=E \varepsilon / \sigma_{*}, \quad \tilde{\delta}=E \delta / \sigma_{*} l_{*}, \quad \tilde{t}=t / t_{*}$ The problem characteristic parameters are denoted by an asterisk, E - Young's modulus. The superscripts of dimensionless values are omitted below, the dimensioned values are given with indication of the measurement units. 
Let's discuss a problem of the stresses concentration at a fault in rock massif at the stress state change provoked by a man-made disturbance. The calculations were fulfilled for particular fault in Khibiny the displacement along which was registered during man-made earthquake at April 161989 during carrying out the explosion. The intensity of earthquake in epicenter is equal IV, the seismic stations data allow to estimate its magnitude as $M=4.8-5$ which corresponds to the seismic energy $E=10^{12}$ Joules. It was shown above that the process of huge crack forming with dimensions $1000 \times 1000 \mathrm{~m}$ coinciding at whole extension with the fault of $V$ rank could be the possible mechanism of given earthquake. The disturbance of the rock massif balance could be provoked by removal of large volumes of rocks (up to 25\% of initial volume) which led to decrease of free surface to $300-400 \mathrm{~m}$ and to the decrease of vertical lithostatic stresses to 9-12 $\mathrm{MPa}$ at preserving of subhorizontal tectonic stresses 30-80 MPa acting in the massif.

In the beginning the calculations of stress state and displacement estimation in the massif along a plane corresponding to the mentioned fault position with the presence of lithostatic $\rho g h$ and tectonic $T$ stresses were fulfilled using elastic model for two variants:non-touched massif (before mining works beginning) and actual state at the earthquake moment taking into account the free surface level decrease and the presence in the massif of some domains filled with crushed rocks. The natural stresses field of non-touched massif can be given with relations:

$$
\sigma_{v}=\rho g h, \quad \sigma_{h}=\zeta \rho g h=T_{0}+\nabla \sigma_{T} h
$$

where h -depth, $\rho$-density of massif, $\zeta=v /(1-v), v$ Poison's ratio, $\mathrm{T}_{0}$ - the module of horizontal tectonic stresses directly close to earth surface at the level of local basis of erosion, $\nabla \sigma_{T}$ - vertical gradient of tectonic stresses. There are no sufficient data at present time for precise defining the last parameter and the tectonic component of horizontal stresses for discussed depths was taken for calculations to be constant

$$
T=\text { const }
$$

Because the initial profile of Kukiswoomchorr massif before the mining works beginning and its actual profile taking into account the changes provoked by large-scale mining works are known it is possible to compute elastic stresses in 
the fault plane for both variants. The shear stresses $\tau$ and the stresses normal to the fault planes $\sigma_{n}$ were computed. The computation results are presented at Fig.3.9 and Fig.5.2. The results show the increase of shear stresses $\tau$ at fault plane in second variant compared to first on e. For the mark +252 ( medium of three worked out horizons) the value of $\tau$ increases to the critical values: from 9 to $12 \mathrm{MPa}$ for $\mathrm{T}=30 \mathrm{MPa}$ and from 18 to $29 \mathrm{MPa}$ for $\mathrm{T}=50 \mathrm{MPa}$ with corresponding decrease of compressing stresses at the areas perpendicular to the crack plàne.

The estimation of displacement along the fault mentioned above was got in following manner. It is not difficult to compute the elastic displacements values in the fault plane in tangential direction for two mentioned variants $U_{e}(1)$ and $U_{e}{ }^{(2)}$ using the elasticity theory relations. It is possible to suppose that the difference of those values $\Delta U$ is the estimation of the displacement value along the fault: the points of upper part of the massif have to be displaced for $\Delta U$ relatively to motionless lower part at the loading change. The difference $\Delta U$ for the horizons mentioned above $(+322$ and +252$)$ is 6-8 cm which is practically coincides with the displacement measured value.

The use of a solid state model with dissipative structure enables to discuss the local stresses concentration process in the vicinity of fault in time under influence of man-made factors indicated above. It was taken that the vertical stresses is decreasing linearly from $15 \mathrm{MPa}$ to $3 \mathrm{MPa}$ during some time $t$. and that the constant stresses $50 \mathrm{MPa}$ acts in horizontal direction. The calculations for $t .=10$ years and the relaxation rate $10-5 \mathrm{~cm} / \mathrm{sec}$ yield the local shear stresses $\tau^{\prime}$ increase at heterogeneities with dimensions $10 \mathrm{~m}$ and more from 18 to $30 \mathrm{MPa}$ (Fig.5.1). By that the normal compressing stresses in the fault plane $\sigma_{n}^{\prime}$ are decreasing from 25 to $15 \mathrm{MPa}$. Corresponding curves for a point inside massif are given by dashed line (the ratio of Young's moduli for materials of the fault and the massif in calculations was taken as 0.5). The calculated values of shear stresses are confronted at Fig.5.2 on the fault plane in elastic statement and in present solution:the comparison shows that the local shear stresses level concentrated at the heterogeneities is noticeably higher.

The value of the shear displacement work was estimated above according to the displacements known from natural measurements and the calculated stress state in the fault vicinity at the earthquake moment. On the basis of results of 
this calculations that value can be estimated as $A_{1}=2 \cdot 10^{12}$ Joules. The value of $A_{1}$. corresponds to elastic energy released in a massif at displacement along the fault plane. Let's remind that the earthquake energy evaluation yields the value $E_{s}=10^{12}$ Joules which in the order of value coincides with $A_{1}$.

To connect the earthquake hotbed volume $V$ as the source of elastic oscillations to radiated energy $E_{s}$ usually the empirical dependance is used (Tsuboy, 1961).

$$
\lg \mathbf{E}_{s}=\lg \mathbf{V}+\mathbf{a}
$$

where the value a is equal to $2.7, \mathrm{~V}=\mathrm{s}^{3 / 2}$ and $\mathrm{s}$ is taken equal to the aftershocks zone projection to the earth surface. In our case the value $S$ can be estimated as an area of the crack itself. Then the formula gives the estimation of seismic energy $E_{s}=0.5 \cdot 10^{12}$ Joules.

Thus, the stress state change in a massif as a result of large-scale engineering activity creates the local stresses concentration at the fault corresponding to the critical values. At the external influences absence during long time those stresses can relaxate to safe level but before completion of that period the large-scale influence to massif (explosive one in discussed example) can provoke dangerous and even catastrophic consequences. Let's note once more that it is necessary to know the spatial structure and deformation regime besides stress state to prognosticate the man-made influence factors.

Let's come to the basic problem of this section - the problem of the stresses concentration in the vicinity of cylindrical underground gallery. The domains of the tensile stresses concentration at heterogeneities in closest vicinity of the gallery contour are of utmost interest for the purposes of present work. Namely those zones can be the source of the rock pressure dynamic manifestation in the process of further mining works or of exploitation of an underground construction: rockbursts, rockfalls, blocks displacements provoking the destruction of gallery support etc. In given case the series of practically important questions can be formulated, in particular:

1) the defining of zones dimensions with increased concentration of stresses and especially tensile stresses at heterogeneities; 
2) the estimation of possible destructions in the gallery vicinity: characteristic dimensions of cracks and blocks to which the zone can be divided;

3) possible ways to decrease the indicated dangerous effects, in particular, at the expense of the selection of proper pace of mining works.

In the beginning let's study the model problem of the stress state in the cylindrical gallery vicinity at the decrease of vertical loading according to linear law similar to one discussed above. Such decrease of loading in given case corresponds to the decrease of lithostatic pressure to gallery as a result of removal of considerable volumes of rocks from above at mining works or at cutting of a slot. The characteristic parameters of the problem: $I_{*}=10 \mathrm{~m}, \sigma_{*}=10 \mathrm{MPa}$,

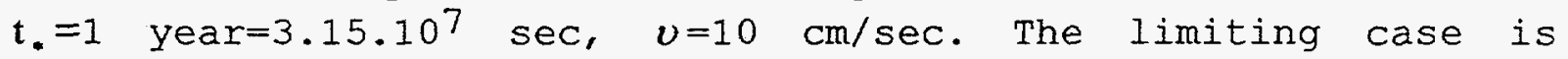
studied: the vertical loading falls down to zero at preserving of considerable side pressure. In that case the effects of arising of tensile stresses at heterogeneities capable to provoke the destructions in a massif are easily singled out. Fig.5.3 illustrates the stresses distribution at gallery contour in a moment $t=1$ (the termination of unloading process). The dependencies $\sigma_{x}(\varphi)$ and $\sigma_{y}(\varphi)$ correspond to known solutions and are given for comparison with the additional stresses values. Total stress $\sigma_{y}$ at side walls of gallery (Fig.5.3) becomes in the process of such deformation tensile one and reaches the considerable value. Besides, the tensile vertical stresses at heterogeneities appear to be considerable in the same zone: at 0.01 they exceed total stress and reach 10 $\mathrm{MPa}$. It is evident that at selected parameters of problem the appearance of subhorizontal cracks is possible at gallery walls at $\varphi>55^{\circ}$. The evaluation of the tensile stresses zone according to calculation data yields the value $0.4 R$ ( $R$ gallery radius). The calculated dependencies of stresses upon time at side wall in the deformation process are given at Fig.5.4. The additional stresses attain the maximum to the moment of the massif unloading termination and at $l=10^{-3}$ quickly relaxate and at large 1 the stresses at heterogeneities are preserved during long time after deformation termination.

Thus, the fulfilled calculations yield the qualitative picture of the tensile stresses zone appearance in the vicinity of a cylindrical gallery in the deformation process and enable to evaluate the dimensions of that zone. 
Let's study further the basic problem - the problem of the stress state in the vicinity of a gallery of large cross section at its excavation.

At Fig.5.5-5.6 the scheme of calculation domain of studied problem is given. The sequence of the rock volumes removal of the gallery contour is indicated by figures (as a whole, without dividing into elements). Several variants of excavation were studied, two of them are presented at figures: a - regular downward excavation (Fig.5.5) and $b$ - the excavation from some intermediate horizon (Fig.5.6). The values of displacements; deformations, total and elastic stresses in a medium, additional and local stresses at heterogeneities of different

scale were calculated and averaged inelastic stresses $\sigma_{i k}$ as well.

The particular analysis is carried out for an gallery with a radius $\mathrm{R}=10 \mathrm{~m}$ in rock massif at the depth $1 \mathrm{~km}$ with the presence of tectonic stresses.

The medium parameters were taken to be equal: $\rho=2.7 .10^{3}$ $\mathrm{kg} / \mathrm{m}^{3}$, Young's modulus $E=6.5 .10^{4} \mathrm{MPa}$. The characteristic parameters in calculations were selected as: $\sigma_{*}=10 \mathrm{MPa}, I_{\star}=10 \mathrm{~m}$, $t_{\star}=2$ years. For particular estimations the main attention will be given to the variant with numerical values of parameters characteristic for majority of rock massifs at further discussion: $Q=35$ and $v=10^{-6} \mathrm{~cm} / \mathrm{sec}$.

The results of calculations are presented at Fig.5.7-5.10. At Fig.5.7 the dependencies of local stresses and additional stresses at heterogeneities versus time in the gallery wall at its horizontal diameter are given. As it is seen from figure the difference between curves at the excavation stage $(t<1)$ is not essential. The noticeable differences are observed at the stage of stresses relaxation $(t>1)$. Let's note as well nonmonotonous behavior of those dependencies at the initial stage of excavation conditioned by redistribution of total compressing stresses. After the moment when the excavation reaches the given horizon the total normal stresses at the gallery wall fall down to the zero, that is why the values $\sigma_{x}^{\prime}$ and $\Delta \sigma_{x}$ appear to be close. As it is seen from given curves the local tensile stresses near to gallery walls can reach the dangerous values $15-20 \mathrm{MPa}$ for heterogeneities compared in dimensions to the gallery scale. For heterogeneities of smaller scale $l=0.01$ those stresses appear to be considerably less (up to two times) and quickly relax: they are close to zero for $t=2$.

The question about the value of such stresses zones in the near-contour massif is important. The analysis of possible destructions of a massif around the gallery in near-contour 
zone is of practical interest. The corresponding diagrams are presented at Fig.5.8-5.10 illustrating the local stresses distributions at massif heterogeneities. All diagrams are made for principal local stresses.

The isolines of maximal principal stresses $\left(\sigma_{1}^{\prime}>\sigma_{2}^{\prime}\right)$ in the gallery vicinity are presented at the diagram Fig.5.8-5.9 for distinct moments of time from $t=0.1$ to $t=5$ and two dimensions of heterogeneities $l=0.1$ and $l=1$. Two zones can be singled out at those figures. First one - the zone in which tensile stresses exist is limited by the isoline (0). The second one the zone where the tensile stresses exceed corresponding strength limit $\sigma_{T}$. If the compression strength of those rocks is equal to $110-150 \mathrm{MPa}$ then it is possible to believe that $\sigma_{T}$ doesn't exceed $15 \mathrm{MPa}$ which corresponds to $\sigma_{T}=1.5$ in adopted normalized values of stresses.

The diagrams enable to present obviously the picture of the indicated zones appearance, their growth and disappearance as far as the excavation works proceed. For large heterogeneities $1=1$ compared in dimension to the gallery radius (Fig.5.9) the second domain appears in the gallery upper part $\left(\varphi \approx 45^{\circ}\right)$ and gradually embraces whole near-contour zone. The domain attains the maximum dimensions (from 0.1 to 0.25 of gallery radius $\mathrm{R}$ ) to the moment of excavation termination.

The dimensions of the first zone - the zone of the tensile stresses appearance $\left(\sigma_{1}^{l}>0\right)$ are from 0.25 to 0.8 R. Further for heterogeneities $l=1$ the dimensions of first zone change not considerably: at the moment $t=5 \mathrm{i} . \mathrm{e}$. later for a period 5 times larger than the excavation time (10 years) some decrease of the second zone dimensions is only observed. So the stresses at large heterogeneities are preserved during long time.

For small heterogeneities $l=0.1$ at initial stages the differences in dynamics of arising and in dimensions of indicated zones are not significant. However, already to the moment $t=1$ the noticeable differences are seen. If the first zone dimensions differ to $10-15 \%$ then the second one doesn't embrace whole gallery contour and is observed only in sectors $\varphi=30-60^{\circ}$ and its dimensions don't exceed $0.15 \mathrm{R}$. Further to the moment $t=2$ the second zone practically disappears but to $t=5$ all tensile stresses relax at the heterogeneities of that scale in near-contour zone.

At three-dimensional diagrams Fig.5.10 the same isolines of principal stresses are shown in coordinates $\left(\mathrm{x}, \mathrm{y}, \sigma_{1}^{l}\right)$. The surfaces $\sigma_{1}^{l}(\mathrm{x}, \mathrm{y})$ are shown in the figure plane from the gallery 
roof side at some angle. The zones $\sigma_{1}^{l}>0$ can be easily found with the aid of horizontal section $\sigma_{1}^{\prime}=0$.

For a comparison at diagram Fig.5.11 the isolines of the largest principal stress in near-contour zone are given for elastic solution at moment $t=1$. Let's remind that in this case the picture doesn't change any further. Confronting of received diagrams for stresses at heterogeneities with elastic solution demonstrates the possibility of taking into account with the aid of the model of solid body with dissipative structure the processes of concentration and relaxation of stresses at the massif heterogeneities, the calculated estimation of the zones arising and dimensions defining the safety of mining works and stability of gallery.

In calculations for a simplest case of a rectangle sample deformation (Syrnikov \& Sisov, 1994) it was shown that whereas the total stress at areas parallel to side surface of sample is equal to zero the local stresses at heterogeneities can reach considerable values and provoke the formation of the cracks network of corresponding orientation. Such cracks are observed in laboratory experiments and in massif at destruction of pillars in underground openings.

The similar result in discussed case is got for a vicinity of cylindrical gallery: total stresses in near-contour zone are compressing ones (the radial stresses are equal to zero at the gallery contour) but local stresses at heterogeneities tensile ones to be exceeding the strength characteristics of rocks in a domain considerable with its dimensions.

The estimations of the tensile stresses zones dimensions got as a result of calculations have importance not only to solve a question about necessity and manner of additional support of near-contour zone. They are necessary for the prognosis of massif behavior in those domains at external (dynamic) influence. The parameters necessary for subsequent estimations in that case are the dimensions of corresponding zones and probable dimension of blocks into which the rock massif has been already divided in the excavation period or can be divided as a result of external influence.

Main results are given above for heterogeneities dimensions $1=1$ and 0.1 . According to the model ideas in first case the block dimension is $50-100 \mathrm{~m}$, in the second one - 5-10 $m$. It is seen from those results that it is possible to speak about the probability of such blocks appearance for $l=1$ and $1=0.1$.

The largest interest for practical purposes the heterogeneities of dimension 0.1 and blocks corresponding to them present because just they can appear to be movable as a result of external influence. The period of dangerous stresses 
existence at those heterogeneities (before their essential decrease in a period of relaxation) will be practically defined by the time during which the probability of arising of dynamic phenomena (rockbursts) in the gallery near-contour zone exists. The zone dimensions define the probable volume of the rock throwing off into the gallery and the energy accumulated in the zone during the deformation process - the seismic effect. As it was indicated above the different external influences which are often beyond accounting can serve as a trigger mechanism for this process implementation.

As for large heterogeneities then the stresses concentration at those of them which fall to zone $\sigma_{1}^{l}>0$ (not more than two heterogeneities $l=1$ can appear according to the model ideas in calculation domain of Fig.5.9) can lead either to destruction of medium with forming of a crack of large dimension or when that has not occureed to arising in that zone of stress state for a long time facilitating the displacement of movable blocks of lower hierarchy to the direction of cut out space.

As it was indicated above the decreasing of dangerous effects of stresses concentration can be attained at the expense of selection of proper pace of mining works. The pace of stoping works at deposits is mainly defined by the economical considerations but the temporary stops of works are widely used here in distinct openings and in whole regions of massifs: the possibility of sequential processing of different deposit sites often being remote from each other is envisaged by the mining works plan. At the construction of permanent underground openings such stops or slowing down the pace for providing the massif and underground constructions stability at further exploitation are necessary. The selection of excavation pace has to be carried out in conformity with particular conditions of massif and features of a construction. An example illustration the possibilities of our simulation is given below.

The variant of excavation of cylindrical gallery described above was considered with the same parameters that in basic case $\left(Q=35, \quad v=10^{-6} \mathrm{~cm} / \mathrm{sec}\right)$ but with different pace of excavation: later than $t=0.5$ (excavation termination of upper half of gallery) the excavation is stopped for a period $\Delta t=1$ and since the moment $t=1.5$ to $t=2$ the excavation of lower part of gallery cross section is finished. If to come to the real time scale then at $t_{*}=2$ years the pace of mining works will be looked at as follows: during 1 year the upper part of section is excavated, then after 2-year stopping the rest part is excavated during 1 year. 
The results of that illustrative calculation are presented at Fig.5.12-5.13. The comparison of corresponding diagrams for isolines of principal stresses (Fig.5.8-5.9) to basic variant shows that the differences in dimensions of tensile stresses zones $\sigma_{1}^{l}>0$ and $\sigma_{1}^{l}>\sigma_{T}$ for large heterogeneities are not essential as to the moment of excavation termination as to the moment $t=5$ (10 years later): the decrease of those dimensions in the second variant being compared to first one doesn't exceed 10-15\%.

The changes in dimensions of similar zones for small heterogeneities $1=0.1$ (Fig.5.12) appear to be essential. To the moment of excavation termination $(t=1$ in first variant and $t=2$ in the second one) in second case the zone $\sigma_{1}^{l}>\sigma_{T}$ is absent at all - considerable tensile stresses at heterogeneities have relaxed. The zone $\sigma_{1}^{\prime}>0$ in second variant is 2 times less being compared to first one. To the moment $t=5$ in both variants practically all tensile stresses relax at heterogeneities of that dimension.

In spite of that the calculation results in latter case could be seen at as illustrative ones the particular inferences can be made from received results. First, the possibility to give quantitative estimates of stress state parameters of inhomogeneous near-contour zone is demonstrated at different manners and time regimes of engineering interference into deformation regime of a massif. Second, the application of developed method for selected particular case demonstrates the practical approach to essential decrease of the arising probability of dynamic phenomena of rockburst, rockfall etc. type in near-contour zone i.e. approach to decrease the potential energy reserve accumulated in near-contour zone in the deformation process at excavation.

One of measures for safe carrying out the permanent underground openings in burst dangerous rocks is their excavation in two stages - by initially decreased section, then with widening to the project section.

As the examples discussed above show such manner of excavation provokes the local stresses initial concentration at heterogeneities of smaller scale which have time to relax to safe level to the beginning of the excavation second stage. Besides, the actual dimension of the dangerous zones arising by that is decreased as well which decreases the risk of the dynamic phenomena arising at second stage.

The developed calculation methods enable to analyze for every particular case the technological schemes different with pace and sequence of excavation applied to decrease the risk of rockbursts and to provide the mining works safety. 
The examples of the calculation methods application for particular objects are the calculation estimation of rheological deformations of massif around underground openings of Rogunskata Hydro (Syrnikov \& Syzov, 1994) and the change of the stress-strain state in the foundation of arch dam on Inguri river (Syrnikov \& Osipov, 1994). In the latter case the variable of external loading was defined by the cyclical changes of the storage lake level. In those examples as well as in the problem of the gallery excavation the question is before all about the heterogeneities of comparatively small scale $(1-10 \mathrm{~m})$ and corresponding scale of dynamic phenomena. The analysis of stress state seems to be more complicated at large geological heterogeneities when the discharge of which creates powerful rock tectonic bursts and earthquakes. First, as the calculation given above shows such analysis has to be carried out for particular structural heterogeneity taking into account many external factors; second, the stresses relaxation period at such structures is at least tenths of years and in that case it is possible to speak about the problem of long-term stability of large structural elements of rock massif. 


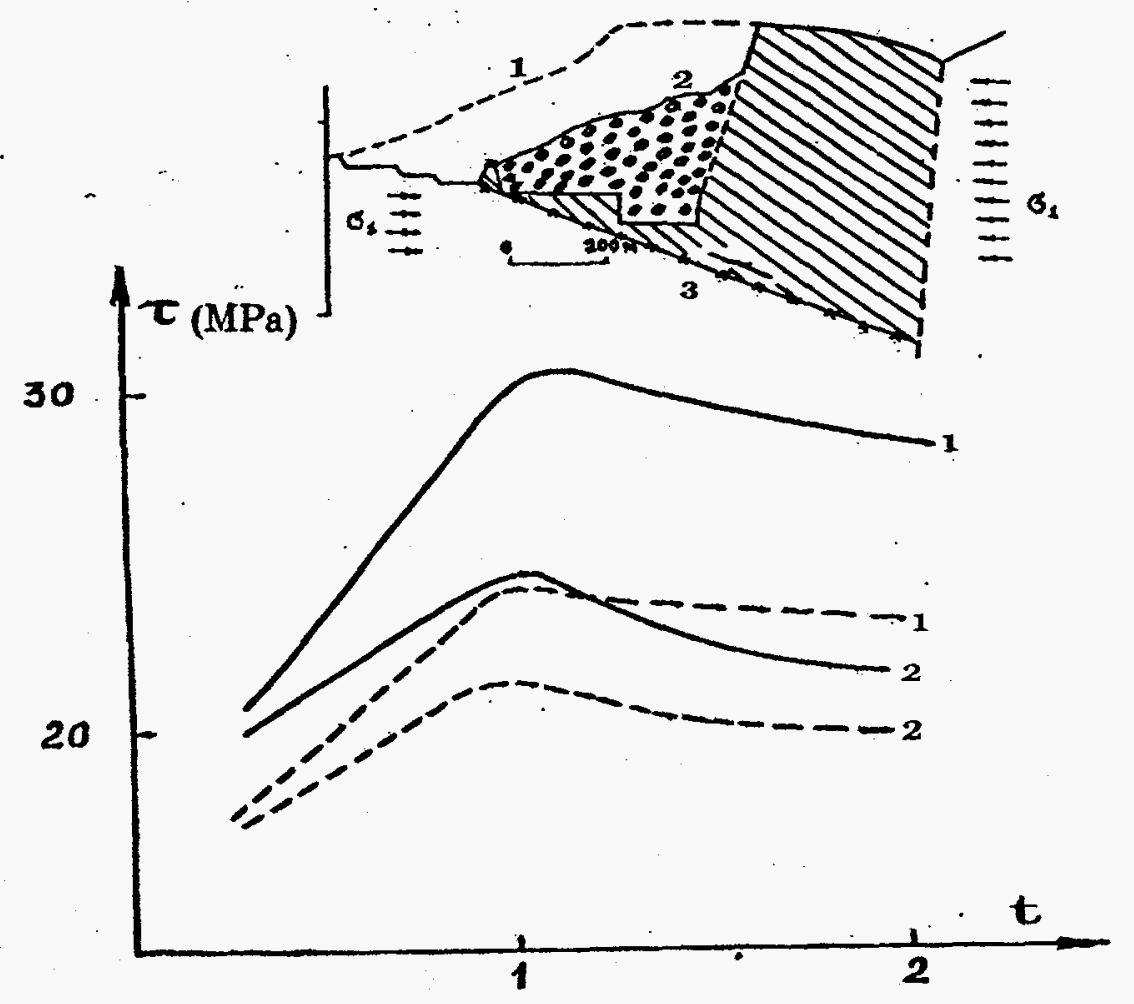

Fig.5.1. The local shear stresses in the fault (solid line) and within the mass (dashed line) versus time, $1-l=1,2-l=0.1(l=100 \mathrm{~m}) ;($ a) - the outline of the shift along the fault during the man-made earthquake on Kola Peninsula, 1 - the relief before the beginning of mining, 2 - the modern relief and destroyed rocks, 3 - the fault.

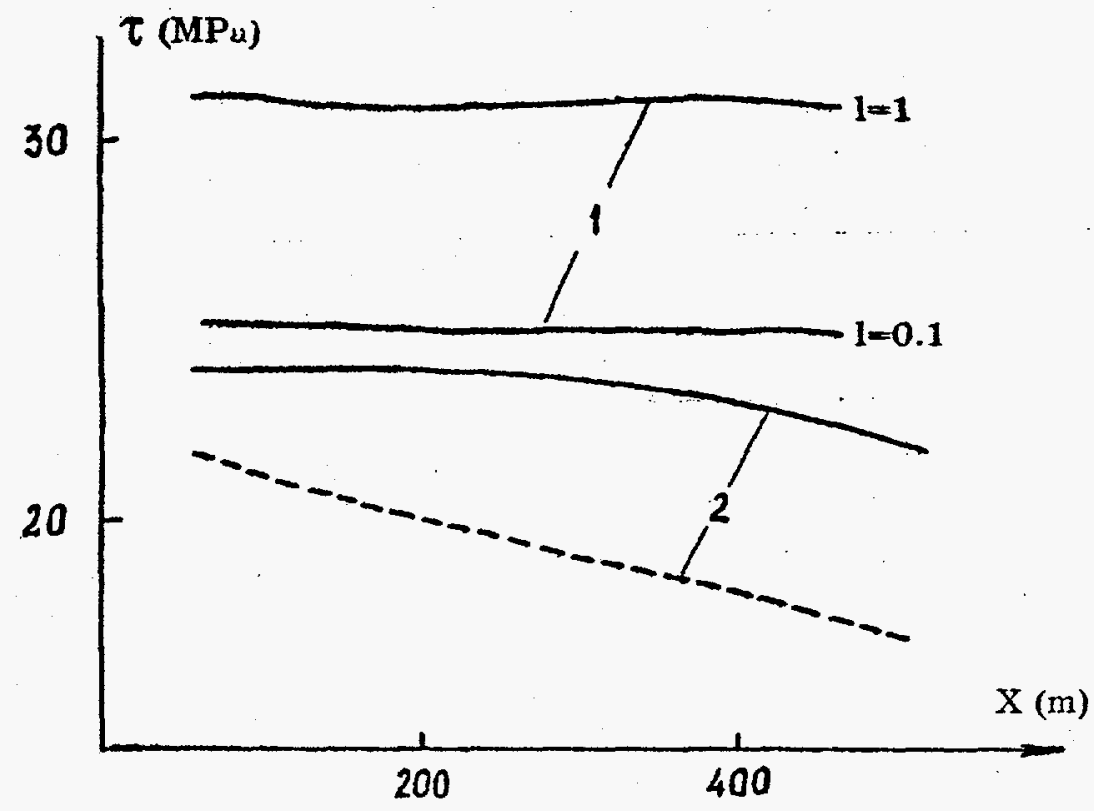

Fig.5.2. The shear stresses on the fault plane: 1 - calculated local shear stresses $(t=1), 2$ elastic shear stresses (Syrnikov \& Tryapitsin, 1990), dashed line - for the relief before the beginning of mining, solid line - for the modern relief (at the time of earthquake). 


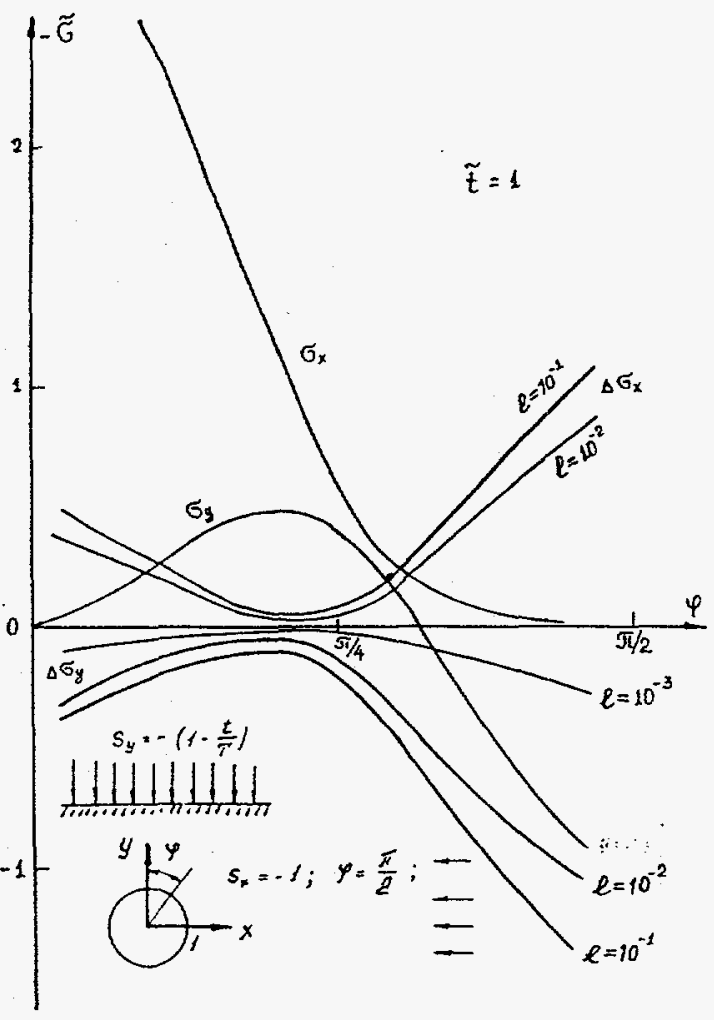

Fig.5.3. Stresses at the gallery contour $(t=1)$.

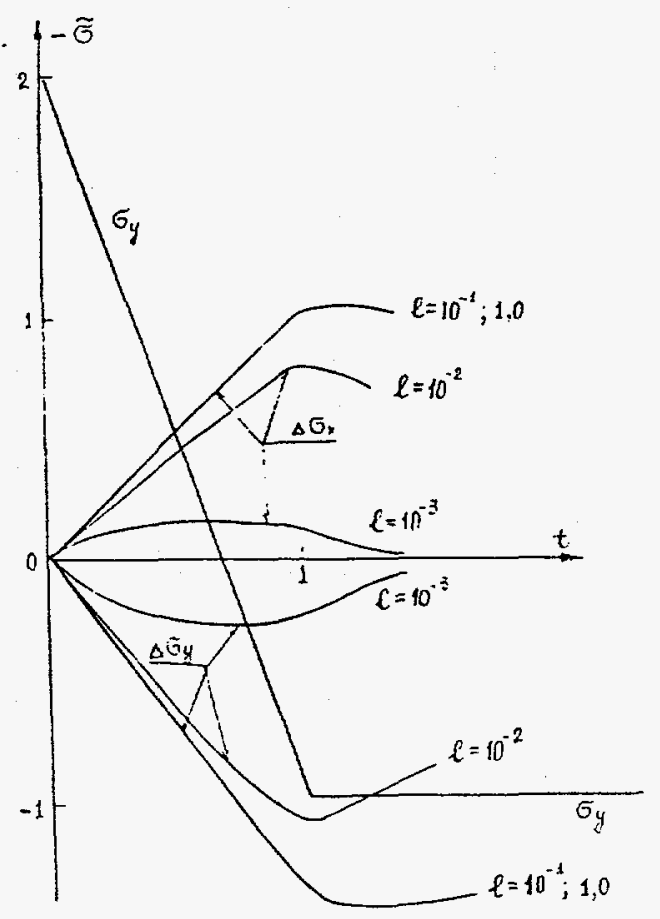

Fig.5.4. Additional stresses at the gallery wall $(\varphi=\pi / 2)$ versus time. 
a)

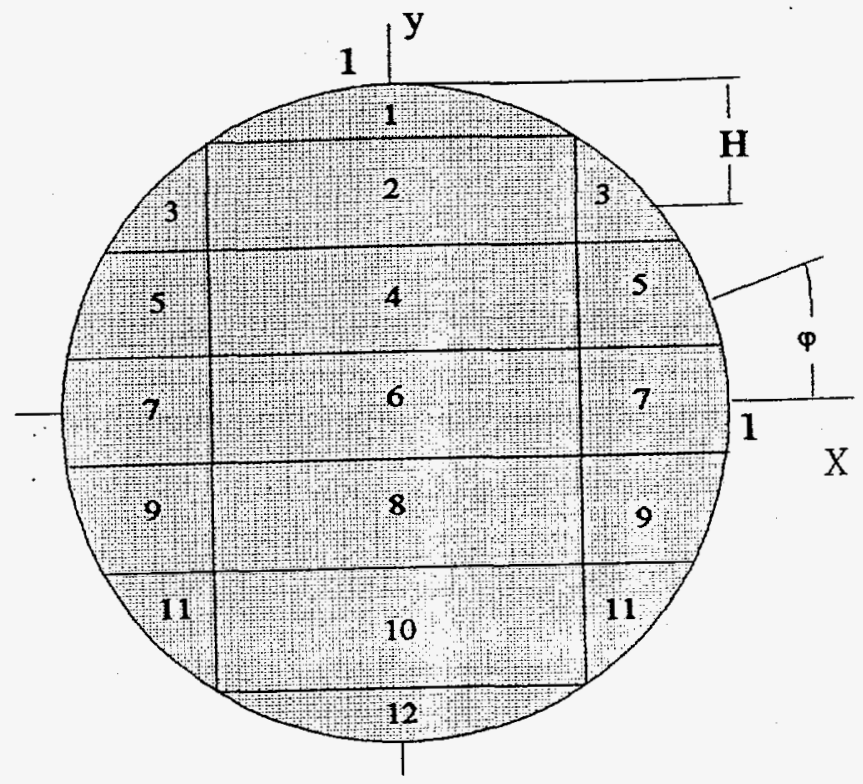

Fig. 5.5. Sheme of calculation domain of gallery excavation problem

( variant (a) - regular downward excavation)

b)

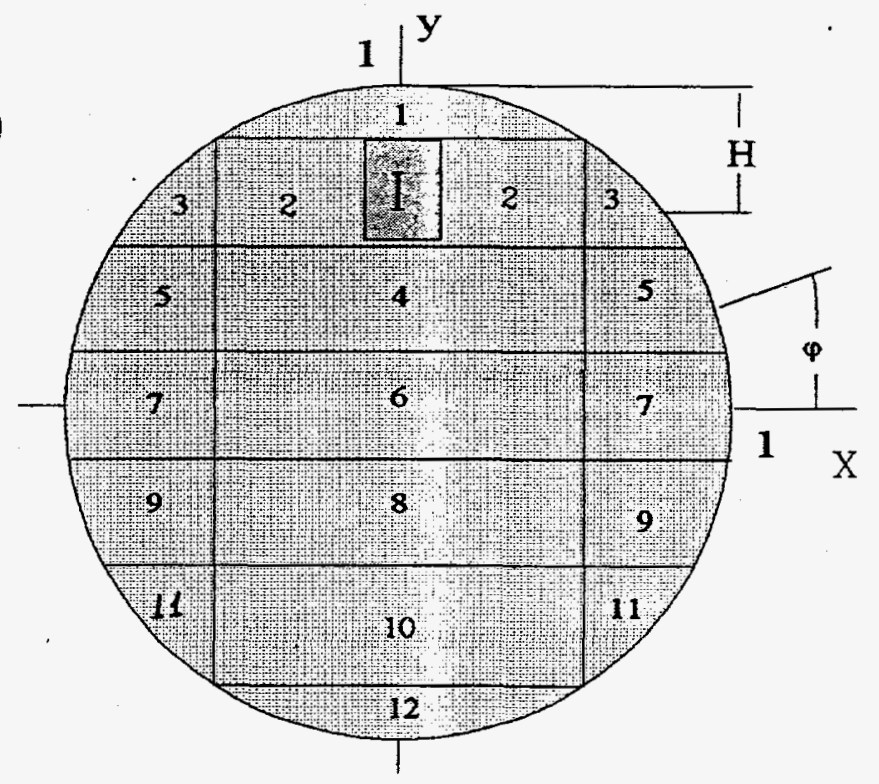

Fig. 5.6. Sheme of calculation domain of gallery excavation problem

(variant (b) - excavation from intermediate horizon I) 


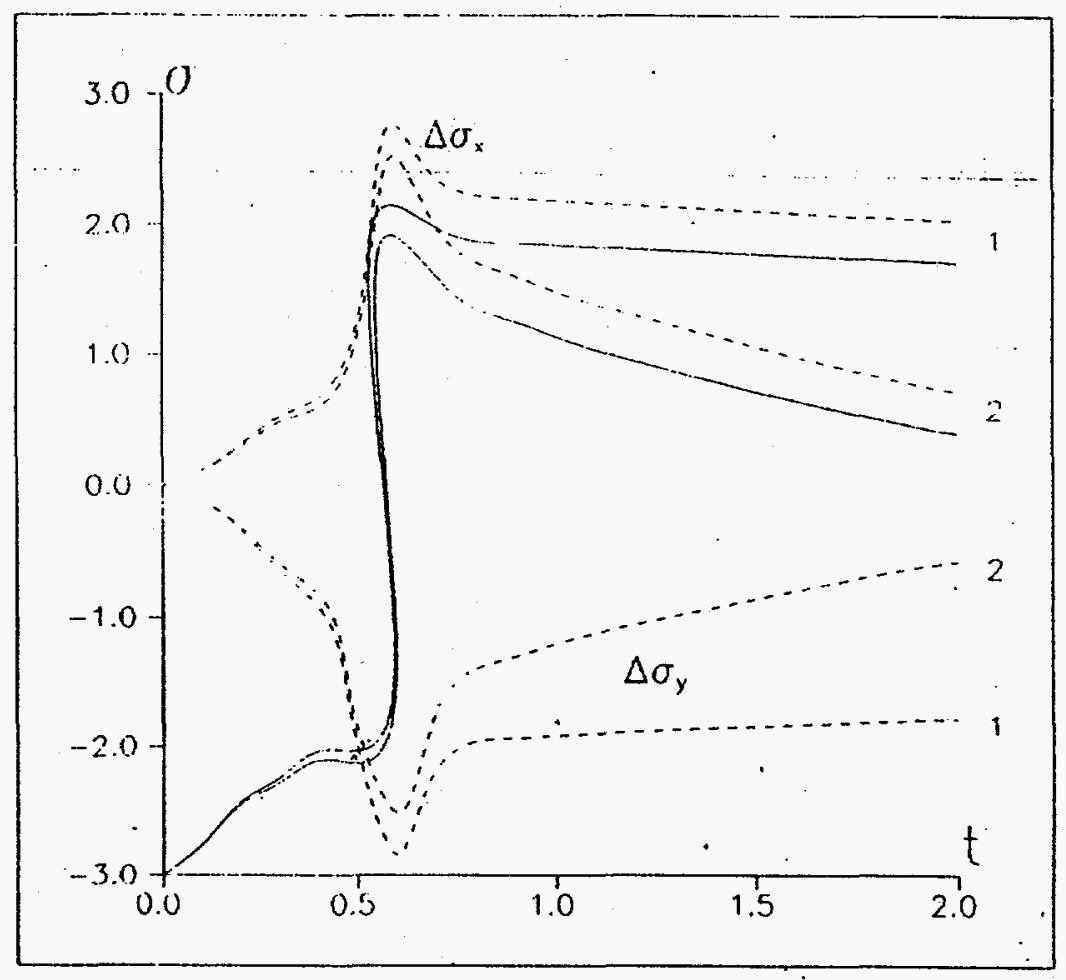

Fig.5.7. The local stresses $\sigma_{x}^{l}$ (solid line) and the additional stresses $\Delta \sigma_{x}, \Delta \sigma_{y}$ (dashed line) versus time, $1-l=1,2-l=0.1$ 


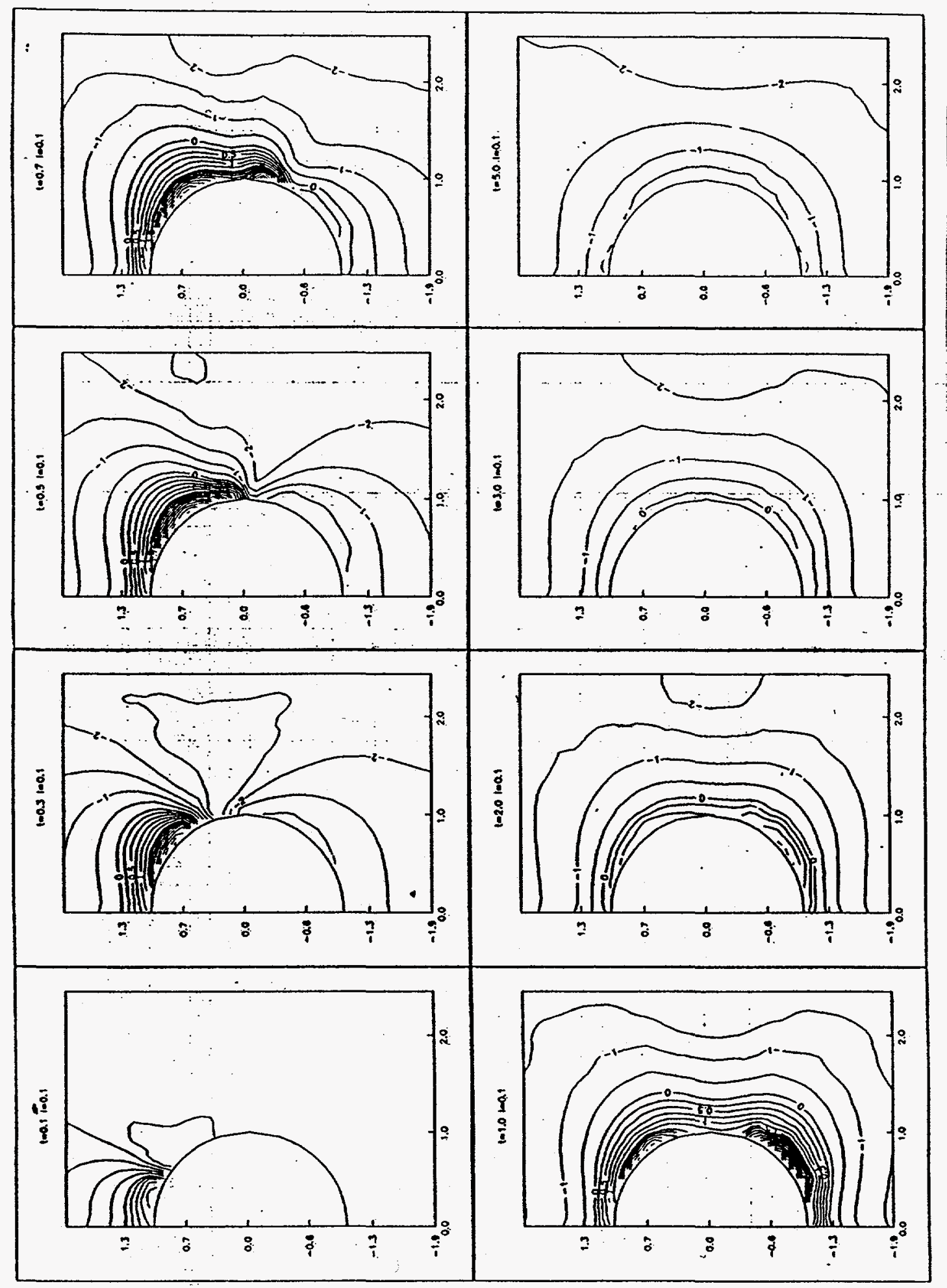

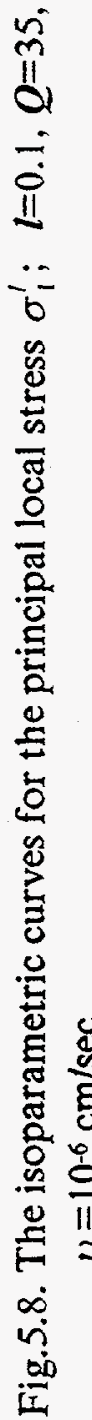



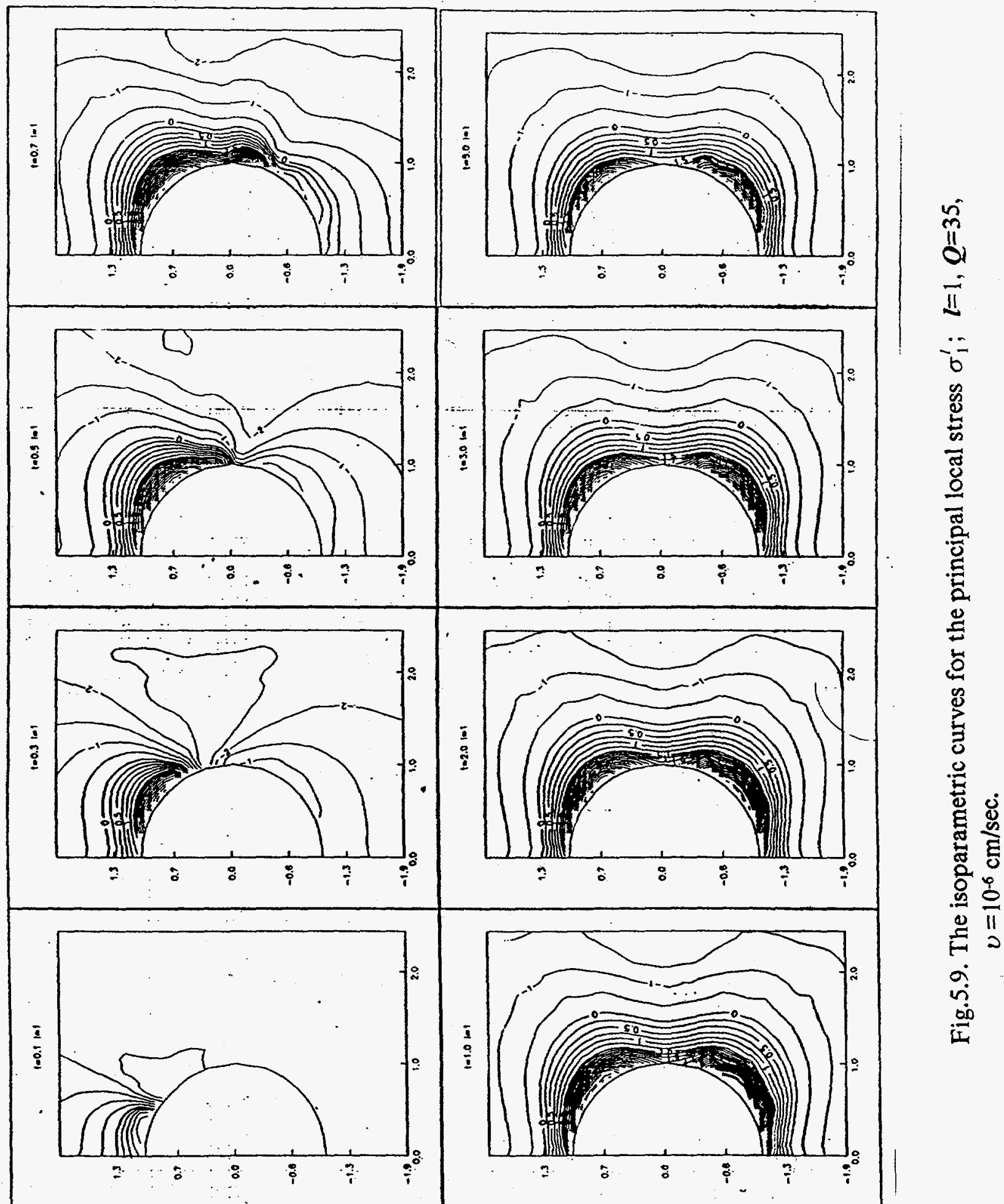


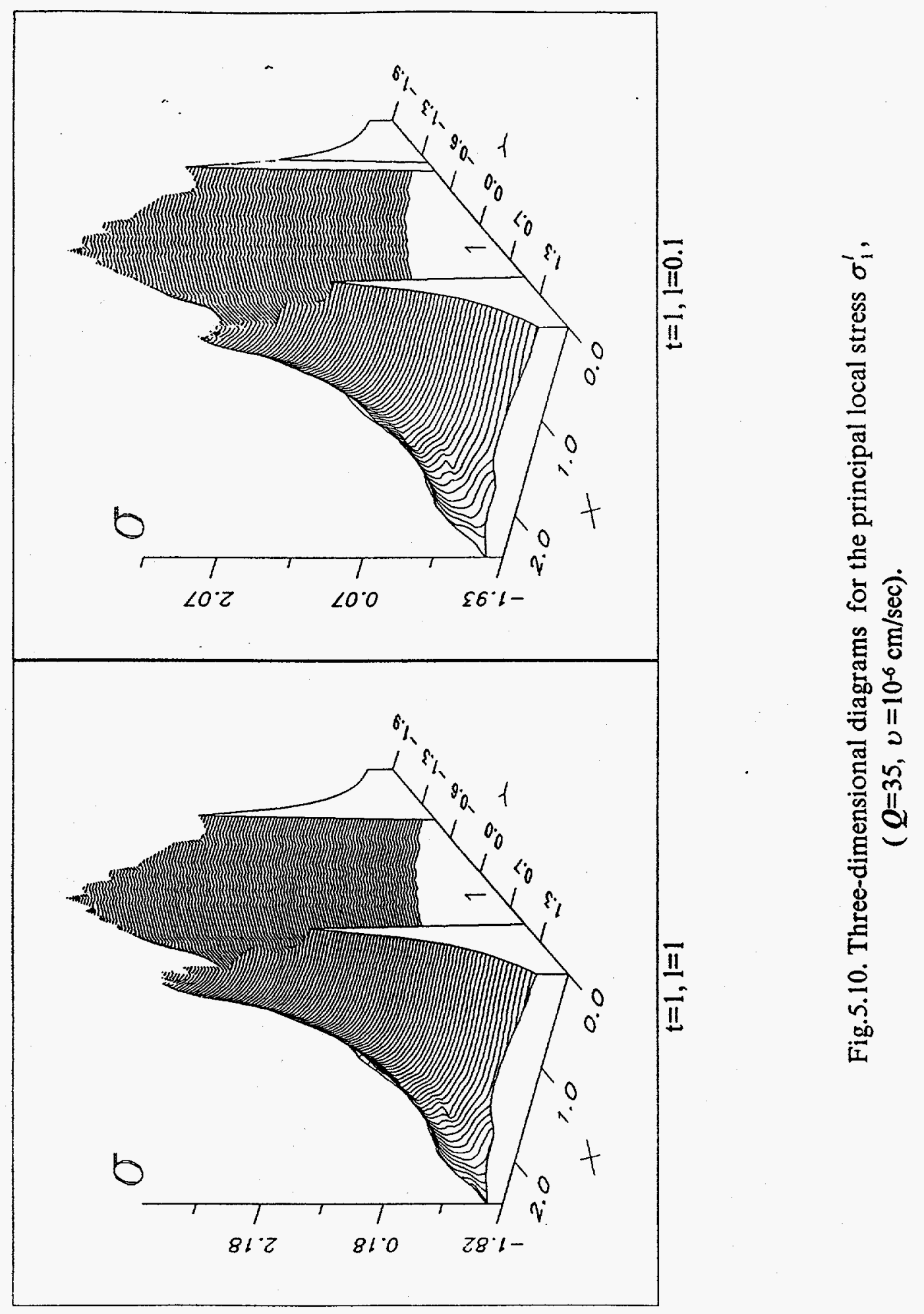




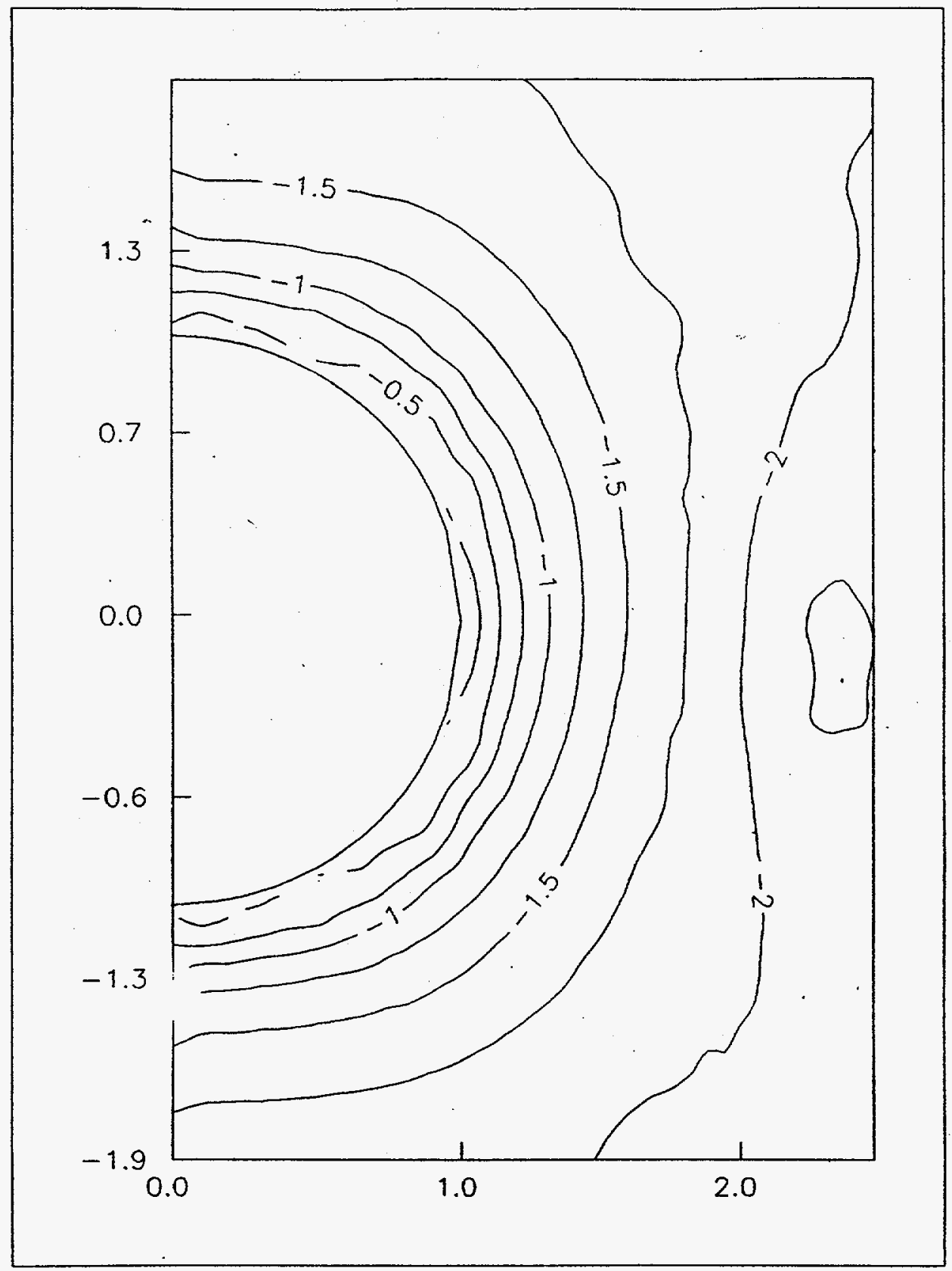

Fig.5.11. The isolines of principal stress $\sigma_{1}$ (elastic solution), $\mathrm{t}=1$. 


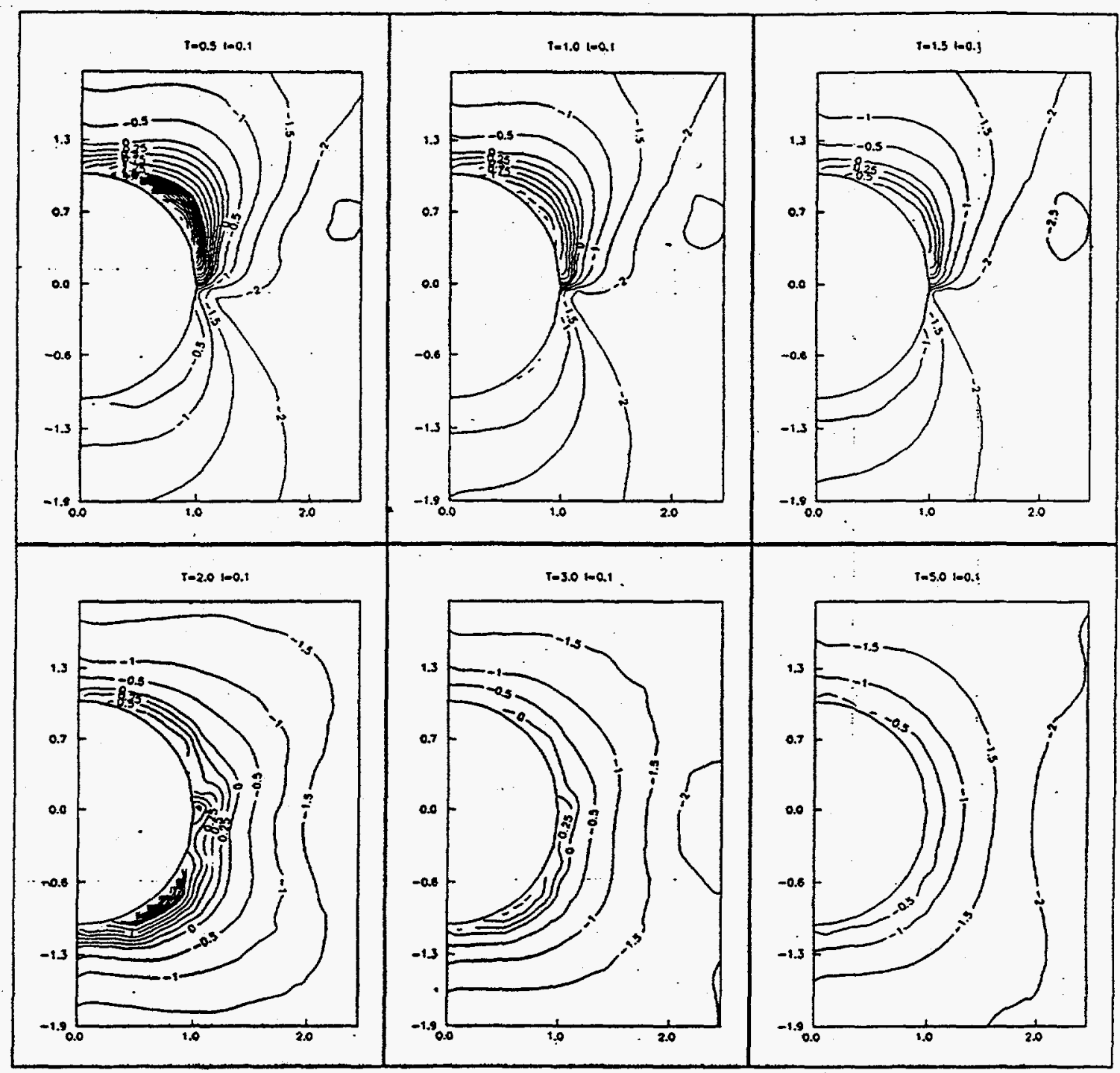

Fig.5.12. The isoparametric curves for the principal local stress $\sigma_{1}^{l} ; l=0.1, Q=35$, $v=10^{-6} \mathrm{~cm} / \mathrm{sec}$, (variant with the stopping of excavation). 


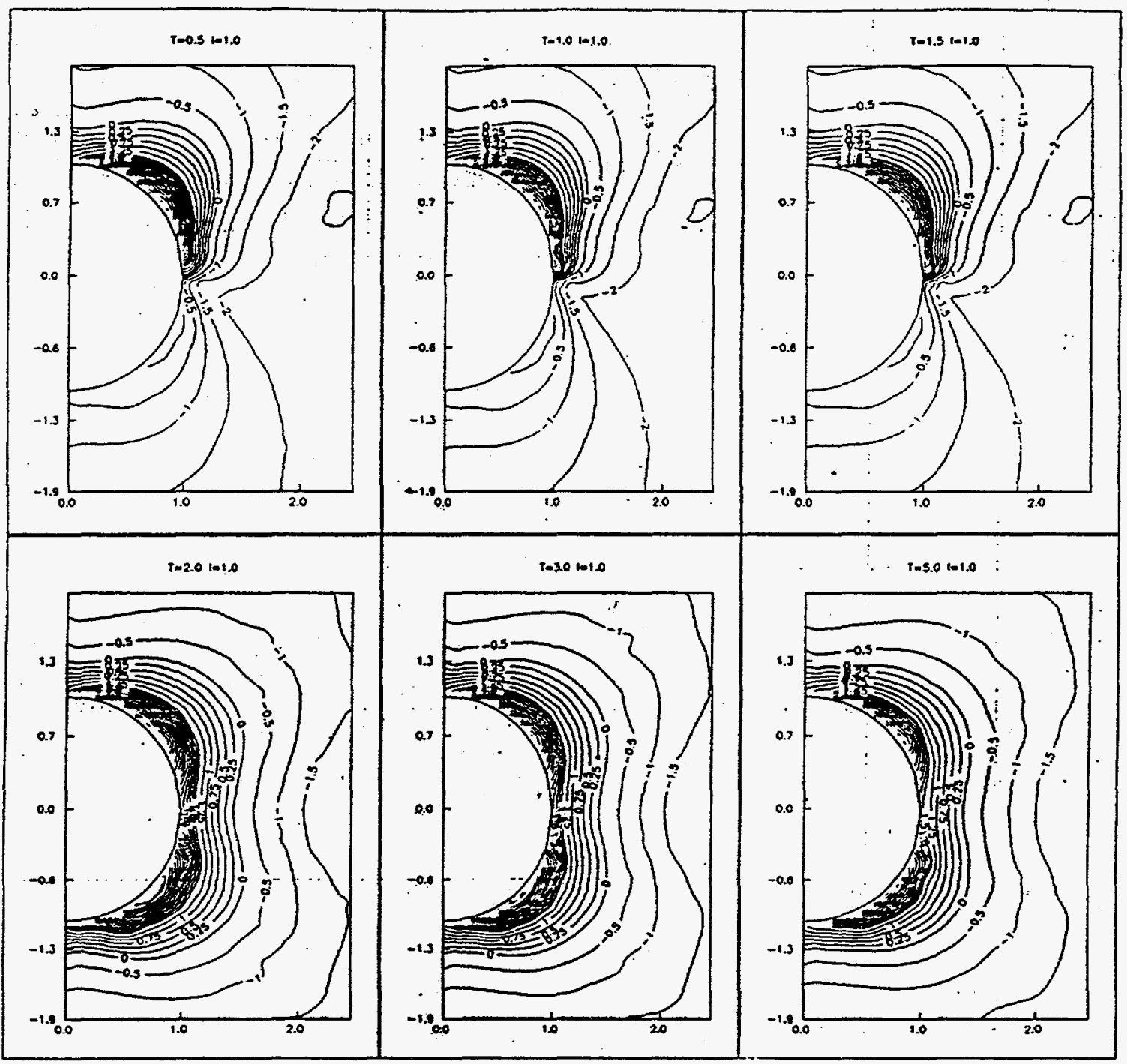

Fig.5.13. The isoparametric curves for the principal local stress $\sigma_{1}^{l} ; l=1, Q=35$, $v=10^{-6} \mathrm{~cm} / \mathrm{sec}$ (variant with the stopping of excavation). 


\section{NEW IDEAS IN DESTRUCTION MECHANICS.}

The ideas development of destruction mechanics conformably to the geomechanics problems leads naturally to the discussion of data about step-wise deformation development beyond the conditional elasticity limit. First time such idea about such solid state behavior was introduced in (Nikiforovskij \& Shemyakin, 1979) although the series of studies in destruction mechanics (Slepyan \& Troyankina,1976; Nikitin,1987) and some new experimental data about arising and development of block structure in an initially homogeneous and isotropic medium (Revushenko \& Shemyakin, 1977) confirm such clause as well.

The essential fact to which new notions lean - a proposal known in destruction mechanics - introduction into a mathematical model of some critical dimension connected either to the irreversible deformations zone dimensions (Dugdal, 1960; Shemyakin, 1974) or to the value of sliding along the probable destruction plane (Revushenko \& Shemyakin, 1977) or to bringing of material points apart to some distance which is just called the destruction. An example of such description is simple case of anti-plane deformation as well as applied problems of mining (Shemyakin,1974) although the principal role was plaid by the experimental data about development of irreversible shear deformations and dilatance in the new notions development.

According to those notions the coming from elastic (reversible) to irreversible (residual) deformations by which the plasticity, creeping deformations are called in the mechanics of solid deformable body is characterized at the expense of stresses relaxation by appearance of slidings along definite planes (which are most often close to the surfaces of maximal tangential stresses) and by manifestations of volume deformations (dilatancy) connected to main shears. At test machines with particular sample dimensions those slidings are characterized by a dimension (a value measured in length units) and the mechanicists paid attention to that circumstance (Palmer \& Rice, 1973).

Just the appearance of sliding itself ( and consequently of a dimension) along definite planes beyond the elasticity limit enables to call the irreversible deformations domain as the domain of predestruction although neither the "destruction" domain dimensions nor the time of its occurring remain unclear (the time in usual sense as the time of withstanding of definite loading to a sample or the time of supporting of definite deformation). The answers to those questions are the more important because the sample size and time of test influence is manifested in all known experiments with samples 
of solid bodies and rocks for destruction (stavrogin \& Protosenya, 1979; Chircov, 1976).

That point of view to the irreversible deformations development at the expense of the sliding at a sliding plane, their systems and the systems close to the main shear surfaces doesn't contradict to the facts from the solid state physics according to which the elasticity feature is defined by a deformations of crystal lattice or of crystal group included into the body and the feature to acquire residual deformations - by the sliding presence between those crystals or along surfaces inside crystals (Nadai,1963). Certainly that physical picture is justified not for all solid bodies but its suitability to describe deformation and destruction of rocks doesn't provoke any doubts. The development of sliding surfaces themselves in the domain of irreversible deformations and especially the time factors influence presents an interest from the point of view of physical-chemical features of arising surfaces (arising of sliding surface, change of surface energy, healing after un- loading and aging) - those questions remain. But one is without a question - the development of domains with irreversible deformations is the surface effect even if those surfaces fill studied domain with definite distance between them (size).

The ideas about the connection of sliding mechanism along areas of main shear with conversion from elasticity to "plasticity" and from "plasticity" to destruction should be complemented by the dilatancy effect in order to describe the destruction process with tearing off but not only at the expense of shear.

Generally speaking the dilatancy phenomenon (positive or negative onel always is accompanied by shear including real sliding. It is possible to think only that small slidings along sliding areas in the irreversible deformations domain lead to small (weak) manifestation of accompanying changes of volume but considerable slidings in destruction domain lead to essential changes of volume especially of that sum of normal deformations which is connected to the normal to the sliding area. That change of normal deformations just describes the destruction by tearing off.

Besides at the spatial situations analysis it is necessary to introduce the Lode-Nadai parameter i.e. to take into account the kind of stress state or joint participation of sliding areas of different families in the spatial deforming and destructing situation of rocks (Nadai,1963).

Thus as the domain of irreversible deformations (plasticity, creeping) as the domain of unhardening (destruction, dividing of a body into parts) are described within framework of the same model in which there are only two 
features:elastic deformation and sliding. In the hardening domain the irreversible deformations (at the expense of sliding) don't lead to dividing of a body into parts - that is only predestruction - and unloading is elastic and in the unhardening domain a body is divided into parts at the expense of large slidings which (parts) can be divided elastically - a new material arises composed of distinct parts, blocks; the new material behavior description requires to introduce into model the features of aroused surfaces (friction, surface energy, healing).

General diagram "stress-deformation" at the stepwise development of irreversible deformations and destructions has an appearance indicated at Fig.6.1.

It is supposed in the model that:

1) all inclined segments of illustrative diagram $\sigma(\varepsilon)$ or $\tau(\gamma)$ have the same inclination defining the elasticity module (E -at the diagram for a rod);

2) in the end of each segment the strains downkick occurs along a vertical line (at constant deformation);

3) hardening is defined by that the next step is characterized by larger stress than the stress of previous step;

4) unhardening is defined by that the next step is characterized by the smaller stress than the stress of previous step;

5) unloading in the hardening domain begins with elastic module ( $E$ - for a rod).

The unloading at rigid machine is carried out by decrease of attained displacement (deformation), according to that the deformed elements can decrease the absolute values of attained deformations at the expense of accumulated elastic energy if it is not spent for sliding. Certainly there is the same question: whether the accumulated elastic energy can not produce the sliding with reversed sign including one along new sliding areas? There is a variant of evident answer: yes, can if the sliding resistance is larger of such in direct act. The second variant of answer: direct deformation act has changed the sliding resistance in such a way that it has changed in reverse act either. It is possible that the discussion of those questions is useful for an explanation of Baushinger effect in studied model.

Let's consider the illustration of general ideas at the example of diagram "maximal tangential stress - main shear" believing that they take place at one area oriented relatively to main directions by known manner (Fig.6.2). We shall take the Lode parameter to be equal to zero i.e. for the state of pure torsion. 
Let's take the case of plane deformation. The square with the side $L$ ) and the cub with dimension $L$ across drawing is converted into a rhombus then is divided by the line (surface) of sliding (Fig.6.3). After attaining of limiting shear $\gamma=\gamma_{e}$ the conversion to irreversible deformations occurs (plasticity), the sliding occurs.Being different to free destruction not whole energy but only its part is spent to sliding.

At unloading from $\tau_{\max }$ to $\tau_{\text {res }}$ the elastic energy is excreted in the volume $\mathrm{L}^{3}$

$$
\frac{1}{2 \mu}\left(\tau_{\max }^{2}-\tau_{r e s}^{2}\right) L^{3}
$$

which is spent to sliding

$$
\delta=\frac{\tau_{\max }-\tau_{\text {res }}}{\mu} L
$$

for which the work is spent

$$
\frac{\tau_{\max }-\tau_{r e s}}{\mu} L\left(\tau^{\bullet} L^{2}\right)
$$

The work in (6.3) is calculated as the average value of integral from 0 to $\delta$ with variable possibly resistance $\tau$ * (Revushenko \& Shemyakin, 1977) which is defined from comparison of $(6.1)$ and $(6.3)$ as an average

$$
\tau^{*}=\frac{1}{2}\left(\tau_{\max }+\tau_{\text {res }}\right)
$$

Strictly speaking it is necessary to introduce into model the function of resistance to sliding $\tau^{*}\left(\delta^{*}\right)$ where $\tau^{*}, \delta^{*}$ variables. So that the introduced $\tau^{*}, \delta^{*}$ - some average values in the interval of change. The surface energy can be interpreted as the work of those forces: at hardening this energy is smaller than the accumulated elastic energy but at the conversion to unhardening this energy they are equal. In a case of ideal plasticity the whole work brought in from outside is spent to sliding along sliding surfaces with constant $\tau^{*}=\tau_{s}$. 
The defined in such manner $\delta$ - sliding can be the suummary one for several sliding surfaces $\mathrm{n}: \delta=n \delta^{*}$ where $\delta^{*}$ - the elementary sliding in $\mathrm{mm}$ tolerated by the material and characterizing the coming to irreversible deformations at given stress state. As far as all the rest values reflect the material constants and process parameters $\tau_{\max } \mu, \tau_{\text {res }}$ then from here the critical size of a sample is defined with one siding surface

$$
\delta^{*}=\frac{1}{\mu}\left(\tau_{\max }-\tau_{r e s}\right) \frac{L}{n}=\frac{\tau_{\max }-\tau_{r e s}}{\mu} L^{*}
$$

or

$$
L^{*}=\frac{\mu \delta^{*}}{\tau_{\max }-\tau_{r e s}},\left(L^{*}=\frac{L}{n}\right)
$$

Strictly speaking only the ratio $\delta^{*} / L^{*}$ is defined for given boundary conditions. Or at fixed size $L^{*}$ for which there is the only sliding surface the connection of $\delta$ to $\tau_{\text {res }}$ is defined;as far as $\tau_{\text {res }}$ is found from experiment then the opportunity appears to calculate $\delta^{*}$ and to get the estimation of dependance of $\delta^{*}$ upon the loading conditions.

So possible dependance of $\tau_{\text {res }}$ or $\delta^{*}$ upon normal stress (Fig.6.3) is of great interest as well as the possibility to construct a diagram $\left(\tau / \sigma_{n}, \gamma\right)$ which is necessary to estimate the dilatancy. That circumstance can be evaluated if other values of $\tau_{s}$ are considered at the tests. Further according to general ideas about the model we shall believe that the value $\sigma_{n}$ at the sliding area at the segment of hardening doesn't male an essential influence to the deformations development at the expense of sliding $\left(\delta^{*}\right.$ doesn't depend upon $\left.\sigma_{n}\right)$; the dilatancy is not manifested either. (It is possible that this is not so in the range of large deformation velocities and the influence of will be already essential as well as the dilatancy manifestation). That enables to develop the model without any contradictions at the hardening segment taking $\tau_{\text {res }}$ and $\delta^{\bullet}$ as the "constants" of a material although only linear hardening (Prandtl model) evidently can be described in such manner - see Fig.6.1.

The relation (6.5) remains the basic one 


$$
\frac{\delta^{\bullet}}{L^{\bullet}}=\frac{\tau_{\max }-\tau_{r e s}}{\mu}
$$

from which in particular follows that the diagram inclination in the hardening domain is connected to $\tau_{\text {res }}$ (at fixed $\left.\delta^{*} / L^{*}\right)$ and changes at definite $\tau_{\text {res }}$ with a change of $L^{*}$ at fixed $\delta^{*}$. That doesn't contradict to known facts about that the dividing of aroused segments between the sliding lines by additional sliding lines occurs in the hardening domain (decrease of $L^{\star}$ ).

From (6.5) it follows that the value $\delta / L^{*}$ is the value of order of $\gamma_{e}$ (or less) i.e. for a distance between aroused sliding lines (Luders-Chernov lines) about out $1 \mathrm{~cm}$ the sliding value $\delta^{*}$ has an amount $1 \cdot 10^{-3} \mathrm{~cm}$.

The diagram development with sliding area can be presented in natural manner as repeating of sliding at Fig.6.2. By that the work brought in from outside is entirely spent for sliding in a form of sequential jumps and of the elastic energy accumulated in an elementary volume $\tau_{\text {res }}^{2} / 2 \mu$. Actually that residual elastic energy is just possible source of dynamic manifestations (in this statement), large value of $\tau_{\text {res }}$ follows from here.

From methodical point of view the values of $\tau_{\text {res }}$ discovery at the experiment as it was stated above and the work measurement spent for sliding in experiments with discovered area are very important to estimate dynamic phenomena. At the processing of experimental data received at "rigid" machine (6.4) and (6.5) preserve the force by that due to the values $\tau_{\max }$ and $\tau_{\text {res }}$ being close it is possible to take the stress at the sliding area to be equal to $(6.4)$. It is important to underline that $\tau_{\max }$ and $\tau_{\text {res }}$ are practically the same at each step.

Let's consider the local hardening module estimate with simplest suppositions: $\delta^{*}, L^{*}$ are constant. Let at $\mathrm{n}$-th step

$$
\tau_{\max }^{(n)}>\tau_{o}^{(n)}
$$

which means the hardening according to the definition

$$
\tau_{\max }^{(n)}=\tau_{o}^{(n+1)}
$$


Let's calculate $\tau_{\max }^{(n)}$ with those suppositions for which let's set the difference

$$
\Delta \tau^{(n)}=\tau_{r e s}^{(n)}-\tau_{r e s}^{(n-1)}>0
$$

This value $\Delta \tau^{(n)}$ defines the stress at $n$-th step of hardening (compare to ideal plasticity, $\Delta \tau^{(n)}=0$ ) because the hardening deformation $-\Delta \tau^{(n)} / \mu$ and the increment of elastic energy -

$$
\frac{\Delta \tau^{(n)}}{2}
$$

Then the hardening module can be calculated

$$
\frac{\mu_{p}}{\mu}=\frac{\tau_{r s}^{(n)}-\tau_{0}^{(n)}}{\tau_{\max }^{(n)}-\tau_{0}^{(n)}}, \quad\left(\mu_{p}=\frac{\Delta \tau}{\Delta \gamma}\right)
$$

at $n$-th step of hardening. The range of change $\mu_{p}$, where $0<\mu_{p}<\mu$ is evident as well as the ways of calculation of module at the expense of possible changes of $\delta^{*}$ and especially of $L^{*}$ (the latter is important as it was noted above if in the domain of hardening the additional splintering of the sliding lines mesh occurs).

At the transition to the load-deflection curves the same phenomenon occurs that is laid in the basis of free destruction of solid bodies. If the elastic energy was accumulated then at the unhardening the accumulated energy and brought in energy are spent for sliding along already present sliding surfaces and for dividing of a body into parts.

It is possible to believe that at the hardening the surface energy increase is not sufficient from the point of view of dividing a body into parts and the transition to destruction (unhardening) is defined by that the sufficient amount of elastic energy is accumulated to form destruction surfaces as it was defined for free destruction.

Perhaps the function $\tau^{*}\left(\delta^{*}\right)$ describes not only the resistance to sliding along sliding surfaces in hardening domain but as well the surface energy (the work of forces $\tau^{*}$ at slidings $\delta^{*}$, which appears explicitly at the transition to load-deflection curves (unhardening domain) as the energy spent to forming of new domains. How much of such surfaces arises and 
what is the elementary size of $I^{\star}$ the elastic energy of a sample accumulated to the transition time should define. That is the essential difference between unhardening and hardening.

The deformation localization surfaces manifestation which are as a rule close to the main shear surfaces (taking into account the friction and the dilatancy), dividing of a body into parts enables to think that for unhardening.for loaddeflection curves the expenses for creation of new surfaces, their implementation are basic ones.Although certainly the process of elastic deformation can continue in dividing parts with sliding along sliding surfaces (without dividing of a body into parts along those surfaces). As a whole the loaddeflection curves presents already a new material, new medium with features different to the initial one.

From that point of view the diagrams $\tau(\gamma)$ or $\sigma(\varepsilon)$ beyond the limits of critical deformation marking the transition to load-deflection curves are not representative for initial material. That is manifested in first turn by that the drop of stresses depends in this domain upon the initial sample size i.e. upon the deformation conditions (loading conditions) at such and such installation. The more important to understand the general basics of the deformation and destruction preparation mechanism.

Let's consider the elementary act of deformation with sliding at the segment of unhardening (load-deflection curves). The most important external feature compared to the hardening segment is $\tau_{r e s}>\tau_{0}$. The essence is hiding behind that fact: if not the whole energy was spent for irreversible deformation at the hardening segment and its part was accumulated then at the unhardening segment not only the work brought in from outside but the part of elastic energy are spent as well. It is necessary to borrow the energy from previous step to provide the sliding of needed value. The basic relation (6.5) preserves its force if to exchange $\tau_{\text {res }}$ for $\tau_{0}$ in it, that is related to (6.4) as well. The relation between $\tau_{\text {res }}$ and $\tau_{0}$ influences the hardening module $\mu_{p}$ and the unhardening module. Let's rewrite (6.5) for the unhardening segment

$$
\frac{\delta^{\bullet}}{L^{\bullet}}=\frac{\tau_{\max }-\tau_{o}}{\mu}
$$

where we think the values $\delta^{*}, L^{*}$ and $\mu$ to be the same as for the hardening segment. Let's consider the transition from 
$(m-1)$-th to m-th step in that domain $-\tau_{\max }^{(n)}>\tau_{r e s}^{(n)}$ - and introduce an increment (negative)

$$
\Delta \tau^{(m)}=\tau_{\max }^{(m)}-\tau_{\max }^{(m-1)}=\tau_{o}^{(m)}-\tau_{o}^{(m-1)}=\tau_{r e s}^{(m-1)}-\tau_{o}^{(m-1)}
$$

which enables to estimate the unhardening module with those suppositions:

$$
\frac{\mu_{p}}{\mu}=\frac{\Delta \tau^{(m)}}{\tau_{\max }^{(m)}-\tau_{o}^{(m)}}
$$

According to the definition of $\Delta \tau^{(m)}, \mu$ should be considered as "negative" value or the sign in the formula for should be introduced. The change of $\mu_{p}$ together with $\Delta \tau^{(m)}$ is evident: at $\Delta \tau^{(m)}=0$ the segment with the ideal plasticity area is described and at the sign change it is necessary to come to hardening.

Actually the setting of $\Delta \tau^{(m)}$ defines the module and vice verse from the module definition $\mu_{p}$ in experiments it is possible to estimate $\Delta \tau^{(m)}$ at each segment of unhardening. Indeed more precisely the data processing procedure is such:in the beginning for a given segment $\Delta \tau^{(m)}$ and $\mu_{p} / \mu$ are calculated which permits to define $\tau_{\max }^{(m)}$ according to the formula

$$
\tau_{\max }^{(m)}=\tau_{o}^{(m)}-\frac{\Delta \tau}{\mu_{p} / \mu}
$$

or to estimate relative sliding according to measured data

$$
\frac{\delta^{\bullet}}{L^{\bullet}}=\frac{\Delta \tau}{\mu_{p}}
$$

Certainly the question about values $\delta^{*}$ and $L^{*}$ as distinct ones remains so far to be open; the more important that the real destruction (dividing a body into parts) can occur at the unhardening segment at the expense of the deformations localization development. That is why it is important to carry out measurements in experiments at samples of different size $L$ and to compare those measurements between each other.

To conclude the chapter let's indicate one variant more which differs from free destruction and is connected to the 
elastic "recoil". It can be explained in such way at the elementary act: after attaining of limiting shear (that can be the transition to load-deflection curves as well) occurs as the sliding at the expense of accumulated elastic energy but less one than value as the unloading which releases the energy more than it is necessary for sliding (see hatched domain).

Remained share of energy can be excreted in a form of kinetic energy of elements sliding along each other or being divided (Stavrogin \& Protosenya, 1979). That energy is convenient to be expressed in a form of the energy share in total energy released at unloading

$$
\frac{1}{2 \mu}\left(\tau_{\max }^{2}-\tau_{\text {res }}^{2}\right) L^{2} \cdot 1 \cdot k
$$

where the introduced coefficient $k$ defines the energy share converted into kinetic one: at $k=0$ only sliding occurs, at $\mathrm{k}=1$ the elastic energy can be transformed into kinetic energy of parts formed after destruction.

In that case it is possible to consider the model of radiation of transverse waves from the source which the dividing parts are but that problem as well as the taking into account the destruction time will be solved separately.

At the transition to the test results at samples in the scheme of T.Karman let's consider a simplest situation $\sigma_{1}<\sigma_{2}=\sigma_{3}$. Compressing directions are negative, let $\sigma_{2}=\sigma_{3}=0$, generalizations for a case of nonzero $\sigma_{2}, \sigma_{3}$ will be indicated below.

A1l areas tangential to the cones with axis along first main direction will work according to indicated scheme "elastic deformation + sliding".

$$
\frac{\sigma_{3}-\sigma_{1}}{2}, \quad \frac{\sigma_{2}-\sigma_{1}}{2}
$$

Shall think the volume change to be elastic with volume module $\mathrm{K}=\mathrm{const}$ to a critical point $\gamma=\gamma_{\mathrm{k} p}$ which evidently will answer to maximal value of $\sigma_{1}$ at the diagram $\sigma_{1}\left(\varepsilon_{1}\right)$. So that the volume change

$$
\Delta \varepsilon=\Delta \varepsilon_{1}+\Delta \varepsilon_{2}+\Delta \varepsilon_{3}=\Delta \varepsilon_{1}+2 \Delta \varepsilon_{2}
$$

is proportional to the change of $\sigma_{1}$ 


$$
\Delta \sigma_{1}=3 K\left(\Delta \varepsilon_{1}+2 \Delta \varepsilon_{2}\right), \quad \Delta \sigma_{2}=\Delta \sigma_{3}=0
$$

And the shears change at their areas is proportional to the tangential stresses increment

$$
\frac{\Delta \sigma_{1}}{2}=\mu_{p}\left(\Delta \varepsilon_{1}-\Delta \varepsilon_{3}\right)=\mu_{p}\left(\Delta \varepsilon_{1}-\Delta \varepsilon_{2}\right)
$$

where $\mu_{p}$ - average value of $\tau(\gamma)$ inclination at basic diagram. From here the following dependance is defined:

$$
\Delta \varepsilon_{1}=\frac{\Delta \sigma_{1}}{3}\left(\frac{1}{\mu_{p}}+\frac{1}{3 K}\right), \quad \Delta \varepsilon_{2}=\frac{\Delta \sigma_{1}}{3}\left(\frac{1}{2 \mu_{p}}-\frac{1}{3 K}\right)
$$

and the"Poisson's ratio" change

$$
\frac{\Delta \varepsilon_{2}}{\Delta \varepsilon_{1}}=\frac{\frac{1}{2 \mu_{p}}-\frac{1}{3 K}}{\frac{1}{\mu_{p}}+\frac{1}{K}} \approx \frac{1}{2}, \quad \text { (if } \mu_{p}<\mathrm{K} \text { ) }
$$

After attaining $\gamma=\gamma_{k p}$ or $\sigma_{1}=\sigma_{1 \max }$ it is necessary to take into account the volume change due to the dilatancy.

By that according to basic idea it is necessary to take into account the element volume change "across" of the sliding area

$$
\begin{aligned}
\varepsilon_{n}=\beta \gamma, \text { where } \varepsilon_{n}=\varepsilon_{1}+\varepsilon_{3} & \text { for } \gamma=\varepsilon_{1}-\varepsilon_{3} \\
\text { and } \varepsilon_{n}=\varepsilon_{1}+\varepsilon_{2} & \text { for } \gamma=\varepsilon_{1}-\varepsilon_{2}
\end{aligned}
$$

in the case of loosening $-0<\beta<1$.

The following connections serve for defining of deformations at $\gamma>\gamma_{k p}$ in that description: ,

$$
\begin{aligned}
\Delta \varepsilon_{1}+\Delta \varepsilon_{2} & =\beta\left(\Delta \varepsilon_{1}-\Delta \varepsilon_{2}\right) \text { or } \\
\frac{\Delta \varepsilon_{2}}{\Delta \varepsilon_{1}} & =-\frac{1-\beta}{1+\beta}
\end{aligned}
$$

i.e. the "Poisson's ratio" change at small $\beta$ is unusual.

To define the connection of stresses $\sigma_{1}$ and deformations $\varepsilon_{1}$ and $\varepsilon_{2}$ serve the "dependances" 


$$
\Delta \sigma_{1}=2 \mu_{p}\left(\Delta \varepsilon_{1}-\Delta \varepsilon_{2}\right)=\frac{6 \mu_{p}}{2+\beta} \Delta \varepsilon_{1}
$$

where $\mu_{p}$-average value (negative one) at downward segment. One should remember that this part of diagram essentially depends upon the sample size which in first turn is reflected at the dilatancy coefficient value $\beta$. At the test results processing $\mu_{p}$ is defined from experiments and then $\beta$ is calculated.

Thus, in experiments for one-axis compression the values important for the destruction phenomenon estimation can be defined. $\sigma_{c r}=2 \tau_{\max }, \gamma_{c r} \sim 1.5 \varepsilon_{c r}$ are among them as well as the indices of hardening $\mu_{p}$ and unhardening $\mu_{p}$ and $\beta$ if the latter are of interest.

It is important to enlarge the experiments data use in T.Karman scheme including that for construction of three-axis passport of hardness (Shemyakin, 1975).

Let's note in conclusion that the proportional and monotonic loading $\sigma_{1}, \sigma_{2}=\sigma_{3}$ changes nothing in the results processing. In experients with real three-axis picture of loading (deformation) it is necessary to take into account the way of loading (deformation) and its reflection at the sliding areas.

Thus, the phenomenologic picture of the irreversible deformations development and destruction is presented in given chapter from single position which doesn't contradict to the physical facts. Nevertheless, the plausibility of the model should be checked at the explanation of new phenomena.

Let's give several examples for discussion.

1) At compression of a sample between plane plates (without limiting efforts along side surface, for example) the destruction development goes by one of ways. Either the surface at the expense of friction and dilatancy is manifested, that surface being composed piecewise from the main shear surface pieces. So that the destruction development along distinct sliding surfaces is not symmetrical - at the expense of sliding along one of areas of one family or in turn - which follows from proposed model. By that the friction angle and dilatancy reflect the features of already new, "destructed" material in the beyiond-limit state. That circumstance may appear to be extremely important at the construction of hardness passport.

2) The cleaving of a sample along the direction of largest compressing stress is often observed (slepyan \& 
Troyankina, 1976; Nikitin, 1987). That phenomenon attracts attention of many researchers.

If to take into account the influence of structure, defects and multicomponent composition of conglomerates then it is possible to think that such destruction begins at concentrators and further - the same result: the destruction surface being formed is composed of the sliding surface segments of one family in which different areas enter into the work in turn (Revushenko \& Shemyakin, 1977).

3) The second example is connected to the acoustic emission at destruction. The introduction of size $\delta^{*}$ in the model of destruction enables to indicate the frequency ranges of acoustic emission at consolidating segment (high frequencies) and at load-deflection curves (transition from high to low frequencies). Confronting the data about acoustic emission in materials and rocks at the predestruction stage shows that - the value of an order of crystallite size in metals and alloys and of an order of structural grain in rocks and conglomerates explains entirely the acoustic emission as a result of the energy part release in elementary acts of sliding (Fig.6.2 and 6.3) as kinetic one. By that the frequencies about megacycles in metals and tenths of kilocycles in rocks at the predestruction state are observed. It would be interesting to discuss Kaiser effect and elastic unloading in the predestruction state simultaneously. 


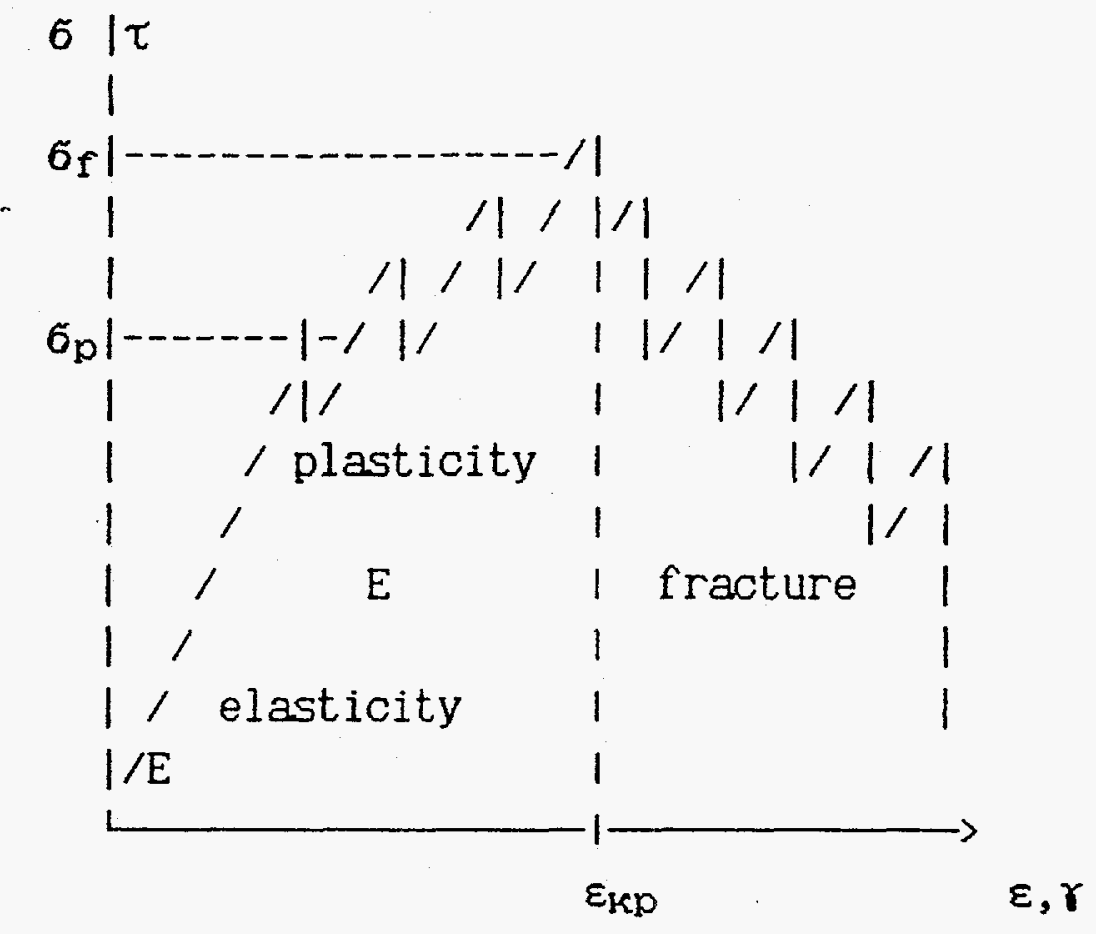

Fig.6.1

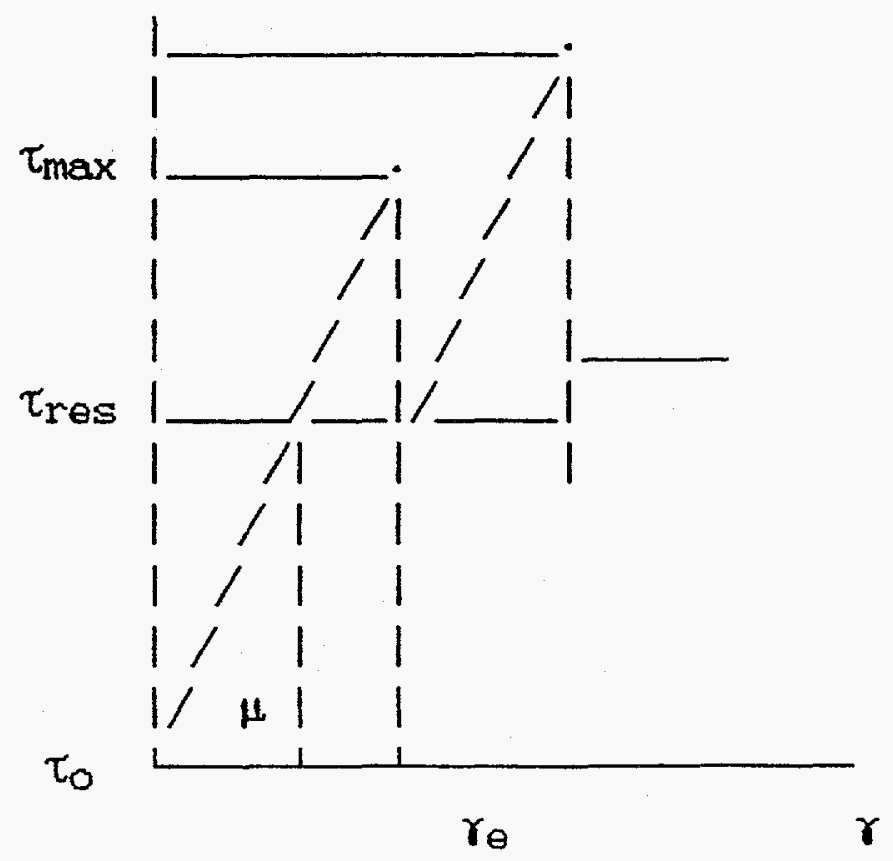

Fig.6.2 


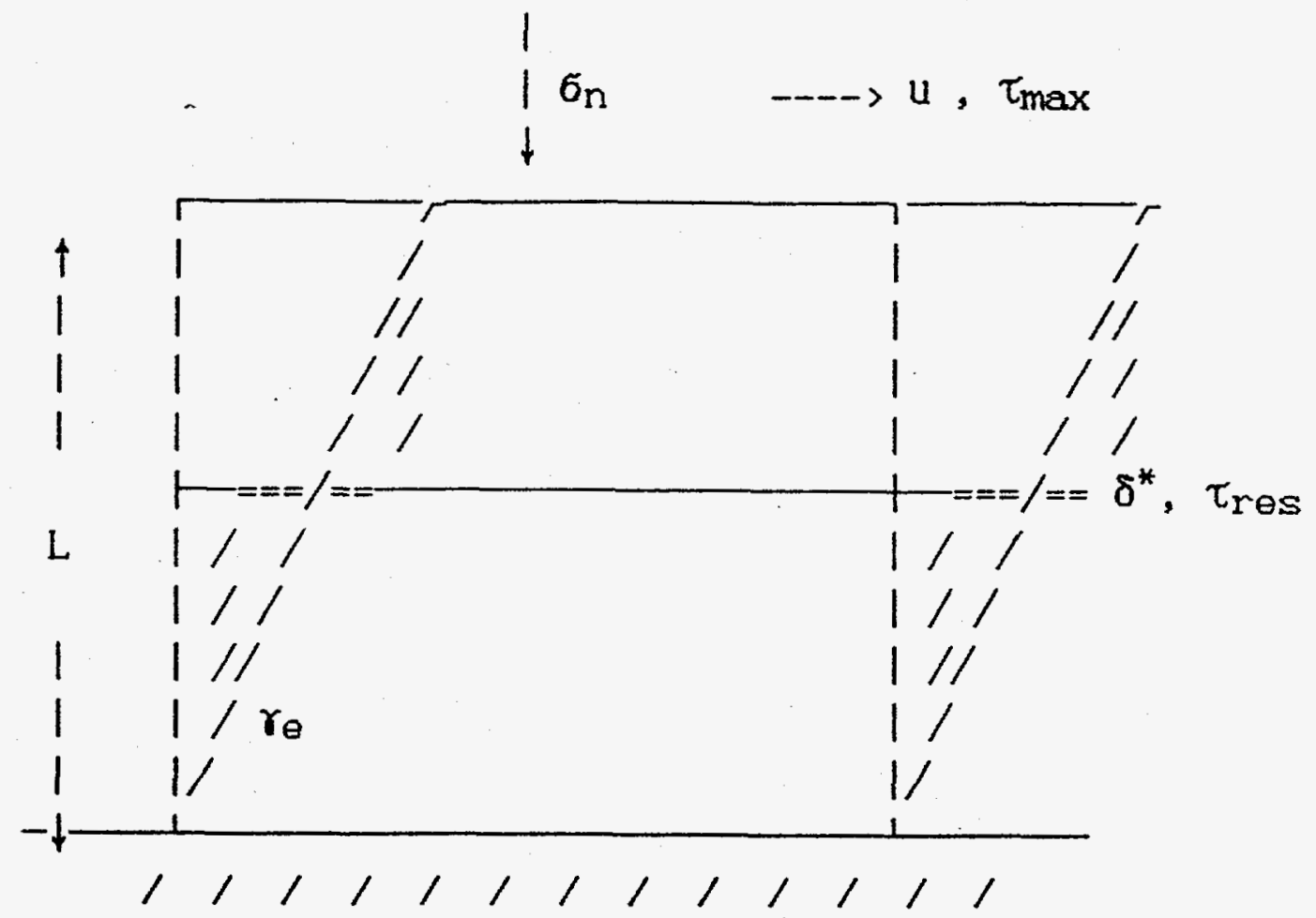

Fig.6.3

$\mathrm{u}$ - given displacement at the machine of "rigid" sliding, $\delta^{*}$ - the value of elementary sliding 


\section{CONCLUSION}

The problem the study of which the given report is devoted on one hand is actual for the mining practice, on other hand is directly connected to the geomechanics fundamental problem creation of the geomechanical model of rock massif as the part of Earth crust.

In mining practice of more than half of the Russia mines the seismic phenomena are observed connected to mining works. The losses from one rockburst reaches 500 thousands roubles (in prices of first half of eighties), the restoration works in series of cases last months. In USA the cost of repairrestoration works after each rockburst reaches 1 million dollars and contributes to the cost of 1 ton of excavated ore from 8 to $18 \%$.

The appearance in last two decades of quantitative descriptions of a rock massif with its block structure and the hierarchy of that structure according to dimensions of possible blocks enables to return to the problems statement about study of the rockbursts mechanism and small focused earthquakes. Actually, from the position of real rock massif structure the blocks or even whole groups of blocks can become the centers of the accumulated energy release and either human activity (construction of openings or openings systems to the mining of useful minerals) or tectonic movements with discharge at suitable block borders or block systems borders can become the sources of the energy. As at this as at that case the devising of phenomenological models of destruction or predestruction of a rock massif appears to be constructive. On one hand that enables to formulate more definitely the requirements to experimental definitions of necessary parameters of a rock and a rock massif site lestimation of block dimensions, of dimensions hierarchy, possible displacements along borders including cracks and faults systems). On other hand the opportunity appears to lay well-based claims to initial mininggeological data in mining and to influence to substantiations of mining works development (preparation and excavation ones, selection of working systems - with collapse or backfilling).

The authors of report lean by that on series of motherland theoretical and, basically, experimental data. Among those data the work of the Institute for Dynamics of Geospheres of Russian Academy of Sciences (M.A.Sadovskij, V.N.Rodionov) and research of the Institute of Mining of Siberian Branch of Russian Academy of Sciences (E.I.Shemyakin, A.F.Revuzhenko, S.B.Stazhevskij). The works of A.A.Skochinsky Institute of Mining (S.E.Chirkov and E.S.Vatolin) and Leningrad school (The Sankt-Petersbourg Mining Institute - A.N.Stavroghin) are 
especially interesting among laboratory studies in that direction. follows:

The results of this report can be shortly delivered as

1. The review of information presented in the literature is given about the rockbursts and mines seismicity at the world mining enterprises as well as of the prognosis and prevention methods for the rockbursts.

2. Geological and tectonophysical characteristics of massifs, the features of man-made influence to a massif, mine seismicity and rockbursts were analyzed in detail for two large mines in Russia: mines PA "Apatit" in Khibinskij massif and the Northern Urals main mine, SUBR.

3. The main principles of forming of the complex monitoring system at underground objects are devised. The instrumental methods developed by authors are delivered in detail.

4. The data of measurements in situ of the seismic activity, massif blocks displacements and geoelectric potential at two mines are given.

5. The calculation methods enable to analyze the stress state changes at mass heterogeneities is proposed. The examples of calculations for practical problems are given.

As it was shown in chapters 1 and 3 of this report it is necessary to carry out the permanent geomechanical control of massif state to develop effective measures to preserve the rock massif and underground constructions stability. The measurements methods for relative displacements, seismoacoustic emission and geoelectric potential developed at the Institute for Dynamics of Geospheres of Russian Academy of Sciences are presented in given report.

As for the seismic and seismoacoustic stations network organization at underground objects and open mines there is no necessity to prove its purposefulness. Such networks were already organized at many mines of the world as well as at other objects in particular to control the slopes stability and to prognosticate the landslides. The basic attention was paid in given report to the use of measurement methods for relative displacements on the basis of DPS and geoelectric potential.

Comparatively simple method DPS enables to organize the mass (multipoint) measurements of the massif blocks displacements in complicated conditions of mining works. The method provides high precision and broad measurements range as in quasistatic as in dynamic processes.

The geoelectric potential changes registration method possessing by comparative simplicity and informativity can be 
successfully applied to the creation of the observation stations network at large area as well.

The creation of such networks essentially supplementing the seismic ones is the next stage of works in this direction.

The instrumental observations in underground openings of Khibiny massif (PA "Apatit") during several years not only confirmed the developed methods workability but enabled to register the processes interesting from the geomechanics point of view: the rockbursts as the reaction to mining works and large explosions, block displacements and the character of change of seismoacoustic emission in a massif after dynamic influence. Besides the measurements disclosed some prognostic features of the preparation of dynamic phenomena in massif.

The carried out analysis of rockbursts at Khibiny mines shows that majority of them are not connected to large-scale explosion works. At the same time the large industrial explosions can serve as triggering mechanism for arising of rockbursts and tectonic rockbursts. The examples are the manmade earthquake 16 April 1989, the rockbursts at the explosion 28 April 1991, the deformation process at the joint of two massif blocks fixed by DPS method at the explosion December 5 1993 presenting the displacement along the fault of $V$ rank not implemented as a result of subsequent relaxation of stresses etc.

The analysis of features of man-made earthquake at Kirovskij mine of PA "Apatit" at April 161989 shows that the proposed earthquake mechanism (the process of crack forming along the fauit at the area $1000 \times 1000 \mathrm{~m})$ corresponds to reality. The man-made influence to rock massif made in such scale may lead to the large cracks forming with considerable seismic effect exceeding as the seismic data show the corresponding effect of large explosion.

other rockbursts and earthquakes of man-made character registered in that region give considerable way to the earthquake of April 161989 according to seismic effect. It should be noted however that some of them have the magnitude comparable to the magnitude of large industrial explosions.

The developed model of solid body with dissipative structure enables to state the problem of massif interaction with underground openings in a new manner. The model gives an opportunity to estimate the time delay of massif reaction connected to relaxation processes and to give a prognosis of the man-made influence to massif. The possibilities of model were illustrated by particular problems of the concentration of stresses at fault as a result of mining works and of the massif stress state change in the process of construction of large underground gallery. 
Proposed calculation methods can serve as a basis to
develop the criteria of information selection in the geomechanical monitoring system of rock massif at particular objects.

As a result of the analysis of seismic regime of NorthUral bauxite deposit the following conclusions can be made.

The slope of magnitude-frequency rlationship in energy form has a value 0.6 - 0.7 which tells about prevailing of weak events. Such value of slope is characteristic to the man-made seismicity.

It is shown that about $50 \%$ of weak seismic events with energy from 100 to $10^{4}$ Joules falls to the time of explosion works carrying out. Strong seismic events (energy is equal to and more than $10^{5}$ Joules) don't reveal the statistical connection to the explosion works carrying out time.

The time intervals between subsequent events (expectation times of events) are distributed by the Weibull distribution. The seismic process in the SUBR is Markov chain but not Poisson process. This fact gives a basis for search of the prognosis features in the seismic activity variation.

The seismic process phase portraits are constructed in coordinates "activity-velocity of activity change". It is shown that the seismic process activity changes in a quasiperiodic manner, the seismic activity oscillations period tends to grow at 15 mine (from approximately 10 months to 20) and to oscillations about the value 15 months at 14 mine.

The great number of seismic events close in time to each other is characteristic for the seismicity of SUBR. It is shown that the lines connecting the epicenters of such events are situated within the limits of seismoactive blocks and related to considerable extent to faults zones.

In mines fields of 14 and 15 mines eight seismically homogeneous blocks are revealed. The tendencies of the position changes of centers of maximum seismic activity are shown up and the seismic activity level changes in those centers are disclosed. The dependance of the increased seismic activity area dimensions upon maximum energy release is established. On the basis of received data the map of areas location of prognosticated increased seismic hazard is drawn.

The received data are the evidence of active seismic processes in a region of North-Ural bauxite deposit. The energy for seismic events is got as a result of the tectonic forces action. However the deposit exploitation exert the activating action to the accumulated energy release in a form of induced seismicity.

The idea about kinetics of transition of a massif to new equilibrium - from seismically activated state to the state of 
seismic rest - can be given by the study of aftershock processes induced by large earthquakes. In definite sense the large earthquakes can be looked at as the analogues of summarized man-made process. At any rate some features of the induced seismicity regime remind very much the aftershock process development features. So the mass of comparatively weak "initial aftershocks" arises immediately after the main shock arising which are localized in its site of origin - similar to that as at initial stages of induced seismicity appearance the dynamic phenomena fault zones are concentrated near to workedout spaces. Then the process of divergence of aftershocks begins consisting of gradual migration of aftershocks into larger vicinity of fault zone of main shock. The phenomenon similar to the aftershocks divergence can be seen as well in gradual spreading of seismic phenomena hypocenters far (up to kilometers) beyond worked-out spaces. The phenomenon of progressing, already partially spontaneous development of induced seismicity was observed not only in connection to mining works. It is typical for example for the evolution of seismicity induced by the reservoir filling.

The data given in the report are the evidence of the human influence to upper layers of lithosphere mounting. The problem of prognosis of construction and exploitation of the excavation complexes influence to the geodynamic processes development becomes to be pressing. The development of recommendations for preventive measures application to prevent or to decrease the negative consequences is nessesary. The distant consequences of meddling with natural processes are connected to the rock massif structure specifics, its stress state and deformation regime as well as depend upon the sensitivity of deformation regimes to weal influences.

*This work was performed under the auspices of the U.S. Department of Energy by Lawrence Livermore National Laboratory under contract No. W-7405-Eng-48. 


\section{REFERENCES}

$236 \mathrm{pp}$.

Avershin S.G. 1955. Rockbursts, Moscow, Ugletechizdat,

Ajtmatov, I.T.1987. Regional forecast of rockburst hazard on ore deposits in Central Asia: Rockburst forecast and prevention on ore deposits. Appatity. p.34-37. .

Arshavsky V.V., Redkin V.A., 1987. Rockburst forecast and prevention on Talnach deposits. in: Rockburst forecast and prevention on ore deposits. Apatity.

Baklashov I.V., Kartozia B.A. 1986. Mechanical processis in rock mass, Moscow, Nedra, 272pp.

Barzitskij V.V., Kremenetskaya E.O. 1989. Modern geodinamical activity of the Baltic region east part. Apatity.

Batugina I.M., Petuchov I.M., 1988. Geodynamic mapping of deposits regions during planing and exploitation of mines. Moscow, Nedra, 166p.

Bolstad D.D., 1990. Rockburst control research by the US Bureau of Mines. in: Rockbursts and seismicity in mines. Rotterdam, Balkema, p.371-376.

Bondarenko A.T. 1972. Electrical properties of Khibini and Lovozerskij masses. Izv.Acad.Sci.USSR, Fizika Zemli,4, 104-105.

Bronnicov D.M., Zamesov N.F., Bogdanov G.M. 1982. Ore mining on deep levels, Moscow, Nedra, 292pp.

Buben J., Rudajev V. 1977. Rock burst and earthquakes Publ. Inst. Geophys. Pol.Acad. Sc., A-5(116).

Catalog of rockbursts on ore and non-ore deposits. 1985. SUBR.: Leningrad, VNIMI 258p..

Chirkov B.E. 1976. Strength of rocks at triaxial non equicomponent compression. FTPRPI, N1, p.11-17.

Cook N.J.W. 1976. Seismicity associated with mining: Eng. Geol., v.10, p.99-122.

Cook N.G.W., Hoek E., Pretorius J.P.G., ortlepp W.D., Salamon M.D.G. 1966. Rock mechanics applied to the study of rockbursts. - J.S.Afric. Ins. Mining and Metallurgy, v.66, No.5, p.435-528.

Cook N.G.W. 1965. A note on rockbursts considered as a problem of stability. - J.S.Afric. Ins. Mining and metallurgy, v. 65, No.8, p.437-446.

Diakovskiy V.V., Yazykov I.S. 1987. Investigation of theoretical basis and justification of methods of rockburst hazard integrated forecast for non-ferrous metal deposits in the exploration stage and during deep mining: Research report, Sverdlovsk.

Dugdale D.S. 1960. Yielding of steel sheets containing slits. J.Mech. and Phys.Solids, v.8,N2, p.100-108.

Elizarov V.K., Syrnikov N.M., Evmenov V.F. 1994. In-situ measurements of seismo-acoustic emission in rock massif under 
industrial explosions. Physical-technical problems of mining, 1: 24-29.

Fucik P.,Rudajev V. 1979. Physical parameters of rock burst sources. Publ. Inst.Geophys. Pol.Acad.Sc. M-2(123), .

Gendzwill D.J., Prugger A.F. 1990. Seismic activity in a flooded Saskatchewan potash mine. in: Rockbursts and seismicity in mines. Rotterdam, Balkema. p.115-120.

Gibowicz S.J. 1990. The mechanism of seismic events induced by mining. A review. in: Rockbursts and seismicity in mines. Rotterdam, Balkema. p.3-27.

Goodman R.E. 1980. Introduction to rock mechanics. John Wiley \& Sons.

Goxberg M.B., Morgunov V.A., Poxotelov O.A. 1988. Seismpoelectromagnetic effects. M.Nauka, $174 \mathrm{pp}$.

Grik A.R., Mamaeva M.B., Nikanorov V.B., Shajdulin Z.G. 1988. Study of geodynamic state Nagornyi fault on Tashtagolskiy deposit with the help of geodesic methods. in: Geodynamics of Deposits. Kemerovo, p.132-135.

Hasagava H.S. 1988. Mining induced seismicity: Pap. Geol. Surv. Can., N1, p.53-58.

Ilyin A.M. 1987. State of rockburst problem in ore industry. in: Rockburst forecast and prevention on ore deposits. Appatity, p.5-10.

Kazimierczyk M., Kijewski P., Szelag T. 1988. Aspekty tectonicznel eksploatayine silnych wstrzasow gorniczych wystepijacych w kopalniach LGOM: Publ. Inst. Geophys. Pol. Ac. SC. N 10. S.187-202.

Kolesov V.A., 1987. Experience of rockburst problem resolving for SUBR. in: Rockburst forecast and prevention on ore deposits. Appatity, p.54-61. .

Kondratyev S.V., Syrnikov N.M., Rybnov Y.S. 1994. Measurement in situof the relative displacement on the fault in rock mass at the large-scale technical action. The dynamic processes in the geospheres: the high power geophysics. Moscow, Nauka, : 80-88.

Kondratyev S.V. 1993. Method of measurement of rock blocks relative displacement. In publ. Rock mass state control. Apatity, p64-73.

Kondratyev S.V. 1989. Sensor for relative displacement of rock. Patent 1681287 USSR, MKI G $01 \mathrm{~V} 1 / 16$.

Kozyrev A.A., Ivanov V.I., Erukhimov A.Kh., Kuzmin I.A. 1987. Prediction and prevention for deposit rock burst hazard based on tectonic forces and automated control of rock mass stressed state and seismic activity. In: Prognoz i predotvrashcheniye gornykh udarov na rudnykh mestorozhdeniyakh. Apatity. Izd. KSC ASR., pp.22-34.

Kozyrev A.A., Lovchikov A.V., Osika V.I., Popov E.I. 1988. Monitoring of present crustal movements in the Lovozero 
massif by high-precision methods. Journal of Geodynamics., $10: 263-274$.

Kozyrev A.A., Panin V.I. 1993. Effect of large-scale mining operation on the geodynamic behavior of the area, and mine-induced seis misity manifestation. A.A. Balcema/Rotterdam/Brookfield/: 841-845.

Krishnamurthy R., Shringarputale Shrikant B., 1990. Rockburst hazards in Kolar Gold Fields. in: Rockbursts and seismicity in mines. Rotterdam, Balkema. p.411-420.

Kurlenya M.V., Aksenov V.K. 1969. Mothodical recomendations for stress change measurements in coal massif by borehole hidravical sen sors. Novosibirsk, 56pp.

Kuzmin I.A., Kremenetskaya E.O., Tryapitsin V.M., Fedorenko Yu.V., Beketova E.B., Nakhshina L.P. 1994. The earthquages in Khibiny in November-December 1993. Apatity, $10 \mathrm{pp}$.

Kuznetsov V.M., 1977. Mathematical models in explosion practice: Novosibirsk, Nauka, 272p. .

Lee M.F., Beer G., Windsor C.R. 1990. Interaction of stopes, stresses and geologic structure at the Mount Charlotte Mine, Western Australia. in: Rockbursts and seismicity in mines. Rot terdam, Balkema, p.337-344.

Leeman E.R. 1964. The measyrement of stress in rock. J.South African Inst. Min.Metall., v.65, N2. p.45-81.

Lovtsov S.V., Ponomarev E.A. 1988. On same mechanisms electric relaxation of the cracks. Publ.of Novosibirskij Univer. Novosibirsk. Science., p24-29.

Markov G.A. 1977. Tectonical stresses and rock pressure in Khibini mines. Leningrad, Nauka, 213pp.

Mastov Sh.R. 1988. Electromagnetic field of a set of brittle failure cracks. Izv.Acad.Sci. USSR, Fizika Zemli, 10, 107-111,.

Maygkin V.J., Kostrov B.V., Sobolev G.A. 1974. Laboratorical and theoretical investigations of process in the earth's const us. Izv.Acad.Sci. USSR, Fizika zemli. 10, 107112 .

Melnikov N.N., Raspopov O.M., Yerukhimov A.Kh., Kuzmin I.A. 1987. A new instrument of investigations in mining geophysics. Vestnik AN SSSR. N5, p.6-15.

Melnikov N.N., Kozyrev A.A., Panin V.I. 1993. Geomechanical control og mining in high-stressed rock mass. Assesment and prevention of falure phenomena in rock engineering. Rotterdam, Balkema, , p.699-701.

Migunov N.I. 1987. On seismoelectric effect of jrebodies. Izv.Acad.Sci.USSR. Fizika Zemli, 11, p.99-107.

Milne W.G., Berry M.J. 1976. Induced seismicity in Canada: Eng. Geol., v.10, p.219-226. 
Morgunov V.A., Poxotelov O.A. 1988. Statistical model distribution of the oscillactors. Izv.Acad.Sci.USSR, Fizika Zemli, 1, p. 55-58.

Verl.

Muller L. 1963. Der Felsbau. Stuttgart, Ferdinand Enke

Nadai A. 1963. Theory of flone and fracture of solids. New York, v.2.

Nikiforovskij V.S., Shemyakin E.I. 1979. Dynamic fructure of solid bodies. Novosibirsk, Nauka.

Moscow.

Nikitin L.V. 1987. Mechanics of the rock fracture. Nauka,

Obert L., Duvall W. 1967. Rock mechanics and the design of structures in rock. - New York e.a., J.Wiley and Sons, $650 \mathrm{pp}$.

Palmer A.C., Rice J.R. 1973. The growth slip surfaces in the progressive failure of over-consolidated clay. Proceedings of the Royal Society. London. A332., p527-548.

Panasenko G.D. 1957. Seismicity of Kola Peninsula and Northen Karelia. Isvestia AN SSSR, N8, p969-978.

Petukhov I.M., Litvin L.V., Kucherskij. 1969. Rockbursts and prevention of them in Kizelovskij coal basin. Perm, Permizdat, 397pp.

Petukhov I.M., Linkov A.M. 1983. Mechanics of rockbursts and rockfalls. Moscow, Nedra, 279pp.

Petukhov I.M., Smirnov V.A., Vinokur B.Sh. 1975. Geophysical investigations of rockbursts. Moscow, Nedra, 136pp.

Petukhov I.M., Egorov N.V., Vinokur B.Sh. 1984. Prevention for rock bursts in mines. M. Nedra, 230p.

Petuhov I.M. 1987. Some decisions of rockburst problem during mining. in: Rockburst forecast and prevention on ore deposits. Appatity, p. 10-16. .

Plouffe M., Cajka M.G., Wetmiller R.J., Andrew M.D. 1990. The Sudbury local telemetered seismograph network: Rockbursts and seismicity in mines. Rotterdam, Balkema, p.221-226.

Poginets A.Y., Mikulin E.I. 1988. About results of block rock massif deformation based on observations on underground geodynamic polygon. in: Geodynamics of Deposits. Kemerovo, p. 99-104.

Ponomaryov V.S., Turuntaev S.B., Voinov K.A., Krakov A.S., Logunov V.A., 1992. Investigation of induced seismicity regime in Severouralsk bauxite mines: Physical-technical problems of mining, N4, p.15-22. .

Prugger A.F., Gendzwill D.J. 1990. Results of microseismic monitoring at the Cory mine, 1981-1984. in: Rockbursts and seismicity in mines. Rotterdam, Balkema, p.215-219.

Revushenko A.F., Shemyakin E.I.1977. Plane deformation of the hardening and fracturing plastic material. PMTF. N3,p156174 . 
Rodionov V.N., Sisov I.A., Tsvetkov V.M. 1986. Foundations of geomechanics, Moscow, Nedra.

Rybnov Y.S. 1993. Method of geoelectrical potential measurement. In publ. Rock mass state control. Apatity, p74-82.

Sadovskiij M.A., Pisarenko V.F. 1991. Seismic process in blockmedia: Moscow, Nauka, 96p. .

Sadovskij M.A., Bolchovitinov L.G., Pisarenko V.F. 1987. Deformation of geophisical medium and seismic process. Moscow, Nauka, pp100.

Scoble M.J. 1986. Strategic and tactical measures to alleviate rockbursting in Canadian underground mining: Mining Dep. Mag., v.38, p.47-53.

Seismic events in Northen Europe. 1989. Helsinky university, N6.

Semadeni T., Rochon P., Niewiadomski J. 1990. Waveform analysis of mine induced seismic events recorded at Rio Algom's Quirke Mine. in: Rockbursts and seismicity in mines. Rotterdam, BaIkema, p.195-198.

Sharov N.V. 1989. Lithosphere of Baltic region acording to seismical data. Apatity.

Shemyakin E.I. 1974. Stress-strain state in the tip of crack at antiplane deformation of elastic-plastic bodies. PMTF, N2, p110-116.

Shemyakin E.I. 1975. Two problems of rock mechanics concerned with mas tering of deep coal and ore deposit. FTPRPI. N6.

Shemyakin E.I., Kurlenya M.V., Kulakov G.I. 1986. On the problem of rock bursts classification. FTPRPI, 5:3-11.

Shrepp B.V. 1987. Control of rockbursts on Tashtagol mine. in: Rockburst forecast and prevention on ore deposits. Appatity, p.50-54. .

Slepian L.I., Troiankina L.V. 1976. Theory of cracks. Leningrad.

Stenczel J. 1988. Vyznam specialinich rezimu trhacich praci $v$ protiotresovem boji na hydrotermalnim uranovem lozisku Pribram: Rudy, v.36, N7, p.187-191.

Stavrogin A.N., Protosenya A.G. 1979. Plasticity of rocks. Nedra, Moscow.

Syrnikov N.M. 1993. On comprehensive sistem of instrumental observation for the rock mass state and underground openings during construction and explosion period. In publ. Rock mass state control. Apatity, p49-64.

Syrnikov N.M., Tryapitsin V.M. 1990. On mechanism of manmade earthquake at the Khibini mountains. DAN USSR, vol.314,N 4 p. 830-833.

Syrnikov N.M., Sizov I.A. 1994. Dissipation processes in rock mass and problem of uderground space use. Proceedings of 
the $\mathrm{X}$ International conference on rock mechanics.IGD Skochinskogo, Moscow, p.39-52

Syrnikov N.M., Osipov K.G. 1994. On some exhibitions of structure disturbances in the earth's crust as the effect of large-scale technical action. The dynamic processes in the geospheres: the high power geophisics.Nauka, Moscow, p.69-79

Szclag T., Bober A., Mroc J., Kazimierczyk M. 1985. Tapania w ZB u "Lubin" i zwalczamie tego zagrozenia: Mater. 1 kraj.konf. nauk.-techn.: Zastosow. metod. geofiz. gorn. kop. statych, Jaworte, 6-8 list., t.2, Krakov, p.267-285..

Tarasov V.G., Durdin V.V. 1983. Geoelectrical control state of massif. M.: Nedra, 215pp.

Tihonov V.I., Gorainov V.T. 1980. Statistical radiotechnical. M.:Sov.radio., 554pp.

Tryapitsyn V.M., Syrnikov N.M. 1991. Some features of rock pressure manifectation during mining od deposits in highstressed testonically-disturbed rock masses. FTPRPI.,5 p.101107.

Tsuboy Ch. 1961. Energy of earthquakes, volume of hypocenteral zone, of aftershocks zone and strength of Earth crust., p.160-164.

Turchaninov I.A., Markov G.A., Ivanov V.I., Kozyrev A.A., 1978. Tectonical stresses in Eaeth's crust and openings stability. Leningrad, Nauka, 256pp.

Turchaninov I.A., Iofis M.A., Kasparian E.V. 1989. Foundations of rockmechanics. Leningrad, Nedra, 488pp.

Turchaninov I.A., Medvedev R.V. 1973. Research phisical properties of rock massifs. L.:Science., 124pp.

Voinov K.A., Krakov A.S., Tomilin N.G., Frolov D.I. 1987. Spatial-temporal analysis of rock massif failure processes on Severouralsk bauxite mines ( $/ 0$ SUBR): Physical-technical problems of mining, N1, p.22-27.

Vorobjev A.A. 1980. Balance and transformation forms of power in masses. Tomsk:Publ. of Tom.Univer., $211 \mathrm{pp}$.

Waldeck H.G. 1990. The monitoring of seismicity and measures implemented to alleviate rockburst damage at Kloof - A division of Kloof Gold Mining Co. Ltd. in: Rockbursts and seismicity in mines. Rotterdam, Balkema, p.395-400.

Williams T.J., Cuvelier D.J. 1990. Report on a field trial of an underhand longwall mining method to alleviate rockburst hazards. in: Rockbursts and seismicity in mines. Rotterdam, Balkema, p.349-353.

Yuan X., Changdo Z. 1990. Investigation and implication of acoustic emission equipment before and after explosions at copper mine Dayao. Nonferrous Metals. 42, N2, p16-20.

Zyl Brink A.v. 1990. Application of a microseismic system at western Deep Levels. in: Rockbursts and seismicity in mines. Rotterdam, Balkema, p.355-361. 